University of South Florida

DIGITAL COMMONS

Digital Commons @ University of

@ UNIVERSITY OF SOUTH FLORIDA

South Florida

Integrative Biology Books

Integrative Biology

1914

\title{
Echinoids of the Indian Museum at Calcutta. I. Spatangoids: A Translation of Échinides du Musée indien à Calcutta. I. Spatangidés
}

René Koehler

John Lawrence

University of South Florida, lawr@usf.edu

Follow this and additional works at: https://digitalcommons.usf.edu/bin_books

\section{Recommended Citation}

Koehler, R. (2020). Echinoids of the Indian Museum at Calcutta. I. Spatangoids: A Translation of Échinides du Musée indien à Calcutta. I. Spatangidés (J. M. Lawrence, Trans.). Herizos Press, Tampa.

This Book is brought to you for free and open access by the Integrative Biology at Digital Commons @ University of South Florida. It has been accepted for inclusion in Integrative Biology Books by an authorized administrator of Digital Commons @ University of South Florida. For more information, please contact digitalcommons@usf.edu. 


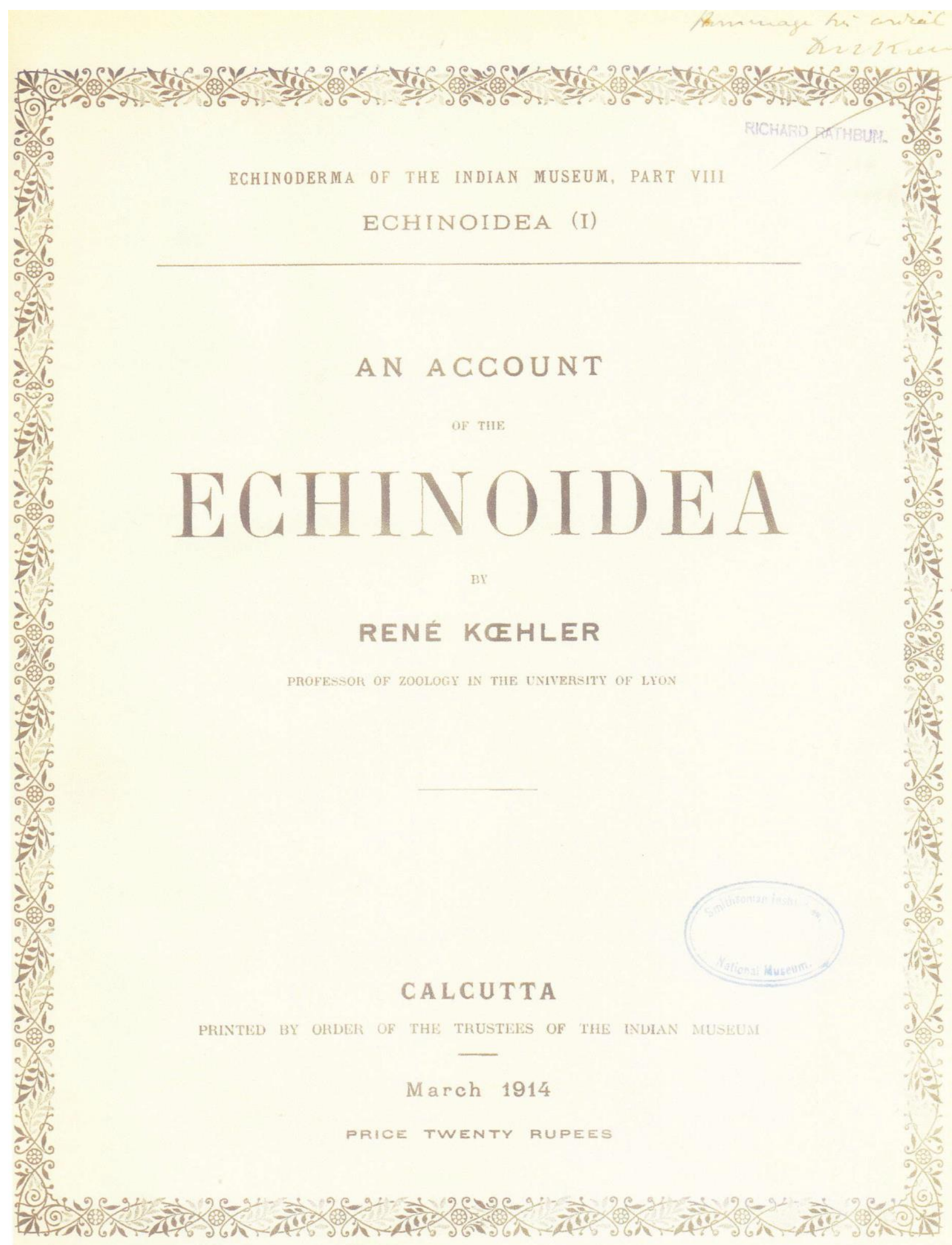


ĖCHINIDES

$\mathrm{H}^{\circ}$

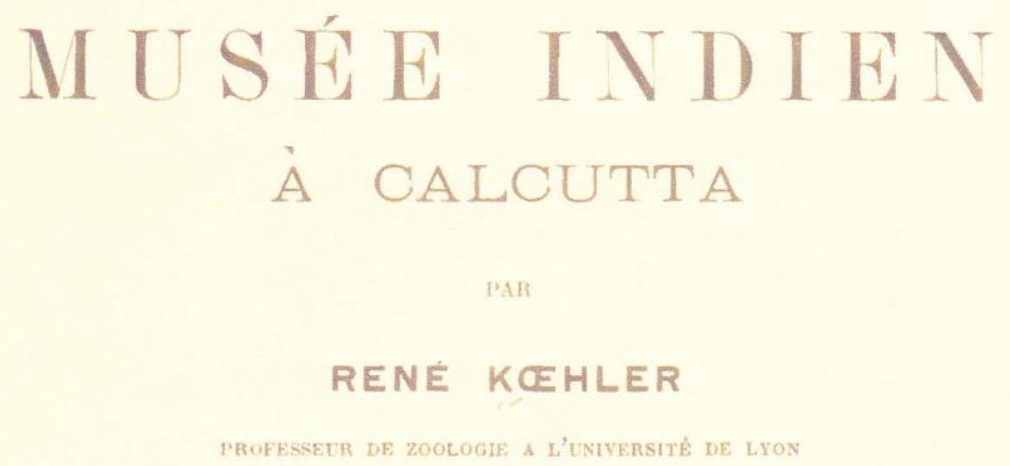

I. Spatangidés

OAICUTTA

Mars 1914 
Koehler, R., 1914. Echinoids of the Indian Museum at Calcutta. I. Spatangoids. A Translation of Échinides du Musée indien à Calcutta. I. Spatangidés. (J. M. Lawrence, Trans.). Herizos Press, Tampa.

${ }^{\circledR}$ John M. Lawrence. Herizos Press, Tampa.

Translator's note.

The memoir was published with the cover printed in English and also in French. I have used the French cover for the citation.

The text spells Lovén as Loven. I have not changed this.

I again thank my excellent friend, Michel Jangoux, for his aid with some of Kœhler's obscure anatomical terms and phrasing. 


\title{
ECHINOIDS
}

\author{
OF THE \\ INDIAN MUSEUM AT CALCUTTA
}

\section{Spatangoids}

The work that I publish today contains the description of a part of the echinoids belonging to the Indian Museum. The collection given to me contains mainly the specimens coming from the campaigns of the INVESTIGATOR is too large for it to be possible to account for in a single volume. I have believed it good to divide the study into three parts that will be published separately. The first, that which appears today, contains the irregular echinoids belonging to the spatangoids. A second will be devoted to the other irregulars (clypeasteroids and cassiduloids). Finally, the regulars will be the subject of the last part.

Among the specimens, a small number have already been described and figured by Alcock, Anderson and Wood-Mason. This is the case, for example, of Homolampus glauca, Lovenia gregalis and Brissopsis Oldhami. I shall complete the descriptions that were sometimes a little brief. Thus, that of Homolampus glauca has four lines supported by two figures. Brissopsis Oldhami was described after a very young individual. Other specimens had a name applied to them by Dr. Anderson without any description having ever been published. I have thus found echinoids labeled Paleopeustes Hemingi, Eupatangus rubens, Schizaster angulatus and Schizaster Investigatoris. I have preserved the specific denominations although they represent only "nomina nuda". Moreover, most of these forms should be placed in different genera than where they had been placed by Anderson. The first of these species was figured by Alcock in 1902 under the name Paleopneustes Hemingi Anderson. The application of the name Anderson is obviously not justified because this author never published the least diagnosis of this species. But because it had been used by Alcock with the name of the author, I have preserved the latter in my description in order to avoid any ambiguity. The other specimens were referred to species already known. Thus, several jars were labeled Lovenia elongata, Lovenia subcarinata, Lovenia gregalis, Metalia maculosa, Maretia alta, Faorina chinensis, etc. determinations that I have verified and find correct, while names given to other specimens such as Paleotropus Loveni, Schizaster gibberulus, Schizaster japonicus, Brissopsis luzonicus are obviously incorrect and are applied to new species.

Two jars had the name Platybrissus Romeri, but they contain only indeterminable debris. One of the specimens, however, had reached the hands of Anderson in fairly good condition. This naturalist had made some drawings that were communicated to me. Bur the specimen must have 
had some blows that crushed it and made it completely unrecognizable. I do not have to take it into account.

I thus establish the following list of irregular echinoids belonging to the spatangoids that I shall study in this memoir. There are thirty-one in all, of which seventeen species are new.

\author{
MERIDOSTERNIENS \\ Pourtalesia Alcocki ${ }^{1}$ \\ AMPHISTERNIENS \\ Aceste Annandalei \\ Paleotropus ovatus \\ Homolampus glauca Wood-Mason and Alcock \\ Archeopneustes Hemingi (Anderson) \\ Linopneuses spectabilis (Meijere) \\ Eurypneustes denudatus \\ Eurypneustes rubens \\ Meijerea humilis (Meijere) \\ Gymnopatagus Sewelli \\ Maretia planulata (Gray) \\ Pseudomaretia alta (Agassiz) \\ Lovenia elongata (Gray) \\ Lovenia subcarinata (Gray) \\ Lovenia triforis \\ Metalia maculosa (Gmelin). \\ Faorina chinesis Gray. \\ Pericosmus macronesius. \\ Hemiaster Hickmani. \\ Hemiaster vanus. \\ Periaster Kempi. \\ Paraster compactus. \\ Prymnaster angulatus. \\ Prymnaster Investigatoris. \\ Brisaster indicus. \\ Brissopsis luzonica (Gray). \\ Brissopsis parallela. \\ Brissopsis Oldhami Alcock. \\ Brissopsis bengalensis.
}

I have not believed it necessary to limit myself strictly to the study of these species. Having the possibility of comparing close diverse forms of specimens that I possess myself or that have been kindly communicated to me by colleagues, I shall indicate, when the occasion presents itself, the peculiarities that I have found in the little known species. Some forms thus examined for comparison are shown to be new. This was the basis for the genera Aceste, Aeropsis and Brissopsis. I shall also report the observations that I have been able to make on some species still insufficiently

\footnotetext{
${ }^{1}$ The species printed in bold are new.
} 
known that we sometimes refer to the genus Schizaster and that are characterized by the presence of four gonopores. We know that Mortensen refers them to the genus Paraster.

I believe it is preferable to delay until later either the examination of the general questions of zoogeography or classification. These will be studied more usefully when I have finished the study of the echinoids of the Indian Museum.

I am happy to give here my most sincere thanks to the persons who have helped me in my work and who communicated to me the specimens, often very rare, that I have needed for comparisons. My excellent friends, Dr. Mortensen and Prof. L. Joubin have loaned me specimens from the Museum of Copenhagen or the Jardin des Plantes. Prof. Max Weber has sent diverse specimens from the "Siboga", collected in the Sonda Archipelago. R. Brown, finally, has sent me Paraster gibberulus from Mozambique. I ask these gentlemen to accept my deepest gratitude for their extreme kindness.

\section{Pourtalesia Alcocki, nov. sp.}

$$
\text { (Pl. I, fig. } 1 \text { to } 14 \text {; Pl. XVI, fig. } 1 \text { to } 15)
$$

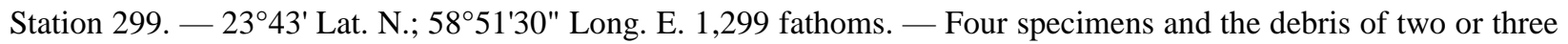
other specimens. No. $\frac{1047-49}{7}$

The specimens are not in very good condition. None of them have an intact test. There are more-or-less extended parts missing, especially from the ventral surface. Even in the largest individual, this surface is completely missing as well as part of the sides. The spines are nearly all lost and fairly well preserved only on the dorsal surface of the individual shown in Pl. I, fig. 1.

The species collected by the INVESTIGATOR belong to the section Pourtalesia s. str. of Mortensen, in which the bivial ambulacral are discontinuous and the dorsal plates of the interradius 5 are biserial, while there is a single pore in the plates I a1 and V b1. The structure of the test brings it close to $P$. Jeffreysi and especially to $P$. Wandeli. But the form of the body is different. By its posterior end that is raised and preceded by a strong periproctal notch, it recalls P. laguncula.

Here are the principal dimensions that I have taken from the four collected specimens that I designate respectively by the letters A to D. 
Length

Maximum width

\begin{tabular}{cccc}
\multicolumn{4}{c}{ Specimen } \\
A & B & C & D \\
$\mathrm{mm}$ & $\mathrm{mm}$ & $\mathrm{mm}$ & $\mathrm{mm}$ \\
45.5 & 42 & 37 & 40 \\
ca. & ca. & & \\
19-20 & 18 & 17 & 17
\end{tabular}

Maximum height

ca.

ca.

Width at the anterior end of the test

Distance between the bottom of the anterior invagination and the anterior border of the test ............................ Width of the invagination at the anterior border of the test ... Width of the posterior end ................................. Width of the periproct

$\begin{array}{llll}10 & 7 & 7 & 7 \\ 4.5 & 5 & 3.5 & 2.5 \\ 8 & 7 & 5.2 & 6 \\ 5 & 4 & 3.6 & 4\end{array}$

I shall describe the species especially after specimens A, B and C.

The test is elongated and relatively narrow (Pl. I, fig. 1 to 6). Seen by the dorsal surface (Pl. I, fig. 1, 2, 5 and 6), the body has an anterior transverse and nearly straight border, that is raised at the sides by round angles a little greater than $90^{\circ}$. After the anterior end, the width increases slightly toward the middle of the length of the body or a little before. The test narrows rapidly and regularly until the anterior border of the periproct where it reaches its minimum width.

It then widens very slowly to the posterior region that has, as usual, the form of trumpet. Seen in profile, the anterior end of the test is vertically truncated, especially in the upper part. But the lower part is directed a little obliquely backwards (fig. 8). The anterior part of the dorsal surface of the test is regularly convex for approximately the first quarter of the body, It keeps this simple convex form up to the point of union of the posterior ambulacra I and V. After this point, the test is raised on the median line in a crest that becomes more and more projecting and that extends to the periproct (fig. 2, 5, 6 and 8). This crest corresponds to the line of separation of the plates of the posterior interradius that are exactly and very regularly joined in successive pairs. The upper border of the test goes to the anterior end by a very round and obtuse border. Then it raises slightly to approximately the first third of the length of the body, where it reaches its maximum height. From there, the profile decreases gradually following a regular curve up to beyond the periproct, thus forming above the anterior and upper border a very noticeable although rounded beak, whose projection is much more pointed than in P. Jeffreysi and Wandeli, and even in P. miranda (fig. 8). The very deep depression that follows this beak, rises gradually to join the posterior part in the form of a prominent trumpet, a little enlarged at the end.

The ventral surface is not completely flat on the median line (fig. 8). It has, at nearly equidistance between the bottom of the anterior notch and the beginning of the sternum, a slight arch that is less pointed than in P. Jeffreysi and behind which is a small depression. Then the contour again becomes convex at the same time than the ventral median line rises into a very sharp keel that extends the length of the median line of the sternal plate $5 \mathrm{~b} 2$ and on two-thirds of the length of the suture of the two following plates $5 \mathrm{a} 2$ and $5 \mathrm{~b} 3$, up to the lower corner of the posterior end where it is crossed by the fasciole (Pl. I, fig. 3). The anterior invagination appears to me a little less open than in $P$. Wandeli. Its end is very round. 
The posterior region of the test, in the form of a trumpet, is well developed. It is slightly enlarged and raised behind the periproct. Seen in profile, it has a straight upper border, directed obliquely above and backwards. It is connected by a fairly sharp corner to the posterior border of the body. This is very convex and broadly round. It goes to the ventral surface following a very regular curve (fig. 8). The posterior surface of the trumpet has, seen from the front, a clearly polygonal contour (fig. 11 and 12). It is constituted of two superposed areas having nearly the same height and joined at a very open corner. The upper area is trapezoidal with the narrower upper border and the lower area is trapezoidal.

The apical system is extremely close to the anterior end. It is located on the round corner that connects this end to the dorsal surface. Its structure is interesting because the genital plates are much more distinct than usual and their boundaries remain fairly clear for nearly all their contour. There are slight variations according to the specimen. The gonopores are large, oval, directed obliquely outwards in each pair. The anterior ones are closer together than the posterior ones. On the non-denuded test, we see a small papilla on each of them.

In specimen B (Pl. I, fig. 14), the two anterior genital plates located on the extension of the anterior series of their respective interradius, are rectangular and of the same form. Only their proximal border is indistinct. These two plates make, in fact, a madreporite that fills the middle of the apical system. It forms a small lozenge-shaped area that has some perforations. It is, in contrast, clearly separated from the posterior genital plates. In front, the two anterior genital plates are separated by the end of the ambulacrum III, whose very small last plates form a wedge that goes between them. The gonopore fills a good part of the surface of the plate and leaves outside it only a fairly narrow border. The two posterior genital plates correspond, to the contrary, respectively to the extension of two ambulacra II and IV. They are separated anteriorly approximately two-thirds of their length by the madreporite that goes between them like a wedge. In their posterior region, where they are closer, these two plates are not separated by a very distinct line of demarcation. It seems a common part has two or three small tubercles. But it is possible however that this part belongs completely to the right plate because I believe I can distinguish a groove leaving from the posterior corner of the madreporite and going obliquely to the left in a way that limits the left posterior genital plate that would be consequently notably smaller than the right. But I cannot confirm this. On the rest of their periphery, the boundaries of the two posterior genital plates are perfectly distinct. The gonopores widen up to their anterior border, leaving behind them a fairly large space.

In specimen A (fig. 13). The apical system is a little smaller and narrower than in specimen B and its constitution is a little different. The contours of the plates always remain rather distinct. The two anterior genital plates are separated for nearly their entire length by the proximal plates of ambulacrum III. The left anterior plate is large and elongated, nearly rectangular, with the two large borders nearly parallel. It extends in the direction of series $a$ of interradius 3. The gonopore, near the madreporite, is rather narrow and very elongated, without however reaching the anterior border of the plate. It fills only part of the surface of the latter. The right anterior plate is, to the contrary, very much smaller, nearly as wide as long. It is nearly all filled by the gonopore that is wider and less elongated. Behind these two plates is the madreporite that is extended somewhat between them and that is moreover fused to them. This madreporite is much smaller than in specimen B. It encroaches on the right posterior genital plate and touches the gonopore of the latter. Its pores are much less numerous, only six. Behind the madreporite, the two posterior plates 
are contiguous for half their length. Their contours are then are very clear. The left plate continues series $b$ of interradius 3 . It is hexagonal, a little longer than wide. Its opening, located toward its middle, is elongated obliquely forward. The right plate continues series $a$ of interradius 2 . It is hexagonal but with an inner corner occupied by the madreporite.

We also find some differences in the arrangements of the plates of the dorsal surface in these two individuals.

The ambulacral and interambulacral regions of specimen A greatly recall that which exists in $P$. Jeffreysi and especially in $P$. Wandeli. The photograph in Pl. I, fig. 4 represents the ventral surface of specimen $\mathrm{C}$. The only one in which, despite a hole, the plates of this surface show in a clear and nearly complete manner. We can confirm that these plates are arranged as in $P$. Wandeli (see Mortensen 07, Pl. V, fig. 6). These are from interradius 5 that have the most characteristic arrangement. The labrum is invisible exteriorly and plates I a1 and V b1 have nearly the same form. The latter however is a little larger. Both are very elongated and narrow greatly in the peristomial region where each has a small ambulacral pore. Apart from these pores, I have been able to recognize with certainty only two other pores on each side. Behind, plates 1b2 and 4b2 are contiguous approximately a third of the anterior length. They are separated behind by plate 1a2 that goes between them like a wedge. This latter plate is elongated and triangular, longer than in $P$. Wandeli. The large unpaired median plate that, according to Loven, represents plates b2 and a2 of interradius 5, and that Mortensen has shown to be only one plate 5b2, separating in front, as in the two species cited above, the two ambulacral plates Ia2 and $\mathrm{Vb} 2$. It is very elongated and relatively narrow, two and a half times longer than wide. Its length equals nearly a quarter of the total length of the test. Simply convex in its anterior third, this plate rises rapidly into a very noticeable median ridge whose section is an acute angle This plate, covered with large, dense primary tubercles, forms a ventral plastron completed by the two following plates. According to the observations of Mortensen, these should be numbered respectively $5 \mathrm{~b} 3$ and 5a2. The ventral keel continues along the median suture up to the point where they are crossed by the anal fasciole. Beyond this point, the plates rise obliquely toward the dorsal surface in forming an obtuse angle. They contribute to the formation of the proboscis-like posterior region. They mainly limit the ventral part.

This posterior part that develops widely behind the periproctal notch and thickens at its terminal end, is in large part formed by the plates of interradius 5. Its posterior surface, as I said above, is pentagonal (fig. 11 and 12), with a straight, horizontal upper side, two very slightly divergent lateral sides and two oblique lower borders anterior, with a sharp ventral corner that meets the end of the ventral keel. The pentagon is not at all regular. The dorsal border is in fact a little larger than the others. The dorso-lateral corners are obtuse while the ventral corner is sharp. The lower part of this pentagonal surface is formed by the plates b3 and a2 of interradius 5, plate $\mathrm{a} 2$ remaining behind $\mathrm{b} 3$. The plates $\mathrm{a} 3$ and $\mathrm{b} 4$ of the following pair form the middle part of the trumpet. The upper border of plate b4 only slightly passes that of plate a3. Plates a4 and b5 form the upper and nearly straight corner of the trumpet. They pass to the dorsal surface of the test where they are crossed by the upper branch of the fasciole. Their respective anterior borders reach nearly the same level. However, plate a4, contrary to what we observed in the preceding, takes a slight advance while in the following pair a5 and b6, this latter passes the other a little. These two latter plates are shorter, wider than long, and they do not reach the periproct. The periphery of the latter is limited by the two pairs a6-b7 and a7-b8. That are at the bottom of the periproctal notch. The 
upper border of the periproct is limited by a small portion of the pair a8-b9. This portion of the plates a8-b9 that fills the periproctal notch of the dorsal side is slightly oblique in front. It is covered with very dense secondary tubercles, but the most extended part of these two plates is developed especially in front of the notch and contributes to form the end of the dorsal keel. Their anterior borders are exactly at the same level. Regarding this point, the dorsal plates of interradius 5 are succeeded by very irregular pairs. They join their congeners following an angle that, in the posterior part of the test is very sharp although slightly rounded. It rapidly becomes more and more obtuse (Pl. I, fig. 6). At the same time, the successive plates become less wide so that instead of being wider than long, as they were in the posterior region, they become longer than wide as they go toward the apical pole. The region that corresponds to the dorsal keel is formed by the succession of plates a8-b9 to a16-b17. The maximum height of the test is at the level of pair a14b15. In specimen B, the two plates a16-b17 are again nearly equal although the plates of 1a series is a little shorter and narrower than in $b$. The keel disappears on these plates and all the dorsal surface in front is simply convex.

If we continue the study of the dorsal plates of specimen B, we shall see (fig. 6 and especially fig. 14) before the pair of slightly unequal plates a16-b17, another pair of plates a17-b18, this time very unequal, plate $b$ being much shorter than $a$. Before this pair, the regular series of plates of interradius 5 is broken by the intercalation of the two posterior interradial pairs 1 and 4 . Their arrangement appears to me to correspond exactly to that Loven has shown in P. Jeffreysi (83, $\mathrm{Pl}$. I, fig. 1). Before the last plate of each series $4 \mathrm{~b}$ and 1a, we recognize first two small plates disposed obliquely in relation to each other, the anterior, a little larger, that undoubtedly correspond to pair a18-b19. The latter is a little larger than a18. Finally, immediately behind the apical system are two large unequal plates, the left smaller than the right that is very large. Both are in contact with the posterior genital plates. These plates represent undoubtedly the last pair a19-b20 of interradius 5. The inequality of these two plates is more noticeable in P. Jeffreys where they are separated from the preceding pair a18-b19, the last of $1 \mathrm{~b}$ being contiguous by an extremely short border with the last plate of $4 \mathrm{a}$. Here these two last plates ( $\mathrm{I} b$ and $4 \mathrm{a}$ ) remain rather separated from each other because of the intercalation of plates a18-b19 of interradius 5 b19 is largely contiguous with the large plate $b 20$.

Another interpretation of the composition of the test in the area of the apical pole is possible if one compares that arrangements that I just described to those we know in P. laguncula. We can, in fact, accept that the left plate a19, which is contiguous with the left genital plate alone ends interradius 5 and remains unpaired, while the larger right plate, which I have called b20, represents the last plate of interradius $1 \mathrm{~b}$. I believe however that the first interpretation is correct.

In specimen $A$, that has a length a little larger than the preceding $(45.5 \mathrm{~mm})$, the arrangement of plates of the posterior interradius 5 is a little different (fig. 5 and 13). The plates that, after the ninth of each series, are arranged on either side of the median keel, decreasing gradually in width up to pair a17-b18 inclusively, on which the keel stops. These two plates are much smaller than the preceding. Without having exactly the same form as each other, they are however both the same length and width. The two large plates that follow them, i.e., the last of series $1 \mathrm{a}$ and $4 \mathrm{~b}$, are back to back nearly their entire length on the dorsal median line. In front of them are two small plates placed obliquely to each other, unequal and arranged as in specimen B. These two small plates that represent obviously a18-b19. It is the latter that is the larger. Finally, between this pair and the posterior genital plates, there are only two large plates. The smaller one on the right is the last of series $1 \mathrm{~b}$ whose relations are the same as for the corresponding plates of specimen $\mathrm{B}$. The other on the right is much larger and ends series 4a. If this point of view is correct, plates a19 and 
b20 are missing in specimen A. It is moreover possible that they are fused with the two large adjacent plates of $4 \mathrm{a}$ and $1 \mathrm{~b}$.

The differences I just indicated between the two specimens A and B are not surprising because we know that Loven and Mortensen have reported variations in the arrangement of plates in various species of Pourtalesia.

The primary tubercles are not numerous on the ventral surface of the test, in the ambulacral zones and in the interradii 1 and 4 (fig. 3 and 4). They appear abruptly on the ventral plastron constituted, as we know, by plate $5 \mathrm{~b} 2$ and the greater part of the two following plates up to the ventral branch of the anal fasciole. They are very large and very dense. The appear again, but smaller and less numerous, behind the fasciole. They continue on the sides of the posterior trunk. Toward the anterior end and on either side of the peristomial invaginaton, the very developed primary tubercles form very regular longitudinal rows that are particularly noticeable on series II b and IV a up to the middle of the height of the test. Each plate has a median row of four or five large tubercles. Similar rows, but a little less developed, appear on the first interradial plates of series $2 \mathrm{a}$ and $3 \mathrm{~b}$. Finally, we find some again on the first plates of IIa and IVb, where they keep their large size but without being arranged in regular rows. On the other plates, these tubercles, two to four per plate, are very irregularly distributed. The primary tubercles of the dorsal surface remain few in number and irregularly dispersed, except on the large plates of interradius 5 that forms the dorsal keel where they are more abundant but always dispersed without order. They are, to the contrary, rarer on the adjacent ambulacral plates, i.e., on the series Ia and Vb. They are seen, moreover, only toward the external border of the plates. This results in the formation of a band nearly lacking in primary tubercles on each side of the keel (fig. 5 and 6).

The miliary tubercles are not dense.

As I said above, the spines are nearly all missing and those that remain are nearly all broken. A single specimen has preserved intact most of the dorsal spines and we can see in the photograph that I have reproduced here (Pl. I, fig. 1) that the large primary spines of the dorsal surface can become very long. These spines, very fine and sharp, are a little curved and they are especially directed backwards. They recall those of $P$. Wandeli, but they appear to me, however, to always remain shorter than in the latter species. The spines of the ventral plastron, as well as they large spines of other parts of the body, are all lost or broken near the base. The surface of the primary spines has very small denticulations, conical and pointed, very spaced on the largest and become more numerous and nearer to each other on the small ones.

The spines of the anterior invagination are shorter and fairly thick, more or less enlarged at the end. They are sometimes curved and then have various forms. They frequently have some spaced denticulations that are seen only on one side of the borders. These spines resemble those that Mortensen figured in Wandeli (07, Pl. IX, fig. 20 and 34). I reproduce here some photographs of the most characteristic forms (PI. XVI, fig. 7 to 10 and 15).

To the contrary, in the periproctal notch, the spines remain cylindrical, smaller, and the round end is slightly or not enlarged. They are also sometimes a little curved. They have denticulations that are very close together, conical and pointed, more numerous on one side, which is the concave side, when the spine is curved. These spines keep the same size up to the end (fig. 1 and 6).

The smallest spines have characters near those that have been described and figured in $P$. Jeffreysi, Wandeli and laguncula. They especially resemble the miliary spine that Meijere has represented in the last species (04, Pl. XXI, fig. 421), but the enlargement at the end is less abrupt. These spines are most often straight. The denticulations scarcely appear until the spine begins to enlarge. They develop more and more toward the end at the same time that they anastomose (fig. 
2 and 5). In the anterior invagination, the terminal part of these small spines often enlarges abruptly and make a more or less noticeable angle with the rest of the spine. The denticulations are scarcely seen on the convex side (fig. 5). Finally, there are simply cylindrical spines, slightly curved toward their terminal third (fig. 11) and identical to the miliary spine shown by Mortensen in $P$. (Helgocystis) carinata (07, Pl. XI, fig. 38).

The clavules of the fascioles are generally lost and nearly all that remain are broken near the end. These clavules resemble, as usual, the miliary spines, but they are smaller, thinner, and with a simpler structure. Their enlarged ends contain a small number of calcareous rods and the lateral teeth are little developed (fig. 4).

I have not seen spicules in the walls of the pedicels of the anterior ambulacrum and the lateral ambulacra.

I have not encountered many pedicellariae, without doubt because the test of most specimens is more or less abraded. I have found tridactyle pedicellariae, always of very small size, two forms of rostrate, but no ophiocephalous pedicellariae.

The tridactyle pedicellariae recall rather the trifoliate that we often encounter in spatangoids. They resemble those that Mortensen has described and figured in P. Jeffreysi (07, p. 61, Pl. XI, fig. 8) and hispidus (p. 79, Pl. XI, fig. 31). The length of the valves does not exceed $0.07 \mathrm{~mm}$. They have together the form of a triangle that narrows very little from the base to the top (fig. 13). The basal region is shorter than the blade. It has on its borders fairly small denticulations that appear toward the middle of its height and continue to the end. These denticulations are regular and of the same size, except the first two or three that are a little smaller. The perforations of the blade extend nearly to the borders as in P. Jeffreysi.

The most numerous rostrate pedicellariae have fairly thin valves, (07, Pl. XI, fig. 10). Their form recalls that which Mortensen has represented in P. Jeffreysi but the blade is relatively a little shorter than in the latter species (fig. 11). The convex terminal border has a row of approximately ten rather strong and recurved teeth. The basal part is triangular and its height is nearly equal to that of the blade. The length of the valves is $0.4 \mathrm{~mm}$ on average. The calcareous stalk of the peduncle articulates directly with the head that is covered with a membranous envelope containing a deep brown pigment.

Other rostrate pedicellariae are rare. I have been able to prepare only some incomplete valves. They are distinguished from the preceding by a very large head, wide and relatively short. The valves stand out by the considerable enlargement of the basal part that is followed by a very reduced blade (fig. 12). They recall those that Mortensen represented in P. (Helgocystis) carinata (07, Pl. XI, fig. 39) and Döderlein in Spatangus capensis (06, Pl. XLVIII, fig. 4b), but the blade is still shorter and more enlarged at the end. The basal part, remarkably enlarged, is nearly two times wider than long. Its blades are strongly rounded. They form together a semi-circle, while the posterior border is simply convex. The borders can have some rudiments of teeth, very low and not obvious. The blade is much shorter than the basal part. It is very narrow at its origin. Then it enlarges rapidly. It ends in a strongly convex border armed with a very regular row of eight or nine equal teeth, very strong, thick and conical. It is strongly curved. Its borders are very thick. Its perforations are small and few, while they are larger and denser in the basal part. The valves have nearly the same length as in the preceding form. They are equally covered by a pigmented tissue. I have not seen transitions between these two forms.

The general coloration of the specimens in alcohol is a pinkish purple, paler on the lateral surfaces, deeper toward the anterior end, on the posterior notch, on the dorsal keel as well as on the ventral plastron. 
SIMILARITIES AND DIFFERENCES. - $P$. Alcocki is referred, as I said above, to the section Pourtalesia s. str., as Mortensen has defined it $(\mathbf{0 7}$, p. 82). It is near P. Jeffreysi and Wandeli. It approaches especially the latter by the general form of the test and by the long spines on the dorsal surface that are slightly curved and directed backwards. But is distinguished by the projection of the sternal plastron, by the depth of the periproctal notch that is inclined forward and by the posterior trumpet that is raised from the dorsal side. The plates of the posterior interradius reach a high number on the dorsal surface. Finally, and this character is important to note, the apical system does not have the almost complete fusion of genital plates that we usually see in the genus Pourtalesia. There is likewise a form of rostrate pedicellaria with a short, stocky head that appears special to our species.

Anderson has reported (99, p. 10) a Pourtalesia coming from the Andaman Islands (Station 228 , depth of 640 fathoms) that was represented only by fragments of two or three tests. I have not found them in the collection sent to me.

I am happy to dedicate this species to Lt. Col. Alcock who was director of the dredges of the INVESTIGATOR for several years and with whom I have had the most cordial relations when he was Superintendent of the Indian Museum.

\section{Aceste Annandalei, nov. sp.}

(PI. I, fig. 15 to 17 ; Pl. II, fig. 1 to 16 ; PI. XVI, fig. 16 to 34; Pl. XVII, fig. 1 to 5)

Station 312. — 1056’15” Lat. N.; 92³3' Long. E. 1,343 fathoms. — One specimen N" $\frac{1788}{7}$.

Station 313. - 15'21' Lat. N.; 02"48"45" Long. E. 1,500 fathoms. — Nine specimens. $\mathrm{N}^{\circ} \frac{1789-92}{7}$ and $\frac{1801-05}{7}$.

$6^{\circ} 18^{\prime}$ Lat. N.; 90"40' Long. E. 1,520 fathoms. — One specimen in bad condition.

The specimens are nearly all of relatively large size. In one of them, the test length reaches or exceeds $35 \mathrm{~mm}$. In most of the others, the length reaches or exceeds $30 \mathrm{~mm}$. Only two individuals are smaller. Here are the principal dimensions I have taken on some of these specimens:

Length of the test. ........................

Width.

Maximum height.

Distance between the middle of the gonopores and the anterior end of the test.

Distance between the middle of the gonopores and the posterior end of the test.

Length of the dorsal ambulacral groove to the bottom of the anterior notch.

Maximum width of the dorsal groove. ....

Depth of anterior notch.

\begin{tabular}{cccccccc}
\multicolumn{7}{c}{ Specimens } \\
$\mathrm{A}$ & $\mathrm{B}$ & $\mathrm{C}$ & $\mathrm{D}$ & $\mathrm{E}$ & $\mathrm{F}$ & $\mathrm{G}$ & $\mathrm{H}$ \\
$\mathrm{mm}$ & $\mathrm{mm}$ & $\mathrm{mm}$ & $\mathrm{mm}$ & $\mathrm{mm}$ & $\mathrm{mm}$ & $\mathrm{mm}$ & $\mathrm{mm}$ \\
35 & 31 & 32 & 32 & 32 & 30 & 25 & 19 \\
25 & 24 & 24 & 24 & 24 & 24 & 19 & 14.5 \\
17.3 & 15 & 15 & 15 & 15.5 & 14.5 & 12.5 & 11 \\
& & & & & & & \\
28 & 24 & 25 & 25 & 26 & 23 & 21 & 15 \\
& & & & & & & \\
7 & 7 & 7 & 7 & 6 & 7 & 4 & 4 \\
27 & 23 & 25 & 23 & 23 & 21 & 18 & 13 \\
10 & 10 & 11.5 & 10.5 & 11 & 10 & 9.5 & 7.5 \\
5 & 4 & 5 & 5 & 5 & 4.5 & 3 & 2.5
\end{tabular}


Length of the fasciole.

$\begin{array}{cccccccc}30 & 25 & 25.5 & 27 & 27 & 25 & 22 & 13.5 \\ 18 & 20 & 20 & 19 & 19.5 & 18 & 16 & 13 \\ 3 & 3 & ? & 3 & 3 & 2.5 & 2.2 & 2 \\ 5 \times 3.2 & 5 \times 3.2 & 5 \times 3.6 & 5.5 \times 5 & 5 \times 4.8 & 4.5 \times 4 & 3.2 \times 3.9 & 3 \times 2.5\end{array}$

I shall describe the species especially after specimens A, B and C.

The test is elongated and, as can be seen in the table above, the ratio between the length and the width varies according to the specimen.

When seen by the dorsal surface (Pl. II, fig. 1 to 3, 5 and 6, 9, 11 and 12), the contour of the test first increases very rapidly for approximately a third of the length of the body. Then the width scarcely increases so that the maximum width is found toward the middle of the length or a little behind. Afterwards, the test rapidly narrows and ends in a broadly rounded border. The dorsal surface has in its middle, and for approximately two-thirds of its length, an enormous depression that is characteristic of the anterior ambulacrum of the genus Aceste. It appears more developed here than in A. bellidifera. This depression has, as a whole, the form of an elongated oval, pointed backwards, truncated in front, with oblique borders (fig. 1 to 3, 5-6 and 11-12). The notch in front is deep, with vertical surfaces. It appears deeper when we look at it from the dorsal side than from the ventral side because the bottom is filled by the peristome that has in front the thick, convex labrum. Seen from the side, the test is thinner anteriorly, thinner than in A. bellidfera. It ends in a round corner (fig. 16 and 17). The dorsal surface rises slowly and regularly. Its profile forms a nearly straight line up to the end of the dorsal groove, i.e., for more than two-thirds the length of the body. From there, it turns obliquely downward at a broad angle, sometimes sharp, sometimes round. Then it joins the posterior end. This has first an upper part that is ordinarily nearly vertical, but sometimes a little oblique behind, which is above the periproct. It is followed, below, by an oblique part in front, two times longer than the preceding, whose upper half is filled by the periproct. This latter part is joined to the ventral surface by a very round curve that is not projecting. This corresponds to the posterior border of the ventral plastron. On either side of the midline at this level, we see a fairly wide, although low, prominence that marks the end of the ventral ambulacra.

Seen in profile, the ventral surface first follows a regular and convex curve that then flattens (fig. 16). The height of the test increases gradually for approximately three-fourths the length of the body up to the point that, in the larger specimens, is 4 or $5 \mathrm{~mm}$ before the posterior border of the ventral plastron. It is at this point, which corresponds to the most elevated place of the dorsal surface, that the test reaches its maximum height. The lower lip forms only an insignificant projection in the profile of the ventral surface. The labrum, which this lip ends in front, has a very convex surface. It is extended in front of the posterior wall of the anterior notch so that the peristome, limited behind by the lower border of the notch, has a horizontal or very slightly oblique position in front. The curve of the ventral surface of the test of $A$. Annandale $i$ is thus very different from that Agassiz has represented in A. bellidifera, as one can be convinced by comparing the figure of this author (81, Pl. XXXIIIa, fig. 3) to the photographs I reproduce here (Pl. II, Fig. 7, 15 and 16).

The apical system is located on a small horizontal area between the posterior end of the dorsal groove and the posterior corner of the peripetalous fasciole. But it is nearer the end of the groove. In specimen B (Pl. I, fig 16, and Pl. II, fig. 11), the two genital plates, transversely widened, have very clear external contours, but they are fused in the median line. The gonopores, with a diameter of $0.7 \mathrm{~mm}$, are very near each other and only $0.3 \mathrm{~mm}$ apart, while the distance that separates them from the external border of the plate is equal or scarcely less than their diameter. Behind these two 
openings is a triangular or pear-shaped region that extends to the end of the posterior ocellar plates. This region, as well as the narrow space that separates the two gonopores, is filled by the large water pores. These continue anteriorly on a more widened plate, limited by the ocellar plates II, III and IV and that is obviously formed by the fusion of the anterior genital plates.

The anterior ocellar plate is large, pentagonal, elongated in the antero-posterior direction and narrowed in the proximal region that is limited by one side narrower than the others. In front, it is limited by two sides that are united at an obtuse and truncated corner from the top of which the opening is brought nearer. Plates II and IV are smaller, triangular, with the opening located nearly equidistance between the top and the base. The posterior plates are short, very widened transversally, two and a half times wider than long, with a wide, convex proximal border, and a shorter, concave distal border. The opening is located toward their middle.

In specimen C (Pl. I, fig. 17, and Pl. II, fig. 12), the fundamental arrangement remains the same but the water pores are less developed and less numerous and the area where they are found is not as wide in front and back of the gonopores as in the preceding example.

The groove that forms the anterior ambulacrum of the dorsal surface of the test is remarkably large and developed. To judge from the figures published by Agassiz, it is larger than in $A$. bellidifera, especially in the anterior half. The groove begins approximately $2 \mathrm{~mm}$ in front of the gonopores in a sharp corner of the top corresponding to ocular plate III. It rapidly becomes deeper and very wide and reaches its maximum width toward the middle of the length of the body. Then it gradually narrows in front. Its borders are continuous with those of the anterior notch toward the place where they meet the fasciole or a little behind this point. The lateral walls of the groove are oblique, but its floor remains horizontal for approximately three-quarters of its length, while it rises toward its posterior end. The two poriferous zones are arranged parallel to each other on the horizontal part, where they are separated by a space greater than $4 \mathrm{~mm}$. Then they approach each other in the area of the apical system toward which they converge. The pores are always geminate. The five pairs of plates closest to this system are extremely reduced, very short. We do not see any peripodial differentiation around their pores. The following pairs are, to the contrary, very developed. Each pair is surrounded by an oral protrusion of which the posterior border is particularly accentuated. The internal pores are narrow and elongated, direct obliquely forward, while the external pores are round. The large peripodia are very dense and contiguous, except for the two or three last ones that are gradually separated from each other. We can see these peripodia up to a short distance behind the anterior notch. Thus in specimen $\mathrm{C}$ ( $\mathrm{Pl}$. II, fig. 12), the second plate that is found behind the fasciole has again a large peripode. The following plate, that immediately precedes the fasciole, has only two rudimentary pores. These are quite indistinct on the plate crossed by the fasciole. These pairs of large pores that have rosette pédicelles thus extend on both sides of the dorsal groove, much more forward than in A. bellidifera, as we can see in comparing the figure of Agassiz (Pl. XXXIIIa, fig. 1 and 7) to the photographs I give here (Pl. II, fig. 1 to 3, 5 and 6, 11 and 12). The pore pairs are also more numerous. I count in all nineteen pairs in individual $\mathrm{C}$ while, according to the figures of Agassiz, there are only eleven pairs in $A$. bellidifera.

Toward the anterior end of the test, the borders of the dorsal groove come together and form a deep notch limited by two parallel vertical surfaces. In its posterior third, this notch has a floor that first takes a direction very oblique toward the ventral surface, but that rises and becomes horizontal in the terminal part where the peristome is found. The anterior notch is limited, on its posterior and dorsal border, by a concave side. It measures approximately $7 \mathrm{~mm}$ in length when we look at the 
body from the dorsal side, while it measures only 4 from the ventral side. The lateral surfaces are separated from each other by an interval of approximately $4 \mathrm{~mm}$.

The oblique sides of the dorsal groove have only a few miliary tubercles. The bottom of the groove, in the interporiferous zone, has primary tubercles of average size, fairly numerous but irregularly dispersed. They are seen especially in the area of each poriferous zone, while the median region has only very dense secondary and miliary tubercles. In the anterior part of the groove, these primary tubercles become more numerous and extend up to the median line. They are continuous beyond the fasciole in the anterior notch, both on the floor and on the sides of the latter. On each side of the groove, the dorsal surface is uniformly covered, on all its extent, with primary tubercles that, outside the fasciole, are denser in the anterior and posterior regions of the test than in the middle part. These are, moreover, always become smaller as they approach the fasciole (fig. 11 and 12). Inside the fasciole, the tubercles are first very small. They become larger as they approach the dorsal groove. On the lateral surfaces of the test, the tubercles are a little smaller than on the anterior end. They are not very dense. They are often arranged in more are less apparent horizontal series (fig. 16). On the ventral surface, they separate slightly from each other and become smaller as they approach the posterior ambulacra. They are small and dense in the posterior region and larger toward the anterior end (fig. 10).

The ventral posterior ambulacra are very narrow (fig. 10). Their plates have only a small number of secondary tubercles, more numerous in series Ib and Va, where they are continuous with the primary tubercles of the adjacent interradius. Each ambulacrum has five pairs of plates. The fifth plate of the internal series, i.e., Ia5 and Vb5, is elongated toward the median interradial line to fill an episternal angle that is due to the enlargement of the preanal plate 4 . The fifth ambulacral plate sometimes participates a little in the formation of the prominence that I have indicated above and that is found at each posterior angle of the ventral plastron. But this is especially constructed at the expense of the preanal plate. The following ambulacral plates are uniformly covered with primary tubercles identical to those of the adjacent interradial plates.

The sternal plastron has the form of a very elongated triangle. The base is narrow and its two posterior corners are indicated by the protuberances that are found at the end of the ambulacra (fig. 10). The width of this base is a little greater than $10 \mathrm{~mm}$, while the height of the plastron is $23 \mathrm{~mm}$. The labrum is wide and thick on its anterior side to form the lower lip. Immediately behind this ledge, it is strongly narrowed. Then is a very slowly widens up to its posterior side. It is a little wider than in A. bellidifera. Its straight lateral borders are slightly divergent. It is nearly two times the length of the first adjacent ambulacral plate and has only some small tubercles on its thick anterior border. As I have said above, the labrum follows the general curve of the ventral surface of the test. It is thus fairly strongly convex, both front and back and side to side. The two sternal plates that follow are very elongated. They are, as usual, covered with primary tubercles arranged in oblique divergent series in which the size increases gradually from the posterior and internal corner. The two episternal plates, covered with very dense tubercles identical to the preceding, are fairly short and subequal. The plate of the series $a$ is however a little longer than its congener. The two following plates, or preanals, are very developed. The plate of series $b$ is a little wider than the other while, in contrast, its congener is more elongated. It is contiguous to the periproct over nearly a third of its half-circumference, while the first touches the periproct only by a very narrow border. Each preanal plate being very much wider than the preceding, a sharp corner results in which penetrates the corresponding ambulacral plate. The plates of the following pair 5-5 are subequal, although plate $b$ is a little wider and its posterior border is carried back a little further back than that of plate $a$. The upper border of the periproct is completed by plates $6-6$. The internal 
region of the preanals is covered with small, spaced primary tubercles. They become, in their external and anterior regions, very much larger and denser. They are continued with some similar tubercles developed on the posterior region of ambulacral plates Ia5 and Vb5. They overlap with the posterior prominences that I reported above. Plates 5-5 and the following ones are uniformly covered with primary tubercles, of average size, identical to what we find at the posterior end of the body.

We see, by what I just said, that the arrangement of the plates that follow the two sternals in interradius 5 is much different from that Loven has described and figured in A. bellidifera. It is much more regular (see Loven, 83, Pl. XX, fig. 234).

The peristome, located as in A. bellidifera at the lower part of the anterior notch, is in a plane directed obliquely downward. Its width is equal to that of the notch in which it is found, approximately $4 \mathrm{~mm}$, and a little greater than its length. The plates that cover it are extremely thin and very small.

The periproct (Pl. II, fig. 13), is generally oval and elongated vertically. However, the height hardly exceeds the width. In the small specimen $\mathrm{G}$, which is $25 \mathrm{~mm}$ in length, it is even a little wider than tall. It is located on the oblique part of the posterior surface, immediately below the vertical portion of this region. It has a marginal row of fairly large plates, especially toward the two upper and lower borders. Inside is a row of much smaller plates, then others that are extremely reduced and irregular. The anus is located toward the middle. The fasciole has, in general, the form of a lozenge with a truncated anterior corner. Its borders are nearly straight or slightly sinuous. The posterior corner, less than a right angle, is generally fairly sharp, although it is sometimes a little round at the end (Pl. II, fig. 1 to 3, 5 and 6,11 and 12). It rather recalls the form represented by Agassiz in 1881 in Pl. XXXIIIa, fig. 1, than that in Pl. XXXII, fig. 8. The thickness of the band that it forms remains constant for the four sides of the lozenge. It is a little greater than $1 \mathrm{~mm}$ and decreases slightly only on the part that crosses the anterior notch. The fasciole approaches this notch toward the middle of the space between its bottom and the anterior end of the test. But the moment where it descends on the vertical wall of the notch, it abruptly curves backward at a sharp angle and turns back in a way to cross the notch at a very small distance before the point where the anterior groove narrows and where its floor, ceasing to be horizontal, takes an oblique direction downward. There are some variations in the form of the fasciole in relation to its length and width. In general, the lateral angle, that is very obtuse, is found a little behind the middle of the test in adult specimens. In the young individual that is shown in Pl. II, fig. 3, these angles are not very noticeable and are more rounded.

Most of the specimens have lost nearly all their spines. They have scarcely kept those of the dorsal groove with the pedicels with a rosette that are so characteristic of the groove. In specimen D however, a good part of the spines still exists. But most of them of the ventral surface, and notably those of the plastron, are broken and incomplete. It is only in the smallest individual that some spatulate spines of the plastron are preserved. I have, however, found at the bottom of the jars some spatulate spines. These can be seen over the entire plastron, as in A. bellidifera. They are identical to those of this species in the same region and that Agassiz has figured (81, Pl. XLI, fig. 13). I have two photographs (Pl. XVII, fig. 2 and 4).

The ventral ambulacra have only some little developed spines up to the level of the posterior end of the plastron, where we see abruptly appear primary spines similar to those found on the rest of the ventral surface. Their length can then reach $5 \mathrm{~mm}$. They are small and cylindrical on half or two-thirds of their length. Then they flatten a little at the same time that they curve and slightly enlarge (Pl. XVII, fig. 3 and 5). But the increase in size is never very great and does not double 
the width of the spine at its base. These spines are particularly elongated on the sides of the anterior notch. They most often have low denticulations on their borders, conical and fairly dense (fig. 1 and 3 ).

On the lateral surfaces of the test as well as on the sides of the dorsal surface, between the ambitus and the fasciole, the primary spines become shorter. But they are much enlarged and flattened toward the end. They take thus a clearly spatulate form, especially in the anterior half of the test. These spatulate spines are distinguished from those of the ventral plastron, first because the terminal part, enlarged and flat, does not appear as abruptly but passes gradually to the preceding cylindrical part. And then because these two parts, instead of remaining as an extension of each other, make together an obtuse corner than corresponds to the curvature of the test. The enlarged part of the spine has the form of a very elongated oval, at least three times longer than wide. The surface turned toward the exterior is slightly concave. Some obtuse and fairly spaced denticulations appear especially toward the point where the spine begins to enlarge. But they disappear on the spatulate part. The structure of these spines is the same as those of the large spatulate spines of the ventral plastron. In particular, the calcareous network extends on all the enlarged part instead of stopping at its base.

These largely spatulate spines are seen on the lateral and dorsal parts of the anterior region of the test. But they do not reach the obtuse corner of the fasciole toward the middle of its path. At this level, the spines rapidly become narrower at their end that still remains a little enlarged. They keep thus a slightly spatulate form as well as those on the sides of the ventral surface.

Inside the fasciole, the spines, very short at first, rapidly elongate in approaching the dorsal groove. They then become very large. Their length can reach $6 \mathrm{~mm}$. They are directed horizontally and meet the congeners from the opposite side, with which they can overlap at their end. Several of them are thick and stronger than the other spines of the body. They are enlarged a little toward the end, but without sensibly flattening. They are very slightly curved. These spines are covered with rugosities or very small denticulations in the first half, but much more noticeable in the distal half where they are transformed into sharp teeth or small conical hooks, slightly curved and directed obliquely backward (Pl. XVI, fig. 23). These hooks are extremely close to each other. They are mainly on the concave side of the spine. These spines that are slightly enlarged toward the end obviously correspond to the capitate spines that Agassiz has observed in A. bellidifera and whose stalk is abruptly swollen at the end in a kind of mushroom with sharp hooks on all its surface. I have found the capitate spines in a specimen of A. bellidifera collected by the "TALISMAN" expedition. I give here the photograph of one of them (P1. XVI, fig. 35) and one can see that those of A. Annandalei are completely different.

The other shorter spines that we see both inside and outside the fasciole, and especially in the posterior region of the body, in the fasciole etc., are always a little enlarged at the end without becoming truly spatulate

The miliary spines, whose length is between 0.4 to $0.5 \mathrm{~mm}$, have nothing special. They have a very delicate calcareous network. They are enlarged slightly in their distal third where denticulations are seen that are extended toward the end of the spine. Those of the dorsal groove do not differ sensibly from the others. They are hardly a little more swollen at the end. The clavules of the fasciole are constituted of a calcareous axis whose structure is nearly identical to that of the miliary spines (Pl. XVI, fig. 22), with a membranous envelope that is enlarged at the end. Their length is approximately $0.4 \mathrm{~mm}$. The calcareous stalk generally has, all along its length, small lateral teeth that correspond to the transverse rods of the calcareous network. They remain short for approximately two-thirds of the length of the stalk. These teeth abruptly become much larger 
at the same time that they anastomose with each other. At this level, the membranous sheath, which was first very thin, abruptly enlarges to be two times larger than on the preceding part. But this terminal enlargement, instead of being round and having a globiform or sptatulate aspect, keeps parallel borders so that the clavules of $A$. Annandalei greatly recall the form shown by Hamann in Schizaster canliferus (Bronn's Thierreich. Echinodermen, Pl. IV, fig. 5). According to the figure that Meijere (04, Pl. XXII, fig. 488) has given of a clavule of an Aceste, referred by him to A. bellidifera (but that is different as we shall see later), the lateral teeth exist only in the terminal part of the calcareous stalk and are less elongated than in A. Annandalei.

The pedicellariae, which are fairly abundant, recall in several forms those that Mortensen has described in A. bellidifera, but they differ however from these latter by very clear characters, especially in the presence of particular forms. They are fairly numerous and in general of large size. They are seen especially in the dorsal anterior groove and in the notch that continues the latter forward. They belong to four types: tridactyle, rostrate, globiferous and trifoliate.

The tridactyle pedicellariae are noted for the numerous variations. I distinguish four principal types. The first contains pedicellariae with very elongated and narrow valves (Pl. XVI, fig. 29 to 31), recalling those that Mortensen represented in A. bellidifera (07, Pl. XV, fig. 51), but they are larger and their valves reach $1 \mathrm{~mm}$ in length. The basal part is very short and does not exceed a fourth or fifth of the total length. The blade is very elongated but it always remains very narrow. It increases slightly in size up toward four-fifths of five-sixths of its length. Then it ends in a round border. In pedicellariae of small size, the blade is reduced and becomes simply oval (fig. 24). The borders have in the external half of the valve, very small and very dense denticulations. These pedicellariae are very widespread on all the surface of the test.

The pedicellaria of the second type (Pl. XVI, fig. 20, 21 and 25) are similar to the second type described by Mortensen in A. bellidifera and that he represented in 1907 (Pl. XV, fig. 22), but the valves are, in general, a little more elongated. Their length can exceed $1 \mathrm{~mm}$. The basal part is wide and very short. The very narrow blade has on its edges large teeth, very wide or with more or less elongated and often rounded lobes whose number varies. They can appear from the base of the blade. The relative dimensions of the blade and the basal part vary greatly in the pedicellariae. Some, that remain stocky and relatively short and thick, have a basal part shorter than the blades (fig. 20 and 21), while in others the latter is narrower and shorter (fig. 25) with less developed teeth. Finally, we reach the pedicellariae in which the blade remains narrow and relatively elongated with teeth still less important than in the preceding form (fig. 38).

The pedicellariae of the third type have very enlarged and short valves. The length of the basal part is nearly equal or little less than that of the blade. They are identical to those I represent in Pl. XVI, fig. 41 in A. Weberi. The blade forms a large oval spoon, round at the end, finely denticulated on the borders and having large perforations. The valves always remain shorter than in the two preceding types. They do not exceed 0.7 to $0.8 \mathrm{~mm}$ in length. Similar pedicellariae have not been reported in A. bellidifera.

There is finally a fourth type of pedicellariae that does not appear to be found in A. bellidifera. Its extremely robust and massive form is to be noted. These pedicellariae, always very large, are particularly numerous in the dorsal groove. The length of their head varies between 1 and $1.3 \mathrm{~mm}$. In the largest, the very enlarged basal part is triangular, nearly as wide as long. It exceeds a little the height of the blade. Their borders are very slightly sinuous. Most often, these sinuosities are connected to each other by small obtuse corners forming the beginnings of denticulations. The blade is oval with a very round distal border. It usually has extremely small denticulations, pointed and very close together (fig. 16). Other pedicellariae, smaller than the preceding are distinguished 
by the reduction of the blade that is shorter and less developed. Its length is only two-fifths of the total length of the valve. The principal part is formed by the basal region. Its borders are a little more convex. They are sometimes smooth, sometimes with very low denticulations, more or less apparent. The convex terminal border of the blade is also denticulated (fig. 17 and 18). These pedicellariae hardly exceed $0.5 \mathrm{~mm}$ in length. They obviously represent a modification of the preceding type.

There are finally other pedicellariae that it is perhaps more correct to refer to the tridactyle type than to the rostrate type. They are also notable by their massive form. The length of the valves is nearly the same as in the preceding and measures approximately $0.5 \mathrm{~mm}$. The blade is always very reduced. Its external surface is strongly convex. Its borders, very thick and prominent, limit a more or less deep cavity. They have some low and not very prominent tuberosities (fig. 19, 26, 33 and 34). The relative dimensions of the blade and the basal region can have some variations. This type of pedicellaria is obviously fairly peculiar, but it appears to me however to have a connection to the tridactyle pedicellaria of the fourth type.

None of these pedicellariae are related to those that Mortensen has indicated in A. bellidifera. Perhaps they can approach those that Agassiz has presented in his echinoids of the CHALLENGER (83, Pl. XLII, fig. 27). Moreover, it appears to me that they can be compared to the short types of tridactyle pedicellariae that we know in diverse species of the genus Spatangus and similar to those that Mortensen figured in 1907 (Pl. XVI, fig. 3, 11, 17, 25, etc.).

The rostrate pedicellariae strictly speaking appear very poorly represented in the new species. I have in fact observed only one very small form among the clavules of the fasciole in the middle of adjacent spines (fig. 28). The head of these pedicellariae did not reach even $0.01 \mathrm{~mm}$ in length. The valves are fairly thick. The blade is nearly as long as the basal part. It has large conical and pointed denticulations in its distal half. I did not find rostrate pedicellariae similar to those that Mortensen has represented in A. bellidifera (07, XV, fig. 10 and 32).

The globiferous pedicellariae are fairly abundant in the dorsal groove. They are relatively very large. The length of their head is $1 \mathrm{~mm}$ (fig. 27). The structure recalls that which Mortensen indicated in A. bellidifera, but the basal part of the valves appears comparatively more enlarged and more developed. Each valve ends equally in two hooks that appear to me a little shorter than in $A$. bellidifera. These globiferous pedicellariae are extremely close to those that Agassiz represented in 1883 (PL. XLII, fig. 20).

The trifoliate pedicellariae are very widespread on all the surface of the test. The head measures approximately $0.2 \mathrm{~mm}$. The valves show nothing special.

The pedicels of the dorsal ambulacral groove has the well-known form characteristic of the genus Aceste. Each ends in a wide circular rosette whose border has small lobes. In the largest specimen whose length reaches $0.35 \mathrm{~mm}$, I count up to fifteen of these pedicels on each side. But the number falls to ten or twelve in the smaller specimens whose length is 30 to $32 \mathrm{~mm}$. The length of the contracted tubes is approximately $5 \mathrm{~mm}$. The rosettes have a diameter of $2 \mathrm{~mm}$. The cylindrical part has very dense spicules, sometimes straight but most often curved. They are arranged parallel to each other, perpendicularly to the axis of the tube. They have fairly numerous conical teeth, more toward the ends. Sometimes two adjacent teeth unite with each other to make a circular opening. But this structure is not very frequent and is generally seen only at one end of the spicule. In a general way, the spicules of $A$. Annandale $i$ have more numerous denticulations than in A. bellidifera. The number of rods in the terminal rosette varies around thirty. These rods remain fairly narrow for their entire length (fig. 32). The distal region is not particularly enlarged as Loven has represented in A. bellidifera (83, Pl. X, fig. 96). I should note, on this subject, that 
Mortensen reports some rods, narrow, elongated and flat in A. bellidifera (07, p. 95 and Pl. X, fig. 10) that are the characters that I find in A. bellidifera from the expedition of the TALLISMAN (fig. 36). In A. Annandalei, the basal part of the rods has a constitution similar to that which Mortensen has represented in A. bellidifera (07, Pl. SV, fig. 39), but the apophysis that ends this part is notably more elongated into a hook. The length of the rods varies from 0.8 to $0.9 \mathrm{~mm}$. They appear a little more numerous in the new species than in A. bellidifera where, according to Loven, each rosette contains twenty to twenty-seven rods.

In the specimen that has kept its spines, the color of the test is a brownish violet and the spines are whitish or greyish. The other individuals, more or less lacking spines, are greyish or pinkish grey. The tube feet of the dorsal groove are pinkish gray. The fasciole is brown or violet brown.

Here are some observations that I have made relative to the internal organization of $A$. Annandalei (Pl. II fig. 14). The esophagus is fairly narrow and thin. Its walls, yellowish in color, has fairly close folds. It is directed toward the posterior end of the test, bypassing on the right a voluminous pocket belonging to the terminal intestine and forming a strong projection on the ventral side. Then, after having run approximately three-quarters of the length of the body, it rises a little toward the dorsal surface and passes above the last portion of the first intestinal loop at the same time it curves toward ambulacrum I. It then passes to the intestine strictly speaking in which the diameter is a little greater and it takes a cylindrical form. This first intestinal loop, or ventral loop, climbs toward ambulacrum III, following a very regular curve. It passes successively by radiii IV, V and I to arrive at ambulacrum II. It then turns back and continues with the dorsal loop. This is placed at first outside the preceding, returns toward to posterior interradius 5, then goes forward past the middle of the body to reach radius IV. At this point, the intestine abruptly turns backward, but develops at the same time a considerable dilation in the form of a kind of pocket that is developed toward the ventral side. It appears, in an animal opened by this side, between the esophagus and the beginning of the intestine strictly speaking. This pocket measures, in the specimen that I opened, $9 \mathrm{~mm}$ in length and 4 in width. Seen by the ventral side, it has an ovoid form. We can give it the name rectal ampulla or stercorale. The rectum that follows is very narrow and ends at the posterior end. There is no diverticulum.

The rectal ampulla that I just noted certainly is not an artificial dilation of any accumulation of mud in the terminal part of he intestine. It must represent a constant attribute because I find it in a second specimen whose test in part is broken and thus the digestive tube is incomplete (this is the dried specimen that is designated above by the letter $\mathrm{C}$.

The intestinal siphon, very easily recognizable, follows a path nearly parallel to that of the esophagus. Its proximal end opens into the intestine near radius II, its distal end a little after interradius 5. We recognize very well in the photograph I reproduce in Pl. II, fig. 14 the distal end that is slightly sinuous. The digestive tube that is fairly deep gray in color in its first part abruptly takes on a violet color after this second opening. This continues to weaken little by little to the end of the ventral loop where it disappears. The dorsal loop takes on the same gray color as the first part of the digestive tube.

The two external and internal marginal lacunae are fairly easily recognizable thanks to their white color. The internal lacuna continues beyond the distal end of the siphon up to the end of the ventral loop.

The digestive tube keeps for nearly all its length a fairly uniform diameter greater than $2 \mathrm{~mm}$. The esophagus and especially the rectum are narrower.

The two gonads (Pl. I, fig. 15) form two nearly equal masses in the posterior region of the body, between the end of the dorsal ambulacral groove and the posterior corner of the test. It 
reaches, in the specimen I have examined, $7 \mathrm{~mm}$ in length and 4 to $4.5 \mathrm{~mm}$ in width. Their acini are relatively voluminous.

SiMILARITIES AND DIFFERENCES. - A. Annandale $i$ is noted first by its greater size than in the other species of the genus. Among the latter, A. bellidifera is especially known from the remarks that Loven (83) and Mortensen (07) have added to the very incomplete description of Agassiz. It is possible, as Mortensen noted, that there are two different species among the individuals united by Agassiz under the name of $A$. bellidifera. I have been able to study a specimen of $A$. bellidifera coming from the Atlantic and collection by the expedition of the TALLISMAN. This specimen, that is preserved in the Jardin des Plantes, is not in a very good state of preservation. I have however found in it all the characters noted by Mortensen in the specimens of the CHALLENGER that he examined. I consider that the specimen belongs satisfactorily to A. bellidifera. It served me as the basis for comparison.

A. Annandalei is distinguished from A. bellidifera by a different form of the test. The dorsal surface is flatter, while the ventral surface is more convex with the anterior end more depressed. The successive pairs of large pores of the dorsal ambulacral groove are more numerous and they continue further forward to the anterior end. The pedicels with a rosette are more numerous. They contained denser and more denticulated spicules. Finally, the rosettes are supported by more calcareous rods. The arrangement of the interradial plates that follow the two sternals, i.e., the two episternals and the two preanals, are completely different. The periproct is also more elongated in the new species and the apical system has a different structure. Finally, the pedicellariae of $A$. Annandalei is notable for the variety of tridactyles among which we see forms that do not exist in A. bellidifera, while the true rostrates are very small and unimportant. The capitate spines of the dorsal groove are replaced by slightly curved spines that are slightly enlarged at the end and with dense hooked points for most of their length.

The extreme lengths of the test indicated by Agassiz in A. bellidifera are respectively 27 and $14 \mathrm{~mm}$. Two specimens collected by the ALBATROSS and mentioned by Rathbun $(\mathbf{8 5}, \mathrm{p} .89)$ are respectively 26 and $10 \mathrm{~mm}$ in length.

A. Annandalei is certainly distinct from the two species from the Hawaiian Islands indicated by Agassiz and Clark in 1907, which measured 19 and $22 \mathrm{~mm}$ in length. The authors have given only a very brief diagnosis. But the nearly vertical posterior end, the very deep posterior groove with nearly vertical borders, the absolutely flat form of the ventral plastron that does not continue below the mouth, and finally the extension of the plastron separates these two species from $A$. Annandalei.

Meijere found A. bellidifera among the echinoids collected by the SIBOGA in the Sunda Islands. But actually it is another species. Already Mortensen, after having suggesting that the Aceste collected by the CHALLENGER in the Pacific (station 272) between the Hawaiian Islands and Poamotou at 2,600 fathoms, should not be A. bellidifera, added (07, p. 90) that if the specimens of the Pacific belong to another species, the specimen of the SIBOGA indicated by Meijere (p. 190) was certainly no longer $A$. bellidifera.

I thought it would be interesting to compare this specimen with those of the INVESTIGATOR. Prof. Max Weber has had the extreme kindness in sending it to me. This Aceste, as indicated by Meijere, has a length of $23 \mathrm{~mm}$. It is thus intermediate in size between the two smaller specimens collected by the INVESTIGATOR. By its exterior form, it much more recalls A. Annandalei than A. bellidifera. I reproduce here two photographs of this individual beside those of the small specimens from the INVESTIGATOR. (Pl. II, fig. 4 and 8). We see that in the Aceste of the SIBOGA, the dorsal 
surface is nearly flat and that the ventral surface, very swollen, follows a regular curve from the posterior end of the ventral plastron to the anterior end without the lower lip forming a very appreciable projection on the ventral surface. The posterior end is obliquely truncated only before the lower half only. Moreover, the pedicels of the dorsal groove are not really developed and have their large terminal rosette only in the posterior half of the groove, while in all the individuals of the INVESIGATOR, even in the two smallest, these tubes with a rosette extend further forward, as we see in Pl. II, fig. 1 to 3 and 5-6.

Although the specimen from the SIBOGA is in part lacking its spines, I have, however, encountered some pedicellariae. But it has been impossible to find the most characteristic forms of $A$. Annandalei that must not exist. The globiferous pedicellariae are very voluminous and rather larger in A. Annandalei. They are found, as in the latter, in the dorsal groove between the large pedicels. They recall absolutely those that I described above. The two terminal hooks are perhaps a little stronger. The tridactyle pedicellariae include pedicellariae with elongated valves, with a few large teeth on their borders that are thick and round, often arranged in a fairly regular way (Pl. XVI, fig. 38 and 42). They are similar to those of the second type that I described in A. Annandalei. Although they also have variations in the relative length of the blade and the basal part, they remain in general slender with the basal part slightly enlarged. The same form is found moreover in $A$. Annandalei. Other tridactyle pedicellariae are identical to those that I distinguish as the third type in A. Annandalei. The valves are wide and short (fig. 41). I have not encountered these large tridactyle pedicellariae nor the pedicellariae with a thick and swollen head whose valves end in a very short blade that is so characteristic of $A$. Annandalei. In contrast, the rostrate pedicellariae are large and well developed (Pl. XVI, fig. 40). They are very near those that Mortensen represented in $A$. bellildifera $(\mathbf{0 7}, \mathrm{Pl}$. XV, fig. 22). In summary, as a whole, the pedicellariae greatly recall much more those of $A$, bellidifera than those of the Indian species.

The calcareous rods of the rosettes (fig. 43) also recall those of $A$. bellidifera. The apophysis that ends the basal part is short, nearly straight and not curved and elongated as in A. Annandalei. The spicules are slightly arched and have fairly numerous denticulations.

I have not found in the dorsal grove capitate spines characteristic of A. bellidifera. They are replaced, as in A. Annandalei, by large cylindrical spines that are very slightly enlarged toward the end. They are very only slightly or not at all curved (fig. 39). The teeth that cover all the surface are arranged in regular rows. They are short, nearly as wide as long. They keep the same width up to their end that is obtuse or even sometimes slightly enlarged, but always more or less concave. This form is very different from that shown by the elongated teeth that are recurved into very pointed hooks of A. Annandalei (see fig. 23).

We see by these few observations that the Aceste of the SIBOGA is near by some characters to A. bellidifera and by others to A. Annandalei. But it is distinguished from the two species and can be united neither to one nor the other. It is obviously a new species to which I propose to give the name A. Weberi, and ask the scholarly professor of the University of Amsterdam accept this dedication.

Although the INVESTIGATOR collected no representative of the genus Aeropsis (a name that Mortensen proposes to substitute for the name Aerope that is already used), I believe that it is not useless to complete the contribution that I seek to support here the study of the Acestidæ, to give some complementary information on an Aeropsis, of which the SIBOGA has collected two specimens at a depth of 1,788 meters at $5^{\circ} 46^{\prime} 7^{\prime \prime} \mathrm{S}$. and $134^{\circ} \mathrm{W}$. We know that Meijere has referred these two specimens to A. fulva Agassiz (04, p. 195) and briefly described the spines and 
pedicellariae. Now, in 1907, Mortensen had the opportunity to examine the type of $A$. fulva and to compare the pedicellariae to those of $A$. rostrata and asked $(\mathbf{0 7}$, p. 94$)$ if the Aeropsis collected by the CHALLENGER in the Arafura Sea and united by Agassiz with A. rostrata, would not represent a third species. He notes, in addition, that the inadequate figures that Meijere has given of the pedicellariae of Aeropsis collected by the SIBOGA do not allow us to decide if it is near A. fulva or the individual dredged by the CHALLENGER in the Arafura Sea.

The question was worth the effort to examine closely. Max Weber, having the kindness of sending me one of the two specimens of the SIBOGA, I can complete the information furnished by Meijere. I am convinced that this specimen belongs to a different species both of $A$. fulva and rostrata. I consider it as new.

The individual that has been sent me is the smaller of the two individuals collected by the SIBOGA. Its length, indicated by Meijere, is $28 \mathrm{~mm}$. I naturally wanted to respect the external form of this specimen and did not believe I was authorized to remove some of the spines to study the characters of the test. I shall content myself to reproduce here the photographs that I took (Pl. II, fig. 17, 18, and 19). I took only a few spines and pedicellariae. The latter, represented by the tridactyle and rostrate types, are very characteristic, especially the rostrate. They differ from those that Mortensen describes and figures in A. fulva and rostrata. The head of the rostrate pedicellariae measures on average $1 \mathrm{~mm}$ in length. The neck is very short. The stalk of the peduncle is formed by a compact calcareous tissue. It is abruptly thickened at its end to form a very enlarged head, very much wider than tall (Pl. XVII, fig. 15). It has on its surface, and on a good part of its length, small, fairly short, conical teeth that are close together. The valves (fig. 17) remain fairly narrow for their entire length. They are slightly curved and touch only at the end. The basal part is fairly narrow, triangular, longer than wide and well separated from the blade. They keep nearly the same width for their entire length. It widens only, in a manner not very appreciable, at a short distance from its end to then narrow to end in an obtuse point. Only in the terminal part are there some very developed round and short denticulations. These pedicellariae appear fairly abundant. I have found them especially on the dorsal surface and inside the fasciole as well as on the ventral surface near the peristome. We can see that they are very different from the rostrate pedicellariae that Mortensen has described and figured in A. rostrata and fulva (07, Pl. XV, fig. 1,13 and 31).

The tridactyle pedicellariae are also fairly abundant. They are found on all regions of the test. They recall, better than the rostrates, the forms described by Mortensen, while nevertheless differing from it. The most important are the large pedicellariae with elongated valves (fig. 7) whose fundamental structure is similar to that which Mortensen has observed in A. rostrata (Pl. $\mathrm{XV}$, fig. 2) and in A. fulva (fig. 6 and 27). The valves have, however, a comparatively more elongated and narrower blade than in A. fulva (fig. 6 and 27). The borders of the valves are fused for a more or less large part of their length, sometimes for a third only, sometimes for two-thirds. The part that follows enlarges gradually into a concave spoon that ends in an obtuse point. In its second half are very small and slightly irregular teeth. The perforations are large, oval and numerous. The basal part is scarcely a quarter of the total height. It is a little wider than tall. The neck is very short. The calcareous stalk of the peduncle enlarges gradually at its end and not abruptly as in the rostrate pedicellariae. Its surface is smooth (fig. 18).

The valves of the large tridactyle pedicellariae can be more elongated than in the typical form I just described. Their length reaches or even exceeds $1.3 \mathrm{~mm}$, while the maximum width is rather smaller. I represent in fig. 6 a valve of one of these pedicellariae with a very elongated and narrow head. 
There are, finally, other tridactyle pedicellariae much smaller than the preceding, because their head measures only $0.25 \mathrm{~mm}$ in length (fig. 14). The valves are comparatively larger. These pedicellariae are very near to those that Mortensen has represented in A. fulva (07, Pl. XV, fig. 12). The valves appear to me only a little narrower, much less however than in A. rostrata. The blade widens gradually into an oval spoon that ends in an obtuse point. It has very small denticulations all along its length. The pedicellariae represented by Meijere (04, Pl. XXIII, fig. 485 and 486) probably refer to this latter form. As for the pedicellariae of fig. 484, it is probably a large tridactyle of the type that I described above, but the figure is so inadequate that we can obtain no information from it.

I have not found tridactyle pedicellariae similar to those that Mortensen has reported in $S$. rostrata that he has represented in $\mathrm{Pl}$. XV, fig. 8 and 21.

The characteristics of the tube feet spicules and the rods that support the rosettes of the large frontal pedicels have not been indicated in A fulva. Mortensen said that in A. rostrata, the spicules of the frontal pedicels are elongated and nearly smooth. In the Aeropsis of the SIBOGA, these spicules are a little arched. Their borders are always armed with strong teeth, conical and fairly numerous. The rods of the rosettes (fig. 11 and 12) are curved into a gutter in their lower part. But the borders of the gutter remain far apart. I have never observed transverse trabeculae that connect them in A. rostrata. Then these rods flatten gradually as they widen a little. The thick heel that forms the basal part produces a wide, short apophysis on the side of the cavity of the rod. The other ends as in A. rostrata in a thin and strongly arched hook that seems to me a little shorter than in this latter species, if I can judge from the figure of Mortensen.

Likewise, as in A. rostrata, the large pedicels with a rosette of the dorsal ambulacrum do not extend to the apical system. They are followed by some pairs of elongated and narrow pedicels that end in a round point. Their walls completely lack spicules, as also happens in the peristomial pedicels.

The characters of the spines have been indicated by Mortensen. I represent here two spatulate spines (fig. 8 and 9). I shall add that we observe, on the dorsal surface of the test and inside the fasciole, some primary spines that are not spatulate at all, but that thicken gradually and slightly in their terminal part (fig. 10). They are covered with small, fine and very narrow teeth that are not very dense and remain pressed against the surface. They recall thus the spines that I have indicated in the dorsal groove in Aceste Annandalei and Weberi.

As for the miliary spines (fig. 13), they end in a very large bulb, more developed than in $A$. rostrata and nearly symmetrical in form. They are constituted of a membranous tissue that is continuous with the sheath of the spine.

It is incontestable that the Aeropsis of the SIBOGA is different from A. fulva and rostrata. In particular, the pedicellariae are very different from those that Mortensen has seen in the two latter. Is the species identical to the Aeropsis that the CHALLENGER collected in the Arafura Sea? This is what I cannot decide given the insufficiency of the information. But it is certain that it cannot be referred to any of the known species. I propose to designate as A. sibogae. 


\section{Paleostoma mirabile (Gray)}

(Pl. III, fig. 1, 2, 6, 8 and 9; Pl. XVII, fig. 19 to 29)

See for the bibliography:

Paleostoma mirbhile, Meijere (04), p. 172.

Station 328. - $14^{\circ} 46^{\prime}$ N.; $95^{\circ} 51^{\prime}$ E. 61 fathoms. - Six specimens, all of very small size and debris of two others. $\mathrm{N}^{\circ}$ $\underline{5246}$.

In the largest specimen, the length of the body does not exceed approximately $7 \mathrm{~mm}$. But it lacks a part of the posterior region on the ventral side of the test. In the others, the length varies between 5 and $6 \mathrm{~mm}$. All, for the most part, lack their spines.

Although the size of these individuals is very small, all already have their two gonopores and they conform well to the figures that have been published by Gray and more recently by Loven. The test is very tall, thick and short, strongly swollen in the posterior region (Pl. III, fig. 1 and 2).

Among the echinoids collected by the SIBOGA, Meijeere has reported (04, p. 172) two $P$. mirabile. In one of them, the test measures $16 \mathrm{~mm}$. It agrees well with the figures of Loven. In the other, which is smaller with a length of only $12 \mathrm{~mm}$ (Meijere indicated 13), the test is much flatter and the fasciole reaches its greatest width in the posterior part of the body, while in the first individual this greatest width is a little behind the middle of the test.

Thanks to the kindness of Prof. Max Weber, who has kindly sent it to me, I have been able to study this latter specimen. It appears to me interesting to say a few words about its comparison to the smaller individuals collected by the INVESTIGATOR because the differences that I see in the form of the test are truly very important. The material I have in hand do not permit me to decide if the individual is specifically distinct from the other specimen collected by the SIBOGA and if it should be referred to $P$. mirabile or not, but I consider it certain that the specimens of the INVESTIGATOR belong to the latter species. The photographs that I reproduce here of the largest of the specimens (Pl. III, fig. 1, 2 and 6) show well, I think, that this point of view is correct. I also give two photographs of the specimen of the SIBOGA (Pl. III, fig. 8 and 9).

Here are some dimensions that I have taken from these two individuals:

\begin{tabular}{|c|c|c|}
\hline & $\begin{array}{l}\text { Specimen of the } \\
\text { INVESTIGATOR } \\
\text { mm }\end{array}$ & $\begin{array}{l}\text { Specimen of the } \\
\text { SIBOGA } \\
\qquad \mathrm{mm}\end{array}$ \\
\hline Length & 7 & 12 \\
\hline Width ........ & 6.4 & 10.7 \\
\hline 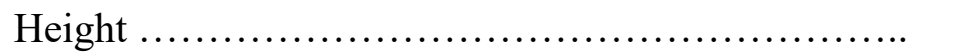 & 6.3 & 8.4 \\
\hline $\begin{array}{l}\text { Distance between the gonopores and the anterior end of } \\
\text { the test } \ldots \ldots \ldots \ldots \ldots \ldots \ldots \ldots \ldots \ldots \ldots \ldots \ldots \ldots \ldots \ldots \ldots \ldots \ldots\end{array}$ & 3.6 & 5.7 \\
\hline $\begin{array}{l}\text { Distance between the gonopores and the posterior end of } \\
\text { the test } \ldots \ldots \ldots \ldots \ldots \ldots \ldots \ldots \ldots \ldots \ldots \ldots \ldots \ldots \ldots \ldots\end{array}$ & 3.4 & 6.3 \\
\hline Length of the peripetalous fasciole $\ldots \ldots \ldots \ldots \ldots \ldots \ldots$. & 5.3 & 8.5 \\
\hline Width of the peripetalous fasciole $\ldots \ldots \ldots \ldots \ldots \ldots \ldots \ldots$ & 4.6 & 9.1 \\
\hline
\end{tabular}


The small individuals of the INVESTIGATOR hardly allowed me to examine the frontal pedicels, but I can add some observations to the information that Meijere gave on the pedicellariae he encountered in the specimens of the SIBOGA.

This author reported very numerous ophiocephalous pedicellariae in the largest specimen, whose head measured $0.75 \mathrm{~mm}$. I have found some ophiocephalous pedicellariae in the small specimen that were sent to me (Pl. XVII, fig. 21). But I have also encountered globiferous pedicellariae as well as some others that can be referred to the tridactyle form that Meijere did not indicate.

The gobiferous pedicellariae are quite common in the petals. Their head is fairly large, measuring 0.2 to $0.25 \mathrm{~mm}$ in length. They are articulated directly on a stalk whose end abruptly swells into a globulose head, nearly as wide as tall. The valves (Pl. XVII, fig. 22 and 23) have a triangular basal part, nearly as wide as long They very rapidly narrow into a narrow blade whose end has a single curved hook, small and sharp. The tube is not very wide in the basal region. This form of valve greatly recalls that Mortensen has figured in Hemiaser zonatus (07, Pl. XV, fig. 3 and 7), but with a larger basal part.

The tridactyle pedicellariae are much smaller. Their head does not measure more than 0.1 to $0.12 \mathrm{~mm}$. The basal part of the valves (fig. 29) is a little wider than long. The blade that is one and a half longer is not very narrow at its origin. It widens gradually for nearly two-thirds of its length. The terminal part, that has conical and fairly strong teeth, narrows rapidly as it curves. The perforations of the blade are relatively large, elongated and sparse.

The large primary spines, slightly spatulate at the end, are inserted the length of the dorsal ambulacra. They cover them more or less completely, as can be seen in the photograph of the dorsal surface (Pl. III, fig. 8). I have also represented one of the larger spines (Pl. XVII, fig. 28). The other smaller spines are often a little enlarged at the end (fig. 25). I also represent two secondary spines (fig. 19 and 24) and a miliary spine (fig. 20) as well as one clavule (fig. 26) without having anything special to report about them.

The spicules of the pedicels have been figured by Loven (83, Pl. XVI, fig. 194 and 195). I reproduce here a photograph of two rods of a rosette of a frontal pedicel (Pl. XVII, fig. 27). These rods are more pointed and their contour is more fusiform that in the figure of Loven (ib., fig. 194).

Paleotropus ovatus, nov. sp.

(PI. III, fig. 3, 4, 5, 11 and 12; PI. XVII, fig. 32 to 35)

Station 238. - 13'16’N; 83"08' E. 75-60 fathoms. - A single specimen. $\mathrm{N}^{\circ} \frac{396}{7}$

The specimen is small and in bad condition. The test, nearly completely lacking in spines, is very thin. It has several breaks: most of the posterior region and a part of the lateral surfaces are missing. Nevertheless, the individual can be studied and described despite some holes. I have been able to take some photographs that I reproduce here. They give a sufficient idea of its exterior characters. This specimen is labeled Paleotropus Loveni, a determination that is obviously incorrect. It belongs to a new species as we can show by the description that follows.

Here are some dimensions I have taken: 
Length.

$\mathrm{mm}$

Approximate maximum width.

12.4

Maximum height a little before the posterior end.

Distance between the two posterior gonopores and the anterior end of the test ......

Distance between the two posterior gonopores and the posterior end.

Distance between the anterior border of the peristome and the anterior end of the test.

Distance between the posterior border of the peristome and the posterior end of the test.

Peristome (width and length).

Periproct (width and height)

Seen from above (fig. 3) the test has a contour fairly regularly oval, with a round anterior end. The posterior end, also round, appears to follow a curve of the same radius. The maximum width is found a little toward the middle of the body. The apical system, moved far forward, is found a little above the peristome. The dorsal surface is not very convex. Seen from the side (fig. 11), this surface rises gradually from the anterior end that is round and very low, following a nearly straight and slightly oblique line up to approximately three-quarters of the total length where the maximum height is reached. Then the dorsal surface declines slightly in following a very convex contour to join the posterior end that is truncated vertically. It has the periproct in its upper part, very near the dorsal surface. The ventral surface is nearly flat in its anterior part. Then it rises a little in the sternal region in forming in the median line a keel that is not very noticeable. Behind it joins the posterior end.

The form that I just indicated differs thus from that which we observe in the other species of the genus Paleotropus. In P. Hirondellei, the test is comparatively shorter and wider. It is also taller as a whole. Its anterior end is thicker and the dorsal surface rises rapidly. In $P$. Josephince, the test is clearly narrow in its posterior part and the maximum width found in front. To the contrary, in P. Loveni, the anterior end is narrower than the posterior end and the maximum width is moved quite near the latter. Moreover, the ventral median keel is very noticeable. However, by its general structure, $P$. ovatus recalls especially $P$. Loveni, but there are nevertheless important differences that I shall indicate later.

The apical system (fig. 3 and 5) is constituted, as usual, by a single polygonal plate, a little longer than wide and whose sides are separated by the same number of re-entrant angles occupied by the ocellar plates. This plate measures approximately 1.3 by $1.2 \mathrm{~mm}$. At its surface, we distinguish with difficulty three small prominences, each with an extremely small depression. They undoubtedly represent tuberosities with the gonopores. The posterior left prominence is a little more noticeable than the other. There thus would be two posterior gonopores and a right anterior, as in $P$. Loveni, but if the unpaired anterior gonopore occupies the position that I suspect, it would be nearer the corresponding posterior gonopore than in the latter species. These gonopores are very badly formed, without doubt because the individual is young. Moreover, the state of preservation of the apical system leaves much to be desired, which makes observation very difficult. The ocellar plates are triangular, with a round top and very distinct opening.

The ambulacra of the dorsal surface have two rows of alternating plates, both in the bivium and in the trivium. The two posterior ambulacra are narrower than the anteriors in the proximal part, as in P. Loveni, but interradius 5 is a little wider than in the latter. Each of the two lateral ambulacra, II and IV, make an angle of approximately $80^{\circ}$ with the long axis of the body. The 
posteriors make an angle of $25^{\circ}$ with the same axis. The two ambulacra of the same side are separated by an angle of $75^{\circ}$. In each radius, the adjacent plates of the apical system are much smaller and have only very small tubercles. Each of the following have one or two primary tubercles, a little smaller than the adjacent interradial tubercles with, in addition, secondary and milliary tubercles.

On the ventral surface, the unpaired anterior ambulacrum has only small tubercles. It is narrower than ambulacra II and IV. These acquire, toward the ambitus, primary tubercles identical to those of the adjacent interradii. The two posterior ambulacra I and V are not much wider than the preceding. They have, in addition to miliary tubercles, some secondary tubercles.

The primary tubercles of the dorsal interradial plates are of average size and not abundant. They become notably larger on the ventral surface, especially in the anterior region of the ventral plastron.

The plates of interradius 5 recall better P. Josephina than P. Loveni. The labrum (fig. 4) is pentagonal, nearly as long as wide, with a very wide and nearly straight anterior border, slightly divergent sides and a nearly straight posterior angle. It forms an insignificant protrusion on the ventral surface. The anterior border, not very thick, has only some secondary tubercles. The two sternal plates are large and triangular. They measure $3.5 \mathrm{~mm}$ in length. Their maximum width, which is reached near the posterior border, is $1.8 \mathrm{~mm}$. This slightly sinuous posterior border reaches the middle of the fifth adjacent ambulacral plate. Each sternal has at first, in its anterior half, four or five very large primaries. The others are much smaller. These tubercles do not reach the external border of the plates. There is outside of them a bare space that makes the posterior ambulacra appear even wider.

Unfortunately, I cannot give any information on the interradial plates that come after the sternum because they are in very bad condition or are missing in my specimen. The subanal fasciole, that I distinguish for part of its path, crosses the episternal plates a short distance behind the posterior border of the sterna. Its upper branch is approximately $1.7 \mathrm{~mm}$ above the lower border of the periproct. But I cannot indicate its exact form.

The peristome (Pl. III, fig. 4) is hardly sunken. The interior border, strongly convex, is continuous with the very rounded sides, but the posterior border is nearly straight. It is covered, in front and on the sides, by seven large triangular plates that occupy the larger part. Two smaller and shorter plates extend along the length of the posterior border. Between these two rows are some much smaller plates. The arrangement greatly recalls that which Agassiz figured in a specimen of P. Lovini that was $17 \mathrm{~mm}$ in length (04, Pl. 169, fig. 243). The periphery of the peristome is constituted in front by the plates of each ambulacral series II, III and IV. The two plates of the unpaired ambulacrum are a little narrower. They limit a portion of the peristome nearly equal to that limited by the first two plates of interradii 2 and 3. The triangular first plate of interradii 1 and 4 , to the contrary, touches the peristome only by an extremely short border.

The periproct (Pl. III, fig. 12) is located nearer the dorsal surface than the ventral surface. It is a little wider than tall, with a convex lower border and two upper sides that are joined by a very obtuse border. It is covered by a first border of large plates, larger on the dorsal side. Inside it are other smaller plates, polygonal and irregular. The anus is located in the middle.

The test is nearly completely bare. The rare primary spines that remain are all broken. I observe some secondary spines that are curved in the second half (Pl. XVII, fi. 33). The miliary spines have, on two-thirds of the length, very small conical denticulations that abruptly transform at the end into a bundle of parallel and anastomosed rods. 
I have encountered only a few pedicellariae of naturally very small dimensions. They are tridactyle and ophiocephalous types. The head of the tridactyle pedicellariae does not exceed 0.12 $\mathrm{mm}$. The basal part of the valves (Pl. XVII, fig. 35) is equal to two-fifths the total length. The enlarged blade, in the form of a concave cup, has on each side about a dozen strong conical and pointed teeth that become larger toward the end. It ends in a tooth more developed than the preceding.

The valves of the ophiocephalous pedicellariae (fig. 34) measure only $0.09 \mathrm{~mm}$. The arches are shorter than in $P$. Hirondellei, as we can be convinced by comparing the photograph I give here to the figure I published in 1910 (10, Pl. XXX, fig. 22).

The living individual must have been violet red in color. In alcohol, it has preserved some traces of this color on the dorsal surface. The sutures of the plates are marked by lines of purple red. On the peristome and periproct, they are a very deep purple. The ventral surface is completely colorless.

SIMILARITIES AND DIFFERENCES. - I have indicated above the very clear differences in the form of the test that separate $P$. ovatus from the three principal known species of the genus. I have had the opportunity to note that it is nearer $P$. Loveni than the two others. The relation is accentuated by the probable presence of three gonopores, by dorsal ambulacra each with two rows of plates up to apical system and by the anterior location of this system. But the new species is distinguished from $P$. Loveni by the contour of the test, by the form of the labrum, by the larger peristome and especially by the more elongated sternum.

We know, from the observations of Loven, that the dorsal ambulacra of P. Josephince have only a single row of plates, an arrangement that is particularly noticeable on the two posterior ambulacra. In taking up the study of $P$. Hirondellei, I have been able to confirm that the dorsal ambulara are quite identical to those of $P$. Josephince. I shall take this opportunity to correct the figure that I published in 1898 that was done according to a specimen that was doubtlessly abnormal, unless there was a lithographic error that I missed (98, Pl. V, fig. 13). Agassiz has already noted (04, p. 171 that $P$. Hirondellei was notably separated from $P$. Loveni and $P$. Josephina by the constitution of the dorsal ambulacra as I have indicated. In that, he was perfectly correct. But I have never understood why he added that the sternum of P. Hirondellei differed radically from that of the other species. I have already given my opinion on the subject of this remark of Agassiz (10, 245). To make an easier comparison between P. Hirondellei and the new species, I reproduce here the photograph of a portion of the dorsal surface coming from a specimen of the first species whose dimensions are nearly the same as my single specimen of $P$. ovatus. It measures $10.5 \mathrm{~mm}$ in length (Pl. III, fig. 7). We can see in this photograph that the arrangement of the apical system and the adjacent plates greatly recall that which Agassiz has indicated in $P$. Josephince and the five last plates of radii I and $\mathrm{V}$ that follow in a single row. The two very large gonopores are found on two very noticeable conical prominences. The madreporite, located in front, has several openings. This arrangement is very different from that shown by $P$. Loveni and ovatus.

I no longer have in hand the specimen that served me for the figure of the dorsal surface of $P$. Hirondelli that I published in 1898. Consequently, I cannot indicate the origin of the error, but it is incontestable that the figure is incorrect in what concerned the apical system and the adjacent plates. In a specimen $18 \mathrm{~mm}$ in length and consequently near to that which served as the type, I find arrangements similar to those of the small individual represented in Pl. III, fig. 7. The number of unpaired ambulacral plates of the posterior series I and V have increased to seven in each series. 
It is very curious to see that the gonopores are comparatively smaller than in the small specimen. The pores of the madreporite are also less numerous. There are only five of them in all that are arranged following a slightly sinuous line. In addition, there is an interruption in radius I, whose last plate does not reach the apical system. The last plate of row $5 \mathrm{~b}$ is, in fact, contiguous for most of its length with the last plate of Ia. As a result of this coming together, the last plate of ambulacrum I is separated from the apical system. This arrangement does not exist to the left and the last plate of ambulacrum $\mathrm{V}$ reaches the system

I also note that, in the small individual of $P$. Hirondellei, the posterior border of the sternum reaches only — although this plate is very elongated - to the end of the corresponding fourth ambulacral plate, while in the largest individual, it reaches the middle of the fifth plate as I represented in 1898 and is also the case in $P$. ovatus whose length is only $11 \mathrm{~mm}$.

I shall add a remark again relative to the globiferous pedicellariae of $P$. Hirondellei. In making new preparations, I confirm that the intact valves always end in two equal hooks, we can see in the photographs I give here (Pl. VII, fig. 30 and 31). The valves that I represented in 1910 with only one terminal hook were obviously incomplete.

In speaking above of the arrangement of the dorsal ambulacral plates of $P$. Josephina, I recalled the observations of Loven whose uniserial arrangement became known to us either in 1874 (Pl. XII, fig. 105 and Pl. XIII, fig. 109) or in 1883 (Pl. XVII, fig. 208) and left no doubt on this subject. But as Duncan (90, p. 274-275) had already remarked, the figures published by Agassiz in 1883 (Pl. XXIII, fig. 7 and 12) according to specimens from the BLAKE, show a double row of plates in the five dorsal ambulacra. I think these last figures are incorrect and that there must have been an error in preparation. Moreover, in 1904, regarding the echinoids of the ALBATROSS, but without making any remarks on this subject, Agassiz implicitly accepted the interpretation of Loven, because in a figure of the apical system and the adjacent region of $P$. Josephina, he represents in the five dorsal ambulacra a single row of plates in the area of the apical system $(\mathbf{0 4}$, p. 247). To the contrary, in the different figures that he published of $P$. Loveni (ib., fig. 245 and Pl. XXXVII, fig. 2 and 6), the dorsal ambulacra always have a double series of plates, without the author giving any description of this structure that he had already passed in silence in his original description of $P$. Loveni $(\mathbf{8 1}$, p. 158).

If we put aside $P$. Thompsoni of which we have only very vague information, we can divide the presently known species of the genus Paleotropus into two very distinct groups. The first, containing P. Josephina and Hirondellei, in which the last plates of the five dorsal ambulacra are arranged in a single row and have two gonopores and a second with $P$. Loveni and ovatus, in which the dorsal ambulacra contain a double row of plates up to the apical system and which have three gonopores (this latter character is not absolutely certain in $P$. ovatus). These differences appear very important to me and I think they justify a generic separation if it is proven the number of gonopores is always related to the arrangement of the dorsal ambulacral plates. I am of the opinion of leaving in the genus Paleotropus, P. Josephince and Hirondellei, the first species being the type of the genus and of creating a new genus, to which I shall propose to give the name of Paleotrema, for the two others with $P$. Loveni as type. I would not have hesitated to adopt this last generic name for the new species found by the INVESTIGATOR if I had been able to distinguish in it, with all the desired certainty, three gonopores. But I dare not, for the moment, refer to this character. 


\section{Homolampas glauca, Wood-Mason and Alcock}

(PI. III, fig. 10; PI. IV, fig. 4 and 5; PI. XVIII, fig. 21 to 28)

Homolampas glauca, Wood-Mason et Alcock, (91), p. 441.

Homolampas glauca, Anderson (99), p. 11.

Homolampas glauca, Alcock (02), p. 289.

Station 111. - Bay of Bengal, depth 1,644 fathoms. - One specimen.

Wood-Mason and Alcock have not published the description of this interesting species. They only said that it differed from $H$. fulva Agassiz by its more depressed form, by the truncated and not concave posterior end, and by the narrower ventral plastron. They published in 1801 two figures representing respectively the dorsal and the ventral surfaces. These authors reported four specimens that came from the same station 111, the largest measuring $93 \mathrm{~mm}$ in length. Moreover, in 1902, Alcock published a figure of the lateral surface of the test (02, p. 289). These three figures are sufficient to give an idea of the exterior characters of the new species, although the two first ones are not very complete, as the figure shows not the least trace of the peripetalous fasciole.

I have found in the collection that was given to me only an incomplete specimen broken into three fragments that I had to put together. They represent a nearly entire dorsal surface with the anterior end. Unfortunately, one of the breaks concerned the apical system. I thus cannot give a complete description of $H$. glauca.

The total length is $82 \mathrm{~mm}$. The maximum width that is reached toward the middle of the length is $61 \mathrm{~mm}$. The apical system is $26 \mathrm{~mm}$ from the anterior end and $56 \mathrm{~mm}$ from the posterior end. It is located a short distance behind the tallest part of the test; This height is approximately 26 to 27 $\mathrm{mm}$.

Seen from above (Pl. IV, fig. 4), the anterior border of the test has, in its middle, a very large, but very shallow notch, which the unpaired anterior ambulacrum begins to form 15 to $16 \mathrm{~mm}$ above the ventral surface. It becomes wider and deeper as it approaches this surface. On both sides of the anterior notch, the border of the test follows a fairly regular convex curve. It increases rapidly at the level of the apical system and then more slowly up to the middle of the length of the body. After this point, the width decreases very rapidly and the test narrows more and more to the posterior end that is extremely narrow, its width not greater than $12 \mathrm{~mm}$.

Seen in profile (fig. 5), the test rises at first very rapidly following a curve with a fairly short radius. The height increases very quickly to approximately $10 \mathrm{~mm}$ in front of the apical system. From there, the test decreases gradually, its contour following at first a curve whose radius increases very quickly in a way to pass a nearly straight line that is directed obliquely toward the bottom to join, in a nearly $90^{\circ}$ angle, the posterior end. The latter is truncated and directed forward a little obliquely. This profile is made remarkable by the rapid rise of the test in the first quarter and the subsequent progressive flattening. This form is very different from that of Alcock, according to which the test is notably less tall and the profile more rounded in the anterior region, and decreasing in a less rapid manner in the part between the apical system and the posterior end. The form that I observe in my specimen approaches more that Agassiz has represented in $H$. fulva, but the corner that precedes that apical system remains very rounded in the species of the Indian Ocean.

The apical system appears to me very near that of $H$. falca, at least as much as I can see in my specimen in bad condition (Pl. III, fig. 10). The four gonopores are very close together, especially 
the two anterior ones that are elongated longitudinally and separated by a single, very thin blade. The madreporite is very elongated, pear-shaped and narrow proximally. It is located between the two posterior gonopores. It extends in enlarging into the posterior interradius. I cannot distinguish the boundaries of the genital plates that appear fused into a single piece, as is the rule in the genus Homolampas. But I also cannot distinguish the contours of the ocellar plates whose openings are, however, distinct. I can no better recognize the contours of adjacent ambulacral and interambulacral plates of the apical system. The collodion that I have used to glue the fragments of the specimen together having more or less hidden these contours.

The unpaired anterior ambulacrum is very narrow at its origin, where it scarcely measures one millimeter. It widens very slowly. At two centimeters before the middle of the apical system, when it sinks obliquely toward the ventral surface, it measures approximately $3.5 \mathrm{~mm}$ in width. It is at this level that it begins to be depressed. Actually, its depression is relatively unimportant. It is instead the adjacent interradial regions that are raised more and more and determine the anterior notch whose depth at the ambitus is approximately $4 \mathrm{~mm}$ with a width of $12 \mathrm{~mm}$. The poriferous zones are very near each other. The pores, very small, remained paired in the posterior part of the ambulacrum, but become single when they go down toward the ventral surface. The ambulacral plates have some secondary and miliary tubercles. At first, they are not dense but become very numerous in the oblique anterior part. They continue to be very dense when the ambulacrum passes to the ventral surface on which I cannot follow them.

The anterior lateral ambulacra remain absolutely flush with the test and do not show the least tendency to take a petaloid character. These ambulacra widen gradually and regularly to the ambitus, both inside and outside the peripetalous fasciole. All the proximal plates, nine to ten pairs at least on each ambulacrum, have paired pores. They then become single a little before they meet the fasciole. In general, there are on each side, inside the fasciole, three plates with single pores. The ambulacral plates have fairly abundant secondary and miliary tubercles. Beyond the fasciole, they have absolutely the same characters as the adjacent interradial plates.

The dorsal interradial plates are noted by the presence of large primary tubercles inside the fasciole that have been reported in different species of Homolampus. In the two anterior interradii, the plates of the internal rows $2 b$ and $3 a$, except for the small secondary and miliary tubercles, have each only a secondary tubercle larger than the adjacent ones. These tubercles form a fairly regular row the length of the borders of the groove. The large primary tubercles appear only on the plates of the rows $2 \mathrm{a}$ and $3 \mathrm{~b}$. Toward the third plate, there is first only one per plate. Then we see two and even three of them that form small transverse rows. But these large tubercles do not reach the ambitus. Their dimensions decrease moreover as they move away from the apical system. In each transverse series, the size deceases equally from the external tubercle to the internal tubercle. In the latero-posterior interradii 1 and 4, the number of large primary tubercles is less. There are only six to seven on each side. The unpaired posterior interradius has, in all, nine primary tubercles in my specimen, three on the left and five on the right, the ante-penultimate plate of series $5 \mathrm{~b}$ having three tubercles. Outside these large primary tubercles, the plates have some secondary and miliary tubercles, forming a very uniform covering that keeps the same character on all the dorsal surface of the test in both the ambulacral and interambulacral regions. The small secondary tubercles are arranged more or less regularly in transverse rows. Only the few secondary tubercles that cover the corner separating the dorsal surface from the posterior end of the test become a little larger. They form, above the periproct that is contiguous with this corner, two or three irregular rows that we find in the interradii 1 and 4 . The scrobicular circle that surrounds the large primary 
tubercles reaches, in the largest, a diameter of $2.5 \mathrm{~mm}$. The depression it forms is not visible on the internal surface of the test.

I have not been able to examine the peristome. The periproct is preserved in very great part and it lacks only a narrow portion of its interior border. It occupies, as I have said above, the upper part of the small posterior vertical surface. Its upper border reaches exactly the level of the dorsal border of this surface. It must be wider than tall. Its width is $8.5 \mathrm{~mm}$ and the height should not be greater than $7 \mathrm{~mm}$. At the level of the median interradial line, the upper border forms a small barely apparent obtuse corner. The plates that cover it are larger at the periphery and in the inner region that has numerous small spines. The anus is found near the middle of the periproct.

The region below the periproct is completely lacking in my specimen. I can say nothing about the subanal fasciole. As for the peripetalous fasciole, the area that it surrounds is not very extensive (Pl. IV, fig. 5). The posterior border of this fasciole passes nearly $23 \mathrm{~mm}$ behind the middle of the apical system. On the sides, it is separated from this system by a distance a little less, $22 \mathrm{~mm}$. In front, it comes very close to the ambitus. It approaches the groove a little below the vertical part, but it disappears on the groove itself, mixing with the miliary granules that cover it. If we take the border of the dorsal groove as the beginning of the fasciole, we see it rising fairly rapidly on the anterior interradius. Then, after having passed the region of large primary tubercles, it forms first a nearly right angle in reaching ambulacrum II (or IV). Then a second angle leaving the same ambulacrum when it reaches interradius 1 (or 4). The fasciole then is found nearly equidistance from the ambitus and the top of the test. It extends more and more from the ambitus and reaches the posterior interradius to join the opposite branch following a very obtuse angle. The band that constitutes the peripetalous fasciole is very narrow. But it remains distinct for its entire extent, except at the anterior groove as I have just said.

The primary spines are all broken in my specimen. The secondary spines of the dorsal surface are short, cylindrical, sometimes curved at the end. Those that remain straight end in a sharp point, small and hyaline. The others enlarge very slightly before the end that is round. They can remain smooth or have two or three small, extremely small denticulations. But the secondary spines have special characters in the anterior and ventral part of the ambulacral groove. These spines of variable length (Pl. XVIII, fig. 21) are in general more or less curved. They have on their concave border a series of very strong conical teeth directed obliquely toward the end of the spine with a very round end. These teeth are found especially on the distal half of the spines. They are more or less close together and more or less numerous according to their length. The end of the spines also is a point whose tissue is hyaline like that of the teeth. This structure recalls that of the spines of $H$. hastata that Agassiz has figured (81, Pl. XLIII, fig. 8 to 10). The secondary spines are not enlarged at the end that tapers gradually. Some, however, enlarge a little before their end. But these always stay narrow. The smallest spines are more or less curved and slightly enlarged in their last third. But they always lack denticulations.

The pedicellariae are very numerous on the fragments I have at my disposition. They occur on the dorsal surface between the spines. But they are particularly abundant in the anterior groove toward the ambitus and in the area of the peristome. They belong to the three types: tridactyle, rostrate and trifoliate.

The tridactyle pedicellariae are of two types. There are first large pedicellariae, whose large and wide head reaches and exceeds even $1 \mathrm{~mm}$ in length. It has a fairly short neck. The valves remain in contact on a fairly large part of their length. The basal region (Pl. XVIII, fig. 24) is not very developed. Its length hardly reaches a fifth of the total length. The blade widens rapidly into a fairly wide spoon that reaches its maximum width before the middle of the length of the valve. 
Then it narrows very slowly to an end that is round. It has first on its lower quarter, low, conical and small teeth that are fairly spaced. Then comes a series of extremely teeth, small, sharp, very close together and regular. The perforations, of average size and round, are arranged regularly on the blade in oblique series. Some pedicellariae have valves narrower than those of the type I just described (fig. 23). We thus pass to the small pedicellariae whose valves are extremely narrow, with denticulated borders except at the base of the blade that remains nearly smooth (fig. 25).

The pedicellariae of the second type have a fairly elongated head, supported by a long peduncle. The basal part (fig. 22 and 28) is triangular, first very wide, then it narrows rapidly. The blade, a little widened at the base, narrows to the pointed tip. It takes a lanceolate form. Its borders are nearly smooth or very finely denticulated. Its width does not much exceed in general that of the basal part. The perforations are small, round and found the entire length of the blade. The length of the valves varies between 0.3 and $0.35 \mathrm{~mm}$. We find a similar form in some other genera such as Lovenia and Metalia.

The rostrate pedicellariae (fig. 26 and 27) are of large size. The head reaches 0.9 to $1 \mathrm{~mm}$ in length. It is preceded by a neck of variable length, but generally fairly long. The valves are thin, separated from each other and slightly curved. They touch only toward the end. The welldeveloped basal region is triangular, a little longer than wide. Its length can reach a third of the total length. It has, toward its top, two or three large spines, conical, pointed, fairly spaced and generally fairly strong, although their development is variable. The blade remains rather narrow its entire length. It scarcely widens toward its middle. It has, after a short tubular part, some low teeth, widened, not very projecting and widely separated. The teeth approach each other more in the terminal part where they then become rather small, pointed, and close together. They form a border that goes around the end of the valve. The round perforations are not very large. They remain fairly far from each other.

The trifoliate pedicellariae have nothing special. Their head reaches $0.15 \mathrm{~mm}$ in length on average. The basal part is rather narrow. The blade, oval in form, has a narrow and round end.

SIMILARITIES AND DIFFERENCES. - Among the known species of the genus Homolampas, $H$. glauca can especially be compared with $H$. fulva and hastata described by Agassiz. It recalls $H$. fulva by its large size and by the form of the test that rapidly reaches its maximum height very near the anterior end, and then decreases gradually to its posterior end that is very small and short. But it is separated from it by the very form of its end that, instead of being concave and truncate, remains flat as in H. hastata. This latter species has a less elevated test and the profile of the dorsal surface is more regular.

Wood-Mason and Alcock have given a figure of $\mathrm{H}$. glauca whose test is less elevated than in the specimen I have studied. They were able to say that the species of the INVESTIGATOR was more depressed than $H$. hastata. This is not the case for my specimen whose form is very near that of $H$. fulva. The only difference that I see from this point of view is that the angle formed by the dorsal surface of test when regarded in profile and that separates the very short anterior part from the very elongated posterior part is very noticeable and nearly at right angles in the figure that Agassiz gave of $H$. fulva, while in $H$. glauca this angle is replaced by a rounded curve.

H. glauca is much more separated from H. fragilis Agassiz from the Atlantic.

I do not speak here of a species of Homolampas that Meijere has reported in the echinoids of the SIBOGA and that he called $H$. rostrata. Agassiz has already noted $(\mathbf{0 4}$, p. 175$)$ that this urchin is certainly not a Homolampas, but it is impossible to know even to which genus we should refer it according to the figures given by Meijere. The scholarly American naturalist made a rather 
severe evaluation of some of the figures by treating them as caricatures of echinoids (sic), but it is however difficult to excuse their very great simplicity.

In the diagnosis of the genus Homolampas that Agassiz gave in 1872 (72, p. 347), it is said that the pores are single on the entire length of the ambulacra. This character is mentioned again (p. 348) in the description of $H$. fragilis. In describing H. fulva (81, p.164), Agassiz gives no special indication relative to the arrangement and number of pores, but in some figures of Pl. XXIV, I see in some regions double ambulacral pores and in other regions single pores. Thus in fig 1, some proximal plates of ambulacrum IV have double pores while they are single in ambulacrum V. In fig. 2, some proximal plates of ambulacra IV and V have double pores, while ambulacrum III has only single pores on all the dorsal region. Finally, in fig. 12, the four ambulacral pairs have double pores on plates adjacent to the apical system and ambulacrum III appears to have only single pores. Moreover, in the description of H. hastata (04, p. 177), Agassiz says that five or six of the dorsal ambulacral plates have double pores and that these plates are found with three or four of the following that have single pores, inside the peripetalous fasciole. However, in the figure that is found on the same page (fig. 259, p. 159) and that is reproduced in Pl. LXIII, fig. 4, all the dorsal ambulacra are represented with single pores. To the contrary, in fig. 3 of this same plate, several plates of ambulacrum III have double pores, and all the other ambulacral plates have single pores, except one of ambulacrum II that has two pores.

In the figure representing the dorsal surface of $H$. glauca published by Wood-Mason and Alcock, the plates of ambulacrum III have double pores on all their length that is figured. The plates adjacent to the apical system of the four other ambulacra also have geminate pores. This is the arrangement that I have observed in my single specimen, with this difference, however, that the geminate pores do not extend as far forward on ambulacrum III.

There is thus at least one species in which the plates in which the plates adjacent to the apical system are surely geminate pairs. Agassiz indicated formally the same arrangement in $\mathrm{H}$. hastata, at least for the lateral ambulacra. And although his figures are in contradiction with his text in this regard, we can take the text as correct. Finally, if we judge by some figures of $H$. fulva published by the same author, this species also has double pores on the ambulacral plates adjacent to the apical system. Although new observations are necessary to clarify this subject, we see it is now necessary to modify the diagnosis of the genus Homolampus given in Agassiz in 1872 in which the ambulacral pores are said to be uniseriate, a character that was mentioned again by Duncan (90, p. 275).

\section{Archeopneustes Hemingi (Anderson)}

(Pl. IV, fîg. 1 and 2: Pl. V, fig. 1. 2. 4, 5 and 8; Pl. XVIII, fig. 1 to 11)

Paleopneustes, Anderson (99), p. 7.

Paleopneustes Hemingi, Anderson. Alcock (02), p. 108, fig. 22.1

Station 248. - 8"37' N.; 75"37'30'"E. 224-284 fathoms - Very numerous specimens.

Only a few were sent to me that were respectively $N^{\circ} \frac{368-373}{7}, \frac{356-357}{7}$ and $1911-1916$.

This echinoid was reported in 1899 by Anderson who simply mentioned it, without naming or describing it. He said only that "one of the most interesting captures of station 248 is that of more than two hundred specimens of a Paleopneustes species, but different from P. hystrix of the Antilles. These individuals have a somber red brown color that becomes a superb purple color in 
alcohol." In 1902, Alcock published a figure of the test seen in profile. He designated the species under the name of $P$. Hemingi Anderson. It is also good to say that it has been discovered in the waters of the Laccadive Islands and that it differs from P. cristatus Agassiz of the Antilles. I have preserved the specific name Hemingi, chosen by Andersson and consecrated by the figure that Alcock had given in 1902 although no description had been published of this urchin.

One of the specimens sent to me has been partly stripped of its spines. I represent it in $\mathrm{Pl}$. IV, fig.1 and 11 and Pl. V, fig.1, 4 and 5. It measures $5 \mathrm{~mm}$ in length. But this length can even be exceeded. It is this specimen that I shall call A, that will serve me as type for the description of the species. I represent in Pl. IV, fig. 2, another individual (B) whose test has a form more conical than the others, while in a third individual (C), the top of the test is, in contrast, round ( $\mathrm{Pl}$. V, fig. 2).

Here are the principal dimensions that I have taken of these three individuals as well as a fourth smaller one whose test is only $97 \mathrm{~mm}$ in length.

\begin{tabular}{|c|c|c|c|c|}
\hline & \multicolumn{4}{|c|}{ Specimen } \\
\hline & $\frac{\mathrm{A}}{\mathrm{mm}}$ & $\underline{\mathrm{B}}$ & $\underline{\mathrm{C}}$ & $\underline{\mathrm{D}}$ \\
\hline Length. & 115 & 104 & 108 & 97 \\
\hline Width. ................................ & 94 & 86 & 90 & 81 \\
\hline Maximum height a little before the apical system. .. & 74 & 76 & 70 & 59 \\
\hline $\begin{array}{l}\text { Distance between the middle of the apical system } \\
\text { and the anterior. end of the test (projected)........ }\end{array}$ & 47 & 43 & 48 & 42 \\
\hline $\begin{array}{l}\text { Distance between the middle of the apical system } \\
\text { and the posterior end of the test (projected)....... }\end{array}$ & 68 & 64 & 60 & 54 \\
\hline $\begin{array}{l}\text { Distance between the anterior border of the } \\
\text { peristome and the anterior end....................... }\end{array}$ & 45 & 40 & 44 & 38 \\
\hline 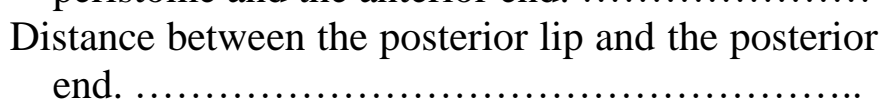 & 65 & 62 & 42 & 56 \\
\hline Length of the anterior petal (measured on the test). & 80 & 70 & 75 & 60 \\
\hline Length of the posterior petal (measured on the test). & 97 & 76 & 75 & 65 \\
\hline Maximum width of the anterior petal. ............... & 11.5 & 11 & 12 & 9 \\
\hline Maximum width of the posterior petal. ............... & 11 & 13.5 & 14 & 12 \\
\hline 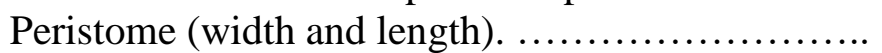 & $20 \times 8$ & $17 \times 6$ & $17 \times 6$ & $15 \times 15$ \\
\hline Periproct (height and width) $\ldots \ldots \ldots \ldots \ldots \ldots \ldots \ldots \ldots \ldots \ldots \ldots \ldots \ldots$ & $14 \times 12$ & $14.5 \times 13.5$ & $13 \times 13$ & $11 \times 12$ \\
\hline
\end{tabular}

What is striking first of all in A. Hemingi, is the very tall and strongly conical form of the test, with the apical pole moved forward. The most projecting region does not quite correspond to the apical system, but is located approximately $3 \mathrm{~mm}$ before the anterior gonopores. The small projection that forms at this point in ambulacrum III is more or less noticeable according to the specimen. It is especially accentuated in individual B. If we examine the test in profile ( $\mathrm{Pl}$. V, fig. 5), we see that the anterior border, connected to the ventral surface by a strongly rounded corner, rises rapidly and directed obliquely backwards following a very regular, but slightly convex, curve to the most projecting point of the test. From there, the profile lowers a little to reach the apical system that is placed horizontally. Behind this system, the height of the test decreases, at first fairly slowly, then very rapidly in following a slightly convex curve to the posterior end that is short, 
narrow and truncated obliquely in front, to which the dorsal surface is connected a by a rounded angle a little greater than $90^{\circ}$.

Seen from above (Pl. V, fig. 1), the contour of the test is slightly ovoid. It follows in front a very open curve that widens regularly toward the middle of the length, i.e., toward the middle of the anterior row of plates of interradii 1 and 4 . Then the test narrows more rapidly to the posterior end. We see at the ambitus, as the level of the anterior and posterior petals, a sight depression, while interradii 1 and 4 are very slightly swollen. The ventral surface joins the lateral surfaces by a very wide border, round and thick. It is slightly depressed at the level of the five radii, especially in the peristomial region. But the depressions that exist do not even reach the ambitus. The ensemble of this surface remains flat. The peristome is fairly evident. Seen in profile, (fig. 5), the ventral surface appears nearly flat with a slight depression corresponding to the anterior part of interradius 1 (or 4) and two slightly projecting parts that correspond to the radial pairs. In the sternal region, the interradial line rises as it approaches the posterior end to form an inconspicuous keel that is obtuse and very rounded. On the dorsal surface, the posterior interradius does not form any appreciable projection. It overhangs very slightly the posterior end of the test that is narrow, short and moreover poorly defined because it is connected to the adjacent regions by largely round parts. Two-thirds of its height is filled by the periproct.

The apical system is small (Pl. VI, fig. 8). The four gonopores are not located symmetrically in specimen A that I describe. As it occurs also in individual B, the anterior and posterior openings are not located on completely parallel lines and these are not exactly perpendicular to the anteroposterior axis. The four gonopores are equal, but the posterior ones are much more separated than the anterior ones. In specimen A, the centers are separated by a distance a little greater than $3 \mathrm{~mm}$. The genital plates are pentagonal, nearly as long as wide. The opening, which is near the proximal angle, is surrounded by very small granules. The madreporite is elongated, pentagonal or pearshaped, a little variable in its contours. It is three times longer than wide. It is developed behind the posterior gonopores and keeps nearly the same width to its posterior end that is truncated obliquely (A), or it narrows in its terminal part (B). Its extra-genital portion is longer than the part included in the apical system. The ocellar plates are irregular, relatively large, with a very small opening. This system greatly recalls that of Paleopneustes hystrix represented by Agassiz (04, Pl. LXLVII, fig. 2) and that Wagner has figured in Archeopneustes (Paleopnuestes) niasicus, a species very near A. Hemingi (03, Pl. 21, fig. 8).

The anterior ambulacrum (Pl. V, fig. 1) begins on the dorsal surface by an extremely narrow part. It widens slowly and gradually to reach approximately $20 \mathrm{~mm}$ in width at the ambitus. I count thirty-one plates up to the ambitus. Each has a geminate pore that seems to be a little more developed than in A. niasicius. Beyond the first plates, each pair of pores is surrounded by a very clear, oval periopode in which the two very small pores are connected by a groove that belongs especially to the anterior pore and is nearly parallel to the antero-posterior axis. Inside the periopode, each plate has first a secondary tubercle with rare miliary tubercles. These tubercles form a very regular row in the proximal half of the ambulacrum. Then they disappear and we see then here and there some more or less constant primary tubercles. Toward the ambitus, these tubercles are seen more regularly without exceeding one per plate. There are fairly numerous secondary tubercles.

The lateral ambulacra remain flush with the test. They extend to the ambitus where they have a very slight depression that is more noticeable on the two anterior ambulacra. The latter form on each side an angle of $70^{\circ}$ with the antero-posterior axis. The posterior petals make an angle of $40^{\circ}$ with the same axis. The two petals of each side make together an angle of $70^{\circ}$. The anterior 
ambulacral pairs widen rapidly from their base on the first eight or ten pairs of plates and then much more slowly. Toward the end of the petals, they measure $15 \mathrm{~mm}$ in width, while in the petaloid part itself they are $11.5 \mathrm{~mm}$ in width. The interporiferous zone is a little wider than each poriferous zone. They have a few secondary tubercles, irregularly arranged. They become larger toward the ambitus. They pass to the small primary tubercles on the ventral surface. There are, in addition, some very small granules that are continuous between the successive pore pairs, often forming a small regular row of three or four very widely spaced granules. The internal pores are a little wider transversely, but they always remain narrower than the external pores that are elongated, slender and pear-shaped. Each poriferous zone measures approximately $3.5 \mathrm{~mm}$ in width and the interporiferous zone, $4 \mathrm{~mm}$. I count forty-one pore pairs in specimen A. Only the first two or three are rudimentary. The last or the two last parts are sometimes smaller, irregular and close to the opposite poriferous zone so that the petals have a very slight tendency to close their distal end. Moreover, the three last pore pairs of each zone are much more separated from each other than the preceding.

The posterior ambulacral zones are a little more widened than the anterior ones. They reach 19 $\mathrm{mm}$ toward the end of the petals that are nearly $14 \mathrm{~mm}$ in width. The widening is mainly due to the interporiferous zone that is $6 \mathrm{~mm}$ wide. I count in all forty-five pore pairs. The last two or three pairs are a little irregular, smaller and a little closer to their congeners, as in their anterior petals. The two poriferous zones do not approach each other at the end of the posterior petals. They keep nearly the same alignment. In any case, these petals have not the least tendency to open at their end.

It is a little above the ambitus that the anterior ambulacrum has the largest tubercles. They are not numerous at first. Then, at the ambitus, their number increases at the same time that their size decreases, and they pass to those of the ventral surface. Toward the periphery of the test, the primary tubercles are uniformly distributed over all the width of the ambulacral zone. They are separated by sparse miliary granules. Then, at equidistance between the ambitus and the anterior border of the peristome, they disappear on the median line at the same time that they become smaller and less numerous on the sides of the ambulacrum. This bare median band is sunken a little and widens toward the peristome. We see the same arrangement, to a degree still more developed, on the four other ambulacra in a way to form a kind of floscelle around the peristome. The phyllode constituted by the anterior ambulacrum contains eight pairs of plates. It looks like an elongated triangle that is gradually depressed toward the peristome. On radii II and IV, each phyllode forms a more elongated triangle with a little wider base. Large peripodia occur on the first eleven pairs of plates in each of them. The posterior ambulacra I and V form a narrower phyllode and the large peripodia occur only on the first nine plates. The plates of these phyllodes are very short and the peripodes that limit the pores are nearly contiguous with the adjacent ones. These regions are nearly completely lacking in tubercles. They appear only outside the pores. They first have the size of small secondary tubercles that pass gradually to the primary tubercles of the adjacent interradial regions.

The petals stop almost at the ambitus. The last pair of pores is not more than $5 \mathrm{~mm}$ from the ventral surface, especially in the anterior petals whose last pairs are very separated in each zone. Outside the petals, the primary tubercles become larger at the ambitus, especially in the posterior ambulacra. Then they pass abruptly to the tubercles of the ventral surface that are much smaller. The tubercles remain few on the anterior ambulacra, whose phyllode region extends over half the distance between the peristome and the border of the test, while in the posterior ambulacra, whose phyllodes are shorter and also narrower, they do not reach half the distance to the ambitus. Outside 
this region, the primary tubercles form on the posterior ambulacra a uniform covering identical to that of the adjacent interradial regions.

The interradial pairs of the dorsal surface are large and wide. the plates increase in size rapidly going away from the apical system. They become very wide, with a concave upper border and a convex lower border in form of a very open V. The surface is simply round and not at all swollen or projecting. From their origin, each plate has first a small row of secondary tubercle. These very rapidly take the dimensions of primary tubercles, but they always remain few, especially in the series $2 \mathrm{~b}$ and $3 \mathrm{a}$ where the each of the largest plates, above the ambitus, generally have more than four large primary tubercles. These are a little more numerous on the other series. They appear rather toward the posterior border. The miliary granules are very sparse, especially in the area of the median interradial line. A little above the ambitus, the primary tubercles become more numerous. The miliary granules are also denser and a little larger. In passing to the ventral surface, the tubercles become abruptly smaller. They form a covering that is uniformly continuous on the entire extent of this surface, except at the level of the phyllodes. The first plate of interradii 2 and 3 touches the peristome only by a very narrow obtuse point.

The same arrangements are seen on the posterior interradius pairs, where the large primary tubercles are however a little more numerous on the dorsal surface than on the anterior interradii. These primary tubercles are much larger than those of the other regions of the test. They are surrounded by a very apparent scrobicular circle.

The posterior interradius has no special characters on the dorsal surface. The tubercles, arranged as in the other interradii, undergo no change in the vicinity of the periproct. But, in passing to the ventral surface, they become abruptly smaller to take the dimensions of the tubercles of this surface. These have no regular arrangement in the sternal region. They continue, in separating more and more, on the labrum up to the lower lip, whose free border has a very dense covering of secondary and miliary tubercles. This lip, very thick and round on its free border, protrudes very strongly forward following a very convex curve. It covers a good part of the peristome, but the lip makes no projection on the ventral surface and remains flush with the test. The labrum is short, wider than long, with two convergent lateral borders and a fairly narrow, straight posterior border that is found at the height of the end of the first ambulacral plate. It appears to be a little wider here than in A. niasicus. The form and arrangement of the interradial plates that follow the labrum are very like those we know in the latter species. The figure published by Wagner $(\mathbf{0 3}, \mathrm{p}$. 17) can be applied to this species. The sternum is triangular with the anterior corner truncated and the base very slightly oblique outside. It measures $13 \mathrm{~mm}$ in length. The length of the plate is $20 \mathrm{~mm}$ only. The two episternal plates that follow are large and trapezoidal, with two large parallel borders. A little before the internal and posterior border, and very near the median line, each plate has a small conical protuberance, very low and scarcely apparent. The two preanal plates $4-4$ are a little shorter. All these plates are very uniformly covered with small primary tubercles arranged without order. But they become a larger and less numerous toward the posterior border of the preanal plates. On the following plates, they take the size of the large primary tubercle of the dorsal surface and are very spaced. The periproct is limited by a part of plates 5-5 and a part of plates 7-7.

The primary tubercles of $A$. Hemingi undergo a modification similar to that I shall study later in some detail in Eurypneustes denudatus. It consists in a kind of more or less complete resorption of some of them. This resorption affects, on the dorsal surface, only some of the large tubercles and is never very great because we always recognize the base of the tubercle and its scrobicular circle. On the ventral surface, the resorption can be more noticeable. It occurs on very small plates, moreover, such as toward the left border of the sternum of specimen A. 
The peristome is very wide and slightly depressed. It is short and in large part hidden by the labrum that projects forward on two-thirds of its length. Its anterior border has a row of large polygonal plates having small secondary tubercles and, behind, small plates irregularly arranged.

The periproct (Pl. V, fig. 4), slightly variable in form, is in general a little taller than wide. However, in the smaller specimen D, it is a little shorter. Sometimes the upper border forms an obtuse angle as in specimen B. Sometimes the two upper and lower borders are round. The plates of the marginal row are pentagonal, as long as wide and larger toward the upper border than toward the bottom, where they are rectangular and low. The rest is covered with very small plates. All these plates have some small tubercles. The anus is near the lower border.

The primary spines are rarely preserved whole. The large spines of the dorsal surface never reach a great length and hardly exceed 15 to $16 \mathrm{~mm}$. These spines have in general toward their base a slight curve as in A. niasicus. In their distal half, they flatten a little at the same time that they enlarge slightly (Pl. XVIII, fig. 6 and 7). Some spines are not curved toward the base and, instead of being flat, they taper to the end. These cylindrical spines are in generally a little larger than the preceding and can reach 2 centimeters. The spines have on their entire length very low and wide denticulations, with an obtuse top directed toward the end of the spine. On the ventral surface, the primary spines are much smaller and shorter. The hardly reach 8 to $9 \mathrm{~mm}$ and often remain even shorter. These spines are in generally a little curved toward their base, but they are not flattened at the end. The denticulations of their surface are very small or even lacking.

The small spines of the dorsal surface reach a length of 5 to $8 \mathrm{~mm}$ and always remain straight (fig. 8). They are small and, cylindrical. Their surface has teeth relatively stronger than on the primary spines. Their end is sometimes pointed and hyaline. The teeth disappear before reaching it. But in general, this end remains round without, moreover, any widening. On nearing it, the denticulations come closer together at the same time that they become smaller. These spines thus resemble the slightly thickened spines at the end of the genera Aceste, Pourtalesia, etc.

The very small miliary spines do not exceed 2 or $3 \mathrm{~mm}$. They have the same structure as the preceding. They remain naturally thinner and are formed by fewer calcareous columns. Their end is round.

The pedicellariae are not very abundant, especially on the ventral surface. They are however fairly widespread in the dorsal ambulacra. They are principally tridactyles and globiferous. The tridactyle, rostrate, ophiocephalous and trifoliate pedicellariae greatly recall those that Döderlein has described in A. niasicus (07, p. 245, Pl. XL, fig 8), but there are also very remarkable globiferous pedicellariae that have not been reported in this last species.

The tridactyle pedicellariae are very rare. I have observed only one form very near that which Döderlein has figured in A, niasicus (fig. 8, i, $\mathrm{k}$ and 1). The head is $0.5 \mathrm{~mm}$ long on average (Pl. XVIII, fig. 5). The blade, in the form of a fairly wide and convex spoon, has a blunt point. The borders have very small denticulations, while at the base, they have two or three low teeth, widened, conical and fairly strong. The number and size vary. I have mainly found these pedicellariae in the petals.

The rostrate pedicellariae correspond to those that Dôderlein has described in A. niasicus. I distinguish, like this scholar, a large and a small form. In the large rostrates, the length of the head varies between 0.7 and $1.5 \mathrm{~mm}$. They are nearly identical to those that Dôderlein has represented (07, Pl. XLVIII, fig. 8). Sometimes, the basal part is comparatively narrower and a little taller. The enlarged terminal part is armed with strong teeth, conical and pointed, that end in posterior round angles. (Pl. XVIII, fig. 2). This part constitutes a kind of funnel with an incomplete border that opens widely into the narrow part of the blade. This is transformed into a tube, sometimes for most 
of its length, sometimes for the distal half only. The perforations are fairly small and dense. In the small rostrate pedicellariae, the length of the head does not exceed $0.5 \mathrm{~mm}$ (Pl. XVIII, fig. 1 and 4). The enlarged terminal part of the blade, triangular in form, is wide open in the tubular part that precedes it and thus is more separated than in the large form. The teeth on the borders are likewise continuous on the posterior border of the opening. The tubular part can be extended on the entire thin part of the blade. But most often we observe at its end a small median slit of variable length. Sometimes there is a large tooth at the base of the blade (fig. 4). The rostrate pedicellariae are found mainly in the dorsal ambulacra and in the area of the peristome.

The globiferous pedicellaria are seen on the dorsal surface to the middle of the pedicels of the petals. They are very large. Their head measures $1.2 \mathrm{~mm}$ in length. It is articulated directly on the stalk. It is covered as usual by a strongly pigmented blackish brown tissue. The basal part of the valves (fig. 3) is very large and wide, triangular, with convex sides. It is as long as wide or a little wider than long. Its length is equal to two-fifths the total length of the valve. The region that follows it forms a fairly narrow tube whose diameter increases a little as it nears the terminal part. This has on its inner surface a large elongated opening, three times longer than wide, and whose length is equal to half the total length of the blade. It is armed, in the distal half, with a row of extremely strong and large teeth, elongated, conical, slightly curved in the form of a hook, and that continues on the rounded end of the valve. Their presence gives to these pedicellariae a fairly particular characteristic. The perforations on the tubular part are round, a little larger and less dense than the basal part. These pedicellariae are very remarkable and no similar form has yet been encountered in the close genera Paleoponeuses, Linopneustes, etc. By the large elongated opening and the very long teeth that surround it, they approach the globiferous pedicellariae figured by Mortensen in Echinocardium flavescens (07, Pl. XVII, fig. 4 and 10).

The ophiophalous pedicellariae conform to those of $A$. niasicus studied by Döderlein $(\mathbf{0 6}, \mathrm{Pl}$. $\mathrm{XL}$, fig. 8, a-d), and, as in them, their head is very large, The valves, including the lower arches, measure in fact more than $0.4 \mathrm{~mm}$ in length (Pl. XVII, fig. 11). They are strongly narrowed toward their middle. In spite of the dimensions of the head, the stalk that supports it is relatively little enlarged at the end and the terminal cup appears to me a little less wide than in A. niasicus. Its diameter hardly reaches half the width of the valves.

Finally, the trifoliate pedicellariae have the usual structure. Their head measures approximately $0.12 \mathrm{~mm}$. The round blade is one and a half times longer than wide (fig. 9).

The ambulacral pedicellariae contain, in their stalk, spicules of various forms. They begin as a slightly curved and spiny rod. Its teeth often meet and form some openings as Döderlein has represented in A. niasicus (06, Pl. XLVIII, fig. 8, t) and that end in forming perforated plates with very a irregular contour and several openings. These plates are similar to those that Meijere has figured in L. spectabilis (04, Pl. XXI, fig 224), but here the openings are even more numerous. The pedicels of the dorsal anterior ambulacrum also have arched spicules and the perforated plates constitute an extremely fine calcareous network. The rods the occupy the axis of the terminal branches do not follow an absolutely regular curve and it can have some very slight turns.

The color of the test of specimens in alcohol is a more or less deep brown. The ambulacral tubes are brown, nearly black. But the spines, to the contrary, are paler. Anderson has noted, as I have said above, that living individuals were a somber deep reddish brown.

As far as I can judge, the internal organization of $A$. Hemingi conforms to that of $A$. niasicus studied with much care by Wagner. 
SIMILARITIES AND DIFFERENCES. - Archeopneustes Hemingi has been placed by Anderson in the genus Paleopneustes. Alcock, in giving a figure of this species, maintains it in the same genus. It is not useless to recall on this subject that the genus Paleopneustes has undergone various transformations since its introduction into science. Agassiz himself had first referred P. cristatus, hystrix, longispinus and Murrayi to it. Then he removed the two latter species that he placed into a new genus Linopneustes. In 1904, he has a long discussion of the respective characters of these two genera (04, p. 178 to 186). But the limits of the genus Paleopneustes must be even more restricted. It appears to me necessary to separate the species of the INVESTIGATOR and place it into the genus Archeopneustes, created by Gregory in 1892 for a fossil form. This author considered the type of the genus Paleopneustes is P. cristatus, whose petals are short and that has a test with a circular contour with a central mouth. In the genus Archeopneustes, in which he would include $P$. hystrix Agassiz, the petals reach the ambitus, the test is oval and the mouth is more or less eccentric. I shall add that, in P. cristatus, the ventral plastron and the posterior ambulacra are very distinct and that the spines, rather short, are similar on both surfaces of the test. To the contrary, in the genus Archeopneustes, the spines uniformly cover the ventral surface and we cannot distinguish the plastron and the posterior ambulacra. They remain short on this side while they greatly elongate on the dorsal surface and are, in contrast, less numerous.

These characters are certainly that of the species of the INVESTIGATOR and its introduction into the genus Archeopneustes is perfectly justified.

It is appropriate to relate to this same genus, the species collected by the VALDIVIA and described by Döderlein under the name Paleopneustes niasicus. The two species are very close but $P$. Hemingi is however very different from $P$. niasicus. It is distinguished by the form of the test that is very tall, conical, and more or less pointed, with the apex moved forward. The ventral surface is nearly flat and not concave. The petals have no tendency to open at the end where the last pores are, to the contrary, a little closer together. The spines are rather thick and shorter than in P. niasicus, if I judge from the photographs of Wagner (03, fig. 4 and 5, p. 8 and 10).

\title{
Linopneustes spectabilis (Meijere)
}

\author{
(Pl. V, fig. 3 and 6; Pl. XI, fig. 7 and 8; Pl. XVII, fig. 36 to 51)
}

Paleopneustes spectabilis, Meijere (04), p. 172: Pl. VIII, fig. 86 to 90, and PI. XXI, fig. 422 to 426

Station 322. - 9 $9^{\circ} 31^{\prime} 57^{\prime \prime}$ N.; 75³6’30" E. 406 fathoms. - Some fragments that arrived in a broken and absolutely dry jar. (I have not found the number).

The two largest fragments come from two different individuals. The larger is represented in Pl. XI, fig. 8. Both contain a large part of the dorsal surface, but the ventral surface is nearly completely missing. A small forward portion only is preserved. Nevertheless, these fragments give an idea of the general form of the test. It indicates it was relatively flat, as is represented in the photograph in $\mathrm{Pl}$. XL. This form is thus very different from that shown in the photograph published by Meijere (04, Pl. VIII, fig. 87). In the text this author says moreover that the test is "oben kegelförmig gewolbet" and that its anterior border has only a shallow notch. Also, in comparing the fragments collected by the INVESTIGATOR to the photographs and the description published by Meijere of $L$. spectabilis, I first asked myself if it were not a matter of different species. This point of view seems supported by examination of the pedicellariae I have observed. 
But Prof. Max Weber, having the kindness of sending me various fragments of L. spectabilis collected by the SIBOGA and determined by Meijere, I have found, not without some surprise, that they are absolutely identical to the fragments collected by the INVESTIGATOR. The test of the specimens that were sent me is, in fact, very low. The dorsal surface is very strongly convex, but not at all conical. The anterior border has a very deep notch. Moreover, the pedicellariae that, contrary to what Meijere said, are extremely numerous and most often of very large size, are completely identical to those that I have encountered on the specimens of the INVESTIGATOR. I believe thus necessary to keep the name of L. spectabilis for the latter. I shall indicate later the reasons that make me refer the species to the genus Linopneustes and not to the genus Paleopneustes where Meijere placed it.

The result of what I just said and the comparison that we can make between the specimen whose photograph I reproduce here (Pl. XI, fig. 8) with the photograph published by Meijere (04, Pl. VIII, fig. 87), is that the test of our species varies in its form, and that the dorsal surface, more or less convex, can, in some individuals like those that Meijere has photographed, take the form of a fairly low cone, while in others, as those of the INVESTIGATOR and those sent me by Max Weber, the test is flatter and the dorsal surface is simply convex.

The study that I have made with the fragments of the INVESTIGATOR and the SIBOGA permit me to complete different points of the description of Meijere. It is equally necessary to describe in a detailed manner the pedicellariae that were, so to speak, not studied by this author and that are, I say again, very abundant and very apparent.

As I just said, the fragments of the INVESTIGATOR belong to the dorsal surface and from specimens of large size, whose total length reached or passed $180 \mathrm{~mm}$.

Here are some dimensions that I took on the two largest fragments:

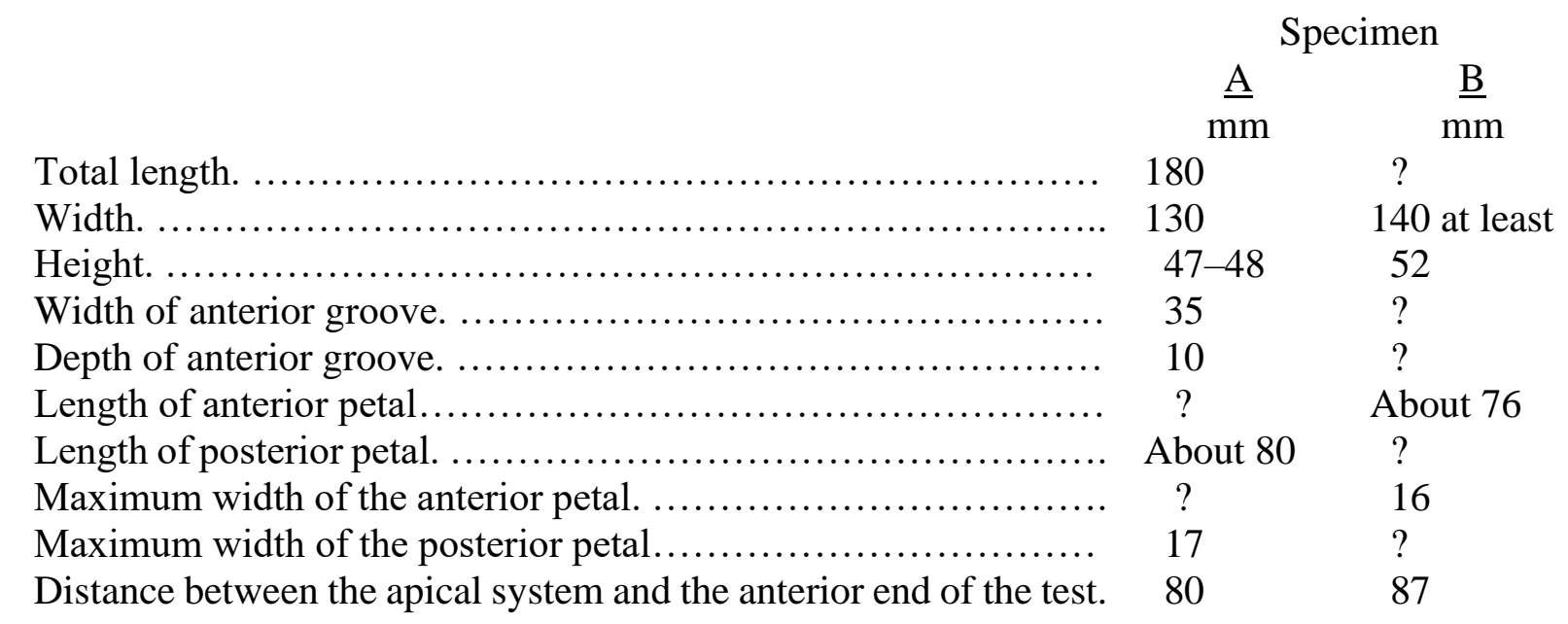

Among the fragments is a small piece of the posterior end with the periproct nearly complete. But it is possible that it does not belong to one of the two specimens above because the periproct, which is oval, is very small and measures only $8 \mathrm{~mm}$ in height and $12 \mathrm{~mm}$ in width.

Seen from above, the contour of the test is clearly angular on the anterior border. The anterior groove forms at the ambitus an obtuse, open angle of approximately $115^{\circ}$ with a round top but straight borders directed obliquely forward and outward, measuring approximately $20 \mathrm{~mm}$ in 
length. Outside, each of these borders joins with a small side directly obliquely backward, making with the border of the groove an angle of approximately $130^{\circ}$, measuring 23 to $24 \mathrm{~mm}$ in length. Then, after having formed a still more open angle of approximately $150^{\circ}$, the test appears to follow a very regular curved line. This angular form of the anterior border of the test is apparent in the photograph of Meijere, but it is more noticeable in the specimen that I received from Weber as it is also in the individual from the INVESTIGATOR, where the anterior groove likewise is deeper.

The anterior petals of individual B are gradually enlarged on approximately four-fifths of its length. They then keep the same length. They are vey elongated and their distal end is very near the ambitus. To judge from the preserved part of individual A, it must be the same for the posterior petals.

The small part of the ventral surface is preserved in individual B, but for a width of only 15 to $20 \mathrm{~mm}$, from the anterior groove up to the level of the right posterior radius. We can then study the remarkable shortening of the plates of the test at the ambitus in the anterior and posterior radii as well as in the antero-lateral radii. This shortening of the plates is comparable to that which Agassiz indicated in L. longispinus (04, p. 184-185, fig. 274 and 275) and which we shall also find some traces in Eurypneustes denudatus that I shall study later.

The shortening of the plates is especially noticeable in the posterior interradius 1 ( $\mathrm{Pl}$. V, fig. 6). The plates above the ambitus with a height of 5 or $4 \mathrm{~mm}$ are followed at the same ambitus by a series of three plates whose height does not exceed $1 \mathrm{~mm}$. In row $b$, that is kept across its entire width in the fragment, the first of these shortened plates is as wide as the preceding. It is contiguous with radius II. But it narrows at its anterior end so as to touch this ambulacrum only by its extremely small and sharp end. The two following plates remain, in addition, shorter and do not reach the ambulacral plates IIa, The plates of series Ia exist in only part of the specimen. The two series of plates in interradius 2 are preserved, to the contrary, up to the ventral surface. In the anterior series, the three shortened plates decrease gradually in width. The two first ones reach ambulacrum III, but the third, which is extremely thin, ends in an extremely sharp corner and no longer touches this ambulacrum. In the posterior series, the first and third marginal plates hardy pass the middle of the preceding. The second, very narrow, extends a little further. But the third alone is developed on its entire width of the series reaches the adjacent ambulacrum. The arrangement of the plates is similar in interradius 2 of specimen A, where the anterior border of the test is preserved for some distance.

The anterior ambulacrum remains flush with the test nearly all its length. It is sunken only in the area of the ambitus and is sunken gradually to form the anterior notch. The pores are geminate, but extremely small and very close together. The posterior pore is round and a little larger than the anterior pore that is small and elongated. A small peripodial circle surrounds each pair of pores, Reaching the ventral surface, the ambulacrum remains first wide and sunken. But it soon rises and rapidly narrows.

Meijere did not mention at all the characters of the bare test. There is, in his description of $L$. spectabilis, an important inadequateness in regard to the arrangement of the plates of interradius 5 on the ventral surface. He only figured the labrum (04, Pl. XXI, fig. 422). But the author says nothing of the following plates. Now it is very important to know the form of the sternal and preanal plates, and especially to know if there exist or not in this species, an episternal corner receiving some widened ambulacral plates from rows Ia and $\mathrm{Vb}$. I can give some information on this subject. Although the fragment of $L$ spectabilis of the SIBOGA has kept part of the interradial plates that are found under the periproct, I do not believe I am authorized to remove the spines from this fragment. I have contented myself with studying the internal surface of the test, which is 
perfectly sufficient. I reproduce here (Pl. V, fig. 3) a photograph of this region of the test where we can see the path of the ambulacral canals as well as the contour of the plates. We can see the existence of a very pronounced episternal corner that is filled by the ambulacral plates Ia6, 7 and 8 and Vb6, 7 and 8 that are very abruptly widened at this level. The presence of this corner is made still more apparent when we study the test by the internal surface, because of the very abrupt extension of the lateral water branch corresponding to plate a6 (or b6) that becomes three times longer than the preceding. The ambulacral plate 6 bypasses the convex posterior border of the episternal plates and goes very near the median interradial line. The following plates are notably less enlarged and the corresponding water branches are also shortened. This arrangement, very comparable to that which we find in Eurypneustes denudatus exists also in L. longispinus (See Agassiz 04, p. 184, fig. 274 and 275). In contrast, there is nothing similar in the genus Paleopneustes s. str.

The path of the fasciole has been described by Meijere. The fasciole is very narrow but, although it does not exceed $0.6 \mathrm{~mm}$ in width, it is very clear and very well defined. It is constituted of four or five oblique rows of very small tubercles. It remains single on the sides of the test, but, in front, it has secondary branches whose arrangement is not constant. The branches appear toward the external corner of the anterior groove. Sometimes they arise from the main fasciole from which they detach at an acute angle. Sometimes they appear beside it in an independent manner. In individual $\mathrm{A}$, the fasciole that comes from the left crosses the anterior groove in an uninterrupted manner in the company of the two accessory branches, one dorsal, the other ventral. These branches are ramified beyond the groove. I count five of them in all the right side. Then, the two lower branches join to form the fasciole strictly speaking that continue its regular path, while the other branches disappear. In specimen B, there are three branches on the left side of the groove. At its base are two very short intercalated branches. One disappears very quickly so that the number of branches is four on the right side of the groove.

The clavules of the fasciole have the ordinary structure (Pl. XVII, fig. 84). They are thin and fairly short. The calcareous stalk is formed of small longitudinal rods connected by transverse anastomoses. In the distal part, they have small, conical lateral teeth that extend to the end of the stalk, anastomosing to constitute a head. But this is not very developed. It forms only an unimportant swelling.

The character of the spines has been indicated by Meijere. The large primary spines have from place to place denticulations that exist nearly their entire length. But they are hardly visible without a magnifying glass. We find them on the smallest spines. I represent in Pl. XVII, fig. 37, 38 and 44 diverse parts of these spines. The secondary and miliary spines are smooth. The latter are often a little curved toward their terminal third, but they have the same structure as the other spines. Their length varies between 2 and $4 \mathrm{~mm}$.

The pedicellariae are, as I have said above, extremely numerous on the fragments of both the INVESTIGATOR and those of the SIBOGA sent me by Weber. They are particularly abundant on the ventral surface, not only in the area of the peristome but between the spines that cover this surface. They are moreover very numerous also on the dorsal surface. It is very curious to see that, in the photograph reproduced by Meijere (04, Pl. VIII, fig. 88), we can perfectly recognize with the magnifying glass several large pedicellariae that I am going to describe. The information that Meijere gave on these pedicellariae is very vague and very incomplete. His figures are completely inadequate. Those that I have observed belong to three types: tridactyle, rostrate and trifoliate.

The tridactyle pedicellariae have diverse forms. In the largest, the head measures 1.2 to 1.3 $\mathrm{mm}$ in length. It is connected by a fairly short and narrow neck to a peduncle whose calcareous 
stalk is fairly strongly enlarged at the end. The basal part of the triangular valves (Pl. XVII, fig. $42,45,46$ and 49) is very wide with convex borders. It exceeds a little over a third of the total length. The blade, first very narrow, widens rapidly into a spoon whose borders are convex. It narrows in the latter third to end in a very projecting point. The borders are armed with small, teeth, conical and pointed, that become a little stronger as they approach the end. These teeth are hardly seen except for the widest region of the blade. However, we sometimes meet, but not constantly, two or three wide teeth, obtuse and short, on the narrow part of the blade. The perforations, that are larger on the blade than on the basal part, are of moderate size. They are numerous and close together. In general, the narrow part of the blade is converted at its base into a very short tube composed of trabeculae that join at the end of the apophysis. Moreover, the concavity of the valves is filled in part by a more or less developed secondary network. I suppose that it is these projections of this network that Meijere took for free points produced from the internal surface of the valves, as indicated in a figure that refers perhaps to the form of pedicellariae I describe (04, Pl. XXI, fig. 426). In the largest pedicellariae, the widened part of the blade equals or hardly exceeds a third of the total length. When the pedicellariae are smaller (fig. 50), this widened part lengthens, to the contrary, and we pass thus to pedicellariae of the second kind.

In these, the valves do not exceed $1 \mathrm{~mm}$ in length. They often measure only 0.5 to $0.8 \mathrm{~mm}$. The basal part (fig. 36, 39, 47) is short and triangular. It reaches only a fourth or fifth of the total length. The blade widens very little and forms an elongated spoon that keeps nearly the same width for nearly all its length. It ends in a blunt point, sometimes bare, sometimes, to the contrary, with a fairly strong terminal tooth. In its narrowest part, i.e., approximately the first quarter of its length, the blade often has some separated teeth, short and triangular. Afterwards is a series of small teeth, close together, with a slightly blunt end that becomes much stronger toward the end.

Finally, in the third type, the valves, while having the same structure as in the preceding type, can stay much narrower. They appear comparatively more elongated (fig. 40). These pedicellariae are always small. The length of the head is between 0.3 and $0.6 \mathrm{~mm}$. The narrow part of the valves is very short. The teeth are present the entire length of the teeth. They are relatively less accentuated than in the widened form. However, I observe pedicellariae whose valves nearly completely lack denticulations. There are, finally, very small tridactyle pedicellariae whose head does not exceed $0.3 \mathrm{~mm}$ in width. The basal part of the valves is longer than wide and its length equals half the total length. The blade is little widened (fig. 51).

The tridactyle pedicellariae are encountered on all the surface of the test. The smallest are particular abundant in the posterior ambulacra.

Some forms similar to those I just described have been figured by Agassiz in L. Murrayi (81, Pl. XLV, fig 11, 14 and 16).

The rostrate pedicellariae are less widespread than the preceding. I find them especially on the ambulacra of the dorsal surface. Their form greatly recalls that Agassiz has figured in the same $L$. Murrayi (81, Pl. XLIII, fig. 6), but the valves are shorter and narrower. The head, that measures 1 $\mathrm{mm}$ on average, is preceded by a narrow, short neck. These valves are little arched (fig. 43). The basal part exceeds a quarter of the length of the blade. This, narrow at first, widens a little to its second third. Then it narrows and ends in a sharp point. The denticulations, that appear in the terminal part only, are first very small, fine and not pointed. Then they develop rapidly, stronger and more pointed as they approach the end.

The trifoliate pedicellariae (fig. 41p) have rather triangular and quite pointed valves resembling those I described in L. longispinus (Pl XVII, fig. 59). Their head measures 0.12 to $0.13 \mathrm{~mm}$ in length. I have not encountered ophiocephalous or globiferous pedicellariae. 
The pedicels contain, as Meijere has indicated, small perforated plates of more or less complicated forms.

The dried specimens are pale chocolate brown with white spines.

SIMILARITIES AND DIFFFERENCES. - Paleopneustes cristatus Agassiz remains the type of the genus Paleopneustes. It is obvious that the echinoid to which Meijere has given the specific name of spectabilis cannot remain in this genus. By the form and arrangement of the ventral plates of interradius 5, by the extension of the labrum and the presence of an episternal corner, by the shortening of the interradial and radial plates at the ambitus, by the presence of a marginal fasciole and an anterior ambulacral notch, etc., it has, in fact, structures eminently characteristic of the genus Linopneustes. We do not find them in either the genus Paleopneustes s. str., or in the genus Archeopneustes. But, moreover, we know that the genus Linopneustes has especially been created because of the presence of a subanal fasciole that is missing in L. spectabilis according to the information given by Meijere. I have not been able to evaluate this because I do not have available the appropriate fragment. I must remark in this regard that the characters furnished by the subanal fasciole are fairly uncertain, as Agassiz himself has recognized. I am not surprised, moreover, that an attentive examination of the test demonstrates the presence in L. spectabilis not of a distinct subanal fasciole but at least of a well differentiated subanal plastron that is comparable to that we encounter in Eurypneustes denudatus for example.

I thus consider that our species is better placed in the genus Linopneustes than in the genus Paleopneustes, the latter being considered in the narrow sense that I have indicated above.

Because of the insufficient information that we have up until now on the pedicellariae of the genus Linopneustes, it has seemed useful to me to describe here those that I have been able to observe in L. longispinus. We hardly know them, in fact, except by the figures published by Agassiz for L. Murrayi (81, Pl. XLIII and XL), but that are not very informative. As for the figures of Meijere, they are completely inadequate. L. longispinus has been described carefully by Agassiz, but this scholar has not spoken of the pedicellariae.

I have studied them in a specimen I have in my collection coming from the cruise of the CHALLENGER. It is unfortunately incomplete and has only the dorsal surface. My observations are thus incomplete. They can nevertheless serve for comparisons.

The pedicellariae that I have been able to observe belong to three types: tridactyle, rostrate and trifoliate. The first are numerous and of different forms. There are first pedicellariae with a very elongated and fairly narrow head that can exceed $1 \mathrm{~mm}$ in length, whose valves touch only on the terminal third. The basal part is fairly narrow, longer than wide. Its length is equal to a fourth of the total length (Pl. XVII, fig. 52, 54 and 57). The apophysis is very projecting and extends forward under the blade by a kind of more or less developed spur. The blade remains very narrow in the form of a gutter for more than half of its length. It then has some short teeth, conical, triangular and widely spaced. It then widens into a spoon varying slightly in length. It never becomes very wide. Its borders are armed with fairly small teeth, a little unequal, conical but not pointed, whose length increases slightly near the end. It ends in a tooth stronger than the preceding. The perforations are very large on the blade but much smaller in the basal part.

From this principal form, we pass to three others that differ especially in the relative dimensions of the constituent parts. We find first very small pedicellariae whose head does not exceed 0.2 to $0.25 \mathrm{~mm}$ (fig. 38). The apophysis is not prominent and the blade has in its distal half small and conical teeth There is no prominent tooth at the end. The other pedicellariae have very 
elongated and narrow valves (fig. 60 and 63). Their blade remains very narrow and keeps nearly the same width its entire length. The teeth of its proximal part are still conical and low, but they are fairly close together and pass gradually to the very small and dense teeth of the distal region. The length of the valves varies between 0.4 and $0.5 \mathrm{~mm}$.

Finally, the other pedicellariae have valves more or less widened and relatively shorter than the preceding (fig. 53 and 55). The basal part is elongated, more than a third of the total length. The apophysis is rather prominent and can even extend a little below the blade. This widens rapidly into a wide spoon that equals or exceeds two-fifths of the total length. Its ends in a strong tooth, conical and pointed, while the borders of the spoon are armed small teeth, unequal, conical and pointed. But the proximal part of the blade remains smooth. The valves are 0.5 to $0.6 \mathrm{~mm}$ in length. Pedicellariae very much smaller (fig. 62), whose valves do not exceed $0.2 \mathrm{~mm}$, can be referred to this form.

All these pedicellariae are found in the midst of the spines of the dorsal surface. They are fairly abundant. The rostrates are, to the contrary, fairly rare. I have encountered them only in the peristomial region that is missing in my specimen. Their valves measure 0.5 to $0.6 \mathrm{~mm}$. The basal part is very developed, wider than long. It exceeds more a third of its total length (fig. 56). The blade remains fairly narrow on more than half its length, with the form of a gutter whose borders are parallel and very close together, but always separate. The terminal part widens abruptly into a strongly concave spoon whose free border, incomplete toward the bottom, has the form of an ellipse with small spines that are close together, slightly pointed and indistinct.

The head of the trifoliate pedicellariae measures $0.1 \mathrm{~mm}$ (fig. 59). The blade is wide and triangular, with a round end.

In summary, the pedicellariae of L. longispinus are related to various forms that I have described above in L. spectabilis or that Agassiz has represented in L. Murrayi (81, Pl. XLIII, fig. 7 and 8; Pl. XLV, fig. 12 to 16). But I see nothing that recalls these large tridactyle pedicellariae that I have found in L. spectabilis. The rostrates are separated also from them as I have indicated in this last species. They are rather close to those of Hemiaster. Moreover, we shall find in the genus Eurypeustes that I shall describe later, tridactyle pedicellariae, some with very thin and elongated valves and others with widened valves that are completely comparable to those of $L$. longispinus.

Eurypneustes, nov. gen.

The test is very flat. The dorsal surface is regularly arched, but little elevated. The contour is ovoid. The anterior region is enlarged while the posterior part narrows gradually to join the posterior surface that is very narrow, short and low, in large part filled by the periproct. The ventral surface is flat. The apical system is very much moved forward. The anterior ambulacrum remains flush with the test on the dorsal surface. It determines on the anterior border only a simple flattening or, at most, the beginning of a hardly apparent depression. On the dorsal surface, the ambulacral pairs are sub-petaloid, but they are never depressed. The petaloid part is very elongated, especially on the posterior ambulacra. The anterior petals extend nearly to the ambitus. These are found nearly exactly on the extension of each other. The poriferous zones remain parallel to each other for nearly all the length of the petal. They have a slight tendency to enlarge at the end in the anterior petals and to narrow, to contrary, a little in the posterior petals. The interradii are very slightly swollen in their middle. There is a peripetalous fasciole that, because of the elongation of 
the petals, is very near the ambitus without taking however the position of a marginal fasciole. The band that constitutes it is extremely narrow and can disappear in places. There is in addition a subanal fasciole, more or less apparent, surrounding a small oval area whose sides are filled with some plates of ambulacra series $1 \mathrm{a}$ and $\mathrm{Vb}$ that fill the episternal corner. Each of them has toward its internal end a large anal pedicel. The ventral branch of the fasciole can be effaced more or less completely, but the subanal plastron always remains perfectly differentiated. The labrum is extremely elongated and very narrow. The sternal plastron is short and moved backward. The peristome is pentagonal with a narrow and slightly protruding posterior lip. The interradial pairs of the dorsal surface have large primary tubercles that can exceed the limits of the peripetalous fasciole.

The genus Eurypneustes is very close to the genus Linopneustes. It likewise has very great affinities with the genus Eupatangus. It recalls the first by its very elongated petals that are not sunken, with parallel and open borders at the distal end. But it is separated from it by its clearly peripetalous fasciole with a very slightly sinuous path, while it is absolutely marginal in the genus Linopneustes where its path is, moreover, completely regular. Moreover, the genus Eurypneustes recalls the genus Eupatangus by the presence of this peripetalous fasciole and by the apical system moved very forward. But it is separated from it first by the elongation of the petals that represses the fasciole very near the ambitus, especially in front and on the sides of the test, as well as by the constitution itself of these petals that are not depressed and whose sides are parallel with the open distal ends, and then by the weak development of the peripetalous fasciole formed by an extremely narrow band that does not prevent the extension of large primary tubercles of the dorsal surface, especially in one of the species of the genus.

Agassiz has already had the occasion to indicate the relations of the genera Linopneustes and Eupatangus. The similarities of the two genera are very great so that this author had first placed $L$. longispinus in the genus Eupatangus (see Agassiz 81, p. 129, 132, 1 57, 159, 167 and 171). The genus whose creation I propose shows how these relations are close because they recall the characters of both. In these conditions, we can ask if the introduction of the new genus is very useful and if the species that I attribute to it would not have found their place in one of the genera Linopneustes or Eupatangus, principally in the latter. The genus Eupatangus presently has only one living species, E. Valenciennesi, whose petals are clearly differentiated, swollen in the middle part and nearly closed at their end, are not very elongated. The peripetalous fasciole is shorter than in the genus Eurypneustes. In the very numerous fossil species in the genus Eupatangus, the petals are always well differentiated with convex poriferous zones. The sternal plastron is also generally more developed than in the genus Eurypneustes. Finally, the peripetalous fasciole establishes a very clear boundary between the large primary tubercles of the dorsal surface and the very small tubercles that cover the plates outside this fasciole.

The character taken from the form of the dorsal ambulacra has a great importance in spatangoids and the differentiation of true petals always indicates the most evolved forms. It is for this reason that I have believed it necessary to establish the genus Eurypneustes that, despite its affinities with the genus Eupatangus, still finds its place in the Paleopneustidae. 


\section{Eurypneustes denudatus, nov. sp.}

(PI. IV, fig. 3; PI. VI, fig. 1 to 10; Pl. XI, fig. 2; PI. XVIII, fig. 12 to 20)

Station 257. $-7^{\circ} 15^{\prime} \mathrm{N} ; 77^{\circ} 46^{\prime}$ E. 143 fathoms. - Several specimens. $\mathrm{N}^{\circ} \frac{802-815}{7}$.

The collection that was sent to me contains, separate from the specimens indicated above, a fairly large number of specimens that are nearly all incomplete and whose tests are more or less broken. The dorsal surfaces are in general intact, but the ventral surface, thin and much less resistant, has been smashed and most often is completely lacking. I have found only a very small number of individuals in which this surface was nearly entire. Two jars only contained the label of station 257 with the numbers reported above. The others had no indication of station. It is possible they also came from the same station 257.

Of the four individuals with $\mathrm{N}^{\circ} 812-815$, two have a complete test (A and B). The two others do not have their ventral surface. As for the specimens 802-11, the jar that contained them arrived broken and the specimens completely dried. No individual had spines. This is doubtless due, for the most part at least, to abrasion of the specimens that certainly accompanied blows and compressions after which the tests were more or less completely broken. But it is possible also that another factor was involved. It is the same with the primary tubercles that I shall discuss later and that made the spines very broken. It is remarkable in fact, that not a single specimen has kept the least spine. All the tests are stripped and cleaned as if they have been carefully brushed. At most, some small spines of the peristome were preserved on the three largest specimens $\mathrm{N}^{\circ} 812-815$. It is only in these individuals that I have been able to find, in these places, some very rare pedicellariae.

The species are always of very large size. Most often, the length varies around $75 \mathrm{~mm}$. It is rare that it falls below 70, while some individuals reach $95 \mathrm{~mm}$ in length. In the largest specimen, reduced to the dorsal surface (D), this length is $104 \mathrm{~mm}$.

Specimens $\mathrm{N}^{\circ} 812-815$ have also kept some trace of their color. The three largest are pale brown with some pink tints. In the smallest, whose length is only $65 \mathrm{~mm}$, this pink tint is on all the dorsal surface and it becomes deeper toward the ambitus. All the other individuals are very pale gray.

The test is very thin and very fragile, especially on the ventral surface where we can even depress it with a very weak pressure of the finger. The general form remains very constant and has only insignificant variations.

Here are some dimensions that I took in different specimens:

\begin{tabular}{|c|c|c|c|c|c|}
\hline & \multicolumn{5}{|c|}{ Specimens } \\
\hline & $\underline{\mathrm{A} \text { and }}$ & $\underline{\mathrm{C}}$ & $\underline{\mathrm{D}}$ & $\underline{\mathrm{E}}$ & $\underline{\mathrm{F}}$ \\
\hline & $\underline{\mathrm{B}}$ & & & & \\
\hline & $\mathrm{mm}$ & $\mathrm{mm}$ & $\mathrm{mm}$ & $\mathrm{mm}$ & $\mathrm{mm}$ \\
\hline Length. . & 89 & 65 & 104 & 77 & 97 \\
\hline Width. ................................ & 71 & 56 & 77 & 35 & 78 \\
\hline Height of the apical system. ............ & 32 & 24 & $?$ & 28 & 35 \\
\hline Maximum height toward a third of the & & & & & \\
\hline posterior interradius. .................. & 34.5 & $?$ & $?$ & 31 & 35 \\
\hline
\end{tabular}


Distance between the center of the apical system and the anterior end of the test. .. Distance between the center of the apical system and the posterior end of the test. .

Distance between the anterior border of the peristome and the anterior end.........

Distance between the posterior border of the peristome and the posterior end....

Length of the anterior petal (measured following the contour of the test)........

Length of the posterior petal (measured

following the contour of the test)........

Maximum width of the anterior petal. .......

Maximum width of the posterior petal. .....

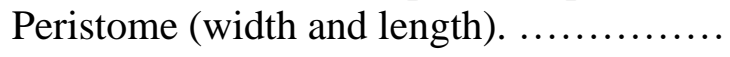

Periproct (width and length). ..............

$\begin{array}{lclll}31 & 23.5 & 36 & 29 & 35 \\ 58 & 41.5 & 68 & 48 & 62 \\ & & & & \\ 24 & ? & ? & 23 & 33 \\ & & & & \\ 58 & ? & ? & 47 & 57 \\ & & & & \\ 40 & 28 & 48 & 38 & 46 \\ 56 & 37 & 62 & 48 & 60 \\ 13 & 9 & 14 & 11.5 & 13 \\ 13 & 10 & 14.5 & 11.5 & 13.5 \\ 11 \times 7 & ? & ? & 10 \times 7 & 13.5 \times 7 \\ 10 \times 9 & 8 \times 7 & ? & 11 \times 10.5 & 115 \times 11\end{array}$

I shall describe the species especially after specimens A and B that are in alcohol. I shall likewise use specimens $\mathrm{C}, \mathrm{E}$ and $\mathrm{F}$ that are dried, because the characters do not always appear with the same clarity according to the state of preservation.

Seen from above (Pl. IV, fig. 3 and Pl. VI, fig. 1), the contour of the test is ovoid, wider in the anterior region. The maximum width is at the level of the apical system that is nearly where the anterior third meets the posterior two-thirds. From there, the test gradually tapers to a narrow and vertically truncated posterior end that is connected to the dorsal surface by an obtuse but very noticeable angle. The contour is always a little angular. The angles, very obtuse and round, correspond to the middle regions of the interradial series of the plates on each of which we see a slight arch. The anterior border is never regularly round. It is sometimes a little flat and we see even at the ambitus, a very slight depression at the level of the anterior ambulacrum, at least in the large specimens, but this depression is hardly apparent.

Seen in profile (Pl. VI, fig 7 and 10), the test rises at first nearly vertically. Then it follows a regularly convex curve up to the apical system. After this, it remains nearly horizontal over a length of approximately $25 \mathrm{~mm}$ in the large individuals. From there it follows a more open and regular curve up to the posterior end. This is short and narrow. It is directed obliquely forward. Its upper border corresponds to the upper border of the periproct.

The ventral surface (Pl. VI, fig. 2, 3 and 8) is somewhat sunken in the region next to the peristome. It rises then very slowly, following the median interradial line to the end of the labrum that is remarkably elongated. Then it rises in a slightly more noticeable manner on the ventral plastron that forms in its middle a keel, becoming a little more apparent toward its end. It always remains very low and unimportant. Behind, this keel is connected by an a very obtuse and round corner to the posterior surface.

The anterior ambulacrum and the lateral ambulacral petaloids remain flush with the test. It is the same for the interradial pairs. Only the posterior interradius is raised on the dorsal surface in an enlarged, but not very noticeable, projection that decreases gradually toward the posterior end.

The apical system is moved very far forward (Pl. VI, fig. 1 and 4). The four gonopores are equal. The two anterior ones hardly nearer each other than the posterior ones. The distance between the latter is little greater than that separating the two openings of the same side. The genital plates 
are pentagonal, with a fairly acute internal corner and a round distal border. The anterior ones are a little smaller than the posteriors. The gonopore is a little nearer the external border than the internal corner. The right plate is continuous with the madreporite that is narrow and little developed. The latter separates the two posterior genital plates, gradually widening. It extends into interradius 5 to a length that does not exceed that of the posterior genital plates. It is pear-shaped and hardly $3 \mathrm{~mm}$ in length and 1.3 in width. The surface of the genital plates is covered with small miliary granules, more or less abundant according to the specimen. They are especially numerous in individual F. The ocellar plates are extremely small. The apical system recalls that of Linopneustes longispinus represented by Agassiz (04, p. 178, fig. 260), but the madreporite is less elongated and the ocellar plates are smaller.

The anterior ambulacrum remains flush with the test to the ambitus. It is narrow and its width is only $9 \mathrm{~mm}$ to the ambitus where it is very slightly sunken. I count twenty-seven pairs of plates from its origin to the point where it is crossed by the peripetalous fasciole. The pores are geminate from the origin and, although very small, they are very distinct on the first plates. The two pores of each pair are first placed very obliquely to each other, the anterior pore being nearer the anteroposterior axis. Then they straighten and are arranged parallel to this axis. At the same time the anterior pore elongates and becomes virguliform, while the posterior pore remains more or less circular. These pores become, moreover, very small beyond the middle of the ambulacrum. The ambulacral plates, at first small, become a little longer than wide after this point. Each of those nearest the apical system have at first, inside the pores, a small tubercle. This results in the formation of a small, fairly regular row. Then, as the plates enlarge, other tubercles are added to the preceding and reach six or eight on the largest plates adjacent to the ambitus.

The anterior petals are nearly located on the extension apart from each other, while the posteriors are nearer the median interradial line (Pl. IV, fig 3 and Pl. VI, fig. 1). The anterior petals make an angle of approximately $85^{\circ}$ with the antero-posterior axis and the posteriors an angle of only $35^{\circ}$ with the same axis. The two petals of the same side make together an angle varying from 60 to $65^{\circ}$. These petals are nearly flush with the test, the poriferous zones being hardly sunken. All are widely open at their end, and even in the anterior petals, the interporiferous zones widen slightly at the end. The anterior petals extend to the immediate area of the ambitus. They begin by a very narrow part. Then they widen rapidly, thanks especially to the inflection of the anterior poriferous zone that follows a slightly convex curve for its first third. From there, this zone continues its course following a slightly concave line. It nears the posterior zone, separating again at the end of the petal. The posterior zone follows a very slightly, but regularly convex curve its entire length. The maximum width of the petal, in individual $\mathrm{F}$, is toward the first third where it is greater than $13.5 \mathrm{~mm}$, while it is only $10 \mathrm{~mm}$ at the end. The interporiferous zone measures $6 \mathrm{~mm}$ on the wider part. The width falls to $4 \mathrm{~mm}$ a little before the end of the petal but returns again to 6 $\mathrm{mm}$ between the pores of the last pair. I count thirty-six pairs of pores in the anterior zone. The first six are extremely small, the three following are larger, but still little developed. In the posterior zone, there are in all thirty-seven pairs, whose first five are very rudimentary. The internal pores are round. The external ones are elongated and verguliform They are close to the distal border of the plate. Between the successive pairs, we see a small lozenge-shaped depression, lacking granules. These remain localized on each side of the borders of the poriferous zone without forming continuous rows separating successive pairs. The interporiferous zone is widely provided with tubercles, most of them miliary, but usually each plate also has two secondary tubercles.

The posterior petals, very much longer than the anteriors, stop at several millimeters from the ambitus. They are also very narrow at their origin. Then they widen gradually thanks to a slight 
inflection of the anterior poriferous zone that takes moreover fairly quickly a nearly straight path. The posterior poriferous zone follows a nearly straight path, but it approaches a little the anterior zone at the level of the two last pairs. The petals keep nearly the same width, $13.0 \mathrm{~mm}$, for most of its length. But the last pair of pores of each zone come a little closer to each other and the petal measure only $10 \mathrm{~mm}$ at it end. The poriferous zones remain a little narrower than on the anterior petal. They do not exceed a width of $5 \mathrm{~mm}$. For the remainder, the posterior petals have the same structure as the anteriors.

The ambulacral plates that follow it to the petaloid part, abruptly widen at the end of the petals. As we already said, on the last five or six plates, and especially on the posterior petals, the pores of each external series separate from the border of each plate, principally on the last two or three plates that become much narrower than the preceding ones. It is for this reason that the posterior petal undergoes some narrowing at its end. The space that is thus freed between the last three or four pore pairs and the adjacent interradial plates, is occupied by the ambulacral plate that forms the end of the petal and that widens in its external part to fill the empty space thus produced by the narrowing of the preceding plates. This ambulacral plate is crossed by the marginal fasciole that will be discussed below. The plates between the latter and the ambitus have large primary tubercles, two or three per plate in general, with secondary and miliary tubercles. These tubercles, that are larger and more constant on the posterior ambulacra, do not pass the ambitus. The plates that follow and that form the posterior part of the ventral ambulacra, have peculiar characters to which I shall soon return. As for the anterior ambulacrum and the two latero-anteriors, they pass to the ventral surface, conspicuously increasing the dimensions of their plates. Then they are sunken a little in approaching the peristome at the same time as they widen. They then take a very elongated form and, thanks to the large peripodia that are very close together that have their plates near the peristome, they each make a beginning of the phyllode. The anterior ambulacrum has phyllodes with peripodia on the first four plates of each series. A last smaller one is still seen on plate a5. Ambulacra II and IV have peripodia on the phyllodes on their first six plates. The plates with these large peripodia have only a few insignificant granules. Those that then follow are much more elongated. Then on ambulacrum III they acquire secondary tubercles whose dimensions increase toward the ambitus. Ambulacra II and IV have large, fairly spaced tubercles that become denser and smaller toward the ambitus.

The posterior ambulacra that form on the ventral surface can reach $13 \mathrm{~mm}$ in width. The peripodia of the phyllodes can be seen on the first three plates of each series. A last rudimentary one can exist on the fourth plate. The length of these plates increases rapidly in the third, fourth and fifth pairs that, moreover, have nothing peculiar. But the following plates have characters identical to those that Agassiz indicated and figured in Linopneustes longispinus. In fact, plates Ia6 and Vb6 are much shorter than the preceding.

Each of them has the form of a very low triangle directed obliquely toward the median interradial line in bypassing the oblique lateral border of the episternum. Their narrow internal region contributes to fill the very accentuated episternal corner whose posterior side is formed by the external border, oblique outside, of the preanal plate. The form of this plate I a6 (or Vb6) is similar to that of the corresponding plate in L. longispinus. The three following plates Ia7-a9 (or Vb7-b9) are rectangular, but they remain extremely short while keeping the width of the other plates of the ambulacrum. Their larger borders are parallel (PI. VI, fig. 6). Finally, plate 10, a little less short than the preceding, has an extension toward the median interradial line similar to that of plate 6, but directed in the inverse direction, i.e., obliquely forward and which, bypassing the anterior border of plate 5 of the posterior interradius, contributes with the four preceding 
ambulacral plates, to form the corner that closes the episternal angle. The following ambulacral plates 12, 13 etc., become taller and narrower. They have nothing peculiar. Plates 1a6-a9 and Vb6-b9 has each, a short distance from the internal border and inside a very small prominence that we see on their surface, a large geminate pore surrounded by a peripode that represents the insertion of an anal pedicel. In the two other series, plates $1 \mathrm{~b} 6$ and Va6 are still fairly long, but less long than wide. Plate 7 is much shorter and very wide. Plates 8, 9 and 10 are still shorter. They are identical to their homologues of the internal series 7 to 9 . Then their length increases after plate 11 at the same time that their width decreases.

The posterior ambulacra are, so to speak, lacking in tubercles. We find only some secondary tubercles at the level of the peripodia on the first plates. But these remain nearly bare to the posterior end of the test, except for some rare, very small tubercles on their internal and external sides. It is only on the internal ends of the plates of the episternal corner as well as on plate 8 of each series, that small primary tubercles abruptly appear, arranged on each plate in a small transverse row accompanied by miliary tubercles. These tubercles are continuous with those of the dorsal surface of the test.

The lateral anterior and posterior interradii are filled, on the dorsal surface, by large and wide plates that have, on either side of the median interradial line of each zone, a small very obtuse prominence, very low and always inconspicuous, that corresponds to the angles reported above at the ambitus. At some distance from the apical system, the interradial plates acquire large primary tubercles. At first there are only one or two on each plate. Then their number increases rapidly toward the ambitus. The large tubercles are at first arranged, on the plates of the middle region of the interradius, in a single row that forms a kind of V very open at the top. On the shorter plates that are found near the ambitus, the row becomes more irregular. There are seven to eight tubercles per plate. We can find one or two of them outside the principal row. The size of the tubercles decreases, moreover, very rapidly toward the ambitus. The rest of the surface of the plates is covered with miliary granules, more of less numerous according to the specimen, with a very variable number of secondary tubercles. In particular, they are very abundant and very apparent on specimen F, but they can be much less developed. As for the unpaired posterior interradius, it has on the dorsal surface of the test, some small secondary tubercles, few in number and arranged without order, with a variable number of miliary granules according to the specimen. The large primary tubercles are surrounded each by a well-developed scrobicular circle. The mamelon is perforated and crenulated.

At the ambitus, the large primary tubercles of the anterior and posterior interradii disappear completely. They are suddenly replaced with a covering of very numerous and fairly dense tubercles of small size. We could call them secondary tubercles. However, in passing to the ventral surface, these tubercles become larger and larger toward the peristome. Then then merit the name of primary tubercles, all while always remaining much smaller than the large tubercles on the dorsal surface. In the anterior interradius, these tubercles stop at a large distance from the peristome, while in the posterior interradius, they approach it much more and likewise continue to the limit of the posterior ambulacra.

The plates of the anterior and posterior interradii recall, by their arrangement, Linopneustes longispinus. The first plate of the anterior interradius reaches the peristome only by a very narrow blade having a row of secondary tubercles. It is regularly polygonal for the rest of its periphery and larger than in L. longispinus. Plates 2-2 are very large and extend to the ambitus. The following ones become very short, very wide, and rectangular. The first plate of each posterior interradius pair reaches likewise the peristome only by a very narrow part having a row of secondary tubercles. 
The rest of this plate forms a triangle with a nearly straight base. The two following plates, enormous and triangular, extend to the ambitus. They are followed, as in the anterior interradii, by rectangular plates, wide and very short. I shall return a little later to these remarkably shortened plates.

Regarding the plates of the posterior interradius of the ventral surface, the labrum is made remarkable by its extension. It recalls that which we know in the genus Linopneustes, but here it is particularly elongated and reaches a total length of $22 \mathrm{~mm}$ (Pl. VI, fig. 2, 3 and 8). Its anterior border is swollen and thick to form a lower lip. But this makes only a very weak projection on the ventral surface. It is directed obliquely inward. It has small secondary tubercles, irregularly arranged in three fairly dense rows. The width of the lower lip is equal to approximately half the width of the peristome. Behind this lip, the labrum first narrows in following, on each side, a concave curve corresponding to the first ambulacral plate. Toward the end of this, it widens a little, then it narrows again, first very slowly on approximately two-fifths of its length. Then it continues in the form of a very narrow blade whose width does not reach even $1 \mathrm{~mm}$ in some specimens. Finally, it widens a little toward its posterior end, which is found at the level of the first third of the fourth ambulacral plate. Its maximum width, 4 or $5 \mathrm{~mm}$ behind the lower lip, does not reach 4 $\mathrm{mm}$. Its surface is completely bare. Following the labrum, the sternal plates, each of which begins by a very narrow end, enlarges rapidly to reach approximately $17 \mathrm{~mm}$ at the level of the posterior border of the corresponding fifth ambulacral plate. This width remains nearly constant to the posterior side that is directed obliquely backward. The form is thus pentagonal with the anterior corner very elongated and sharp and a posterior side directed obliquely backward. The two plates 3-3, or episternal, that follow have nearly the same width as the sternum. But their posterior border is oblique and nearly parallel to the anterior border. This results in the formation on each side of an episternal corner limited behind by the anterior side of the following or preanal plate. The total length of the sternal and episterna plates is $32 \mathrm{~mm}$. The preanal plates 4-4 are first very narrow at the level of the top of the episternal corner where they measure only $3 \mathrm{~mm}$. Then they enlarge and reach approximately $6 \mathrm{~mm}$, which is also their length. The posterior and upper sides of plates 4-4 limit the lower border of the periproct, whose periphery is completed by the four pairs of following plates 5 to 8 . The preanal plates and the internal parts of the four interradial plates follow form the posterior surface of the face that is very narrow and that, above the preanal plates, is entire filled by the periproct.

I said above the unpaired interradius has, in the middle of the ventral plastron, a very slight median keel. This keel appears at some distance behind the anterior corner of the sternal plates. It extends, becoming a little more noticeable at a small distance from the posterior end of the episterna. Each of its sides has in the median line, a very small obtuse prominence beyond which the ventral surface joins obliquely the posterior end of the test. The ventral plastron is covered with dense primary tubercles arranged in oblique rows that leave from the end of the median keel and extend forward and on the sides toward the adjacent ambulacral plates, increasing rapidly in size. Behind, these tubercles continue to the anterior border of the preanal plates. The latter have in general only sparse secondary tubercles whose number varies with the specimen. The tubercles are likewise not dense on the following plates. It is only in the immediate vicinity of the periproct that these plates have some slightly larger tubercles. In addition, all along the length of the lower border of the periproct, we note a band formed of extremely dense miliary granules, placed very regularly side by side, whose aspect recalls the granules of a fasciole. I shall return to this later.

Agassiz has remarked (04, p. 183-184) that in L. longispinus, there are at the ambitus, some very short plates in the form of a very low triangle, both in the interradius and the radii, except in 
ambulacra II and IV. According to the figures that this author published, the number of these plates increases with the size of the individual, as we can see in comparing the specimens having respectively 82 and $110 \mathrm{~mm}(\mathbf{0 4}$, fig. 274 and 275). A similar arrangement has likewise been reported by the same author for Phryssocystis acaleata. As a consequence, it gives more solidity to the test toward its periphery. This structure is hardly indicated in E. denudatus in the two paired posterior interradii, but it is a little more noticeable in the two posterior radii. I have already mentioned above in passing, the presence in ambulacra I and V of these very short plates that correspond to the episternal corner. Now, in some specimens such as individual E, the plates of series Ia and $\mathrm{Vb}$ are simply rectangular after the seventh to the tenth and beyond. But in the two other series $\mathrm{Ib}$ and $\mathrm{Va}$, the tenth plate has the form of a very elongated triangle. Its pointed end does not reach the external border of the adjacent interradius, thus recalling the arrangement that Agassiz has represented in L. longispinus (04, fig. 274), with the difference that in the latter it is the ninth plate that takes the triangular form. Moreover, in my species, I have seen these extremely short plates only in the posterior ambulacra I and V. They are not seen in the lateral interradii or in the paired anterior ambulacral. This disposition is found to a more or less noticeable degree in other specimens, but it does not appear connected to the size of the individuals.

The peristome has a generally pentagonal form with round corners. It is relatively long in relation to its width. It is completely visible when we look at the test by the ventral surface, the posterior lip being slightly convex. The plates that cover its anterior part are very large. They form a triangle with a posterior corner. There are four of them. Then, on each side, is a little smaller and rectangular plate. Finally, along the length of the posterior border, are some very short rectangular plate, generally four in number in the small specimens and five in the large ones. Behind the large anterior plates are some fairly large plates, in the form of a lozenge, then others much smaller and irregularly arranged.

The periproct (Pl. VI, fig. 5) is fairly large, a little wider than long or, exceptionally in some individuals, as wide as long. Its contour is sometimes a little quadrangular, the lower border convex breaking down into two small round sides and joining at a very obtuse angle. The two upper sides, strongly convex, together form a more or less open corner, sometimes a little elongated. The marginal plates are quadrangular, a little higher on the upper side. They become lower and lower on the lower border. They have small spines. The anus is nearer the lower border.

There is a marginal fasciole that is often slightly apparent and that can even disappear completely on more or less extended regions in many individuals, so that it can be unnoticed. I readily accept that the abrasion my specimens underwent has contributed in large part to the disappearance of this fasciole. This is quite apparent in the four specimens $\mathrm{N}^{\circ} 812-815$ that are fairly well preserved. It is likewise very noticeable in individual $\mathrm{F}$ whose test is also in fairly good condition. If we study its path in individual A (Pl. VI, fig. 5, 7 and 9), we see that it follows fairly exactly the contour of ambitus anteriorly and on the sides of the test. It crosses the middle of anterior ambulacrum III at 7 or $8 \mathrm{~mm}$ above the ventral surface, is raised very slightly in the anterior interradius, then lowers a little at the end of the anterior petals. From there, the fasciole separates slightly from the ambitus to the posterior petals that it bypasses and rises a little to cross the posterior interradius at the level of the ninth plate. It crosses the left plate in its middle and grazes the lower part of the right plate. It is constituted, throughout its path, of an extremely narrow band that does not measure more than 0.4 to $0.5 \mathrm{~mm}$. It is composed most often of only two rows, or rarely three, of extremely small and very dense granules. In the smallest of the four specimens 813-815, this fasciole is perfectly clear and quite distinct for its entire extent (Pl. VI, fig 10). But exceptionally it does not follow a direct path to the level of radius III. In fact, a little before reaching 
it, it abruptly rises in the form of a nearly right but round angle. Then after approximately $2 \mathrm{~mm}$, it abruptly curves again to take its horizontal path.

The subanal fasciole is extremely reduced. It can even be completely missing. I have noted above the presence along the lower border of the periproct, of a band of very small granules that recall a fasciole. In the small specimen $\mathrm{C}$, this band is more distinct than in the others and fairly limited (Pl. VI, fig. 6 and Pl. XI, fig. 2). In addition, it is clearly curved on the sides rising toward the dorsal surface. It thus contributes to limit a wide transverse space that contains the preanal plates and the internal regions of the adjacent interradials to which are added the inner parts with tubercles of the ambulacral plates 7, 8 and 9, that are wedged into the episternal angle. This oval space is distinguished in addition from the adjacent regions by the larger and denser granules that cover it. But, apart from the beginning of the lateral branch that I just mentioned, no formation borders this area on part of its sides and on its anterior border. We nevertheless have the impression, in considering the posterior end of the specimen, that there is, below the periproct, a clearly differentiated plastron whose fascicular border is developed only on the upper edge and a little on the sides, but that has disappeared on the rest of the periphery. If we compare to this small specimen a second species of the genus Eurypneustes, E. rubens, which I shall describe later after an individual of a fairly similar size, and that has well differentiated subanal fasciole, we realize it would take very little for the first species to acquire the structure we see in the second. I have placed beside each other photographs representing the posterior end of each of these specimens so we can judge more easily this resemblance (Pl. XI, fig. 2 and 4).

In some larger individuals, we can still find the rest of the subanal fasciole, as in the two larger ones from station 257 . We clearly distinguish, below the periproct, a dorsal branch that disappears little by little on the sides that limits a well differentiated subanal area.

Other individuals no longer have the least trace of this fasciole. Is this because it does not exist or is it not because of the abrasion the specimens were subjected to and especially to resorption of the granules similar to that we see so clearly in the primary tubercles of which I shall speak later. Whatever it is, we always find, below the periproct, a very distinct area, widened transversely, with a concave upper border, a convex lower border and whose round sides correspond to a very slight prominence provided by each of the posterior ambulacral plates 7 to 10 , immediately outside their respective peripode. The ridge formed by these projections continues forward and in the direction of the median line, towards the point of meeting of the episternal and preanal plates. The ensemble always gives the impression of a well limited plastron which lacks, to be complete, only a fascicular border, especially on the lateral and lower borders. Along the lower border of the periproct, we find in a more or less apparent manner according to the individual, this band of very small granules that represents the upper branch of the atrophied subanal fasciole.

I have simply mentioned above the presence of primary tubercles of diverse sizes with describing the particular characters they have in E. denudatus. Agassiz has remarked (04, p. 181) that in Paleopneustes crisatus, represented by him (Pl. XCLV), the posterior interradial regions and a part of the ventral surface of the ventral surface have the remains of scrobicular circles belonging to the primary tubercles that have disappeared. The ambulacral regions can also have the same peculiarity. In P. hystrix, Agassiz observed equally on the ventral surface, as well on the interradius as on the radius, similar scrobicular areas lacking their central tubercle, but without the general aspect being sensibly modified, while in P. cristatus, the ventral surface is, to the contrary, covered with more or less extended bare patches that contrast clearly to the other parts of the test. Agassiz adds even that the figure published by Alcock in 1902 of Paleopneustes Hemingi shows some primary tubercles reduced to a simple circle. The American author suggests that the tubercles 
in this species have likewise been subjected to similar resorption. I have spoken of it above, but this phenomenon is particularly developed in E. denudatus It has seemed preferable to study it here.

In fact, in E. denudatus, this resorption of tubercles can be complete. It extends even to scrobicular circles so that in some individuals, we no longer see the place of the tubercles that have completely disappeared, only a small circle paler than the rest of the test and no longer having the least projection on the surface. Sometimes even, this circle is so little apparent that it is very difficult to find a trace of the preexisting tubercle. This resorption is shown especially on the ventral surface and principally in the lateral interradius, but it can occur all over this surface. Thus in specimen E (Pl. VI, fig. 2), all the primary tubercles of the ventral surface have completely disappeared and we no longer find in their place pale circles, not very noticeable in general and whose limits are even sometimes completely indistinct. Specimen B, represented in Pl. VI, fig. 3, still has some intact tubercles. In the individual that is reproduced in fig. 8, the resorption of the tubercles is even less noticeable and the scrobicular circles always remain well preserved around affected primary tubercles and even some of these form a very appreciable projection. Finally, in other individuals, such as F, most of the primary tubercles of the ventral surface are preserved and the others have been affected only on relatively small areas of the anterior and posterior interradii and the beginning of the sternal plastron. Moreover, these tubercles are not completely destroyed because they even form some projection on the surface of the test and their scrobicular circles are intact. On the dorsal surface, similar phenomena are seen in the large primary tubercles of the lateral interradius that can also be resorbed more or less completely and whose scrobicular circles themselves can disappear in part. This resorption is fairly noticeable in individual D (Pl. IV, fig. 3 ). It is less advanced in the others. I believe, moreover, that the secondary and miliary tubercles can also be partially resorbed, on both the dorsal and ventral surfaces. This explains the variations I have observed according to individuals, such as F, that has tubercles much more numerous and more noticeable than the others.

This resorption of primary tubercles is not related with the size of the specimen because I have found it very noticeable in individual $\mathrm{K}$, whose length is only $77 \mathrm{~mm}$, and very little apparent, to the contrary, in the much larger individual F. It does not occur by the death of the animal, because there are remains of the digestive tube and gonads, although torn, in specimens whose primary tubercles have mostly disappeared. Nor do I believe we can attribute this more or less complete destruction to abrasion, because it is not possible that all the individuals collected by the INVESTIGATOR - and we know they were numerous - had experienced fairly intense abrasion so that the test was not only brushed and cleaned but that the tubercles were worn down as deeply as I have seen. This explanation is even less acceptable as it is especially on the ventral surface that the tubercles disappear. This part of the test is particularly thin. It is so little resistant that it is missing in most of the specimens. It is certain that abrasion and fairly energetic blows strong enough to cause the tubercles to disappear would have cause the complete loss of his surface.

The resorption of the primary tubercles and without doubt also of smaller tubercles occurs in E. denudatus with very great intensity and is accompanied by the loss of spines. Thus would be explained their complete disappearance in all the specimens that have been collected, at least when the phenomenon of resorption has reached the degree that we see in individual E. But when the tubercles are seen to be still numerous and appear normal but the spines are missing, it is difficult to say if the fall of the spines is due to abrasion or not. It is possible, however, that this cause is still not the principal one and we can imagine that even before all external and apparent modification of the primary tubercles, their calcareous tissue has undergone some modifications 
that have caused or permitted the detachment of connective and muscular tissues connecting the spine to the test and thus caused their loss.

It is curious to state that this phenomenon of resorption is seen likewise in different species of the related genera Paleopneustes, Linopneustes and Archeopneustes.

Thus, I can say nothing about the primary spines. In the best preserved specimens, there still remain on the peristome, or at its periphery, rare secondary spines. These are straight or a little curved. Their surface is smooth without denticulations or rugosities. The keep nearly the same thickness to the end that is round (Pl. XVIII, fig. 15).

Because of the condition of the specimens, I have been able to find only a very few pedicellariae. I have encountered them only in specimens $N^{\circ} 812-815$ and only in the peristomial region. There are the three forms: tridactyle, rostrate and trifoliate.

The tridactyle pedicellariae are of three different types. The first have a very large head reaching $0.4 \mathrm{~mm}$ in length and preceded by a rather short neck. The basal part of the valves is fairly tall and relatively narrow (Pl. XVIII, fig. 12 and 19). Its length reaches nearly half the total length of the valve. It is separated from the blade by a shallow constriction. This is strongly convex. It widens gradually toward the middle of its length. Then it narrows more rapidly to the end that is narrow. It extends as a short, fairly sharp beak. The borders have very small, pointed denticulations that continue from the widest part of the blade to its end, while the preceding region has some wide denticulations, short and obtuse, separated from each other and moreover variable in number and size. The valves are rather thick. The perforations of the blade, rather large, make a fairly wide border at the periphery. These pedicellariae are comparable to those of Linopneustes Murrayi represented by Agassiz (81, Pl. XLV, fig. 16).

The tridactyle pedicellariae of the second form (fig. 13) are of small size, the head measuring only 0.2 to $0.25 \mathrm{~mm}$. The head, very elongated and narrow, follows a fairly long neck. The basal part of the valves is fairly narrow and short. Its length does not reach a quarter of the total length. The blade, in the form of a thin, elongated spoon, remains nearly as wide or a little wider than the basal part. It has along its length very small teeth, conical and dense. The valve ends in a small beak. These pedicellariae are comparable to one of those that Agassiz represented in 1881 ( $\mathrm{Pl}$. XLV, fig. 15).

This are finally large pedicellariae whose head, very elongated and narrow, can exceed $1.3 \mathrm{~mm}$ in length, with extremely thin valves. They recall those of L. spectabilis and especially those that I shall study later in Eurypneustes rubens. They appear to me to be fairly close to those that Agassiz has figured in L. Murrayi (81, Pl. XLIII, fig. 7). I have unfortunately encountered only one of these pedicellariae and even the valves were incomplete. I represent in Pl. XVIII, fig. 17, the one that has kept nearly all its length. I think it is missing only a small portion of the terminal region. It must have reached 1.4 to $1.5 \mathrm{~mm}$ in all. The basal region is very short, wider than long. Its width equals a fifth or a sixth of its total length. The apophysis is very prominent. The blade is extremely narrow from the base. It hardly widens in its terminal part. It first has conical teeth, low and short, fairly separated from each other. Then, in the terminal part, the teeth abruptly come closer together and are very tight, sharp and fine. The perforations of the blade are round and fairly close together. They are very numerous, small and dense in the basal region.

The trifoliate pedicellariae have nothing peculiar. Their head measures $0.1 \mathrm{~mm}$ (fig. 14).

The stalk of the buccal pedicellariae contains slightly arched spicules armed with fairly dense teeth. At their distal end, and at the base of the digitations, are numerous perforated plates (fig. 16), similar to those that Mortensen has represented in Brisaster fragilis (07, Pl. XIV, fig. 13a) and Meijere in Linopneustes spectabilis (04, fig. 424). 
In spite of the incomplete information that I can give on the pedicellariae of E. denudatus, they are sufficient however to make some comparison. We shall find identical forms in the second species of the genus Eurypneustes that I describe below.

Regarding the internal organization, I observe, as well as I can judge from the specimens in a bad state of preservation, a remarkable resemblance with the arrangement that Wagner has made known in Archeopneustes niasicus. The path of the digestive tube is the same as in the latter. The diverticulum is narrow and very elongated. The principal intestinal siphon is slightly longer than in the latter species. Its distal opening is a little nearer the end of the ventral loop. There is likewise an accessory siphon a little more elongated than in A. niasicus and whose distal opening is located a little nearer interradius 5 . The wall of the digestive tube is very thin. They are also more or less torn in those specimens in which the intestine is preserved. They are also extremely transparent when they are empty and completely colorless. There are always four gonads. They are very little developed in all the individuals where I have been able to observe them. The two posterior gonads are found located fairly far from the apical system to which they are connected by an elongated canal measuring 15 to $20 \mathrm{~mm}$, while the two smaller anterior gonads are closer to it. The ambulacral vesicles of the dorsal ambulacra are very large. They are nearly full of mud.

Although the state of preservation of the specimens hardly lends itself to histological examination, I have however been able to find, in the wall of the digestive tube, between the end of the esophagus and the proximal opening of the principal siphon, glands identical to those that I made know previously in Spatangus purpureus and other spatangoids of the Mediterranean $(\mathbf{8 3}$, p. 45). I shall recall on this subject that Wagner has encountered these same glands, in the same region, in Archeopneustes niasicus (03, p. 33). I shall add finally that I have found them, and with the same characters, in all the spatangoids that I have been able to investigate. I have seen them notably in Faorina chinensis and in two new forms that I shall describe later, Hemiaster Hickmani and Brissopsis bengalensis.

I readily insist on these facts because in 1891 Cuénot has spoken with some scepticism of the glands that I discovered in Spatangus. Wager, in his finding them in A. niasicius, has done justice to this criticism (03, p. 333 and 34). The existence of these glands is thus proven in some spatangoids fairly separated from each other. We can suppose that they are more or less widespread throughout the order. I greatly regret that the insufficient preservation and the limited number of specimens I have had in hand have prevented me from undertaking more extensive research on this interesting point.

\section{Eurypneustes rubens nov. sp.}

(PI. XI, fig. 1, 3, 4, 10, 11, 12 and 13; PI. XVIII, fig. 29 to 38)

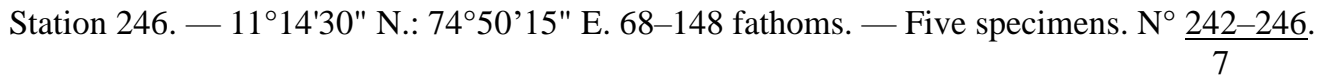

Station $465 .-5^{\circ} 56^{\prime}$ N.; $81^{\circ} 22^{\prime}$ E. 109-132 fathoms. — One specimen. $\mathrm{N}^{\circ} \frac{5259}{7}$.

These echinoids have been referred to the genus Eupatangus by Anderson (99, p. 71) and the jar that contains the specimens from station 246 has the label Eupatangus rubens. It is not inconvenient to keep this specific name that recalls the color that the urchin still has in alcohol, 
but I think the species should be placed in the new genus Eurypneustes, whose characters I have indicated above, and not in the genus Eupatangus.

The specimen from station 465 and one of those from station 246 are very large. Their length reaches respectively 53 and $57 \mathrm{~mm}$. The others are much smaller and only two are entire. They measure 31 and $32 \mathrm{~mm}$. The rest consists of fragments coming principally from the dorsal surface.

I shall describe the species mainly after the large specimen from station 246 that was in fairly good condition and that I have represented in Pl. XI, fig. 1, 3, 4, 10, 12 and 13.

Here are its principal dimensions, to which I add to make comparison, those of a small specimen that was reduced to the dorsal surface only.

Length.

Width.

Height.

Distance between the center of the apical system and the anterior end of the test.

$\begin{array}{cr}\text { Type } & \begin{array}{c}\text { Smaller } \\ \text { specimen }\end{array} \\ \underline{\mathrm{A}} & \underline{\mathrm{B}} \\ \mathrm{mm} & \mathrm{mm}\end{array}$

Distance between the center of the apical system and the posterior end. ....................................................

Distance between the anterior border of the peristome and the anterior end.

53

41

18

41.3

32.5

$?$

17

13.5

36

27.8

Distance between the posterior border of the peristome and the posterior end.

Length of the anterior petal.

Width of the anterior petal.

Length of the posterior petal.

Width of the posterior petal.

Length of the peripetalous fasciole.

30

Peristome (width and length)

Periproct (Height and width).

$8 \times 7$

The contour of the test seen from above (fig. 13) is fairly regularly oval with a narrow posterior end and obliquely truncated in front. The anterior border is flat at the level of the umpaired anterior ambulacrum and not at all depressed. The ambulacrum itself remains absolutely flush with the test on the dorsal surface. The test widens gradually in following a very regular curve toward the middle of the body. Then the width decreases rapidly to the posterior end that hardly measures a centimeter in width. Seen in profile (fig. 3), the test rises rapidly at first. Then it follows a curve with a larger radius to the apical system that is located very far forward and then remains nearly horizontal. Then it rises again behind following a curve with a very large radius toward the middle of the posterior interradius where it reaches its maximum height. It then goes down, following the same curve as before to the posterior surface that it joins by a round angle much less than $90^{\circ}$. The latter is directed obliquely forward. It is nearly entirely occupied by the periproct. 
The ventral surface (fig. 1) is nearly flat in its anterior half, with the peristome slightly sunken. Then it rises little by little to the median line in a keel that becomes rather projecting in approaching the subanal fasciole. On the same path as the latter, it has a small obtuse prominence. At some millimeters before it, we find a similar prominence that corresponds to the posterior and internal angle of each sternal plate.

The apical system is small (fig. 11 and 12). The two anterior genital plates are narrow, hexagonal, as long but narrower than the posteriors, and nearly two times longer than wide. The opening, very small, is located toward the middle. The posterior genital plates are not much longer than the anteriors, but they are very wide. Their form is also hexagonal and the opening is near the proximal corner. Thsee posterior openings are larger and more separated than the anteriors. The madreporite, largely fused to the right anterior plate, spreads back between the posterior genital plates. It continues in interradius 5 for a distance of approximately that of the posterior genital plates. The ocellar plates are very small and triangular.

The unpaired anterior ambulacrum, very narrow at its origin on the dorsal surface, widens very slowly to the ambitus. The plates that constitute it are first very small and wider than long. Then they become as long as wide. They are pentagonal and the pores are a little nearer the anterior and external borders of the plate. These pores are geminate, both very small and circular. The posterior pore is a little more apparent, however. Each pair is surrounded by a peripodia imprint in which the pores are separated by a small granule. In the large specimen A, I count twenty-three pairs of plates before the one crossed by the fasciole and that is found toward the middle of the anterior border of the test. The three pairs of plates that follow still belong to the anterior end. The following ones, that are more elongated, are located on the ventral surface. Each plate has at first one, then two or three secondary tubercles with sparse miliary granules. Beyond the fasciole, the tubercles become larger, a little more numerous and, at the anterior end of the test, they reach nearly the size of the adjacent primary tubercles.

The anterior petals are found nearly exactly on the extension from one another. They make an angle of $90^{\circ}$ with the antero-posterior axis, while the posterior petals make only a $20^{\circ}$ angle with this axis. The two petals of each side are separated by $70^{\circ}$. The anterior petals extend to two or three millimeters from the ambitus, while the posteriors, although much longer, do not go as close to the ambitus. The anterior poriferous zone of the former extends transversely. Its path remains nearly straight for nearly all its length, except in the proximal region where it has an oblique inward direction. The posterior poriferous zone follows a slightly convex curve especially in its second half. The interporiferous zone keeps nearly the same width except at its origin. It also narrows a little at its distal end where the petals have a slight tendency to close. The pores of the first eleven pairs of the anterior zone are small, especially those of the first seven pairs that remain rudimentary. The following eighteen pairs are well formed but the three last ones are located a little irregularly on specimen A and nearer the posterior zone in specimen B. In this one the number of pore pairs is twenty-eight in all and the petals remain largely open outside. In the posterior zone, the first five only are rudimentary. All these pores are enlarged and slightly verguliform. Those of the external row are a little larger than the internals. The successive pairs are separated by a small projection lacking tubercles. These are seen only in the interporiferous zone where we see some secondary tubercles and miliary granules. The width of the latter is a little less than the sum of the width of the two poriferous zones. The posterior petals have a little more regular form in their ensemble than the anteriors. They taper gradually at their origin, especially because of a narrowing of the poriferous zones, while the width of the interporiferous zone does not vary much. Th anterior poriferous zone is slightly curved inward at its proximal part, while the posterior zone curves a 
little in the inverse direction at its distal end. I count thirty-nine pairs of pores in the two zones. The first seven are very small in the anterior zone. The two poriferous zones approach each other a little at the end of the petals, but they remain widely open. The two zones are equally developed but the external pores are a little wider than the inner pores. In the smaller specimen B, there are only thirty-four pore pairs.

Beyond the petals, the ambulacra widen rapidly. The plate that follows the last pore of series IIb (or IVa) is crossed by the peripetalous fasciole. It widens very abruptly, while plate IIa (or $\mathrm{IVb}$ ), crossed by the fasciole, is preceded by a plate lacking pores. The plates that follow acquire gradually fairly numerous primary tubercles that become larger and less dense in passing to the ventral surface. But they do not reach the peristome. They completely disappear in the plates with phyllode peripodia. The posterior petals reach the fasciole. The pair of plates crossed by the latter not only is very widened, but its proximal border is developed obliquely inside and extends the length of the external border of the last three preceding poriferous plates as in E. denudatus. The following plates acquire numerous primary tubercles that become larger at the ambitus, but that disappear completely on the ventral surface. The plates of anterior ambulacrum III also lose their tubercles on the ventral surface.

On this latter, the ambulacra are fairly wide in the area of the peristome. Pair IIIa3-b3 is particularly widened. Then the width decreases after the following pair 4-4. The first three pairs have phyllode peripodia. The ambulacra II and IV have these same peripodia on the first five pairs of plates. The fourth is wider than the others. As for ambulacra I and V, their first two pairs of plates, that alone have large peripodia, are fairly narrow. But the following ones become very wide. Plates Ia3 and Vb3 are particularly widened. They nearly touch the median interradial line behind the posterior point of the labrum (Pl. I, fig. 1). They are however separated by the very narrow corner of the two sternums. The two following plates 4 and 5 are narrower. To the contrary, the five plates $6,7,8,9$ and 10 are extremely wide, but very short. They penetrate into the area surrounded by the subanal fasciole to fill the episternal corner that is very noticeable (fig. 10). Plates 6-6 extend the length of the posterior border of the episternals. They nearly touch the median interradial line. Plates 10-10 are a little longer than the preceding. They extend less far into the subanal area. Each of the four intermediary plates 7, 8, 9 and 10 has a geminate pore near their internal end and has an anal pedicel. The corresponding plates of the external series Ib and Va are equally short and wide.

The interradial pairs are simply convex at the dorsal surface of the test. It is with difficulty that we recognize on the two posterior interradii a slight arch toward the middle of each of their respective plates. Interradius 5, to the contrary, forms a projection that is very round. It attenuates as it nears the posterior end. The plates of the four interradial pairs acquire, at some distance from the apical system, very large primary tubercles. At first there is only one per plate, but they become more numerous toward peripetalous fasciole, especially in the posterior interradius where there are four to six per plate. They form ordinarily some longitudinal rows. Their dimensions decrease toward the ambitus. On the two anterior interradii, these tubercles continue beyond the fasciole toward the ambitus and become smaller. Then they pass to the ventral surface where their size increases again. On the posterior interradius, the large primary tubercles stop at the fasciole in individual A. Outside the fasciole, the plates have, independently of the miliary granules, only secondary tubercles that increase to the ambitus and reach the size of primary tubercles in passing to the ventral surface. To the contrary, in individual B, we still find one or two large primary tubercles on the plates that follow those crossed by the fasciole. 
The labrum is very narrow and very elongated. Its length reaches $12 \mathrm{~mm}$ in individual $\mathrm{A}$. It is slightly enlarged at its anterior end that hardly limits only half of the posterior border of the peristome without forming the slightest elevation recalling a lower lip. It is to the contrary slightly sunken in its anterior region that has some secondary tubercles. It then narrows, then widens a little toward the level of the posterior border of the second ambulacral plate. From there, it tapers to end in a round point toward the posterior border of the third ambulacral plate. The two sternal plates that follow are very narrow in front. They widen gradually. They measure $13 \mathrm{~mm}$ in length and the posterior borders reach the same level. The following plates 3-3 are triangular and wider than long. Their convex external border makes, with the anterior border of preanal plates 4-4, a very deep episternal angle nearly reaching the median line. The projection that each episternal plate has toward its middle, in the region of the anterior branch of the subanal fasciole, nearly merges with its congener. Beyond, the ventral surface rises to join the posterior end by a very round corner. This region is filled with the preanal plates 4-4 that are taller than wide and reach the periproct and limit its inner border. Its sides are thus formed by the series of plates 5 to 8 placed symmetrically on each side (Pl. XI, fig. 4). Each of the plates 4 to 7 have a small conical and rounded projection. The projections follow each to a small distance from the periproct. The sternal plastron is very small. The tubercles that leave in oblique lines from the unpaired posterior sternal prominence only reach the size of primary tubercles on the borders of the plastron. Likewise, the tubercles of the subanal area reach the size of primary tubercles only in the area of the median line.

A good part of the subanal plastron belongs to the ventral surface of the test. We see it entirely when we look at the urchin by its ventral surface. We can see at the same time all the periproct because of the obliqueness of the posterior surface. This subanal region is heart-shaped and wider than long. It is surrounded by a wide fasciole, very noticeable on all its periphery and slightly concave under the periproct. The band that forms it is a little wider on the sides, where the very tight granules that constitute it number twelve to fifteen in each row.

The peripetalous fasciole is reduced to the contrary to an extremely narrow band, having only three miliary granules in each oblique row (fig. 3 and 13). It is near the ambitus because of the elongation of the petals. It even takes a completely marginal location in front. Then it separates little by little from the ambitus and crosses the posterior interradius at approximately $8 \mathrm{~mm}$ in front of the posterior end. Its path is very regular, without inflexion or branching. In spite of its extreme thinness, its periphery remains distinct.

The peristome (fig. 1) is a little sunken. It is pentagonal with a larger posterior border directed transversely. The corners correspond to large plates that cover the anterior portion. There are four on each side. The two lateral ones are smaller and rather rectangular in form. The two anterior ones are larger and triangular. The rest of the peristome is filled with smaller plates.

The periproct (fig. 4) occupies a good part of the posterior end of the test. Its lower border is contiguous with the slightly concave dorsal branch of the subanal fasciole. It is rather pear-shaped and taller than wide with a sharp upper corner. The anus is nearer the lower border.

The primary spines have a length of 9 to $10 \mathrm{~mm}$ on the dorsal surface. They are slightly curved at their base and remain cylindrical to the end that is thin and pointed. Their surface has inconspicuous and sparse denticulations that become more apparent and closer together toward the end. The spines of the sternal plastron do not appear much different from the others. But I have rarely found them intact. Their end is slightly enlarged. The secondary spines have a nearly smooth surface. They are often curved in their distal half. The smallest are not much longer than miliary spines. They keep nearly the same width their entire length. The end is round. The miliary spines 
have the usual structure, the same for the calcareous stalk of the clavules. They are hardly wider at the end and have only very small teeth on their surface. They are a millimeter in length.

The pedicellariae are in general not very abundant. They have four types: tridactyle, rostrate, ophiocephalous and trifoliate.

The tridactyle pedicellariae, that are seen all over the surface of the test, are of two types. In the first form (Pl. III, fig 37), the valves are very wide. The head measures $0.4 \mathrm{~mm}$ in length. It follows a rather short neck. The basal part of the valves is fairly large and nearly as wide as long or a little longer than wide. Its length equals three and a half times the total length of the valve. The blade, first very narrow, widens into a very convex spoon that ends in an obtuse point. Its first part that is widening usually has two or three triangular teeth obtuse and low Then, afterwards, come extremely small teeth, dense, pointed and very regular that extend without change in character to the end. The perforations of the blade are large and oval. The valves are sometimes narrower than usual (fig. 35).

The pedicellariae of the second type (fig. 31) have, to the contrary, very elongated and very thin valves, recalling those that Mortensen has represented in Spatangus purpureus (07, Pl. XVI, fig. 1), but they are more delicate. The head, perhaps a little more elongated than in the preceding form, can reach $0.5 \mathrm{~mm}$ in length. But it does not exceed 0.2 to 0.25 in the smallest. The valves have a basal part relatively very enlarged and very short. Its length hardly reaches a fifth of the total length. The apophysis is very projecting. The blade remains extremely narrow, especially in the first half. It enlarges a little toward its middle. Then it gradually narrows to the end that is curved into a sharp beak. The borders have in the first half, conical and spaced teeth, fairly short. It is only in the second half that appear extremely small and very tight teeth that, in the preceding form, existed for the greater part of the length of the blade. The perforations are of moderate size and fairly close to each other. These pedicellariae are extremely close to the large tridactyle pedicellariae with thin and very elongated valve that I have indicated in E. denudatus where I have not been able to obtain them complete. We can moreover observe some variations in the relative lengths of the blade and basal part (fig. 30 and 32). Other pedicellariae, that constitute perhaps a third form, have extremely narrow valves, with a little developed basal part that is poorly separated from the blade that remains very thin for its entire length, with inconspicuous teeth (fig. 33).

The rostrate pedicellariae are larger than the tridactyles. Their head can reach up to $1.2 \mathrm{~mm}$. It is supported by a narrow and elongated neck whose length exceeds half the length of the valves. Its basal part (fig. 34) is relatively large and reaches approximately a quarter of the total length. The blade remains very narrow its entire length, without even sensibly enlarging toward its end. It has on its distal third extremely small teeth. pointed and near each other. Their size increases toward the end. The perforations are small and dense. The basal part usually has three or four small teeth, short, triangular and low in the second half. These pedicellariae are seen here and there on the dorsal surface, but they are more numerous in the area of the peristome.

The ophiocephalous pedicellariae (fig. 35 and 38) greatly resemble those of Spatangus purpureus that Mortensen has figured (07, Pl. XVI, fig. 6). The valves are relatively elongated, very narrow above the articulating part. Their free border is a little narrower than in this species. They measure $0.2 \mathrm{~mm}$ in length. These pedicellariae are very abundant on the ambulacra of the ventral surface. As for the trifoliate pedicellariae, they have nothing peculiar. Their head measures approximately $0.12 \mathrm{~mm}$ in length.

The peristomial pedicellariae have abundant spicules in their stalk, fairly strongly curved and with numerous, close teeth. They resemble those that Mortensen has represented in Hemiaster florigerus (07, Pl. XV, fig. 28), but the curve is more pronounced while the teeth are lower and 
fairly obtuse. Some are transformed into perforated plates, but generally remain fairly simple in an elongated form. We can however encounter larger plates with numerous perforations. The frontal pedicellariae, that have a small terminal disk, have spicules in their fairly short stalk, a little arched and with less numerous denticulations. The spicules become denser at the end of the pedicel. They are then transformed into small elongated plates with an irregularly round periphery and with numerous perforations.

The specimens in alcohol that have kept their spines have a very conspicuous brick red color on the dorsal surface. The ventral surface is nearly colorless. The test lacking spines are pink on the dorsal surface.

SiMILARITIES AND DIFFERENCES. - E. rubens appears to me to have its place in the genus Eurypneustes as I have defined it above. It could, as well as E. denudatus, be the type. It is especially distinguished from the latter by the presence of a well differentiated subanal fasciole very distinct for its entire periphery, by the labrum a little less elongated, by the position of the subanal plastron on the ventral surface, by the petals a little less short, by the elongated peripetalous fasciole of the ambitus in its posterior region and by the large primary tubercles of the dorsal interradius that hardly pass the peripetalous fasciole in the posterior interradius.

\section{Meijerea humilis (Meijere)}

(PI. XIX, fig. 46)

See for the bibliography:

Meijerea humilis. Döderlein (06), p. 242.

From the debris of Gymnopatangus of Station 310, found associated with a small fragment of the ventral surface that has all the characters of the genus Phryssocystis Agassiz, that Döderlein has separated the genus Meijerea. It is very probable it is the form discovered by the SIBOGA in the Banda Sea. I find on this fragment different tridactyle pedicellariae identical to those that Döderlein has represented (06, Pl. XLIX, fig. 7, g-l and s-u).

The valves of the ophiocephalous pedicellariae that I observe have a contour little different from that shown in the photographs published by this author. Their general form is squarer with slightly convex sides. I reproduce here the photograph of one of these valves (Pl. XIX, fig. 46). I can only note this slight difference. I refer provisionally the fragment found by the INVESTIGATOR to the species of the Sunda Isles. 


\section{Gymnopatangus Sewelli, nov. sp.}

(PI. XIII, fig. 1 to 7; PI. XIX, fig. 51 to 60)

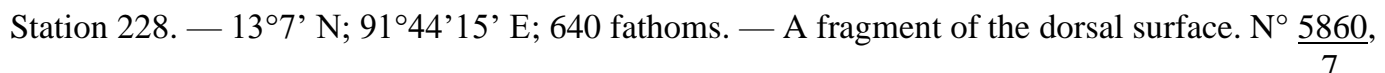

Station $310 .-13^{\circ} 29^{\prime} 30^{\prime \prime}$ N: $95^{\circ} 09^{\prime}$ E. 960 fathoms. - Several dried fragments: the jar that contained them arrived broken.

The fragment from Station 228, in alcohol, is found in a jar labeled Cionobrissus (?) martabaricus. It is incontestable that the fragment cannot be referred to the genus Cionobrissus. It has absolutely the same characters as those of station 310 and it belongs, like it, to the genus Gymnopatangus. The fragment, that I represent in Pl XIII, fig. 3, measures $0.5 \mathrm{~mm}$ in length. As for the fragments of station 310, the largest consists of a nearly complete dorsal surface that has kept the periproct with a small part of the subanal fasciole (Pl. XIII, fig. 1 and 5). The total length of this fragment is $105 \mathrm{~mm}$. The apical system, moved forward, is located $30 \mathrm{~mm}$ from the anterior border. I shall designate this fragment by the letter A. I have been able to assemble from other fragments that have given me a fairly extended portion of the dorsal surface of a larger individual than the preceding (because the distance between the apical system and the anterior end is $50 \mathrm{~mm}$ ) and that I shall call B. Finally, among the other much smaller fragments, is found a part of the anterior end of the test that I shall call $\mathrm{C}$, and on which we can follow the path of the anterior part of the fasciole. There are moreover also visible, on two other fragments, a periproct with a portion of the subanal fasciole and a small part of the ventral surface with part of the labrum.

In spite of the nearly complete absence of the ventral surface, it is nevertheless possible to have an idea of the characters of this echinoid, whose place in the genus Gymnopatangus cannot be doubted. It is incontestably very near the G. magnus reported from Japan by Agassiz and L. Clark in 1907. But the few lines that these authors have consecrated to this species do not constitute a description and until it has been fully studied it will not be possible to make a comparison between the two forms.

Here the dimensions that I took on the two fragments A and B.

Approximate length. ......................................

Width.

Height.

Distance between the middle of the apical system and the anterior end of the test.

Distance between the middle of the apical system and the posterior end.

Length of the anterior petals.

Maximum width of the anterior petals.

Length of the posterior petals.

Maximum width of the posterior petals.

Distance between the middle of the apical system and the posterior border of the peripetalous fasciole. ................

Length of the peripetalous fasciole.

$\begin{array}{ccc}\frac{\text { Fragment A }}{\mathrm{mm}} & & \text { Fragment B } \\ 108 & & \mathrm{~mm} \\ 90 & & 130 \\ 30 & \text { ca. } 105 \\ & ? \\ 30 & 50 \\ & \\ 71 & ? \\ 33 & 48 \\ 11 & 13 \\ 40 & 52 \\ 10 & 12 \\ 49 & 61 \\ 76 & ?\end{array}$


Width of the peripetalous fasciole. .........................

I shall describe the species mainly after fragment A that is more complete.

The anterior border of the test (Pl. XIII, fig.4) has a very wide notch, the maximum width measuring approximately $26 \mathrm{~mm}$ with of only $9 \mathrm{~mm}$ of depth. Seen from above, the contour appears regularly ovoid on either side of this notch although very slightly angular. The maximum width of the body is behind the apical system, toward the middle of the posterior lateral interradius. After this point, it decreases rapidly toward to the posterior end that is vertically truncated and vary narrow, because its width scarcely exceeds that of the periproct. The anterior ambulacrum remains flush with the test for a good part of its length.

Seen in profile (fig. 5), the test rises following a regular curve that attenuates a little before the apical system. Then, beyond the latter, the dorsal surface decreases very slowly to the posterior end to which it is connected by a rounded, but very sharp angle of approximately $120^{\circ}$. In front, the dorsal surface meets at the anterior end by a slightly rounded angle measuring only $90^{\circ}$, while at the other end the angle is fairly obtuse that allows us to suppose that the ventral surface was very convex posteriorly. The posterior surface, small, short and narrow, hardly measures $18 \mathrm{~mm}$ in height and $17 \mathrm{~mm}$ in width. It is connected to the dorsal and ventral surfaces by very clear although rounded angles and to the sides of the test by much more open and very widely rounded angles.

The apical system is, all together, of very small size (fig. 2). The four gonopores are very close together and the two anteriors are even confluent in my specimen. They are a little larger than the posteriors that are separated are separated by a very narrow interval, a little thicker however than the very thin blade separating the two anterior openings from the posteriors. These openings occupy nearly half the length of their respective plates. The genital pates are small and polygonal. The posteriors are a little more elongated than the anteriors. The madreporite forms in front a corner that separates the two posterior plates. Then it spreads out posteriorly in the form of a fairly wide ovoid plate whose length nearly equals that of the apical system. Because of the closeness and size of the gonopores, the madreporite takes a symmetrical form. Its anterior end touches the right anterior opening without encroaching onto the corresponding plate. The ocellar plates are small, triangular and a little wider than tall with a slightly arched opening.

The unpaired anterior ambulacrum (fig. 3 and 4) remains flush with the test for approximately half of its length. Then it sinks, first very slowly and then in a much more accentuated manner at the same time that it widens. Its form is thus that of an extremely elongated triangle that regularly widens to the ambitus where its base is strongly notched. I count thirty-one pairs of plates to the ambitus. The first are very small, as wide as long. But the following become wider than long. The pores, which are all geminate, remain very small, very close together and subequal. The first are directed obliquely inward. Then they are arranged parallel to the antero-posterior axis for the greatest part of the ambulacrum. They are finally placed a little obliquely outward in its sunken portion. The are very near the anterior border and the internal corner of the plates. They have fairly numerous miliary tubercles with some secondary tubercles that soon appear toward their ambulacral border. They become more numerous and larger toward the ambitus.

The anterior petals are notably shorter, but relatively wider in relation to their length than the posterior petals. They are very divergent and form an angle of $60^{\circ}$ with the antero-posterior axis, while the posteriors make a $30^{\circ}$ angle with the same axis. The two petals of each side together male an angle of approximately $90^{\circ}$. The anterior petals widen rapidly from their origin and reach 
their maximum width, $11 \mathrm{~mm}$, before their middle. Then they gradually narrow to measure only 6 $\mathrm{mm}$ at a short distance from their end where they remain open. The poriferous zones are relatively narrow, especially the anteriors, and measure approximately $2.5 \mathrm{~mm}$ each, while the interporiferous zone is wide and reaches nearly $6.5 \mathrm{~mm}$ in its widest part to fall to $2.5 \mathrm{~mm}$ in its narrowest region. The anterior zone has thirty-one pairs of pores in all. The first nine are rudimentary and inconspicuous. The following twenty-two pairs are to the contrary well formed. In the posterior row, the first five pairs alone are rudimentary. The pores of the anterior zone are unequal, smaller and closer together than in the posterior zone where they are a little elongated. The successive pairs are separated by a slight projection of the posterior border of the plate. It has, toward each end, some very small granules. These are continuous with the fairly numerous miliary granules of the interporiferal zone, in the middle of which are seen, on each plate, one and sometimes two secondary tubercles.

The posterior petals, more elongated and of a more regular form than the anterior petal, widen more slowly. But they reach nevertheless their maximum width, which is $10 \mathrm{~mm}$, toward their anterior third. From there, they narrow gradually to the end that remains open and measures 5.5. $\mathrm{mm}$. I count in the anterior zone forty pore pairs of which the first eight are very reduced while in the posterior row the rudimentary pairs number ten. The pores are identical in each zone. They resemble the posterior pores of the anterior petals.

Beyond the end of the petals, the ambulacral plates widen in a very rapid way, especially in the anterior ambulacra. They become rectangular. But the fasciole does not mark the distal end of the petal. In the anterior ambulacra, it is the fourth plate after the last pore that is crossed by the fasciole in the anterior series, and the third plate in the posterior series. The end of the posterior ambulacra is nearer the faciole. It is the plate that immediately follows the last pore that is cut by the fasciole in the posterior series, and the second in the anterior series. These plates have, up to the ambitus, a regular covering of secondary tubercles, forming on each plate, two or three regular, well spaced rows with sparse intercalated miliary granules. At the ambitus, these tubercles become very large and, on the anterior ambulacra, they pass to the primary tubercles of the ventral surface while on the posteriors they stop abruptly at the ambulacra that have only miliary granules. I cannot speak about the ventral surface that is missing in all the specimens that I have received.

The two anterior interradii are not very developed on the dorsal surface of the test. They reach their maximum width, $25 \mathrm{~mm}$, at the level of the distal end of the anterior petals. After this point, they narrow up to the ambitus because of the extremely rapid widening of the anterior ambulacral pairs. Also, their form is more comparable to a pentagon than a triangle. The plates between the apical system and the peripetalous fasciole have large primary tubercles of moderate size. Their number increases toward the fasciole. They form then more or less regular transverse rows, especially on the plates of the posterior series $2 \mathrm{a}$ and $3 \mathrm{~b}$. The dimensions of these tubercles are moreover very unequal. I count more than fifty of them in each interradius. Between thee tubercles are secondary and miliary granules, numerous and fairly dense. Beyond the fasciole the primary tubercles disappear abruptly in the posterior series. The secondary and miliary tubercles alone remain up to the ambitus. The covering of the plates is therefore absolutely identical to that of the adjacent ambulacral plates. In the anterior series $2 \mathrm{~b}$ and $3 \mathrm{a}$. The primary tubercles do not stop as abruptly. They continue beyond the fasciole but become smaller and smaller. The posterior interradial pairs have the same characters as the preceding. Each has approximately seventy primary tubercles, moreover very unequal in size, but larger as a whole than in the anterior interradius. They never pass the peripetalous fasciole. Finally, the unpaired interradius is slightly convex, without forming however a very noticeable projection. It is fairly narrow. It has in all 
about fifty primary tubercles that do not pass the peripetalous fasciole. All the primary interradial tubercles have very variable dimensions. The scrobicular circles vary both in width and depth. Some of them, moreover fairly rare, are a little effaced. They have perhaps begun resorption similar to that we have seen in the genus Eurypneustes.

Beyond the peripetalous fasciole, the dorsal interradial areas have a very uniform and uninterrupted covering of secondary and miliary tubercles absolutely identical to that of the ambulacral zones. The secondary tubercles become a little larger at the ambitus. They gradually pass to the primary tubercles of the ventral surface that I cannot describe. I have, in fact, only insignificant debris of this surface. I have however found a portion of the labrum that shows that this plate was elongated and very narrow, especially in the distal region.

I likewise can say nothing about the peristome of which I have only debris. The periproct is preserved on the large fragment A. I find it intact on another fragment where it is even larger as it measures $10.5 \mathrm{~mm}$ in height and $12 \mathrm{~mm}$ in width. In individual A (Pl. XIII, fig 1), the periproct is as long as wide, a nearly circular form with a convex lower border and a very obtuse dorsal corner. The marginal row of the plates is larger on the ventral side. Inside are several series of smaller plates arranged irregularly. The anus is nearly central, a little nearer however to the dorsal corner. The dorsal surface of the periproct coincides exactly with the corner that separates the dorsal surface from the posterior surface.

The peripetalous fasciole is constituted of a narrow band that especially keeps in its path a constant width of 0.6 to $0.7 \mathrm{~mm}$. It crosss the anterior ambulacral notch nearly at the ambitus. But it rises fairly rapidly and, after having formed two successive angles of approximately $90^{\circ}$, it nears the end of the posterior petal. A little before crossing the posterior interradius, it forms two rather obtuse angles but it always remains far from the posterior end. In the large fragment of the dorsal surface A that I describe, the peripetalous fasciole remains single throughout its path, but in fragment C (Pl. III, fig. 6), I note in front a small recurrent branch that exists only for approximately $15 \mathrm{~mm}$. It leaves the top of the corner formed by the fasciole near the anterior groove. This branch is directed backward parallel to the ambitus. It is not slow though to disappear. In individual B (fig.7). the fasciole makes first a nearly right angle without bifurcating. Then, on the very edge of the groove, it forms a narrower angle, from the top of which leaves a recurrent branch approximately $16 \mathrm{~mm}$ in length.

I can report only the presence of a subanal fasciole whose dorsal part alone is preserved. It is at least two times wider than the peripetalous fasciole and exceeds $3 \mathrm{~mm}$ above the periproct.

The large primary spines of the dorsal interradial areas are thin and very elongated. Their average length varies between 35 and $40 \mathrm{~mm}$, but they can reach up to $55 \mathrm{~mm}$. They have on their surface extremely low denticulations, conical, fairly wide and very spaced. They are nearer each other and more noticeable on the terminal part of the spine. They are visible only with a microscope (Pl. XIX, fig. 56). The other spines are much smaller. Their length does not exceed 4 or $5 \mathrm{~mm}$. They conform to those that Döderlein has represented in G. Valdiciae (06, Pl. XLIII, fig. 7, s). They are curved toward the last third and generally are a little flat and widened at the end. Their surface is smooth or has only some insignificant denticulations (Fig. 51). The miliary spines end in a slightly enlarged head. They are made up of a small number of calcareous rods.

The clavules of the fascioles are very thin and very elongated. The length of their calcareous stem can reach 1.2 to $1.4 \mathrm{~mm}$, while the width does not exceed $0.04 \mathrm{~mm}$. They are made up of a small number of longitudinal rods. The lateral teeth appear from the base of the calcareous stem. They are abruptly lengthened in the terminal part and become numerous in a way to form a very 
elongated head than can be $0.3 \mathrm{~mm}$ in length. It gradually widens to reach four or five times the diameter of the stem, 0.15 to 0.20 on average (fig. 54).

The pedicellariae are very abundantly distributed on all parts of the test. I have encountered only the three forms tridactyle, rostrate and trifoliate.

The tridactyle pedicellariae have a very thin and elongated head, preceded by a neck that nearly equals half its length. It reaches $0.8 \mathrm{~mm}$ on average. The basal part (fig. 53 and 57), little enlarged, is very short. It does not exceed a sixth of the total length of the valve. The apophysis is fairly projecting. The very narrow blade keeps at first the same width on half its length. Then it widens a little into a narrow spoon that ends in an obtuse point. In the narrow proximal half of the spoon are some wide denticulations, conical and short, while in the terminal part the teeth are very small and very tight. In the small pedicellariae, the widened part is relatively a little larger. It reaches two-thirds of the length of the blade (fig. 60). This form greatly recalls the tridactyle pedicellariae of Spatangus purpureus described by Mortensen (07, Pl. XVI, fig. 1), as well as those that I have found in Linopneustes spectabilis and Eurpneustes rubens.

There is a second form of tridactyle pedicellariae (fig. 58 and 59) that always remains at a small size. The length of the head varies from 0.3 to $0.35 \mathrm{~mm}$. The valves are comparatively wider and the row of small teeth extends over nearly the entire length of the blade. At its base, we can find two or three conical, stronger teeth. The pedicellariae represented by Döderlein in G. Valdicia (Pl. XLVIII, fig 7, k) are perhaps similar.

The rostrate pedicellariae (fig. 55) recall also those of $A$. spectabilis. The head is supported, as in the latter, by a very long neck that reaches or exceeds half its length. The valves are always very narrow. They are longer than in the tridactyle pedicellariae. They can reach $1 \mathrm{~mm}$. The triangular basal part is longer than wide. It exceeds a fourth of the total length. The blade remains narrow for its entire length. It is hardly wider in its last third. The very fine teeth appear only in the area of its end. It does not seem that similar pedicellariae exist in G. Valdiciae.

The head of the trifoliate pedicellariae measures $0.15 \mathrm{~mm}$. The valves have the usual structure (fig. 52). They are fairly strongly narrowed in their basal part. The blade is ovoid and elongated, widened at the base. It narrows gradually to the end that is thin and round. The perforations are rather large and elongated. These pedicellariae are very near those that Döderlein has represented in G. Valdicia (Pl. XLVIII, 06, fig. 7, d-i).

SimiLARITIES AND DifFERENCES. - The type of the genus Gymnopatagus is G. Valdicia described by Dôderlein. It was found by the VALDIVIA off the coasts of east Africa between 700 and 1.400 meters depth. The length of the test of the specimens studied by Dôderlein varied between 39 and $77 \mathrm{~mm}$. The species of the INVESTIGATOR is distinguished from G. Valdiciae by its much larger size, by the higher number of primary tubercles on the interradius of the dorsal surface, by the more open petals, the anterior pair also being wider, by the more pronounced notch of the ambulacral groove, by the slightly sinuous path of the peripetalous fasciole susceptible of splitting in front and finally by the presence of rostrate pedicellariae. On the other hand, our species is certainly very close to G. magnus Agassiz and Clark, found at Japan at 662-624 fathoms and that can reach large sizes, because these authors give, for one of the specimens, a length of $98 \mathrm{~mm}$, a width of $80 \mathrm{~mm}$ and a height of $30 \mathrm{~mm}$. Unfortunately, this form was not described by the American naturalists who, outside the numbers I just gave, scarcely mentioned more than the number of primary tubercles on the dorsal interradius. Now, according to what I observe on the fragments collected by the INVESTIGATOR, the primary tubercles are still more numerous in the 
Indian species. Whatever it is, a definitive comparison cannot be made until a detailed description of G. magnus has been published.

I dedicate this species to Captain R. B. Seymour Sewell, Surgeon Naturalist of the Marine Survey of India.

\section{Maretia planulata (Gray).}

(PI. XI, fig. 18 and 19; PI. XX, fig. 8 to 13).

See for the bibliography:

Maretia planulata, Meijere (04), p. 190;

Maretia planulata, R. Brown (10 bis), p. 43.

Great Coco Island (Andaman). - Twelve specimens. № $\frac{194-195}{7}$.

In the largest individual, the test does not exceed $41 \mathrm{~mm}$. The others are still smaller. Their length varies between 25 and $13 \mathrm{~mm}$.

The characters of the test of this species are well known, but we have only some very summary information on the pedicellariae because the three figures that Meijere has published $(\mathbf{0 4}, \mathrm{Pl}$. XXIII, fig. 478-480) are scarcely demonstrative. Although my specimens are of small size, I can however observe diverse forms of the pedicellariae that I believe it will be useful to make known.

They are mainly tridactyle pedicellariae. The most distributed form does not appear to reach very large sizes. The head does not exceed 0.6 to $0.7 \mathrm{~mm}$ in the larges. This length can fall to 0.3 $\mathrm{mm}$ in the smallest. The valves recall the form represented by Mortensen in Spatangus purpureus (07, Pl. XVI, fig. 1). The basal part is wider than long. Its length equals approximately a fifth of the total length ( $\mathrm{Pl}$. XX, fig. 13). The apophysis is very large and projecting. It can have some conical teeth. The blade remains fairly narrow its entire length. It is armed in its proximal half with conical teeth, low, wide and vary spaced, while in the terminal half, which is wider, the teeth are very small, short, pointed and dense. The end of the blade has a very noticeable hook.

Much larger and stronger pedicellariae have a head that can reach and even exceed $1 \mathrm{~mm}$ (fig. $8,9,11$ and 12). The basal part is very tall, longer than wide. It equals less than a third of the total length. The apophyis is fairly projecting but it is not as prominent as in the preceding form. It is always armed in its upper half with several conical and very strong teeth. The blade is at first vary narrow in its proximal part and has triangular teeth, low and separated. But it widens a little in its distal half and forms a spoon that is fairly abruptly narrowed toward its end to curve into a beak. It has in this portion very unequal denticulations, elongated and round at the end. We pass gradually from this form to other smaller pedicellariae in which the valves do not exceed $0.5 \mathrm{~mm}$ and whose basal part scarcely reaches a fourth of the total length (fig. 10). The blade remains small, in the form of a gutter with the borders fairly close together. It does not enlarge much at the end. It has in the first half only some sparse teeth. They can even be completely missing. They pass gradually to the teeth of the second half that are finer, denser and regular. A more or less accentuated hook ends the valve. 
The trifoliate pedicellariae are very small. Their valves to not exceed $0.08 \mathrm{~mm}$ in length. The blade is oval with nearly smooth borders, the extremely small denticulations being hardly visible.

\section{Pseudomaretia, nov. gen.}

I propose to establish a new genus, whose type will be the Maretia alta of Agassiz, because it appears to me impossible to keep this species in the genus Maretia as has been characterized by Gray and whose type is M. planulata. The new genus is distinguished from the genus Maretia by the following principal characters.

The test is quite tall. The strongly convex dorsal surface rises gradually from the anterior border to the posterior end. This surface is very uniformly covered with secondary tubercles. There is only a very small number of primary tubercles in the two posterior interradii in the area of the ambitus. The gonopores number three only. The posterior ambulacra of the ventral surface are relatively narrow. The posterior end of the test is truncated and directed obliquely forward. Its upper part, above the subanal plastron, is entirely filled by the opening of a wide and deep invagination that projects into the interior of the test. The periproct, which is found at the bottom of this invagination, is transformed into a kind of transverse ampulla widening at each end in a kind of round vesicle fused to the internal surface of the test. The pedicellariae are not abundant. The most developed are tridactyle pedicellariae with a fusiform peduncle, identical to those that Dôderlein made known in Lovenia elongata and subcarinata, that are found on the posterior ambulacra of the ventral surface. Each digitation of the anal pedicels of Echinocardium cordatum has a very strong and thick stem, quite different from the narrow and slender stem that we find in the peristomial pedicels. These different characters do not exist in the genus Maretia.

The form of the test, fairly elevated toward the posterior end, the presence of three gonopores, the narrow posterior ambulacra, etc., are well known, I shall not stop there. In the excellent description that he published on the Maretia alta, Loriol remarked $(\mathbf{8 3}$, p. 51) that some figures published by Agassiz (81, Pl. XXXVII, fig. 2 and 4) do not refer to this species. Meijere shares this point of view (04, p. 192). I have thus believed it necessary to reproduce here some photographs of an individual measuring $29 \mathrm{~mm}$ in length (Pl. XI, fig 14 to 17 and 20). I likewise give photographs of a specimen of Maritia planulata having nearly the same dimensions as the latter to facilitate comparisons (Pl. XI, fig. 18 and 19).

Regarding the periproct, the descriptions of the authors only say that it is found at the bottom of a deep hollow occupying the upper part of the posterior end of the test. But I have found no information on the structure of this region. If we examine the inner surface of the test of a P. alta whose ventral wall has been removed (Pl. XI, fig. 16), we see that the floor of the anal depression forms a kind of demi-tube or gutter whose cavity we naturally do not see and whose borders are fused to the inner surface of the test. This gutter is very widened behind where it connects to the posterior face of the test. It is slightly narrowed in is middle. Its average width is approximately 5 $\mathrm{mm}$ in a specimen measuring $29 \mathrm{~mm}$ in length. In front, this tube has a formation that appears very singular and we cannot explain its nature at first. It is a kind of bowl widened transversely, narrow in its middle and that develops, on the sides, two large swellings, wide and round, fused to the internal surface of the test and reaching both adjacent ambulacral zones I and V. It is in the shortened median part of the bowl into which the rectum opens. If we study closely the structure of this formation, we easily recognize that the ventral wall of the tube is formed of two pairs of 
plates whose sutures are very apparent. The plates of the first pair have nearly the form of a right triangle united on the median interradial line by their hypotenuse. These plates nothing other than the preanal plates 5a4 and b4. The posterior and external side, fairly sinuous, is contiguous with the ambulacral plates that fill the episternal angle. The ventral wall of our tube is completed in front by the posterior pair of interradial plates a 5 and b5 that are very short inside and are especially developed on the sides. They alone form the anterior wall of the tube that has the bowl. This has very thin walls constituted of the polygonal plates, large and unequal, among which we distinguish at first a first row or posterior row, of fairly large plates, arranged the length of the anterior border of plates a5-b5, and, forward, two or three fairly unequal rows of very small plates occupying the sunken part of the bowl, while the enlarged lateral swellings are formed by large, irregularly polygonal plates. I have no doubt that this bowl is not constituted of elements of the periproct compressed inside the test and considerably enlarged.

If we examine the external surface of the test at its posterior end (fig. 17), we see that this periproctal invagination forms a kind of tunnel whose entrance presents a triangle with a dorsal top and round angles. We can distinguish, at the end of the invagination, a median region at the upper part of which is found the anus. On each side of this opening, the subanal fasciole, heartshaped and transversely widened, contains the internal regions of the four adjacent ambulacral plates $6,7,8$ and 9 of series Ia and $\mathrm{Vb}$, with three anal pedicels on each side. The episternal corner is extremely elongated and sharp. It nearly reaches the median interradial line. Each of the two preanal plates have the form of an elongated triangle with a truncated lower top as I indicated above. The following plates a5-b5 are divided into two parts. One penetrates into the interior of the periproctal tunnel where it contributes to a part of the floor as well as the sides. The other remains outside the invagination. It is elongated first above the preceding preanal plate that it borders. Then, above the internal region of ambulacral plate Ia9 (or Vb9), it is crossed by the upper round border of the subanal fasciole. The upper border of the external part of interradial plate 5 is found nearly on the extension of the floor of the tunnel whose sides ae constituted therefore of the following pairs of plates 6,7 and 8 , as it is a normal periproct. All the internal surface of the invagination and the bowl that follows it is covered with numerous secondary and miliary spines identical to those we find on the surface of the test.

I have encountered only tridactyle and trifoliate pedicellariae. The tridactyles have two very different forms. The first belongs to the type of pedicellariae with a fusiform peduncle that Döderlein discovered in Lovenia elongata where he had first considered them as globiferous. They are fairly abundantly distributed in the posterior ventral ambulacra. The peduncle (Pl. XX, fig. 1) is short. Its calcareous stem is strongly swollen in its middle, or rather it is pear-shaped. At its lower part, it gradually tapers into a narrow pedicle, while its upper part, strongly swollen, ends in a small rounded tubercle that articulates directly with the valves. The length of this stem $\ldots 110 \ldots$. is $0.3 \mathrm{~mm}$ on average. The valves (fig. 5), very elongated and narrow, have a basal part longer than wide but that continue insensibly with the blade. This, in the form of a gutter, narrows gradually to the end that is slightly enlarged and has a variable number (three to five) of conical teeth, short and pointed. The basal part has small and tight perforations that continue the entire length of the blade where they have small circular holes arranged in three or four more or less regular longitudinal rows. The length of these valves varies between 0.3 and $0.35 \mathrm{~mm}$. Their calcareous tissue is covered by a membranous envelope, strongly pigmented brown that contrasts clearly with the much paler adjacent tissue.

The tridactyle pedicellariae of the second form are larger than the preceding. The peduncle is thin and elongated with a fairly long neck. The head elongated and narrow, measures $0.5 \mathrm{~mm}$ in 
length. The basal part of the valves (fig. 7) is narrow, triangular, much longer than wide. It is hardly two times narrower at the point where it joins the blade than at its base. The blade also remains very narrow, although it first widens somewhat on approximately the first sixth of its length but without reaching the width of the basal part. Then it narrows gradually to the end that is pointed. It has on its last third extremely small denticulations, dense and scarcely distinct. The perforations are very small, round and undeveloped.

The trifoliate pedicellariae are extremely small. The valves do not exceed $0.08 \mathrm{~mm}$ in length.

The anal pedicels are very developed. They have numerous digitations. The rods they contain (fig. 3) are very large, thick, slightly curved and completely like those Loven has represented in Echinocardium cordatum (83, Pl. VIII, fig. 57). The length of these rods is variable. The largest exceeds $1 \mathrm{~mm}$. In the peristomial pedicels, to the contrary, the rods remain small and slender and their length hardly exceeds $0.4 \mathrm{~mm}$ (fig. 6).

The miliary spines (fig. 1) are very long. They have a makeup similar to that of the clavules of the subanal fasciole, which are likewise very long. This length can exceed $2.5 \mathrm{~mm}$. They have lateral teeth on nearly all their length. These are in general very strong, conical, directed toward the distal end of the spine. Sometimes some of them are elongated considerably in the middle region as I have represented in fig. 2. The distal end of the spine is hardly enlarged. It ends in some small pointed columns.

\section{Pseudomaretia alta (Agassiz)}

(PI. XI, fig. 14 to 17 and 20: PI. XX, fig. 1 to 7)

See for the bibliography:

Maretia alta Meijere, (04), p. 192.

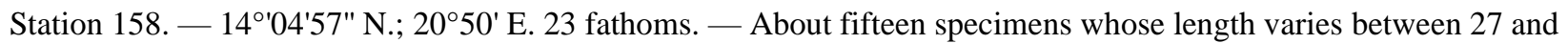
$32 \mathrm{~mm}$, plus a fragment of the dorsal surface belonging to a specimen that should measure at least $37 \mathrm{~mm}$ in length. No number.

Pedro Shoal. — Debris of very small specimens. № $\underline{8909}$.

Andaman Islands. - One specimen. $\mathrm{N}^{\circ} \underline{519}$.

Sept-Pagodes. -5 to 10 fathoms. - Four specimens whose length varies from 12 to $27 \mathrm{~mm}$. $\mathrm{N}^{\circ} \underline{9251}$.

Poorie. - A very small specimen having $9 \mathrm{~mm}$ only. Several of these specimens are in good condition, but the others are more or less incomplete and sometimes reduced to simple fragments. 


\section{Lovenia elongata (Giay).}

(PI. XI, fig. 5 and 6: PI. XII, fig. 10; PI. XIII, fig. 8; PI. XIX. fig. 25 to 32.)

See for the bibliography:

Lovenia elongata Meijere, (04), p. 193:

Lovenia elongata Fourteau, (04), p. 429;

Loepnia elongata Dôderlein, (06, p. 265;

Palk's Straits. 6-10 fathoms. - Six specimens plus some debris. $\mathrm{N}^{\circ} \underline{9096}$.

Terribles. 13 fathoms. - Some debris. $\mathrm{N}^{\circ} \frac{420}{7}$.

Coast of Madras; 20 fathoms. — Palk's Straits; 7 fathoms. — North of the Maldive Islands: 20-30 fathoms. — Eleven specimens all in the same jar.

Bushby Island (Mergui Archipelago). — One specimen. $\mathrm{N}^{\circ} \underline{7773}$.

The length of the specimens is most usually between 60 and $28 \mathrm{~mm}$. Some individuals are smaller. Their length falls to 14 and even $10 \mathrm{~mm}$.

The characters of the test of L elongata are well known. Agassiz (74, p. 584) has recalled the presence in the genus Lovenia of large bowls that correspond to the scrobicular circles of the large primary tubercles and that protrude on the internal surface of the test. He has published two figures of them of which one gives a fairly exact idea of its structure (74, P1. XXXVIII, fig. 28 and 28'). I have believed it useful to reproduce here a photograph showing all the development that these large calcareous bowls can take (Pl. XII, fig. 10). We know moreover that the periproct is deeply sunken in L. elongata. Agassiz said that it is located at the end and on the upper border of the deep tunnel that divides the subanal plastron into two nearly discontinuous parts. But I have not found in the literature precise information on the subject of this invagination, comparable to the one that I have studied in the genus Pseudomaretia. I give here (Pl. XI, fig. 5 and 6) two photographs of the internal surface of the test in the posterior region of the body that clearly shows the characters of the invagination in question, which has a very deep brown color but is only very pale in individuals kept in alcohol. We recognize the presence of a fairly large tube, a little narrower at the posterior base and ended in front by a vertical end to which the convex lateral surfaces are connected by round borders. In the specimen measuring $60 \mathrm{~mm}$, this tube reaches $7 \mathrm{~mm}$ in length and a maximum width of $10 \mathrm{~mm}$. But in front it does not have the least indication of the vast bowl that I have studied above in the genus Pseudomaretia. However, this invagination is made up of the same elements as in the latter. We find, in fact, on its ventral surface, a pair of preanal plates 4-4, each of which has the form of a right triangle, wider than long and that form especially the ventral wall of the tunnel. These two plates curve on the side where they end in a pointed top. One of the sides of the right angle is exactly perpendicular to the median line. It is related to the posterior border of the preceding episternal plate 3. As the two pairs of plates have the same width, there is not the least indication of an episternal angle. The other side of the right angle is contiguous with its congener on the median interradial line of the tube that we consider. The anterior top of the plate that is pointed is extended a little forward. The rest of the wall of the tube is formed by the following pair of plates 5-5. These are strongly convex. Each of them is related to its congener on the median line only by its anterior and internal border, while, on the sides, it extends more and more. The tube, thus formed by the two pairs of posterior interradial plates 4-4 and 5-5, is free for nearly all its extent, except along the dorsal media line and in the posterior part where it is fused 
to the internal surface of interradius 5. In front, the tube is closed by a wall in the form of a triangle whose top is turned from the ventral side and whose dorsal base is a little concave. This wall is constituted mainly of a very large median pentagonal plate that occupies nearly all the surface. Then, toward the base, are seen, on each side, two small triangular plates. All of this forms the anterior vertical wall of the anal tube. Finally, this has a dorsal surface that it is impossible to perceive when we examine the test from the internal side. This surface is constituted of small polygonal and unequal plates, comparable to those that we see habitually on the periproct of urchins. We recognize them easily in examining the test from the exterior. The anus opens onto the surface nearer the posterior end than the anterior wall of the tunnel. I consider the ensemble formed by this dorsal surface, as well as by the anterior wall containing the large median triangular plate and the small lateral plates that I just indicated, to represent the periproct.

The pedicellariae of L. elongatus have already been studied by Dôderlein (06, p. 265). This author has reported, among others, a very peculiar form of tridactyle pedicellaria that he first considered as globiferous. But he has definitively referred it to the tridactyles in his work on the echinoids of the Aru Islands $(\mathbf{1 1}, 247)$. These pedicellariae are characterized by a short peduncle, thick and fusiform, while the valves remain thin and flat. I have found these pedicellariae in my specimens. I give here some photographs of them representing first an entire pedicellaria (Pl. XIX, fig. 25), as well as the valves (fig. 26) and an isolated calcareous stem (fig. 29). This latter was not represented by Dôderlein. The head and the peduncle have nearly the same length and measure on average $0.28 \mathrm{~mm}$ respectively. A more of less brown pigmented membrane covers all of it.

The tridactyle pedicellariae of the ordinary form have also been represented by Dôderlein, who compared them to those of Spatangus purpureus. It seems to me that the valves of these pedicellariae are shorter and wider than those in the latter species. Their length is 0.3 to $0.35 \mathrm{~mm}$. The basal part (fig. 32) is small, its apophysis slightly projecting. The blade, in the form of a rather narrow spoon, has in its lower half some large teeth of variable form, and, in its terminal half, very fine and dense teeth.

I have also found in L. elongatus the third form of tridactyle pedicellariae indicated by Dôderlein, whose valves have a blade nearly completely lacking in perforations. The blade is lanceolate in form with the point rounded (fig. 30). This form of tridactyle pedicellariae greatly recalls that I have reported in Pseudomaretia alta and that we shall find in L. gregalis and Metalia maculosa, where the valves reach a larger size and have normal perforations. The length of these valves in L. elongata is $0.2 \mathrm{~mm}$.

The rostrate pedicellariae have, in general, thinner valves that those that Dôderlein has represented (06, Pl. XLVIII, fig. 5, a and b). Their length is 0.2 to $0.25 \mathrm{~mm}$. The basal part (fig. 31 ) is very rounded, nearly circular, as long as wide or hardly a little longer than wide. The borders are sometimes smooth, but they most often have some teeth, very low, conical and scarcely notable. The perforations are large and dense. The blade is very narrow and thin. But it widens in a very noticeable way in the terminal part that becomes nearly spatulate. It has on its round border, a succession of small teeth, fine and conical. I have moreover encountered pedicellariae identical to those that Döderlein has represented and whose blade is shorter and thicker than in the preceding.

I have also found in L. elongata another form of pedicellaria that Döderlein has not reported. I consider it as a second type of rostrate. They are encountered only in the periproctal invagination. The valves (fig. 27) have nearly the same length as in the preceding, but the basal part is larger, elongated, triangular, longer than wide and with a length nearly half the total length of the valve. The blade is narrow, slightly curved in the form of a gutter on nearly all its length, except at the 
base where it is tubular. The extremity that is not widened, ends in some teeth fairly unequal and irregular, elongated and round at the end. They number six to eight.

The trifoliate pedicellariae (fig. 28) resemble those of Spatangus purpureus as Döderlein has already said. The valves are very elongated. They reach 0.16 to $0.18 \mathrm{~mm}$ in length while their basal part is rudimentary.

\section{Lovenia subcarinata (Gray)}

(Pl. XIX, fig. 47 to 50$)$

See for the bibliography:

Lovenia subcarinata, R. Brown (10), p. 13;

Lovenia subcarinata, R. Brown (10 bis), p. 26.

Lovenia subcarinata, Döderlein (11), p. 24.

Coast of Orissa. 23 miles to the S. W. of Pury. - One specimen. $\mathrm{N}^{\circ} \frac{416}{7}$.

Kings Island (Mergui). - Seven very small specimens. $\mathrm{N}^{\circ} \frac{7781 \text {, }}{6}$

Kabusa Island (Mergui). - One small specimen. $\mathrm{N}^{\circ} \frac{7782}{6}$.

The individuals are of small size. Their length varies between 4 and $9 \mathrm{~mm}$, except in the first where it measures $20 \mathrm{~mm}$. Their test has been more or less attacked by alcohol.

I have not been able to use the specimens for the examination of their pedicellariae. But I have studied them in the specimens that I possess in my collection that came from Java. I find in the posterior ambulacra some tridactyle pedicellariae with a fusiform stem and flat valves comparable to those of L. elongata of which I just spoke and that Döderlein did not indicate in L. subcarinata. The valves (Pl. XIX, fig. 47) are narrow, perhaps narrower still than in L. elongata and more elongated, contiguous with each other for nearly their entire length. This makes the head extremely thin and much narrower than the swollen part of the peduncle. This can reach nearly 0.38 to 0.4 $\mathrm{mm}$ in length. The head is nearly as long, so that the pedicellariae measure in all 0.75 to $0.8 \mathrm{~mm}$ in total length. They are thus a longer than in L. elongata. The peduncle (fig. 50) is enlarged into a spindle over its greatest length. It ends at both extremities in a nearly cylindrical and very short part, rounded on the side of the head and elongated at the other end by which it attaches to the test. The basal part of the valves reaches a quarter of the total length. It is hardly two times wider than the blade to which it gradually passes. They keep nearly the same width up to its end that has two small teeth, conical and short. The head of the pedicellaria is surrounded by a deeply pigmented tissue. The tridactyle pedicellariae do not differ from those of L elongata. The rostrates have valves a little shorter and stronger than those of the latter species (fig. 49). 


\section{Lovenia gregalis Alcock}

See for the bibliography;

(PI. Xll, fig. 6, 7, 8, 9 and 11.: PI. XIX, fig. 33 to 45 )

Lovenia gregalis, Meijere (04), p. 194, pl. X, fig. 97-98;

Lovenia gregalis, Agassiz and L. Clark (07), p. 133;

Lovenia gregalis, L. Clarlc (08), p. 309.

Station 323. - 16 $25 \mathrm{~s}^{\prime}$ N.: $93^{\circ} 43^{\prime} 30^{\prime \prime}$ E. 463 fathoms. — Three specimens. $\mathrm{N}^{\circ} \underline{1958}$

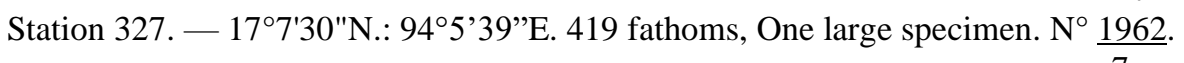

Station 380. - 19 $9^{\circ} 8^{\prime}$ N.: $92^{\circ} 59^{\prime}$ E. 530 fathoms. - One specimen. $\mathrm{N}^{\circ} \frac{3470 .}{7}$.

Station 381. $-18^{\circ} 8^{\prime}$ N.: $93^{\circ} 40^{\prime}$ E. 298 fathoms. - Three specimens. $\mathrm{N}^{\circ} \frac{3463}{7}$.

Station 383. - 17'18' N.: 94"08' E. 517 fathoms. — One specimen. $\mathrm{N}^{\circ} \underline{3469}$.

Bay of Bengal, 475 fathoms, 475 fathoms. - Three specimens. $N^{\circ} \frac{8451-8463}{6}$.

In the largest specimens, the length of the test reaches $76 \mathrm{~mm}$. Most of the others measure 60 to $70 \mathrm{~mm}$. The smallest specimen, coming from station 323 , are only $46 \mathrm{~mm}$. The specimens from the Bay of Bengal are nearly all lacking spines and most of the test. Some are reduced to only the dorsal surface. Other specimens are in general covered with spines.

L. gregalis was described by Alcock in 1893 (93, p. 175, Pl. VIII, fig. 9) after the specimens from the Bay of Bengal reported above. Meijere has also studied this species after individuals capable of reaching the largest dimensions, because the largest measured $86 \mathrm{~mm}$ in length and 64 $\mathrm{mm}$ in width. They differ from those of Alcock only by some differences in the arrangement of the large primary tubercles of the dorsal surface. As for the specimens that Agassiz and L. Clark reported in 1907, which came from Japan (southeast of Koshika Island, 369-401 fathoms), they do not exactly conform with the description of Alcock, but the American authors limit themselves to this simple remark. Finally, the specimen indicated by L. Clark in 1908, also came from Japan but only at a depth of 60 fathoms. It is a very young individual whose determination still remains uncertain.

Alcock represented, first in 1893, then in 1902, the dorsal surface of the test of L. gregalis. Meijere gave, in 1904, two photographs, one representing the dorsal surface with spines and the other the bare ventral surface. But the contours of the plates and the path of the subanal fasciole are completely indistinct in the latter. To complete this documentation, I reproduce here the photograph of a specimen with its spines seen from the ventral surface as well as those of another individual without spines and seen from its different aspects (Pl. XII, fig. 6, 7, 8, 9 and 11).

Here are the principal dimensions of this latter specimen:

$\mathrm{mm}$

Length. ............................................................... 72

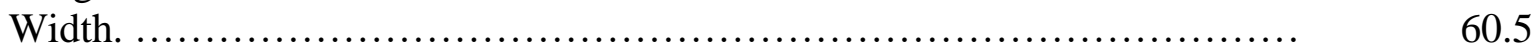

Height at the level of the apical system. ................................ 23 
Distance between the middle of the apical system and the anterior end of the 36

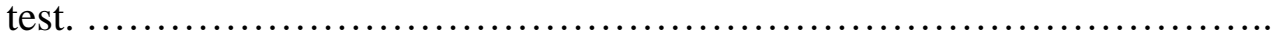

Distance between the middle of the apical system and the posterior end. ..........

Distance between the anterior border of the peristome and the anterior end......

Distance between the posterior border of the peristome and the posterior end....

Distance between the end of ambulacral groove and the anterior end. .............

Width of the internal fasciole at the level of the apical system. .................

Width of the subanal fasciole.

Peristome (length and width).

$7.5 \times 14$

Periproct (height and width)

I can add to the descriptions of Alcock and Meijere some information on the exterior characters of the test of L. gregalis. I shall then describe the pedicellariae that have not yet been studied.

The test is slightly elevated in the form of a very low cone. The ventral surface is flat for nearly all its length. We note only when we examine the profile (Pl. XII, fig. 9), a slight projection formed by the lower lip and a hardly noticeable sternal prominence with an unimportant intermediary depression. The anterior borders of the subanal fasciole make, on each side, a slight prominence. The borders of the test are very widely rounded and fairly high in the posterior half. Then they gradually narrow forward. The apical system is located nearly equidistance from the two ends. The four gonopores, of median dimensions, are very close to each other. The anteriors are a little nearer each other than the posteriors that are separated by a space hardly equal or even a little less than their diameter. The genital plates are small, in the form of elongated hexagon, the anteriors narrower than the posteriors. The gonopore occupies nearly all the proximal half of each of them. The madreporite, narrow, elongated and fusiform, extends for a length of $3 \mathrm{~mm}$ backwards of the posterior gonopores. The ocellar plates, of medium size, are triangular with a small transverse, linear opening.

The anterior ambulacrum, at first very narrow and flush with the test on the dorsal surface, begins to sink only a little before the middle of the interval between the apical system and the end of the notch that it forms in front. At this point, the poriferous zones are separated by barely 2.5 $\mathrm{mm}$. From there, the ambulacrum sinks rapidly and widens little by little. At the bottom of the groove thus formed, the poriferous zones become separated by an interval of $4.5 \mathrm{~mm}$. The borders of the sunken part are flared and round. The anterior notch is very deep and its sides are nearly vertical. Reaching the ventral surface, they spread out more widely than on the dorsal side. But the borders are round on both surfaces. I count twenty-two pairs of pores on the dorsal ambulacrum. The pores of the first seven pairs starting from the apical system are extremely small and hardly visible. The following ones become larger and quite apparent. The posterior pore, a little elongated, is much larger than the anterior pore that remains small and circular. But in the anterior part of the groove, the pores become equal and small. Outside each poriferous row, we see a band of small secondary tubercles that extend the length of the border of the groove to the anterior end of the test.

The anterior and posterior petals are less pointed, and their base is narrower than in L. elongata. The two petals of each side are quite separated at their origin instead of being confluent as in the latter species. The posterior poriferous zone of the lanceolate anterior petals measures $28 \mathrm{~mm}$ in length. They stop at a short distance from the ambitus. Their anterior poriferous zone is very short. It has only nine pairs of large pores that begin beyond the internal fasciole. In fact, the first ambulacral plates that follow the ocellars are less developed than the following and their pores are 
completely rudimentary. These plates number nine. The fifth is crossed by the internal fasciole. We count thus four pairs of rudimentary pores inside the fasciole and four other pairs outside. Then abruptly, and without any transition, the pores acquire the dimensions that they keep to the end of the petals. It is notable that this small series of proximal ambulacral plates with very reduced pores is not found exactly in alignment with the following plates but makes a very obtuse angle with the direction of the latter. The posterior poriferous zone has fifteen pairs of large pores that begin very close to the fasciole. These are preceded by five other pairs of very small pores, smaller even than the pores of the anterior zone at the same height inside the internal fasciole. The large pores are rounded and equal in each pair. The interporiferous zone has only very small tubercles some of which penetrate into the successive pairs of pores, without however reaching the external border of the petal.

The posterior petals measure 27 to $28 \mathrm{~mm}$ in length. They are triangular, but they remain a little more oval at their distal end than the anterior petals. The two poriferous zones are equal. Each of them contains fifteen to sixteen pairs of large pores. In the anterior row, the large pores begin a little outside the internal fasciole. They are preceded by a series of eight pairs of very small pores that form with the latter, an angle still more obtuse than in the anterior petals. The large pores of the posterior row are preceded by only six pairs of rudimentary pores that are found on their extension in the direction of the apical system.

The anterior petals form with the dorsal groove an angle of $50^{\circ}$. The two petals of each side together have an angle of $100^{\circ}$. Finally, the posterior petal and the unpaired interradius make an angle of $30^{\circ}$.

On the ventral surface (fig. 8), the posterior end of the ambulacral notch is found very near the anterior border of the peristome. The phyllode pedicels of the anterior ambulacrum are developed only in the two first rows of plates of each series. Plate IIIa3 has however a rudimentary peripode. The proximal regions of the four ambulacral pairs are flush with the test. The anterior ambulacra, very narrow at the end, widen on the dorsal surface at they approach the ambitus. Then they narrow again as they approach the ventral surface to widen again a little in the area of the peristome. They have, above and below the ambitus, very dense secondary tubercles that are not slow to disappear on the ventral surface where we can see only some rare miliary tubercles. The phyllode pedicels are seen only on the three first plates of each series.

The posterior ambulacral zones gradually widen on the dorsal surface of the first third of the petals that no longer occupy more than a part of their width. These plates have, in their distal half, secondary granules that pass to the ventral surface where they are not slow to disappear. But each of the two internal rows $1 \mathrm{a}$ and $\mathrm{Vb}$, plates $6,7,8$ and 9, a portion of which is inside the subanal fasciole, acquire on their part surrounded by this fasciole a regular row of three to four primary tubercles. Each plate 6, 7 and 8 of each row has, in addition, a fairly developed anal pedicel. But there is no particularly noticeable episternal angle. The part of the ambulacral zones located on the ventral surface constitute the posterior ventral ambulacra. These are at first fairy narrow at the height of plates 5-5 where they measure $7 \mathrm{~mm}$. Then they widen as they approach the peristome and reach a width of $13 \mathrm{~mm}$. They are completely bare. The secondary tubercles appear only in their posterior region, i.e., on the sixth plate. The phyllode pedicels exist only on the two first plates of each series.

The anterior interradii have no projection on the dorsal surface. But the plates on the internal rows $2 \mathrm{~b}$ and $3 \mathrm{a}$ contribute to the formation of the sides and upper corner of the dorsal ambulacral groove. Independently of the miliary granules, the plates have secondary tubercles the length of the groove. The plates of the other series $2 \mathrm{a}$ and $3 \mathrm{~b}$ rapidly become wider than the preceding. Only 
some miliary granules appear at first, but each of the two plates near the ambitus have three large primary tubercles surrounded by very deep scrobiculae. In the posterior interradial pairs, the plates of the anterior rows $1 \mathrm{~b}$ and $4 \mathrm{a}$ are narrower than those of the posterior rows. Both at first show only miliary granules, but the three plates near the ambitus have large primary tubercles. The number varies from two to five and can even reach six on the last plates of the anterior row, while each plate of the posterior row has only one. The primary tubercles of the dorsal surface of the test can, moreover, have some variations that have already been indicated by Meijere. The plates of the posterior interradius have only very small tubercles that become a little larger toward the posterior border and on the posterior surface of the test, on each side and below the periproct.

Each preanal plate has, in their external region, two or three rows of primary tubercles that follow those of the adjacent ambulacral plates 6,7 and 8 . But they very rapidly become smaller as they move away from the external border of the plates. On the ventral surface, the anterior interradii are not very developed. Plate 1 of rows 2 and 3 is narrow and elongated. It touches the peristome only by a very narrow blade. Plates $2 \mathrm{~b} 2$ and $3 \mathrm{a} 2$ are narrow, while plates $2 \mathrm{a} 2$ and $3 \mathrm{~b} 2$ are to the contrary very large and occupy most of the corresponding interradius. The secondary tubercles of the periphery of the test become larger and larger and they quickly take the size of primary tubercles toward the peristome. But they do not even reach plate 1 . On plates $2 \mathrm{a} 2$ and $3 \mathrm{~b} 2$, several of them acquire deep scrobicular circles, without however becoming as large as on the paired posterior interradials. In the latter, plate 1 is also very elongated, widened outside. It touches the peristome only by a very narrow blade. Plates 2 of each series are very large and occupy the sides of the ventral surface. they are covered with large primary tubercles, contiguous and staggered. They rapidly become smaller near the ambitus, to pass to the secondary tubercles of the dorsal surface. The postero-lateral corner of each of plates $1 \mathrm{a} 2$ and $4 \mathrm{~b} 2$ has only secondary tubercles that abruptly succeed the primary tubercles of the rest of the ventral surface.

The labrum is very elongated. Its anterior border that limits all the posterior border of the peristome is very wide. Then the plate narrows strongly, at the same time that it becomes concave on the sides to receive the first ambulacral plate. It continues to gradually narrow to its posterior end that is a round point. Its length is $15 \mathrm{~mm}$. The two sternal plates are quadrangular and a little wider than long. The sternum has on the median internal line and near its posterior end, a small projection from which leave oblique rows of tubercles. These, which scarcely exceed the dimensions of secondary tubercles, cover only approximately a third of the plate whose anterior part remains bare. Some secondary tubercles uniformly cover the episternal and preanal plates.

The peristome is very small and semi-circular. The periproct is located flush with the test on the posterior surface that is directed a little obliquely forward. Its upper border is contiguous with the posterior border of the dorsal surface of the test. It is very large, much wider than long and covered by three concentric rows of plates whose dimensions decrease gradually. The anus is located nearly in its middle.

The area limited by the internal fasciole is distinguished by a little deeper color than the rest of the dorsal surface. The lateral branches of the fasciole are very distinct, but their borders are effaced nearly completely when they reach the anterior ambulacrum. The posterior branches, which are convergent and unite after a sharp angle, become also less and less distinct without, however, disappearing completely. As for the subanal fasciole, it has a contour that is always very clear. The area that it limits is very narrow in its middle because of the concave form of its posterior border and especially or its anterior border, while it is strongly widened and convex on the sides. The middle part of the posterior or dorsal branch, that passes to $1.5 \mathrm{~mm}$ from the lower border of the periproct, follows a nearly transverse direction. This branch is very large, like the anterior 
branch. As I have said above, the subanal fasciole contains the internal parts of ambulacral plates Ia6-a9 and Vb6-b9 and the interradial plates 5b4-b5 and a4-a5. The portions of these plates enveloped by the fasciole are covered with large tubercles, while the rest of the subanal plastron has only secondary tubercles of uniform size.

At the level of the large primary tubercles of the dorsal and ventral surfaces, the internal surface of the test has bowls similar to those we know on in Lovenia elongata, but less developed.

The appearance of the dorsal surface with the large, curved primary spines is well indicated in a photograph of Meijere (04, Pl. X, fig. 97). The large spines appear to reach a development comparable to that we know in Lovenia elongata, but I have rarely seen them intact in my specimens. The small spines of the dorsal surface are extremely fine and dense. They are curved and a little widened at the end. The spines of the dorsal ambulacral groove remain pointed while being a little curved. Their concave border has a series of fairly strong denticulations, like those we see in L. elongata (Pl. XIX, fig. 34).

We can see in the photograph that I reproduce here of the ventral surface of a non-abraded test (Pl. XII, fig. 11), that the primary spines of the lateral interradius are shorter and smaller than in L. elongata. As for the primary spines of the lateral parts of the subanal plastron, I have not seen intact ones, but I think that they must not have a great length.

I have encountered four kinds of pedicellariae that represent respectively the tridactyle, rostrate, globiferous and trifoliate.

The tridactyle pedicellariae have three different types. The first has a very elongated and narrow head whose length reaches and can even exceed $1 \mathrm{~mm}$. It is supported by a slender peduncle with a fairly elongated neck. The valves, thin and very long, touch for a third or two-fifths of their length. The basal part (Pl. XIX, fig. 37) is extremely small, short, and as long as wide. Its length is equal to at least a fifth or a sixth of the total length. The blade, at first a little wide, narrows a little and keeps the same width for approximately three-fifths of its length. Then it gradually widens and ends in a round border. The narrow part has on is entire length, teeth that are wide, conical, short and spaced, while the terminal part, a little wider, has teeth that are very small, dense and regular that continue to the end. The perforations of the blade are large and oval. These pedicellariae are found in all regions of the test. They recall those that Döderlein has indicated in L. elongata and that he compared to the tridactyle pedicellariae of Spatangus purpureus.

The tridactyle pedicellariae of the second type are much smaller than the preceding. The length of the head is on average 0.3 to $0.4 \mathrm{~mm}$. The basal part (fig. 33, 36 and 45) represents a third or even a fourth of the total length. It is always a little wider than long. The blade is formed of a very elongated spoon. It keeps nearly the same width to its end that is round. Its borders have from the first third or middle very small teeth, conical and pointed. At first, they are extremely small. Their length increases gradually to the end. The borders of the blade are ordinarily smooth at the base. Sometimes, however, they have two or three small denticulations, low and spaced. These pedicellariae are very near the preceding. They obviously represent a shortened form.

Finally, I have encountered in the posterior ambulacra, other pedicellariae whose head measures more than 0.3 to $0.33 \mathrm{~mm}$. The stem is very elongated and the valves are very remarkable for their weak development and the perforations that are sparse, small and restricted to the sides of the blade. This one is mainly formed of a compact, hyaline calcareous tissue (fig. 35). The basal part is very developed, wide, triangular, and wider than long. It exceeds a third of the total length of the valve. The blade, in the form of a convex spoon, widens at first very little but without reaching the width of the basal part. Then it narrows fairly rapidly to its obtuse end. It has, after its widest region, extremely small teeth, short dense and inconspicuous. These pedicellariae are 
obviously those that Döderlein encountered in L. elongata and subcarinata. Its valves have nearly the same form as in L. gregalis, but their blade is completely lacking in denticulations.

The rostrate pedicellariae are abundant. In the largest, the head can reach from 1 to $1.3 \mathrm{~mm}$ in length. We find them principally on the periproct and adjacent parts. The others, that we encounter mostly in the peristomial region and the dorsal groove, are smaller, the length of their head varying between 0.4 and $0.7 \mathrm{~mm}$. The basal region (fig. 40 and 42) is large and wide, longer than wide. Its length exceeds a third of the total length of the valve. It generally has in its second half some low and conical denticulations, two or three on each side. The perforations are numerous, dense, small and round. The narrow blade widens a little in the terminal quarter where its border has a row of fairly dense teeth, very small and a little elongated. In addition, there are on the rest of its length some conical and low teeth, widely separated. The perforations are large and elongated.

The globiferous pedicellariae are of small dimensions and sparse. I have mainly observed them toward the end of the ventral ambulacra where they are easily recognized by the deep purple of the integument that covers them. They have an extremely short stem, cylindrical, swollen a little before the end (fig. 41). The valves measure $0.35 \mathrm{~mm}$ in length. They remain fairly thin. The basal part (fig. 43 and 44) is triangular and elongated. It is continuous without any precise border with the blade that is tubular and narrow. The blade widens a little in its terminal end where it shows a border of small, fine teeth, fairly elongated, pointed and close together. The tubular part of the blade remains short. It forms for most of its length a gutter that gradually widens and represents without doubt a very elongated excretory opening. The perforations are fairly numerous, close together and oval.

The head of the trifoliate pedicellariae measures approximately $0.12 \mathrm{~mm}$. The basal part of the valves (fig. 39) is very short and narrow. The blade is widely oval with a narrow end. The large and elongated perforations make a fairly large marginal border where the calcareous tissue is compact. The denticulations are inconspicuous.

The pedicels of the dorsal groove contain spicules of very diverse forms. They go completely progressively from the simple nearly straight rod with a smooth surface to the small plate with an irregular contour and several perforations. The peristomial pedicels have in their stem only smaller spicules reduced to simple nearly straight rods that are sometimes bifurcated.

The specimens in alcohol ae grayish on the dorsal surface with very pale spines, while the pedicels of the petals and the anterior ambulacra are deep brown. The ventral surface is pale brown.

L. gregalis is especially remarkable for the test in the form of a shallow cone, by the enlargement of the posterior part and the corresponding development of the subanal fasciole. The ambulacral groove forms in front a very deep notch. The petals are elongated and not confluent on the sides. Finally, the periproct, that is not at all sunken, is large.

Lovenia triforis, nov. sp.

(PI. XIII, fig. 9 to 13)

Gulf of Martaban. 53 fathoms. - One specimen. $\mathrm{N}^{\circ} \frac{5890}{7}$.

The individual is found in a jar labeled Lovenia gregalis, but it is easy to see that it cannot belong to this species. It also differs from L. elongata and subcarinata while approaching mainly the first species. Although it is of very small size, since the length of the test does not exceed 21.5 
$\mathrm{mm}$, I believe it necessary to report it as a new species because the differences I see with the other known species of the genus Lovenia cannot come from the young age of the specimen. Unfortunately, the specimen is not complete. A part of the ventral surface has been removed, most of the spines are missing, and I have not encountered a single pedicellaria. In the description that follows, I especially compare this individual to a specimen of L. elongata nearly as large, whose test measures $27 \mathrm{~mm}$ in length. I reproduce (Pl. XIII, fig. 8) a photograph of the dorsal surface of this specimen that permits comparison with photographs of the new species (fig. 9 to 13). I have not compared my specimen to a L. gregalis of similar size because the smallest individual of this specimen that I have had in hand is greater than $46 \mathrm{~mm}$ in length.

Here are some dimensions of the new Lovenia and L. elongata to which I shall compare it.

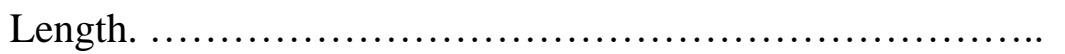

Width.

Height.

Distance between the posterior gonopores and the anterior border of the test.

Distance between the posterior gonopores and the posterior border.

Distance between the anterior border of the peristome and anterior end.

Distance between the posterior border of the peristome and the posterior end.

Length of the anterior petal.

Length of the posterior petal.

Width of the posterior end.

Peristome (width and length).

Periproct (height and width).

$\begin{array}{cc}\begin{array}{c}\text { Lovenia } \\ \text { triforis } \\ \mathrm{mm}\end{array} & \begin{array}{c}\text { Lovenia } \\ \text { elongatus } \\ \mathrm{mm}\end{array} \\ 21.5 & 27 \\ 11 & 22 \\ & \\ 6.5 & 9 \\ & \\ 15 & 18 \\ & \\ 5 & \\ 15 & \\ 6 & 7 \\ 8 & 11.8 \\ 6 & 6 \\ 2.6 \times 1.7 & \\ 2 \times 1.6 & \end{array}$

What is especially striking about the form of the test is the very rapid enlargement of the test that occurs in the anterior region and the maximum width that is reached at the level of the apical system. This was, moreover, first reported much earlier in L. elongata. This enlargement is very noticeable. While the relation of length to width here is $25.1 / 20$, a little more than 1 (1.07 exactly), it is 27.3/22, 1.25, in L. elongata. A glance at fig. 8 and 9 shows the difference in form that results. In contrast, the test narrows gradually toward the posterior end more rapidly in the new species than in L. elongata. This shorter form recalls that of L. gregalus but the posterior region here is much narrower than in the latter species. The dorsal anterior ambulacrum remains flush with the test for most of its length. It is sunken only in the region of the ambitus as in L. elongata, in forming a simple notch much shallower than in L. gregalis. The secondary tubercles that are found on the adjacent interradii of each side of the dorsal ambulacrum are arranged in regular rows directed a little obliquely as in L. elongata.

The most remarkable character of the dorsal surface is the apical system that shows an unexpected arrangement. There are only three gonopores, two to the left and one to the right (fig. 10 and 13). The openings are well-formed, all equal, and they are at least as large if not a little 
larger than in the L. elongata that is $27 \mathrm{~mm}$ in length. As the ventral surface of the test is broken in large part in my specimen, I have been able to see that there are only three gonads, each of which corresponds to one of the openings. The gonad in interradius 2 is completely missing. The madreporite is little developed and little apparent. It has only a small number of pores. It is developed outside the apical system over a length smaller than that of the system itself.

The anterior and posterior petals are fairly short. They stop at a fairly great distance from the ambitus. Their form differs also from that which we know in L. elongata. The anterior ambulacra widen very rapidly over their first third. This widening is due exclusively to the very convex form of the anterior poriferous zone, the posterior zone being very slightly curved. Then the petals narrow abruptly. I count ten pairs of pores in each row, but the pores of the five first pairs of the anterior zone are rudimentary. Except for those of the first pair, all are well developed in the posterior zone. The petals are very narrow at their distal end and clearly separated from the region that follows. The posterior petals, longer, are to the contrary open at their end and their poriferous zones remain parallel. Each of them has eight pairs of well-developed pores, preceded by four rudimentary pairs. The part corresponding to these latter pairs narrows rapidly toward the apical system. The two petals on the same side are not at all confluent. They are still not yet in the small L. elongata that serves for comparison. But the anterior and posterior petals are comparatively longer and their plates wider.

In this L. elongata, the anterior poriferous zones of the anterior petals have a very obtuse angle, separating the first six proximal plates, very small and with rudimentary pores from the seven following plates that have well-formed pores. Each posterior poriferous zone has nine normal pairs of pores, preceded first by a smaller pair and then by two other rudimentary pairs. These petals are triangular. The posterior petals have, to the contrary, two parallel borders. There are seventeen pairs of pores in each zone, with four proximal atrophied pairs in the anterior zone and five in the posterior zone.

The subanal fasciole spreads out more on the ventral surface in the new species than in $L$. elongata without however developing as in L. gregalis.

The posterior end of the test is very narrow, much narrower than in L. gregalis. It is slightly concave above the dorsal branch of the subanal fasciole. It has a simple depression that cannot be compared to the wide and deep depression so developed in L. elongata and that we see already in the individual of $27 \mathrm{~mm}$. This depression has in its upper part a small periproct a little taller than wide that occupies only the upper third. It is thus very different from the large periproct of $L$ elongata that already occupies two-thirds of the anal depression in the specimen of $27 \mathrm{~mm}$. We know, to the contrary, that in L. gregalis the periproct is not sunken and that it is wider than long.

The internal fasciole has nearly the same characters as in L. elongata. However, it extends a little less behind the apical system. The primary tubercles are also arranged as in this species.

My specimen is nearly completely colorless and slightly grayish white. The few spines that are preserved are white and they do not have the white and purple rings that already exist in the small specimen of L. elongata.

The characters of the new species appear in the description above that is mainly comparative. In summary, L. triforis is remarkable by the presence of only three gonopores, by the short, stocky test, very enlarged in front, with a narrow posterior end lacking the anal depression, by the very small periproct, by the rather small petals, by the subanal fasciole encroaching onto the ventral surface, and finally by the inconspicuous anterior ambulacral notch. As I said above, one of these characters belongs to L. gregalis and the other to L. elongata. Perhaps it is a matter of a hybrid between these two species. But, in any case, the specimen cannot be referred to one or the other. 
Agassiz and L. Clark have described recently (07, p. 255), under the name of L. grisea, a species from Japan that is close to L. gregalis. Their single specimen, moreover incomplete, measures $81 \mathrm{~mm}$ in length. The posterior end is narrower than in L. gregalis and the petals are pointed. It obviously is a matter of a different species than L. triforis.

\section{Metalia maculosa (Gmelin)}

(PI. XIX. fig. 61 to 70)

See for the bibliography:

Metalia maculosa, Fourteau (04), p. 431;

Metalia spatagus, Meijere (04), p. 184.

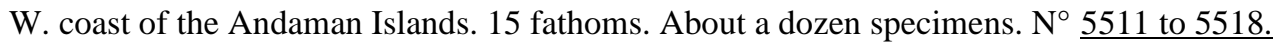

7

Andaman Islands. One specimen.

The specimen that has only the mention of "Andaman" is rather large. Its length reaches 72 $\mathrm{mm}$. The test is nearly intact, but it has lost a large part of its spines. The other individuals are much smaller. They are nearly completely lacking in spines.

The pedicellariae of his species have never been described. In studying M. sternalis Meijere has only mentioned the presence in L. maculosa of tridactyle pedicellariae with long and narrow valves.

I have encountered in the largest specimen some rather characteristic pedicellariae belonging to the four forms: tridactyle, rostrate, globiferous and trifoliate.

The tridactyles are of two very different types. Some are rather large. Their head measures 0.8 to $1 \mathrm{~mm}$ in length. This is preceded by a rather long neck. The basal part of the valves is a little taller than wide. It equals two-fifths of the total length. Its borders are smooth (fig. 61, 62 and 69). The blade remains rather narrow, especially in the proximal part. This, which is longer than the terminal part, has on its borders two or three scarcely noticeable sinuosities but no true teeth. The distal part, at first slightly widened, ends in a round end. Its borders are quite smooth. I have mainly encountered these pedicellariae near the peristome.

Other pedicellariae, smaller than the preceding, are rather abundantly distributed over all the test. The head, supported by a rather long stem, measures 0.3 to $0.35 \mathrm{~mm}$ in length. The basal part of the valves is longer than wide. It exceeds a third of the total length. The blade, at first narrow at the base, widens and takes a lanceolate form with a round point. Its borders have in the distal half extremely small teeth, short and fine. The perforations, rather small, are numerous and close together (fig. 65 and 66).

There is finally a third kind of very small tridactyle whose valves measure 0.25 on average. The basal part is very short. The blade, widened into a spoon, has extremely small teeth, pointed and dense. The perforations are very large (fig. 70). These pedicellariae are very close to the trifoliate, but they cannot be confused with the latter that also exist in M. maculosa and that are much smaller (fig. 68). These differences clearly appear in the two photographs I reproduce here.

The rostrate pedicellariae have a rather small head that does not exceed $0.5 \mathrm{~mm}$, but their valves are rather robust. The basal part is very large and widened, a little taller than wide. Its length is equal to two-fifths of the total length. Its very convex borders have on the upper half some conical and very low teeth (fig. 64). The perforations are very close together, rather small and 
covered by a secondary network. The blade, in the form of a gutter, is rather wide. Its borders, near each other but not connected by beans, separate toward the end. It is armed with very small and little developed teeth. The perforations are small, oval and rather separated.

The globiferous pedicellariae are very remarkable. The valves (fig. 63 and 67), whose length is 0.3 to $0.35 \mathrm{~mm}$ ) are short and stocky, scarcely longer than wide. They are nearly entirely constituted by the basal part in the form of a triangle with rounded borders. The perforations are small and dense. The tube that follows is extremely short and scarcely exceeds twice the height of the terminal opening that is large and transversely widened. The sides of this opening have conical, curved hooks, three or four on each side. The anterior border has in addition a row of similar hooks. The glandular space extends to the articulating part that is short. These pedicellariae greatly recall the form figured by Mortensen in Echinocardim pennatifidum (07, Pl. XVII, fig. 29), but the valves are still stockier in $M$. maculosa. These globiferes are found in the area of the peristome where there are however very rare.

Finally, the trifoliates have a rather short blade, a little longer than wide, with extremely small and inconspicuous teeth. The length of their head is $0.1 \mathrm{~mm}$ (fig. 68).

The pedicels of the dorsal anterior ambulacrum, little developed, have in their walls, small spicules of variable form. Some consist of small straight rods with some denticulations. Others, a little larger, are irregular with angles with stronger teeth or even small secondary branches. The round end of these rods has small perforated plates with a round contour. I have not encountered these spicules in the peristomial pedicels. It has been impossible for me to find a single anal pedicel in my specimens.

\section{Faorina chinensis Gray}

(PI. XIII, fig. 14 and 15; Pl. XIX, fig. 14 to 24)

See for the bibliography:

Faorina chinensis Meijere (04), p. 183.

Station 226. - Gulf of Martaban. 53-100 fathoms. — Several specimens. ํㅗㄷ5 to 5872.

Station 328. - $16^{\circ} 46^{\prime}$ N.; $95^{\circ} 52^{\prime}$ E. 61 fathoms. - Several specimens. $N^{\circ} \frac{19631966 .}{7}$

Station 329. - $14^{\circ} 50^{\prime}$ N.; $96^{\circ} 0^{\prime}$ E. 46 fathoms. - One specimen. $N^{\circ} \frac{1967}{7}$

W. coast of the Andaman Islands. 50 fathoms - Three specimens. $\mathrm{N}^{\circ} \frac{9958 .}{6}$.

Without indication of locality. About a dozen specimens.

The specimens are for the most part in rather good condition. The average length fluctuates around $60 \mathrm{~mm}$. That of Station 329 is largest and reaches $70 \mathrm{~mm}$ in length. All its spines are intact. It has preserved a lovely violet color in alcohol. In the other individuals, the spines are often broken in more or less large part.

The test of this species is rather well known and there is nothing to describe. I shall emphasize however some particular points.

The apical system has been represented in an inaccurate manner by Loven (74, Pl. XXVII). Moreover, Agassiz, in the rather detailed description that he gave in 1874, has scarcely spoken of this region. The gonopores, normally three in number, are equal (Pl. XIII, fig. 14). The anterior 
genital plate is pentagonal, very much longer than wide, with two short and concave anterior sides, two elongated and also concave posterior sides, and a small distal border. The madreporite is large and encroaches a little onto the right genital plate whose internal borders are not clear. It enlarges between the posterior genital plates. It then extends backwards, narrowing over a very short distance and without its pores completely invading the posterior basal plate 5 . The two posterior ocellar plates I and V are very large with the distal border strongly concave and a very small opening. The two anterior ocellar plates II and IV are smaller, but the opening is a little larger than the preceding. Finally, ocellar plate III, located inside the apical system, to the right of the left anterior genital plate, is smallest of all. It is slightly moved to the right by the madreporite. We note in the photograph that I reproduce here, the elongated and very narrow form of first pair of plates of the anterior interradii 2 and 3 that follow the apical system and are compressed by the radii II, III and IV.

The dorsal groove widens regularly. The first five pairs of pores are rudimentary. Their pores are separated by a small scarcely visible grain, without a peripodial imprint. The following pairs develop rapidly. They have a very noticeable peripodial circle, while the grain separating the two pores becomes very projecting. These circles are nearly contiguous on the six or eight pairs that follow the first rudimentary ones. They gradually separate and become smaller on the following plates. The anterior pore is smaller than the posterior pore. In the specimen I have before my eyes, the first branch of the peripetalous fasciole crosses the twenty-fourth pair of plates counted from the apical system. The very noticeable peripodia that we observe after the fifth pair of plates, correspond the well-developed pedicels with a terminal rosette supported by rods.

The lateral fasciole is completely rudimentary. I have observed only a simple indication in the form of a branch that crosses plates 4-4 of the posterior interradius at the point where the ventral surface joins the posterior surface. This is continuous on the plates 5-5, beyond which it disappears.

The pedicellariae of $F$. chinensis have never been described. I have observed, in the individuals collected by the INVESTIGATOR, the four types: tridactyle, rostrate, ophiocephalous and trifoliate.

Because of the large size they can reach, the rostrates are the most characteristic. They belong to two different types. In the largest, the head can reach $1.8 \mathrm{~mm}$ in length. It is supported by an elongated peduncle, enclosing a calcareous stem constituted by a dense tissue, spiny with numerous short denticulations and parallel borders and a round end (Pl. XIX, fig. 23). The head of this stem is a little wider than long. Its length reaches only a seventh or eighth of the total length. The apophysis is very projecting. The articulating space is extended on both sides of the basal part. The blade is extremely narrow in the form of a gutter, with the edges very close together. It keeps the same width for its entire length, except at the end that is slightly enlarged and that has some strong teeth, elongated, conical, pointed and a little irregular that number six to eight on each side. This blade is incurved. The valves are widely separated from each other. The pedicellariae are found principally on the ventral ambulacra in the area of the peristome. They are striking by their large size.

Another kind of pedicellariae forms the transition between the preceding and the true tridactyles. They are smaller and their head does not quite reach $1 \mathrm{~mm}$. The basal part, extremely large, is nearly two times wider than long. The apophysis is always projecting (fig. 15). The blade, first very narrow in the form of a gutter, widens gradually in its terminal quarter to form a small spoon that ends in a short hook, while its borders are denticulated. The calcareous axis of the stem of the peduncle is spiny with small spines as in the preceding form. 
The tridactyle pedicellariae strictly speaking are smaller than the rostrates. Their head scarcely reaches $0.7 \mathrm{~mm}$ in the largest. In general, it does not exceed 0.5 to $0.7 \mathrm{~mm}$. The calcareous stem of the peduncle is smooth. The basal part of the valves is always very developed, wider than long. But its height equals a fourth or fifth of the total length (fig. 14, 16 and 17). The blade widens gradually from the base. If forms a more or less open gutter that has over its first half, or over twothirds of its length, some enlarged teeth, elongated, round at the end that are very spaced from each other. Then it widens more in its distal half to form a wide spoon whose borders are armed with numerous teeth that are close together, sometimes a little irregular. It ends in a round point. The thin end of the spoon forms a curved and rather noticeable hook. The size of these pedicellariae can be greatly decreased without notably changing the structure (fig. 18).

The tridactyle pedicellariae are scattered on the entire surface of the test. It is the same for the trifoliate pedicellariae that remain very small. Their head does not reach even $0.1 \mathrm{~mm}$ in length. The show nothing peculiar. The ophiocephalous pedicellariae are not very abundant. They occur especially on the posterior ambulacra. Their head reaches $0.25 \mathrm{~mm}$ in length on average. The constriction that separates the basal part from the blade remains fairly wide. This is triangular. The teeth on the borders are rather thin, pointed and dense (fig. 24).

The pedicels that are found in the proximal region of the dorsal groove, immediately after the first five pairs of rudimentary pores, end in a rosette with each marginal lobe supported by a calcareous rod whose structure is the same as in Hemiaster Hickmani of which I shall speak later. It measures $0.3 \mathrm{~mm}$ in length. In general, the rods enlarge little by little from their base to narrow toward the end that is never very wide. The meshes of the calcareous network are rather wide in the distal third, without the free ends of the beams forming projecting points. The spicules of the cylindrical part are irregular in form. Some are arched with more of less numerous teeth. Others are shorter and their teeth, more elongated, can even join to form some openings that are not numerous. Similar spicules, but ordinarily of a simpler form, are found in the anal penicillate pedicels. But they are not found in the peristomial pedicels.

Here are some observations that I have been able to make on the arrangement of the internal organs (Pl. XIII, fig. 15).

The esophagus is directed in a nearly straight line toward the posterior end of the body. A little beyond the middle of the test it curves to continue with the first intestinal loop. The siphon, at first rather large at its origin, narrows gradually. After having made a very noticeable curve, it nears the intestine that it accompanies for a very short distance. It opens into it before reaching the level of the posterior interradius. This is also the place that the internal marginal lacuna receives its branches. The color of the wall of the intestine then changes abruptly. Its color that up to here was gray or yellowish, becomes obviously violet. There is an accessory siphon whose path is nearly as long as that of the principal siphon. It begins, in fact, at nearly the height of the mouth and ends a little before the end of the principal siphon. The terminal intestine narrows abruptly at some distance from the anus. The rectum is very narrow.

The portion of the digestive tube that precedes the proximal opening of the siphon contains, in its thickness, glands identical to those that I have described elsewhere in Spatangus purpureus as well as in other species of the Mediterranean $(\mathbf{8 3}$, p. 15) and which I have reported above in Eurypneustes denudatus (see p. 89). We shall find them again in some other species of spatangoids.

There are three gonads in all the specimens I have examined except in one that had only two gonopores. Both are found to the left. The normal opening to the right was atrophied. The two left 
gonads were joined into a single mass but had two distinct gonopores while the other side had no indication of a gonad.

\title{
Pericosmus macronesius, nov. sp.
}

\author{
(PI. XII, fig. 1 to 5)
}

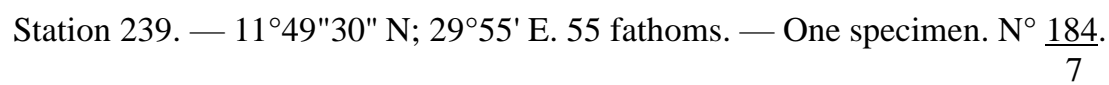

Coast of Long Island, Moscos Island. One specimen. $\mathrm{N}^{\circ} \frac{413}{1}$.

These two specimens were reported in 1899 by Anderson, that is limited to a simple mention (99, p. 10). It was labeled Pericosmus macronesius, a name I have preserved.

The specimen from Station 239 was collected alive. It is preserved in alcohol. But unfortunately it completely lacks its spines. The only external parts that still exist are simple remains of the pedicels on the two right petals. The test still has some trace of the original color. It is moreover in perfect condition.

The other individual without doubt had been dead for a long time when it was collected because the test is covered with calcareous tubes belonging to very small forms of annelids. The test has been subjected to some blows that have destroyed in part the periproct, the peristome and the apical system. It does not appear to have been rolled, but the contours of the plates and the fascioles are not apparent.

Here are the principal dimensions that I have taken on these two individuals.

Length.

A

Specimen

in alcohol

$\mathrm{mm}$

65

64

38

30

35

11

51

22

test)

Len

Maximum width of the anterior petal.

Maximum width of the posterior petal.

Peristome (width and length).

Height at the level of the apical system.

of the test.

end.

Distance between the anterior border of the peristome and the Distance between the posterior border of the peristome and the posterior end of the test.

Length of the anterior petal (measured following the curve of the

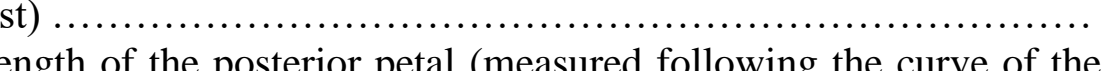
Let. test. 23

\section{B}

Dried specimen

$\mathrm{mm}$

62

60

37

29

33

11

47

21

22

5.5

5

$9 \mathrm{x} 4$ 
I shall describe the species after the individual from station 239.

Seen from above (Pl. XII, fig. 1), the contour of the test is ovoid, but slightly angular, with an anterior notch corresponding to the dorsal groove and whose depth is $4 \mathrm{~mm}$ at the ambitus. On either side of this notch, the test widens rapidly and reaches its maximum width at the level of the apical system, i.e., much nearer the anterior end than the posterior end. It then narrows very rapidly to the end that measures $32 \mathrm{~mm}$ in width. The very obtuse angles that the test has at the ambitus show appear forward of the middle of the posterior rows of interradii 2 and 3 and, on the sides, toward the middle of each row of interradii 1 and 4 . These angles correspond to the very low conical prominences of the two or three interradial plates adjacent to the ambitus. Finally, the sides are connected to the posterior end by a round angle of approximately $120^{\circ}$. The anterior groove is narrow and rather deep for nearly all its length. The petals are narrow and separated by small interradial projections. The posterior interradius is not very projecting either.

When we look at the test in profile (fig. 3), we see that the anterior end, connected to the ventral surface by a very round angle, first rises rapidly to follow a curve with a rather short radius. The test reaches its maximum height approximately $5 \mathrm{~mm}$ in front of the apical system. The dorsal surface remains nearly horizontal up to $10 \mathrm{~mm}$ behind this system. Then it decreases rapidly in following a curve more convex than in the anterior region. It joins by a very open angle the posterior end. This is short, nearly vertical or very slightly oblique forward. It is a little concave. The upper part, which corresponds to the upper border of the periproct, extends very slightly beyond the lower part. The height of this surface, between the upper border of the periproct and the dorsal branch of the marginal fasciole is only $14 \mathrm{~mm}$. It is connected to the ventral surface by a very round angle.

The ventral surface is connected, in front, to the dorsal surface by a slightly noticeable but round angle, less than a right angle. It is directed forward a little obliquely downward, up to the level of the lower lip. Then, behind it, it swells a little toward the posterior two-thirds of the sternum that has, at this level and on the median line, a small low conical prominence. A similar prominence is seen on the episternal plates, very near the median line and a little beyond the middle of each plate. The ventral surface then rises obliquely to reach, by a very round angle, the posterior surface of the test.

The apical system (fig. 1 and 5) is nearer the anterior end than the posterior end. There are three gonopores, two to the left and one to the right. They are nearly equal and of medium size. The two openings of the left are extremely close and separated by a small blade narrower than their diameter. The right opening has its center approximately $3 \mathrm{~mm}$ from the left posterior opening. But instead of being placed at the same transverse level, it is moved a little to the rear and the line that connects the two centers is a little oblique in relation to the antero-posterior axis. It seems to me that these two openings are at the same height in the two specimens. But it is impossible to recognize their position with certainty, a part of the apical system being missing. The genital plates are polygonal. The two posteriors are larger than the anterior. Apart from these respective openings, their surface has some small granules. This apical system is clearly ethmolytic. The madreporite, that is elongated and pear-shaped with rather numerous and dense openings, starts at the right genital plate. It is first narrow, then widens beyond the posterior gonopores that it exceeds in length by half its total length. The right anterior genital plate is very little developed. Its location is in large part occupied by the proximal part of the right anterior ambulacum that advances very near the median line. Ocellar plate III itself reaches a little behind 
the left anterior gonopore. As a result, the tops of ocellar plates III and II are found nearly on the oblique line that connects the centers of left anterior opening and the posterior opening. The left posterior ocellar plate $\mathrm{V}$ is located nearly at the height of the right gonopore, while ocellar plate I is located immediately behind the same opening. The posterior border of the madreporite reaches nearly the same level as the posterior border of ocellar plate I. Despite the asymmetrical arrangement, the five ocellar plates are all the same size. They are rather small, triangular, with a straight transverse opening.

The anterior ambulacrum forms, on the dorsal surface, a groove that is first very narrow and not deep. At two millimeters in front of the anterior gonopores, its width is only $2 \mathrm{~mm}$. Then it widens, rather slowly, at the same time that it is gradually sinking up to the anterior end of the test where its width is approximately $7 \mathrm{~mm}$. It is then very flared and its borders are round. The depth becomes fairly noticeable only near the ambitus where it reaches $4 \mathrm{~mm}$, as I said above. I count twenty-two plates in all to the ambitus. Their limits, except on the first four or five, are very apparent. They are all a little wider than long. The first eight or ten plates are covered with small, very dense tubercles. They become small and more spaced on the following plates, where they are mixed with a uniform covering of miliary granules that they do not exceeds much in size. The numerous branches of the peripetalous fasciole cross the anterior groove, the first at the level of plate 15 , counting from the peristome. The following ones cut it respectively at plates $13,11,8,7$ and 6 (always counting from the peristome). As for the marginal fasciole, which greatly curves toward the ventral surface at the place where it approaches the anterior groove, it crosses the latter nearly at the ambitus, i.e., at the level of plates a4 and b3. The ambulacral pores are double and, in the first half of the groove, they are separated by a small projecting grain that disappears in the other half. These pores, also equal and very small, are very close to each other in each pair. They are found nearly in the middle of the plate, a little nearer however to the external border.

The petals are very narrow and slightly sunken. The anteriors are a little longer and a little wider than the posteriors. The anterior petals make an angle of $60^{\circ}$ with the antero-posterior axis, and the posterior petals an angle of $40^{\circ}$ with the same axis. The two petals of each side are separated by an angle of $80^{\circ}$. The anterior petals are elongated, with a slightly convex anterior border and a nearly straight posterior border. They are very narrow inside and round at their distal end. The petals begin by a very short and very narrow region that remains flush with the test that includes the first two pairs of plates. But they sink very quickly at the same time that the adjacent interradial regions rise to limit their borders. They first widen very rapidly, then more slowly and they keep the same width to the area of their distal end. Their maximum width is $6 \mathrm{~mm}$. The interporiferous zone is very narrow and scarcely exceeds $1 \mathrm{~mm}$. The pores are very transversally enlarged, oval in the internal series and wider in the external, with a tendency to narrow inside. I count thirty to thirty-one pairs of pores in all. The first six pairs of the anterior row and the first five pairs of the posterior row are very small. The successive pairs are separated by a flat blade, having a fairly regular row of seven to eight small granules. The interporiferous zone is nearly completely bare.

The posterior petals are a little shorter, a little narrower and less deep than the anterior petals. Their width does not exceed $5 \mathrm{~mm}$. They also sink more regularly and more gradually at their origin than the anterior petals and are immediately depressed. There are in all twenty-six pairs of pores. The first three are very small.

Outside these petals, the ambulacra widen rapidly. The plates become rectangular and very elongated. At the ambitus the anterior ambulacra measure $20 \mathrm{~mm}$ and the posteriors $17 \mathrm{~mm}$ in 
width. The plates have small primary tubercles, uniformly spaced, that abruptly become larger and denser outside the marginal fasciole.

On the ventral surface, the anterior ambulacrum contains only a very small number of plates, three to the left and two to the right. The phyllode peripodia are seen only on the first two pairs of plates. Immediately beyond the peripodia, the plates are covered with dense granules that disappear at the ambitus. The plates of the two ambulacra I and $\mathrm{V}$ elongate and rapidly widen beyond the first three pairs. The phyllode peripodia are seen on plates b1-b5 and a1-a4 of II, as well as plates $\mathrm{a} 1-\mathrm{a} 4$ and b1-b5 of IV. These plates have very small and sparse granules. The primary tubercles appear after the peripodia. They become very dense toward the ambitus, but their size decreases little by little. They still continue on the sides of the test a little above the ambitus to the marginal fasciole. But, beyond this, they become rarer.

Interradiii 2 and 3 only touch by an extremely narrow border the periphery of the peristome. Interradii 1 and 4 are completely excluded from the latter. To the contrary, the first plates of radii I and V are respectively contiguous to those of radii II and IV around the peristome. Phyllode peripodia are seen on plates $\mathrm{b} 1-\mathrm{b} 3$ and $\mathrm{a} 1-\mathrm{a} 2$ of ambulacrum I, as well as on plates $\mathrm{a} 1-\mathrm{a} 3$ and $\mathrm{b} 1-$ $\mathrm{b} 2$ of $\mathrm{V}$. The first plate of each row $1 \mathrm{a}$ and $\mathrm{Vb}$ and the first two plates of rows $\mathrm{Ib}$ and $\mathrm{Va}$ are very small. But the size and the length increase very rapidly on the following plates and the ventral ambulacra are very wide. They reach $12 \mathrm{~mm}$ in width. The internal plates of each series are nearly bare. They have only a fine superficial reticulum of very sparse milary granules up to the sixth. Toward its posterior border appear primary tubercles that continue on the following plates where they remain numerous and dense, but only to the marginal fasciole. To the contrary, in the two external rows, i.e., Ib and Va, the primary tubercles occur from the third plate and, without being very dense, they occupy at first its external half. Then the portion covered with tubercles becomes wider and wider and, on plates 7 and 8 , there remains only a thin bare internal border. The tubercles become a little smaller on plates 9-9. They rapidly decrease in size on plates 10-10 that are crossed by the marginal fasciole.

The anterior interradii form, on the dorsal surface of the test, each a triangular area with a proximal top narrower and a little more projecting than the two posterior interradii. The plates of the row that borders the groove are a little narrower than those of the external row. They have, nearly at the level of the distal end of the anterior petals, each a small, very low and obtuse prominence, nearer the internal border that I have already had the occasion to indicate above. The tubercles, which are small and very dense at the top of these areas, more and more separate as we move away from them. They pass on to the primary tubercles that appear further, but they always remain rather separated and sparse. These tubercles are mainly in the center of the plates. On the plates of the internal series $2 \mathrm{~b}$ and $3 \mathrm{a}$, the tubercles are a little denser near of the groove, while on the two external series $2 a$ and $3 b$, they hardly exist except on the internal half of the plates. Their external part has only some very small, rare granules. However, along the anterior border of the anterior petals and over a width of 3 to $3.5 \mathrm{~mm}$, these plates have a very abundant covering of tubercles inside the first transverse branch of the peripetalous fasciole. The size of these tubercles decreases rapidly away from the petal. Beyond the marginal fasciole, they become abruptly very numerous and very dense. It also happens in the ambulacral zones. From being very small, they increase rapidly in size to become the primary tubercles of the ventral surface.

The two posterior interradial pairs have a round top and more open than the anteriors. The plates located outside the peripetalous fasciole have, in each row and toward their middle, each a small conical prominence that still exists at the ambitus. The tubercles are very numerous, small and dense at the top of these areas. They remain likewise very dense the length of the posterior 
border of the anterior petal as well as on the anterior border of the posterior petal, while, on the rest of their extent, they become small and more spaced, even more so toward the peripetalous fasciole. Beyond this, the sparse covering is identical to that of the two adjacent ambulacral zones. Then, from the marginal fasciole, the tubercles become very rapidly larger and very dense. They then pass to those of the ventral surface.

These tubercles have the same characters on the posterior interradius, i.e., they remain very dense on all the triangular space between the apical pole and the peripetalous fasciole. They become smaller in this area. Beyond the peripetalous fasciole, the tubercles separate quickly but remain, however, a little dense toward the median interradial suture. On the other hand, they become a little larger in the area of the periproct, especially in the internal part of plates 7, 6 and 5 that limit the latter. Below the periproct, we note a space belonging to plates 5 and 4, covered only with miliary granules that extend to the marginal fasciole. Finally, below this fasciole, the tubercles rapidly become more numerous and denser. They pass to those of the ventral surface. Plates 4-4, which are crossed by the marginal fasciole, have on the same path as the latter, each a small conical prominence that is very noticeable.

On the ventral surface, the anterior interradial pairs occupy a very restricted extent because of the location of the peristome that is moved very forward. The first plate of each series has, in the proximal region, some secondary tubercles. Toward its distal border appear some primary tubercles. These become very numerous and very dense on plates $2-2$ that extend above the ambitus. Each has, at the level of these, a small conical eminence that is not very noticeable. The two posterior interradii 1 and 4 do not reach the peristome. The proximal corner of the first plate is separated from it by $1.5 \mathrm{~mm}$. This first plate is very elongated in the interradial direction. It is pentagonal, with a proximal corner limited by two small sides. Its two large lateral borders are nearly parallel. It is approximately four times longer than wide. The following plates are very large. Plates 2-2 are nearly triangular, plates 3-3 are pentagonal. Plates $1 \mathrm{~b} 3$ and $4 \mathrm{a} 3$ pass the ambitus while plates $1 \mathrm{a} 3$ and $4 \mathrm{~b} 3$ do not quite reach it. These different plates have each a small conical prominence that continues the similar prominences that I reported on the interradius of the dorsal surface of the test. The primary tubercles are numerous and dense on these plates, but they decrease in size toward the ambitus and become very small in passing to the dorsal surface.

The labrum occupies, by its slightly wider anterior side, four-fifths of the posterior border of the peristome. Its surface is fairly convex and its free border is thickened to form a posterior lip. But it does not make any projection on the ventral surface of the body because, at the same time that it thickens, it curves vertically toward the peristome. Behind this lip, the labrum is indented laterally to receive on each side the corresponding ambulacral plates. Then it widens very slightly and continues, keeping the same width, which is $6 \mathrm{~mm}$, to its posterior border. This corresponds to the end of the second ambulacral plate. The two sternal plates are triangular. They are $22 \mathrm{~mm}$ in length. The maximum width is $6 \mathrm{~mm}$ that is reached a little before their posterior end. The median interradial line is slightly projecting. It has, toward the posterior third of plates, a small conical and blunt projection that I have already reported. The two episternal plates are longer than wide. Each has, in the vicinity of the median interradial line, a small conical projection, similar to that which we know on the two following pairs 4-4 and 5-5. All these plates are covered with numerous and very dense primary tubercles that, on the sternum, leave from the median prominence in forming divergent oblique series. On the labrum, the tubercles exist only in the anterior third where they are very separated. All these primary tubercles are smooth and surrounded by a small scrobicular circle. They always keep their small dimensions. 
The peristome is very near the anterior border of the test. It is not horizontal but, because of the great difference of level that exists between the labrum and the first plate of the amblacrum of the trivium, it occupies a very oblique position and is very nearly vertical. The peristome is relatively small, narrow and short. It has at first, along its anterior border, a row of six large polygonal plates. Behind these are smaller plates.

The periproct (fig. 4), rather small, is transversally oval, with a lower border more strongly convex than the upper border that forms a small, very obtuse angle on the median interradial line. The periproct occupies the upper end of the posterior surface of the test, which is, as I have said above, slightly oblique forward. It too is thus found directed a little obliquely. It is covered with a marginal row of fairly large plates that become narrower on the upper side, then, inside, by smaller and irregular plates. The anus is a little nearer the lower corner.

The peripetalous fasciole and the marginal fasciole are both well developed. The first follows, around the petals, a very angular path. In its anterior region, it divides on either side of the dorsal groove, into some transverse branches located one behind the other. One is a little wider, the others are little narrower. I shall study them below. If we leave from the end of an anterior petal (fig. 1), we see the fasciole form around this end an obtuse angle and with a round top measuring approximately $125^{\circ}$. The anterior side of this angle, directed toward the dorsal groove, divides, at approximately a centimeter from the top of the petal, into two branches strongly divergent and nearly diametrically opposed that will be the point of departure of the secondary transverse branches. Behind the top of the petal, the fasciole goes toward the posterior end of the test a little away from the ambitus. Then, after a short distance, it changes direction, forms a nearly right angle and is directed toward the apical system, this over a distance two times less than that on the preceding side. From there, it forms again an angle a little greater than $90^{\circ}$ in taking a path nearly parallel to the antero-posterior axis of the test and, in crossing the median line of interradii 1 and 4, approaches the posterior petal. Following then a path inverse to that we just described and changing direction two times, it approaches the ambitus and goes around the distal end of the posterior petal forming a round nearly right angle. Finally, it goes toward the posterior median interradial line following a curve that is a little concave inside. On all this path, the fasciole keeps the same width that is a little greater than $1 \mathrm{~mm}$. As for its transverse branches that it produces in front, they have an irregular and asymmetrical path. They are not always distinct over all their length. Here is the arrangement that I see in my specimen and that, without doubt, varies from one individual to another. I find at first, leaving from the part parallel to the anterior border of the left anterior petal, three successive transverse branches. The first is narrowest. It crosses the groove at the level of plates 13, 11 and 9, counting from the peristome. The first branch is nearly perpendicular to the groove and its origin to the right is poorly indicated. The two others are convex in front. The second has two roots on the right. The third branch follows an oblique path because it leaves to the left of a point located behind the anterior angle of the peripetalous fasciole, while to the right it ends at the end of the branch parallel to the anterior groove. From this same end leaves a fourth transverse branch, very convex, that ends at the corresponding point of the other side, all while doubling toward its middle, but over a very short length. It crosses the seventh pair of ambulacral plates. It is joined, to the left of the groove and outside it, by a fifth branch that is not connected to the other two. It splits in crossing the groove toward the sixth pair of plates.

The path of the marginal fasciole is much more regular, despite having two curves, one in front when it crosses the anterior groove and the other below the periproct. At the level of the anterior groove, the marginal fasciole makes a convex curve turned downward. It crosses plates IIIa4 and b3. It is thus found very near the lower border of the test from which it is separated by only a few 
millimeters. Then it rapidly goes up the sides of the grooves and runs parallel to the ambitus, at approximately one centimeter above it (fig. 3). It rises again a little in the two posterior interradial pairs that it crosses to the left and to the right at the level of plates a4 and b4. Then it sinks again in radii $\mathrm{V}$ and $\mathrm{I}$. Finally, it abruptly curves from the ventral side toward the middle of plates 5-5 of the posterior interradius. It reaches then the lower border of the posterior end of the test, ; the length of which it runs horizontally for a length of approximately $12 \mathrm{~mm}$, in crossing the posterior median interradial line, to continue on the other side of the test. It passes approximately $6 \mathrm{~mm}$ below the lower border of the periproct (fig. 4). This fasciole has on all its path the same width as the peripetalous fasciole.

Microscopic examination of the remains of the pedicels of the petals has not allowed me to find the least trace of spicules.

The general color of the specimen in alcohol is a fairly pale pinkish gray on the ventral surface as well as on the dorsal surface above the ambitus, but within the peripetalous fasciole the color becomes a deep purple. The primary tubercles are a very deep gray. The fascioles have a more or less conspicuous brownish color.

The dead specimen from Long Island, on which the contours of the plates and fasciole have nearly completely disappeared, the test is a uniform grayish white.

SIMILARITIES AND DIFFERNCES. - In reporting, in 1899, the two specimens of Pericosmus found by the INVESTIGATOR, Anderson noted that this species was the first of the genus that was encountered alive. All the species like the genus Pericosmus, more than fifty, are, in fact, all fossils. Most come from Tertiary deposits. Some species, however, have been reported from the Quaternary Period such as P. timrensis Lambert. Among the fossil forms to which our species approaches most, I shall cite $P$. asperulatus Herklots, Blankerhorni Oppenheim, callosus Manzoni, granulosus Herklots, hispanicus Cotteau, latus (Agassiz), Mazalsi Cotteau, etc. and the more depressed forms Orbignyi Cotteau and spatangoides Loriol. But the new species is clearly separated from all of them.

\section{Hemiaster Hickmani nov. sp.}

(Pl. VII, fig. 4 to 10; PI. XVIII, fig. 39 to 48)

Station $290 .-24^{\circ} 53^{\prime}$ N.; $.57^{\circ} 43^{\prime}$ E. $833-733$ fathoms. A dozen specimens. $\mathrm{N}^{\circ} \frac{1678-1689}{7}$.

Station 297. - 25ำ $11^{\prime} 30^{\prime \prime}$ N.; $57^{\circ} 15^{\prime}$ E. 700-689 fathoms. - Twenty specimens. $\mathrm{N}^{\circ} \frac{1671-1677 .}{7}$

Station $342 .-24^{\circ} 26^{\prime} 15^{\prime}$ N.; $.57^{\circ} 15^{\prime}$ E. 745 fathoms. — Two remains. $\mathrm{N}^{\circ} \underline{2251}$.

Most of the specimens are unfortunately in very bad condition. They are represented only by the dorsal surfaces. Three individuals only, coming from station 290, are nearly entire. One of them, completely lacking spines, is represented in Pl. VII, fig. 5, 6, 8 and 9. It is mainly this one that will serve me for the study of the species, as well as another nearly intact individual with spines that is represented in fig. 4 and 10. 
The specimens have fairly similar dimensions. The length is generally between 35 and $40 \mathrm{~mm}$. Two individuals reach, however, $42 \mathrm{~mm}$ and the smallest does not exceed $23 \mathrm{~mm}$. Here are the principal measurements that I have taken of the two individuals that I shall use for my description:

Length.

SPECIMEN

Without spines

$\mathrm{mm}$

37

36

14

23

26

19

18

10

24

16

13

8

7.5

4

19

29

15.5

$6 \times 3$

$2.6 \times 1.8$
SPECIMEN

With some spines

$\mathrm{mm}$

34.5

35

12

20

25

17.5

16.5

9

21.5

15

11

7

7

3

19

27

15

$4.2 \times 2$

$3 \times 2$

The contour of the test, seen from above (Pl. VII, fig. 5) is nearly circular, but slightly angular. We can distinguish a wide round anterior border, followed on both sides by a first slope followed another much longer one extending to the level of the apical system. Then comes a shorter slope and, finally, a last, longer and a little convex slope, that continues to the end of the test. This forms a fairly narrow angle, slightly prominent although rounded. These successive slopes are connected by obtuse angles. At the top of each, the test forms a small protrusion placed on the path of the peripetalous fasciole and corresponding to the middle of each row of successive interradial plates. On the dorsal surface, these latter are rather narrow because of the widening of the ambulacra. They are fairly protruding. As for the posterior interradius, it rises gradually towards the rear that is nearly exactly vertical.

Seen from the side (fig. 9), the test is notable by the shortness of the anterior region that contrasts with the development of the posterior end. The profile rises gradually and regularly 
following a convex line, up toward the middle of the distance that separates the anterior end and the apical system. From there, it follows a slightly oblique and very regular line to the area of the posterior end. The anterior border is connected by a very round region to the ventral surface, which is flat. It has, when we look at the profile, only a slight projection formed by the lower lip. It passes to the posterior surface by a nearly right and round angle. Seen from the ventral side (fig. 6), this surface shows angles that correspond to those of the dorsal surface, but that are less apparent, so that its contour is more exactly circular.

The apical system (fig. 7) occupies a small horizontal area a little closer to the posterior end than to the anterior end. It is clearly ethmophractic. Its structure recalls $H$. expergitus. The gonopores are of medium size. The two anteriors, a little smaller, are closer together than the posteriors. The distance between the two latter is a little greater than that which separates the two gonopores on the same side. Each gonopore has an extremely elongated papilla. The two anterior genital plates, a little smaller, are separated in front by ocellar plate III. They are contiguous on the posterior half. The left plate is narrow and elongated. It touches inside the internal end of the posterior genital plate of the same side. The opening is nearer its external border. The right anterior genital plate is continuous with the madreporite that is small, round and scarcely exceeds the level of the anterior border of the posterior genital plates. It occupies a location nearly central in the apical system. The two posterior genital plates are fairly narrow, elongated, a little wider than the anteriors. They touch on the median line where they are contiguous for two-thirds of their length. The opening is close to the posterior border. The ocellar plates are triangular, with a fairly open proximal angle. Those of radii II, III and IV separate the corresponding genital plates for approximately half their length.

The dorsal anterior groove begins with a very short part that is flush with the test where the geminate pores are extremely small. Then it sinks a little in widening, but without however, acquiring a great depth. It becomes flush with the test again at the level of the anterior branch of the peripetalous fasciole. I count twenty-two pairs of pores on each side. The first five or six pairs are extremely small and very dense. Those of the latter pairs are also little developed. In the other pairs, the pores are large, arranged a little obliquely, the internal pore nearly circular or triangular, the external pore a little elongated. The two pores of each pair are separated by a small, oblique, slightly projecting blade. There are no distinct peripodia. The successive pairs, fairly close together, are separated by a space the has only some rare, small tubercles. The three or four last pair of pores are more separated. The tubercles are also rare and little developed in the poriferous zones. The ambulacral plates themselves are pentagonal, two times wider than long. The form is a little irregular, their anterior border being convex and their posterior border concave.

The anterior petals of each side make, with the antero-posterior axis, an angle of $60^{\circ}$ and the posterior petals an angle of $30^{\circ}$ with this same axis. The petals of the same side make together a nearly right angle.

The four petals are extremely developed. They form, with the dorsal surface of the test, a rosette that covers a large area. The anterior petals are especially very developed. Their length exceeds that of the posterior petals. Both are sunken in following a very regular cavity with a large radius. But they are never greatly sunken. In no specimen do they appear to form marsupial pouches.

The anterior petals are large, wide and ovovate. They extend up to a small distance from the ambitus, whose end separated by only approximately 2.5 to $3 \mathrm{~mm}$. This end touches the peripetalous fasciole. They are gradually widening from their origin, which is pointed, for at least three-fourths of their length. The maximum width is 8 to $8.5 \mathrm{~mm}$. Beyond that, they rapidly narrow 
and close in a curve with a short ray. The poriferous zones are extremely wide. They reach nearly $4 \mathrm{~mm}$, while the interporiferous zone remains very narrow, its width scarcely exceeding $1 \mathrm{~mm}$. I count in each zone thirty-five to thirty-six pairs of pores. Those of the first four or five are quite rudimentary, while the following ones rapidly become very large. The internal pores are narrow, elongated transversely, four or five times longer than wide and a little thinned outside. The smaller external pores are verguliform. The two lines of pores of the same zone are widely separated from each other except at the end of the petals. The internal pores are elongated perpendicularly to its axis. The external pores are directed perpendicularly to this axis only in the first half of the petal. Beyond that, they take an oblique position and are inclined more and more in relation to this axis. Moreover, these pores are not located exactly opposite to their corresponding pores of the internal zone, but in front of them in a way that is more noticeable toward the end of the petal. The successive pairs are separated by a slightly projecting small protuberance, wider outside than inside. It has a row of fairly spaced granules. This protuberance is not perpendicular to the axis of the petal, but directly obliquely forward, an arrangement that is related to this shift of the pores of each pair that I just indicated.

The posterior petals stop, like the anteriors, exactly at the internal border of the peripetalous fasciole. They have the same structure, but they narrow more toward their end that is a little pointed. They reach, a little beyond their first half, their maximum width of $7.5 \mathrm{~mm}$. I count in all twenty-eight pairs of pores. Those of the first four or five pairs are very small. The small protuberances that separate the successive pairs have each a row of very small and sparse granules. They are directed obliquely backward in a way that becomes more accentuated toward the distal end of the petal.

The dorsal groove disappears in front of the fasciole. It is not sunken at the anterior border of the test. Beyond the fasciole, the ambulacrum abruptly widens. Its plates become hexagonal. They are covered with small primary tubercles, identical to those of the adjacent interradii, up to the area of the peristome. These tubercles are first dense and interspersed with miliary granules. Then, approaching the peristome, the tubercles become rarer and the ambulacrum is slightly sunken. The phyllode pedicels occur only on plates a1, a2 and b4.

The lateral ambulacra rapidly widen on the dorsal surface beyond the fasciole. They keep a fixed width on the lateral surface of the test. Then they narrow more and more on the ventral surface to very slowly widen again when they near the peristome. Their plates have, at the ambitus, primary tubercles less numerous than on the anterior ambulacrum and, on the ventral surface, each of them has no more than one or two primary tubercles with some sparce miliary granules. The phyllode peripodia are on the first three plates of each series.

The two posterior ambulacra also widen very abruptly beyond the fasciole. They constitute each two vertical rows of hexagonal large plates that cover the round parts of the test connecting the posterior surface with the lateral surfaces. These plates have, like the other ambulacra, small, sparse primary tubercles interspersed with miliary granules. The tubercles are, however, more numerous on the plates of internal series Ia5-a9 and Vb5-b9 that have anal pedicels.

On the ventral surface, the posterior ambulacra are narrow and lack primary tubercles that appear only at their posterior end. They have only some rare small granules that are a little more numerous near the peristome. The phyllode peripodia exist on plates Ib1-b3 and Ia1-a2 as well as on $\mathrm{Va} 1-\mathrm{a} 3$ and $\mathrm{Vb} 1-\mathrm{b} 2$. At the posterior end of these ambulacra, we see a series of five geminate pores that each has a large pedicel. The first of these pores is on plates Ia5 and Vb5 that are still on the ventral surface. The following ones continue on plates $6,7,8$ and 9 of the posterior surface 
of the test. These plates are not modified in form in any way. The ambulacrum is a little enlarged at this level, but this is mainly due to the development of the external row.

The interambulacral areas of the dorsal surface are first very narrow because of the width of the petals, but they widen rapidly in their turn toward the fasciole. They are covered with fairly separated primary tubercles of uniform size except at the top of the areas where the tubercles become a little larger. Outside the fasciole, the tubercles also become a little larger at the same time that they are more spaced and the miliary granules become more abundant.

The interradial plates that form the lateral surfaces of the test are swollen toward their middle, each with a small conical prominence. This arrangement is not very noticeable on the anterior interradius. It is especially accentuated on the two posterior interradii. Interradius 5 is the least developed of all the dorsal surface. Inside the fasciole, the median interradial line rises slightly into a keel that ends behind, at its point of meeting the fasciole, in a small conical prominence. Outside the fasciole, this interradius forms the posterior surface of the test that is vertical and flat. We shall soon return to it. On the ventral surface, the two anterior interradii have very dense primary tubercles at the ambitus. They are more and more spaced toward the peristome. The tubercles of the posterior areas are less dense at the ambitus than the anterior interradii. They become very few toward the ventral ambulacra. Between the primary tubercles are miliary granules that are also not dense.

The labrum is fairly large. Its anterior border is swollen and forms a lower lip that is directed nearly vertically downward. Behind this lip, the labrum narrows rapidly. Then it widens again and ends in a round border that passes a little the middle of the adjacent second ambulacral plates. It has only four or five very separated primary tubercles and some miliary granules. The sternal plates both have exactly the same length and form. They are fairly large and triangular, with a truncated anterior top. The sides are slightly convex and form an obtuse angle with the posterior border that is straight and directed obliquely toward the median interradial line. This, that stays at first nearly flat, rises into a slight prominence toward the posterior and internal angle of the sternum. The two following plates, 3-3, are at the border between the ventral and posterior surface. They have, toward their internal angle and very close to the median line, each a very small conical prominence. They are pentagonal, widened transversely and also as wide as the preceding. But the right plate is much shorter than the left plate. Thus is established the regular alternation of the following plates, series $b$ is always in front of series $a$. The posterior surface is formed by plates a4-a7 and b4-b7, that are very large and become taller and taller toward the dorsal surface. The width remains constant. The very small periproct, is bordered only by plates b7 and a6-a7. Plates 8-8 are at the border of the posterior surface and the dorsal surface. Each of them has, toward the median line and above the periproct, a very small conical prominence, similar to that on plates 3-3. The interradial plates of the posterior surface, after the fourth up to the eighth, show also each a small prominence, a little nearer their interior angle and similar to those that we have recognized on the other interradii, but less developed. The primary tubercles of the posterior surface remain small and sparse. We see only a small area where these tubercles are more developed and more numerous. They are found at the level of the two upper anal pores on plates Ia7-a8 and Vb7-b8.

The peristome, of moderate size, has a strongly convex anterior border and a nearly straight posterior border (Pl. VII, fig. 6). It is covered, in front, by some large polygonal plates. But the other plates are extremely small, irregularly rounded and a little imbricated. The lower lip, approximately $3 \mathrm{~mm}$ in width, hides nothing of the peristome when we look at the animal by the ventral surface because of its vertical direction. 
The periproct (fig. 8), extremely small, ovoid and elongated longitudinally, is much longer than wide. It has, in its upper half, some fairly large plates with small spines. In its lower half, the plates remain very small. The anus is near the lower border.

The peripetalous fasciole describes nearly exactly a path around the petals, at the ends of which it is exactly tangent. Its contour is slightly angular and the slightly accentuated prominences of the test correspond to its very obtuse corners. I have reported above these prominences in studying the interradius. The fasciole is fairly narrow and its width, which does not exceed $1.5 \mathrm{~mm}$, remains more or less the same over all its path except in the two posterior interradii where it is a little wider.

The primary spines are elongated, fine and dense on the dorsal, lateral and dorsal surfaces of the test. On the dorsal surface, they are, as usual, particularly developed along the petals that they cover more or less completely, in going obliquely, to meet their congeners. They widen gradually in their terminal part and take a spatulate form with the concave face turned upward. The spines of the posterior end, which are very dense, fairly often also take a spatulate form, but less noticeable than on the borders of the petals.

On the sides of the test, the spines always remain fairly fine. On the ventral surface, the primary spines of the lateral interradial pairs are notably less numerous and less dense than on the dorsal surface. They are fine, elongated, but always remain cylindrical. To the contrary, the large spines of the sternum are widened into a spatula at the end. The widening is more noticeable than on the dorsal spines and also is very abrupt.

The miliary spines are elongated, very fine and straight. They have, on nearly all their length, small teeth that are fairly low and obtuse in the proximal half and elongated in the distal half. Most often, these teeth are developed on only one side. The other appears only near the end when the spine begins to widen. This end is moreover not very wide. It does not quite reach twice the width of the spine. It is in general also a little asymmetrical. The calcareous rods that form it by anastomosing extend each into a small free point.

The clavules of the fasciole end in a fairly wide head, approximately two times longer than wide (Pl. XVIII, fig. 46). This head, ovoid in form, is spiny on nearly all its surface because of the free tips of the rods that constitute it.

I have found on my specimens only tridactyle and rostrate pedicellariae. The tridactyle pedicellariae are of two types. In the first (Pl. XVIII, fig. 41 and 42), the head is wide and thick. It is preceded by a fairly short neck. Its length is 0.7 to $0.8 \mathrm{~mm}$. The basal part of the valves is triangular, wider than long. The blade, at first fairly narrow, widens rapidly into a very convex spoon whose width decreases gradually up to the end where it often tapers into a small round point. The wide part of the blade has all along its length extremely fine teeth that are narrow, triangular and very close together. Its perforations are large, oval and arranged in very regular transverse and oblique series. These pedicellariae are mainly found near the peristome.

The other pedicellariae (fig. 40) have a more elongated and narrower head than the preceding. The neck is also more elongated. The basal part of the valves is triangular and fairly wide. It reaches only a fourth or a fifth of the total length. The blade always remains fairly narrow, five or six times longer than wide. It keeps nearly the same width its entire length. The borders, regular in the small pedicellariae, can take a sinuous and somewhat irregular contour as the size increases. The end is round or forms a blunt point. In the last quarter or fifth of the valves are some small triangular and pointed teeth that become a little stronger toward the end of the valve, while the rest of the border is smooth. In the largest pedicellariae, the length of the valves can reach nearly a millimeter. In the smallest, it is less than $0.4 \mathrm{~mm}$. In the smallest forms (fig. 47 and 48), the valves, extremely thin, have only a few unequal teeth in their distal half. The last or the two last teeth are 
stronger than the others. These valves are then identical to those of the small tridactyle pedicellariae figured by Mortensen in H. expergitus (07, Pl. XV, fig. 30). The perforations of the blade are fairly large, oval and close together. These pedicellariae are widespread on all the test. The largest are seen near the peristome and on the petals.

Forms similar to these pedicellariae with elongated valves have been indicated by Mortensen in Aeropsis rostrata (Pl. XV, fig. 21), in Schizaster canaliferus (Pl. XVI, fig. 28), etc. As for the pedicellariae with a wide head, they recall a form found by Mortensen in Hemiaster of the CHALLENGER called by Agassiz H. gibbosus and represented by him (81, Pl. V, fig. 42), but the widened part of the valves is longer in H. hickmani.

The rostrate pedicellariae also have variations. I distinguish three types of them that are very close to each other. The most characteristic is found in the area of the peristome as well as toward the periproct. The valves (fig. 44 and 45) are very large in the basal part that occupies approximately half the length and narrows rapidly. It can be armed with short, conical and fairly strong teeth. The blade, narrow at first, gradually widens and ends in a convex border. It has twelve to fifteen very strong teeth, elongated, conical and extremely pointed. The perforations are small and dense. The head of these pedicellariae can reach $1 \mathrm{~mm}$. On the dorsal surface, in the petals, I find smaller rostrate pedicellariae. They head is only $0.6 \mathrm{~mm}$ in length. The basal part generally is more than half the length of the valve (fig. 43). The blade remains a little thicker than in the preceding form and its terminal border wider, very strongly convex, with a series of very small teeth, dense, conical and developing over a length a little greater than in the preceding form. Finally, among the rostrate pedicellariae, I note some that can merit the name of tridactyle, that greatly resemble those of H. tenuis that Mortensen has represented in 1907 (Pl. XV, fig. 4) in designating it under this name. In the valves that I observe, the blade is more elongated than the basal part and its distal half, very wide, is oval. They have fine and dense denticulations, similar to those of the preceding form, but small and extending on a still greater length. It does not seem to me that there are very important differences between this form and the preceding. This is why I consider it as rostrate. The length of the head is 0.6 to $0.7 \mathrm{~mm}$. As for the trifoliate pedicellariae, they have the usual structure.

The frontal pedicels end in a rosette whose border has twenty-six to twenty-eight inconspicuous lobes. The stem contains fine, thin spicules usually curved that resemble those that Mortensen has represented in $H$. expergitus. The smallest have in general smooth borders. Others, a little larger and especially thicker, have denticulations more developed than in the figure of Mortensen. The rods of the rosettes measure approximately $0.3 \mathrm{~mm}$ in length (Pl. XVIII, fig. 39). They are flat and fairly wide, especially in their distal half. The basal part has the form of a triangle with a truncated top. The perforations of the widened part are extremely narrow in the first third. Then they become very large in the distal half. Toward the end of the calcareous reticulum, some pointed fibers can form. When the rods are seen in profile, we note that the base forms a kind of heel from which leaves a part that ends in a point, whose border is concave on the side of the heel and convex on the other side. The peristomial pedicels do not contain spicules in their stem, but only a rod in each digitation. It is the same with the anal pedicellariae that are moreover less developed than the preceding and whose digitations are less numerous.

Here are some notes that I have been able to make on the internal organization. The esophagus, very narrow and short, is directed backwards and upwards. Then it continues with the first part of the ventral intestinal loop that is very flat and remains located nearly exactly in the median vertical plate up to the point of insertion of the diverticulum, i.e., up to radius III, where it curves to continue with the dorsal loop. This, always very wide and strongly folded transversely, is separated 
by its orangish yellow color from the grayish color of the ventral loop. The diverticulum is very elongated and not very folded. The intestinal siphon originates a little after the end of the esophagus. It appears as a small canal with a whitish color. It is first directed forward for a short distance. Then it curves rapidly back contiguous with the internal border of the intestine, inside the internal marginal lacuna. It becomes narrower at the same time. Its distal opening is located at the level of interradius 5, while the internal marginal lacuna continues its path and receives branches only a short distance behind the end of the ventral loop. I have verified the presence of differentiated glands in the thickness of the wall of the digestive tube before the proximal opening of the siphon.

There are four gonads, The two anteriors, larger, are moved very strongly forward and we can see the gonad of interradius 3 beside the point of origin of the diverticulum without displacing the digestive tube when the urchin is opened by its ventral surface. The two posterior gonads are found located nearly at the level of the apical system. Their canals are directed transversely.

SimilaritiES AND DifFERENCES. - H. Hickmani is very different from the other known species of the genus Hemiaster. It is separated immediately by the form of the extremely wide petals, shallow and unequal, as well as by the peripetalous fasciole that is very close to the ambitus because of the elongation of the petals. The general structure of the test keeps well the characters of the genus Hemiaster in which it seems to me possible to place the new species.

I dedicate this species to Commander C. S. Hickman, commander of the INVESTIGATOR.

Hemiaster vanus nov. sp.

(P1. VII, fig. 1, 2, 3, 11 and 12; PI. XVIII, fig. 49 to 59)

Station 97. - $18^{\circ} 26^{\prime}$ N.; $85^{\circ} 24^{\prime \prime}$ E. 1310 fathoms. - One dry specimen and some debris coming mainly from the dorsal surface. N" $\underline{428}$.

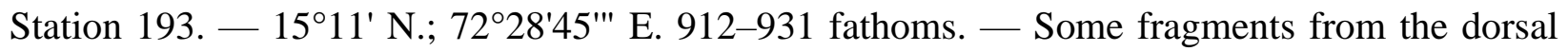
surface coming from much smaller individuals than the preceding. $\mathrm{N}^{\circ} \frac{429}{7}$.

Station 274. - $10^{\circ} 33^{\prime}$ N.; $76^{\circ} 08^{\prime} 22^{\prime \prime}$ E. 836 fathoms. - A fragment of the dorsal surface and some smaller debris. $\mathrm{N}^{\circ} \underline{1295}$.

The large specimen of station 97 is dry. It is nearly complete, but the test, which is extremely fragile, has several fractures. This is the type that I shall describe, keeping for it the name on the label. The fragment of station 274 is a nearly complete dorsal surface with all its spines, but comes from a specimen much smaller than the preceding. I have found on this dorsal surface some pedicellariae identical to those that I have encountered in the debris of the small specimen of station 97. 
Here are the principal dimensions of the large specimen of station 97 that will serve me as the type:

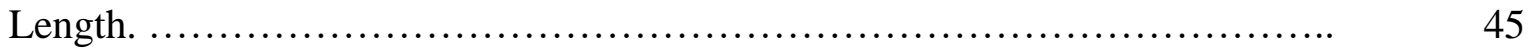

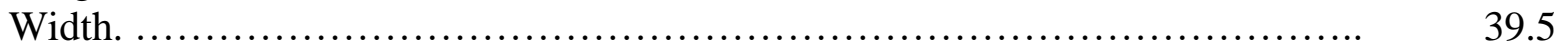

Height at the level of the anterior end of the fasciole. .......................... 27

Maximum height of the test. ......................................... 36

Distance between the middle of the apical system and the anterior border of the

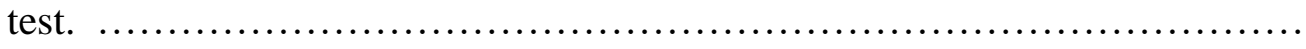

Distance between the middle of the apical system and the posterior border of the test. .......................................................... 21.5

Distance between the anterior border of the peristome and the anterior border of the test.

Distance between the posterior border of the peristome and the posterior border of the test. .......................................................... 30

Length of the anterior petals. ........................................... 13.2

Length of the posterior petals. ........................................ 7.7

Maximum width of the anterior ambulacrum. .............................. 3.2

Maximum width of the anterior petals. ................................... 5

Maximum width of the posterior petals. .................................. 4.6

Distance between the middle of the apical system and the anterior border of the fasciole.

Distance between the middle of the apical system and the posterior border of the

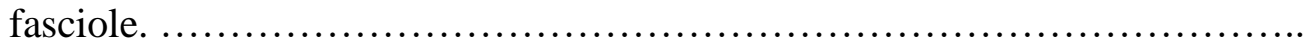

Total length of the fasciole. ...............................................

Maximum width of the fasciole.

Distance between the upper border of the periproct and the supero-posterior angle of the test. ..........................................................

Distance between the lower border of the periproct and the infero-posterior angle

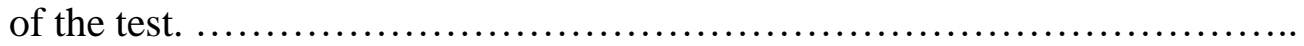

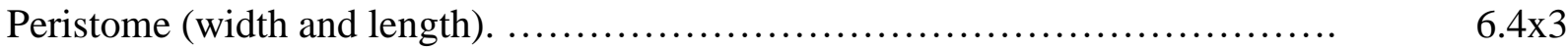

Periproct (height and width). ..................................... $\quad 7 \times 3.2$

The test is short and stocky. It is extremely thin and fragile. The anterior end is round, and the posterior end, remarkably tall, is truncated and directed obliquely backward. It is completely flat in the middle.

Seen from above (Pl. VII, fig. 1), the test has, in its anterior half, a slightly angular border that can be separated into three distinct sides: an anterior, slightly convex side and two nearly straight latero-anterior sides directed very obliquely and joined to the first by very obtuse and rounded angles. The end of the latero-anterior sides are found on the extension of the anterior petals and correspond to the limit of the anterior third of the body. At this level, the test has acquired nearly its full width. We note then, after the preceding sides, two lateral sides, parallel, that extend to the end of the posterior petals. Beyond that, the test narrows and its posterior contour is formed by two sides that join, by a very obtuse and round angle, a convex posterior border. The apical system is found a little nearer the posterior end than the anterior end of the test. 
The anterior ambulacrum is, on the dorsal surface, a shallow groove that does not reach the anterior border of the test. The anterior petals are much longer than the posteriors, but their end also stops very far from the ambitus. The peripetalous fasciole itself envelopes only a relatively small area on the dorsal surface.

Seen from the side (fig. 12), the contour of the test rises at first very rapidly at the anterior end, following a convex curve and that is more rounded at the level of the anterior branch of the fasciole, to pass to the dorsal surface. This it continues to rise obliquely to the posterior border of the fasciole. It is at this level that the test reaches its maximum height. Beyond this, the contour of the dorsal surface curves a little and passes immediately, by an obtuse and round angle, to the posterior surface. This, nearly flat, is directed a little obliquely backwards. It joins the ventral surface by an angle whose top is round, but that is not more than $75^{\circ}$. The ventral surface has a very rounded and convex anterior part that curves inward to join the peristome. This is very sunken and located at the end of a deep notch, limited behind by a very projecting lower lip. Before this notch, the ventral surface follows, up to the posterior corner of the test, a direction nearly straight and slightly oblique toward the top.

Seen from the front (fig. 2), the ventral region has a fairly regularly rounded contour in front and on the sides, the anterior part being a little narrower than the posterior part. This narrows rapidly backwards. It ends in a projecting corner whose top is round and makes an obtuse cone. The posterior end, seen from the front, is nearly flat. It is continuous with the lateral surfaces of the test by very round parts. Its convex upper border has in is middle a projection that corresponds to the unpaired posterior interradius. It is very widened and swollen on its sides, while it narrows very rapidly in its lower third. It is joined to the ventral surface by the conical and obtuse projection that I described above. The posterior surface of the body, with its medial interradial projection on its upper border and its lower part ending in an obtuse point, recalls, when we look at the surface, the form of a top having a blunt lower point that is quite characteristic of $H$. vanus. The periproct is located very near the upper border of this surface.

The plates of the apical system have very distinct contours. The system as a group has the form of an elongated oval in the antero-posterior direction. It is clearly ethmophractic (Pl. XII, fig. 11). The four gonopores are equal, fairly small and located in the angles of a trapezoid, the two anteriors closer together than the posteriors. They are both located toward the external border of their respective plates. The left anterior plate is pentagonal, elongated in the direction of interradius 3 , with an external border slightly indented by ocellar plate IV. The left posterior plate is a little smaller and nearly lozenge-shaped. It is placed nearly transversally while the right posterior plate, that is also placed transversely, is larger, nearly two times longer than wide, a little wider in its external part that has the opening and narrower inside where it separates the madreporite from the two posterior ocellar plates. The right anterior plate is fused to the madreporite that is large, lozenge-shaped and directed obliquely backwards in the direction of interradius 2 . It goes between the three other genital plates without reaching the level of the posterior openings. The unequal ocellar plates are very large and triangular, with round tops and fairly large openings. They are a little wider than long. The two posterior plates are contiguous.

As I have said above, the anterior abulacrum forms, on the dorsal surface of the test, a narrow shallow groove that rises while slightly narrowing in the vicinity of the fasciole and disappears outside it. I count twenty-one plates, whose length gradually increases after the apical system. Each has a pair of pores. These are placed obliquely and nearer the external border than the internal angle. The external or posterior pore is a little wider transversely. The internal or anterior pore is rather pear-shaped. Each pair is surrounded by a very clear peripode. The plates first have, inside 
the pores, each a secondary tubercle. These tubercles form, in the proximal part of the groove, a regular row that disappears further by the addition of some other secondary tubercles and miliary granules. Beyond the fasciole, the plates that abruptly become very large and polygonal, are covered with numerous primary and miliary tubercles, identical to those of the adjacent interradial region.

The anterior petals are elongated, oval and rounded outside. The maximum width is found toward three-quarters of their length. They are shallow. The make an angle of $55^{\circ}$ with the antero-posterior axis and an angle of $95^{\circ}$ with the posterior petals. They abruptly narrow toward their proximal end without becoming, however, very pointed. The interporiferous zone keeps, from its origin, nearly the same width for nearly all its length. It narrows a little only toward its end. To the contrary, the width of the poriferous zone increases gradually. Toward two-thirds of its length, it exceeds that of the interporiferous zone. Then it decreases in its turn. I count in each petal twenty-five to twenty-six pairs of plates separated from each other by small ridges. The pores of the first four or five pairs are very small. Then the following ones develop and widen. They are verguliform and nearly equal in the two rows of each side. Each plate has a triangular transverse row of about six small granules. Some slightly larger tubercles are irregularly distributed on the interporiferal zone.

The posterior petals do not reach half the length of the preceding. They are also a little narrower and not as deep. But their structure is the same. I count on each side about fifteen plates. These petals make with the posterior interradius an angle of $35^{\circ}$.

Beyond the fasciole, the anterior and posterior ambulacral plates widen very rapidly and become polygonal with numerous primary and miliary tubercles.

The five interradial regions of the dorsal surface of the test form, inside each fasciole, a triangular area that widens rapidly after their top. Their proximal parts are rather projecting and separate the petals. In the anterior and posterior interradial pairs, the projection decreases little by little toward the vicinity of the fasciole where the plates are flush with the test. But the projections persist in the posterior interradius up to the fasciole. The plates of the anterior interradius have primary tubercles that are very close together and are often arranged in more or less regular rows. These become larger toward the radial border of the plate, especially in series $2 b$ and $3 a$ where we observe some irregular rows of large tubercles the length of the borders of the anterior ambulacral groove. The two posterior interradii, much shorter, widen more rapidly. They have the same covering as the preceding, but the primary tubercles there remain a little smaller. Interradius 5 , narrow in the region located inside the fasciole, rises into a fairly unimportant median keel. It continues to widen, but gradually sinks toward the posterior end of the test. The primary tubercles, at first large toward the proximal angle, become smaller and smaller in the area of the fasciole and merit the name of secondaries. But, on the other side of the fasciole, they gradually take the usual size of primary tubercles.

Outside the fasciole, the interradial plates rapidly become large and polygonal. They are covered with primary tubercles of uniform size. They are arranged on the lateral surfaces of the test in fairly regular oblique rows and in less regular concentric rows. These tubercles are not very dense in the interradial pairs. The miliary granules are not very abundant. They become a little denser on the plates of the unpaired interradius toward the posterior end of the body. They are also a little larger toward the anterior border of the test, both on the plates of ambulacrum III and the plates of the adjacent interradius. 
The lateral plates of interradii 1 and 4 rise in their middle to form each a conical, low prominence that is fairly apparent while remaining very low. Each plate of interradius 5 also has in their middle, and on each side of the periproct, a similar prominence.

Reaching the ventral surface of the test, the primary tubercles become a little larger, especially on ambulacrum III and the anterior interradii 2 and 3. They are less large and less dense on the posterior interradii 1 and 4. They become even smaller toward the posterior end.

The anterior ambulacrum widens a little in approaching the peristome. At the same time, it is depressed in reaching the anterior border that is slightly sunken. The first three plates of each series have phyllode peripodia. There are thus three in series $a$ and four in series $b$. The anterior ambulacral pairs remain fairly wide up to the peristome. They are also depressed in approaching it. The phyllode peripodia appear on the first six plates and a last rudimentary one on the seventh plate. The primary tubercles do not appear on these plates until the sixth. The posterior ambulacra are not depressed in the peristomial region. They have only three peripodia in each series. The primary tubercles appear on the internal series toward the end of the fourth plate only, at the level of the end of the sternum, and, on the external series, in the middle of the third plate. They become more numerous, but also a little smaller, at the end of the ambulacra and on the posterior surface of the test.

The labrum is very elongated. It measures $12 \mathrm{~mm}$ in length and extends a little beyond the second corresponding ambulacral plate. Its anterior border, strongly thickened and convex, forms a very projecting lower lip. Behind it is a slight notch. The sides are nearly straight and parallel. Unfortunately, the labrum is broken and is mostly missing in my specimen so that I cannot recognize its exact form. We see some primary tubercles toward its posterior border. The two sternal plates that follow are very elongated. They measure approximately $19 \mathrm{~mm}$ in length. They are very narrow. The maximum width that is reached toward the middle is only $6 \mathrm{~mm}$. These plates of slightly narrower in their posterior half. Their external convex border follows the curve of the ambulacra. The surface is a little swollen. In their posterior region, the two sternals are raised a little in forming a median ridge and lean against each other in a very obtuse dihedral angle whose surfaces remain nearly flat. They thus contribute to form, with the following plates $3-3$, the projecting round point so characteristic that is found at the point of joining the ventral and posterior surfaces. The sternal plates are almost completely on the ventral surface. They have, as usual, primary tubercles arranged in regular and slightly divergent rows, in which the size increases gradually from back forward.

The two episternal plates that come afterwards are found at the boundary of the ventral and the posterior surface. They mainly are a part of the latter. They are uniformly covered with primary tubercles, small and dense. They are distinguished from the following plates only by their less apparent projection. These form a very regular series in which the dimensions increased little by little up to plates 7-7 that surround a very large portion of the periproct. The periphery of the latter is completed by plate $5 \mathrm{~b} 8$. Plates $8-8$ are found at the boundary between the posterior surface and the dorsal surface of the test. They begin to rise in the area of the median line. The following plates are more swollen. They form the interradial prominence that the fasciole crosses at the level of plates b9 and a10.

The peristome is located at the bottom of a fairly deep depression, where radii II, III and IV, as well as the interradii 2 and 3 come together. The bottom of this depression is approximately 3.5. $\mathrm{mm}$ above the lower border of the lower lip. The peristome is strongly concave when we look at it in profile. It rises in the posterior part, above the thickened rim that the labrum forms on its free 
side. It is in part hidden by it. It is covered with rather small plates, a little larger toward the anterior border and much reduced toward the posterior border.

The periproct (fig. 3) is moved very high toward the upper part of the posterior surface. It has a very elongated and very narrow oval form, three times longer than wide. It is covered by a marginal row of polygonal plates, very much larger toward the upper and lower poles and very narrow on the sides. Inside this row, we find in its upper region some smaller plates. Then the rest is filled with extremely reduced plates. The anus is near the lower border.

The peripetalous fasciole has an oval contour, a little elongated in the antero-posterior direction. Buts its radius is relatively short, a disposition related to the fairly short length of the petals. Its round posterior border crosses plates b9 and a10 in interradius 5. The contour of the fasciole would be fairly regular if it did not have in front, on both sides of the antero-posterior axis, a transverse and straight part connected to the rest by an obtuse angle. The thickness of band that it forms varies a little according to the region. In fact, the width exceeds $2 \mathrm{~mm}$ at the level of the anterior and posterior petals. The enlargement is especially due to the convex form of the external border of the fasciole, while the narrowest part is at the level of the posterior interradial median line where he width scarcely exceeds $0.5 \mathrm{~mm}$. Toward the middle of the posterior interradial zones, the width is still fairly large, thanks to the convexity of the internal fasciole at this level.

The specimen that I just described was dried and nearly completely lacking in spines. Those that were preserved are nearly all incomplete. I have not to use them to study their characters. Moreover, it has been impossible for me to find pedicellariae. But this lacuna can happily be filled thanks to some other fragments that I reported above and that were in alcohol.

The most important is a fragment coming from station 271 and that contains a large part of the dorsal surface with a small portion of the ventral surface, all covered with spines. This fragment comes from a specimen smaller than our type, but it certainly belongs to the same species. However, after having removed a part of the spines from the test, I have seen small differences that are evidently due to the younger age of the specimen. The most important difference is offered by the fasciole that is sensibly more elongated than in the type and that has a slightly more angular contour. The anterior petals are also very slightly arched at their origin thanks to a more marked convexity of the posterior border, and the slightly narrower interporiferous zones. I do not believe that we can hesitate to refer this fragment to $H$. vanus, mainly because it has pedicellariae identical to those that I find in some fragments coming from station 97 that provided the type of the species.

Here are some dimensions that I took from this fragment from station 274:

\begin{tabular}{|c|c|}
\hline & $\mathrm{mm}$ \\
\hline Anterior ambulacral groove: length and width. ,,,,,,,,,,,,,,,,,,,,,,,,,,,,,,,,,,,,,,,,,,, & $11 \times 4$ \\
\hline 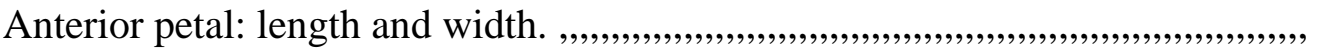 & $9.5 \times 4.5$ \\
\hline 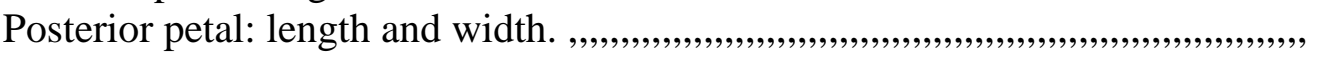 & $5 \times 4$ \\
\hline 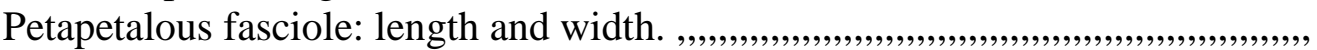 & $23 \times 22$ \\
\hline
\end{tabular}

The primary spines that these fragments have preserved are fine and cylindrical, fairly short on the lateral surfaces of the test as well as on the sides of the dorsal and ventral surfaces. On the dorsal surface, inside the fasciole, the spines adjacent to the petals and the ambulacral groove area are elongated. They widen gradually up to their end without having denticulations. Immediately outside the fasciole, the primary spines are often flat at the end, which is a little curved at the same time. One of the borders has fairly conspicuous denticulations but the number is variable. On the 
sternum, the spines, at first cylindrical, widens abruptly into a terminal, very flat pallet whose white color contrasts clearly with the deep green color of the rest of the spine. The widened part is hyaline only on its edge. All the rest of the spine is a compact calcareous network. Its borders are round and convex without any indication of denticulations or extensions. The form of these spines recalls those that we have seen in H. Hickmani and that also know in the genus Aceste.

The miliary spines have the usual structure. The calcareous stem of clavules, very thin, develops abruptly, at its end, a short and very widened head (Pl. VIII, fig. 51 and 53).

The pedicellariae do not appear to be very abundant on the fragments that are available to me. I have encountered three kinds of tridactyles and rostrates. The tridactyles of the first kind have wide, strong valves, not exceeding 0.4 to $0.5 \mathrm{~mm}$ in length (fig. 56 and 57). The basal part is large, triangular, nearly as long as wide. It can reach nearly half the total length. The blade, narrow at its origin, rapidly widens into a convex spoon, very wide and fairly short, that ends in a round end. The borders have very fine denticulations, dense and regular. The perforations are fairly large. These pedicellariae are mainly found in the petals. The other tridactyle pedicellariae are more abundant and appear to exist in all regions of the test. they are smaller than the preceding. The length of the head varies between 0.2 and $0.4 \mathrm{~mm}$. The basal part (fig. 49 and 50) is short. It scarcely reaches a quarter of the total length of the valve. It is wider than long and much wider than the blade, that remains narrow and keeps the same width up to near the end where it narrows to end in a blunt point. The borders have denticulations that appear at a short distance from the base of the blade. They are fine, conical and pointed. At first, they are extremely small. Then they increase slightly in size. The last two or three teeth can be fairly developed. This happens especially in the small pedicellariae that thus recalls the form that Mortensen has represented in H. expergitus (07, Pl. XV, fig. 30), while in the larger pedicellariae, whose valves reach 0.3 to $0.4 \mathrm{~mm}$ in length, the terminal teeth are less pronounced. In the other pedicellariae, finally, that always remain very small, the very short blade abruptly widens into a wide spoon whose teeth have fine denticulations (fig. 59).

The rostrate pedicellariae are not very large. Their head scarcely exceeds $0.4 \mathrm{~mm}$ (fig. 58). The basal part is very wide, and, in general, wider than long. The blade remains very narrow for the large part of its length. Then it widens fairly rapidly at its end that has regular teeth, conical, fairly strong and elongated.

The rosettes of the frontal pedicellariae have a slightly lobed border. Their rods are constituted as in H. Hickmani (fig. 54 and 55).

The color of the fragments in alcohol is a very deep olive green.

I have believed it likewise possible to refer to $H$. vanus some fragments of the dorsal surface coming from station 193 that belong to two individuals of very small size. The essential characters of the species are found in these fragments. In the smaller, the fasciole is $14 \mathrm{~mm}$ in length and the gonopores are not yet formed. The other fragment, that comes from an individual a little larger, has four gonopores.

SIMILARITIES AND DIFFERENCES. - H. vanus is especially near $H$. expergitus, considering the species in a broad sense as done by Mortensen in 1907 and that he united with $H$. gibbosus, Mentzi and zonatus of Agassiz (07, p. 97). We know that H. expergitus, thus understood, has a vast geographical range. The species of the INVESTIGATOR is especially near $H$. gibbosus, but it is nevertheless very different from it. The form of its test is very characteristic. This one is very stocky and relatively short and slightly narrower in the anterior part than in the posterior part where 
the maximum width is reached. The posterior surface, nearly flat, is directly obliquely downward and outward so that the ventral surface is much more extended backward than the dorsal surface, an arrangement inverse of that we see in $H$. expergitus. The form of this posterior surface, strongly narrowed in the lower part to form a large projection, a kind of obtuse beak that also ends the ventral surface, is quite remarkable. The sternal region is more elongated and narrower than in $H$. expergitus. I measure, in fact, $30 \mathrm{~mm}$, i.e., two-thirds of the total length of the test, between the anterior border of the labrum and the posterior border of the sternal plates. The elongation is due to both the development of the labrum that is longer than in H. expergitus and the length of the two sternal plates that are, in contrast, comparatively narrower than in the latter species. The posterior border of the sternum is also nearer the posterior end of the test. Plates 6-6 remain completely outside the periproct that is limited by plates 7-7 and $8 \mathrm{~b}$. The periproct itself is remarkable elongated and narrow.

My observations on the pedicellariae are unfortunately incomplete. The rostrate pedicellariae and tridactyle pedicellariae with elongated and narrow valves that I observe are very near those of H. expergitus, but the tridactyle pedicellariae with widened valves have not been reported in the latter species. I have encountered a similar form in H. Hickmani. As for the spatulate spines of the sternum, they are always round on their free border and do not have the pointed median extension that Mortensen has indicated in $H$. expergitus.

The excellent figures that have been published by Loven, then more recently by Morttensen, of $H$. expergitus permit a very precise comparison with the new species. I have moreover been able to support my comparison by the examination of various specimens of $H$. expergitus coming from the expeditions of the TRAVAILLEUR and the TALLISMAN that are found in the Jardin des Plantes. Although these are all very small, the length of their test is not greater than $25 \mathrm{~mm}$, these individuals conform very well to the photographs published by Mortensen. I speak here only of the specimens whose determination is correct, as those that come from a dredging at 3,200 meter and labeled $\mathrm{N}^{\circ} 201$.

It is not, in fact, without a definite surprise that I have found at the Museum an echinoid coming from the same expedition and dredged at 1,590 and 1,350 $\mathrm{m}$ (there is no other information) and that had been labeled as H. expergitus by Felix Bernard. This specimen struck me immediately by the elongated form of the test and by a very conspicuous slope before the dorsal surface corresponding to a very low anterior end. I have seen, in addition, that its apical system is clearly ethmolytic and that there is a subanal fasciole. I believe this is a new form and plan to describe it later, in revising the echinoids of the TRAVAILLEUR and the TALISMAN whose determinations, evidently done in a very summary manner by F. Bernard, appear to me subject to caution.

\section{Periaster Kempi nov. sp.}

(Pl. VIII. fig. 1, 2, 3, 5, 7, 8, 9 and 16; PI. XIX, fig. 1 to 13)

Station 274. - 10'33' N; 7608'11' E. 836 fathoms. - Three specimens. $\mathrm{N}^{\circ} \frac{1291-1293}{7}$.

Station 311. - 18 $57^{\prime} N^{\prime} ; 92^{\circ} 32^{\prime} 30^{\prime \prime}$ E. 1192 fathoms. - Three specimens. $N^{\circ} \underline{1793-1795}$.

Two of the specimens from station 274 are entire, as well as one of the three from station 311. In the others, the ventral surface has been broken and is missing. Most of the spines are also missing. The incomplete individual of station 311 is the largest. The length of its test reaches 40 
$\mathrm{mm}$. The length varies between 40 and $43 \mathrm{~mm}$ in the other. The test of two individuals from station 274 is a little narrower than the four others.

I shall take as type the entire individual from station 311 that is represented in Pl. VIII. I give below the principle dimensions (individual A), to which I add measurements taken from the largest specimen (B) as well as those of a specimen with a narrower test from station 274 (C).

Total length. .......................................

Width

Maximum height of the test.

Distance between the apical system and the anterior end of the test

Distance between the apical system and the posterior end.

Distance between the anterior border of the peristome and the posterior end of the test.

Distance between the posterior border of the peristome and the posterior end of the test

Length of the anterior petals.

Length of the posterior petals.

Maximum width of the fasciole.

Peristome (width and height).

Periproct (height and width)
A

$\mathrm{mm}$

42.5

37

28

29

\section{SPECIMENS}

$\mathrm{mm} \quad \mathrm{mm}$

10

29.5

15

6.5

27

$7 \mathrm{X} 3$

$7 \times 5$

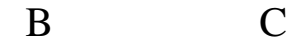

46

37.5

?

?

26

20

18

9

8

C

40

33

23

24

22

29.5

34

16

7

27

$7 \mathrm{X} 3$

$7.5 \times 6$
11

5

23

$7 \mathrm{X} 2.5$

5X4

The test seen from above (Pl. VIII, fig. 1 and 3) has an oval contour, fairly regularly rounded in its anterior part, a little wider and becoming angular after the anterior lateral ambulacra, and then narrowing rapidly backward to a fairly narrow posterior end. The anterior ambulacrum has a notch in front whose depth is only $2 \mathrm{~mm}$. On both sides of this, the anterior interradius forms a regularly convex border. The lateral ambulacra are also found, at the ambitus, in a slight depression following a small convex border. At the end of this, the test reaches its maximum width, i.e., toward the middle of the external anterior rows of interradii 2 and 4. Afterwards comes a small straight lateral border parallel to the antero-posterior axis that ends at the level of the middle of the posterior petal, toward the beginning of the posterior row of interradii 1 and 4 . Finally, the periphery of the test is completed by an elongated and slightly convex border, directed very obliquely inward, that forms with the preceding an obtuse angle and joins the posterior end. This is transversely truncated.

The anterior groove is very slightly depressed. The petals are not deep. The interradial part that separates these parts are not very projecting. The posterior interradial prominence alone is fairly noticeable.

Seen in profile (fig. 2), the test has a relatively low anterior end and a very tall and vertical posterior end. The profile rises at first nearly vertically. Then it follows a slightly convex but very oblique line. It reaches its maximum height of 7 or $8 \mathrm{~mm}$ behind the apical system. It then curves following a very round angle to join the posterior surface. The ventral surface is first flat and 
directed a little obliquely downward to the peristome. Beyond this, it follows a convex profile to the posterior border of the sternal plates. It then rises to continue by a very round border with the posterior surface. On the sides of the test, the plates of the two interradii 1 and 4 have each a conical and round prominence. The posterior surface is also limited on each side by a series of small prominences on plates 3. 4, 5, 6 and 7 of the unpaired interradius. It thus surrounds a triangular area whose top reaches the posterior interradial prominence and that widens gradually toward the bottom.

The apical system (Pl. VIII, fig. 8) greatly recalls that of $P$. limicola figured by Mortensen (07, p. 107), but the madreporite extends backward a little less in the species of the INVESTIGATOR. It stops at the level of the posterior border of the gonopores. These two openings are comparatively smaller than in $P$. limicola. The genital plates are fairly large. The left is a little less wide than the right They occupy together a width of $3 \mathrm{~mm}$. The opening is located nearly in the middle of each plate, but the right one is a little nearer the external border. These plates have a principal part whose contour is irregularly circular and a narrow anterior extension that separates respectively the three anterior ocellar plates from each other. They have some very small tubercles. The madreporite has numerous dense pores that exist mainly on its part between the genital plates that cover a small area one and half times longer than wide. The ocellar plates are arranged as in $P$. limicola, the three anteriors being located on the same transverse line. They have the form of a wide, low triangle with a fairly elongated croissant-shaped opening.

The anterior groove is at first very narrow and scarcely depressed. Then it widens and sinks a little, but it remains flared with round borders. It then rises a little before reaching the fasciole at which it goes back nearly flush with the test. Beyond that, the groove sinks again to form an anterior notch that is very clear although shallow. Beyond the ocellar opening up to the fasciole, I measure $19 \mathrm{~mm}$. The pairs of plate number twenty. These plates are pentagonal with a very obtuse internal angle. They are notable by their length compared to their width. The first ones, extremely small, are a little wider than long, but the following become as long as wide and they finish by being a little longer than wide for more than half the length of the groove. The two plates crossed by the fasciole elongate abruptly. They are at least three times longer than wide. Beyond that, the plates widen and become larger while always remaining much longer than wide. The pores are geminate and near the external and anterior corner. They are very small but fairly separated from each other in each pair. The pores of the first six or seven pairs are reduced and simply located beside each other. In the following pairs, the two pores, more apart, are separated by a kind of very convex ridge in the form of an ovoid grain directed obliquely a little inward. A very faint circular imprint surrounds them. Beyond the fasciole, the pores at first remain double and very close to each other. Then they unite and the peripodia disappear. It seems to me that a structure similar to the dorsal ambulacral groove is seen in P. limicola of the BLAKE, to judge from the figure published by Agassiz (83, Pl. XXVI, fig. 6), but the text gives no information on this subject.

The petals extend up to the internal border of the peripetalous fasciole that is wide at this level. The posteriors are two times shorter than the anteriors. The latter form an angle of $40^{\circ}$ with the antero-posterior axis. The posterior petals, slightly divergent, make an angle of only $30^{\circ}$ with the same axis. Finally, the two petals of each side make an angle of $110^{\circ}$.

The anterior petals are not very narrow at their origin. But they widen very rapidly due to the slightly convex curve that follows the posterior poriferous zone. They reach a width of $5 \mathrm{~mm}$ that they keep to their distal end that is round. The sink gradually up to the area of the end without ever reaching a great depth. The interporiferous zone is a little narrower than each poriferous zone. The anterior poriferous zone has twenty-one pair of pores, of which the first seven are very small, while 
in the posterior zone, the first three pairs only are rudimentary. These pores are located toward the middle of the length of the plates. They are transversely widened and quite separated in each pair. The internal pores are oval and the external pores are virguliforme. The plates are completely flat and no ridge separates the successive pairs. A row of very small granules is found toward the proximal border of each plate, but in the external half only. The interporiferous zone is nearly bare.

The posterior petals are short and oval, thin inside and round at the end that is slightly narrowed. Their maximum width is $4 \mathrm{~mm}$. Each row contains nine well-made pairs and three rudimentary proximal pairs.

Immediately outside their petal, the four anterior and posterior ambulacra greatly narrow to their meeting with the fasciole. They then widen very slowly, but they always remain fairly narrow, especially the anteriors, while their plates to the contrary greatly elongate. The plates of the anterior petals each has a single primary tubercle with some spaced miliary granules. The tubercles continue onto the ventral surface with the same characters. To the contrary, the posterior ambulacra have, outside the fasciole, numerous primary tubercles completely identical in size and number to those of the adjacent interradius. They pass to the ventral surface keeping the same characters. But the primary tubercles disappear rapidly at the posterior end of the ventral ambulacra.

The anterior ambulacrum, a little sunken at the ambitus, narrows in reaching the ventral surface and remains still slightly sunken on the ventral part, which is moreover very short, except in the area of the peristome where it is flush with the test. It is narrow, but its plates, two pairs only, are very elongated. They have only miliary granules each with a small primary tubercle. The two primary plates that touch the peristome are not particularly narrow. The phyllode peripodia are three in number on each side.

The anterior lateral ambulacral, a little sunken at the ambitus, slightly rise in approaching the peristome but without become flush with the test. The first two pairs of plates alone have phyllode peripodia.

The posterior ambulacra that measure approximately $7 \mathrm{~mm}$ in width at several millimeters from the peristome, are wider than the ambulacra of the trivium. They have on their surface only rare miliary granules. The primary tubercles appear only beyond the fourth. The plates of the fifth pair reach a little beyond the posterior border of the two sternums. Plate Ia5 (or Vb5) takes a triangular form. It extends toward the median interradial line by a top that penetrates into the episternal corner where it also meets the internal end of the following plate, but this is much smaller. Moreover, after the latter, the plates of the internal series are much narrower than the external plates. This difference remains very noticeable up to the level of the upper border of the periproct, i.e., on plates Ia7-a11 and Vb7-b11. Plates 6, 7 and 8 each has a pedicel more developed than the others, but the difference is not very great and the peripodial imprint is scarcely differentiated.

The anterior and posterior interradial pairs have, on the dorsal surface and inside the fasciole, a triangular form. They are covered, outside the fasciole, by primary tubercles of small size that become still smaller in the immediate area of the fasciole. Inside it, the anterior interradii are very elongated and their top is very narrow, while in the posterior interradii, the top remains short and very wide. The primary tubercles of interradii 2 and 3 increase in dimensions in approaching the apical system and along the ambulacral groove.

On the ventral surface, the anterior interradii are fairly small. The second plate of each series passes the limits of this surface to pass to the sides of the test. The first plate of each interradius, in the form of a shoe, touches the peristome by a border whose width is nearly equal to that of the combined border of the two plates of ambulacrum III. The first plate of the posterior interradius is 
small and triangular. It extends as usual as a very narrow lobe to reach the peristome. The ventral surface is only covered to the left by plates $2 b$ and $2+3 a$ of interradius 1 , to the right by plates $2 a$, $2 \mathrm{~b}$ and $3 \mathrm{~b}$ of interradius 4 . Toward the ambitus, each of these plates has a fairly strong prominence, obtuse and round, identical to that we observe on the lateral surfaces. All these plates are covered with primary tubercles, larger than on the dorsal surface and denser on the two anterior interradii where their size remains uniform, than on the two posterior radii where their size decreases from the peristome.

On interradius 5, the primary tubercles remain very dense on the dorsal surface. They keep the same characters in passing to the posterior end of the test. However, the primary tubercles disappear or are hardly represented on a small median area that is found immediately below the periproct and that constitutes a small bare space limited on the lower side by the more or less rudimentary branch of subanal fasciole.

Outside the peripetalous fasciole, the plates have a large development, especially in the posterior interradius. They are covered with small primary tubercles, denser in the anterior interradii than in the posteriors. The plates have, on the lateral surface, each a round and obtuse prominence that is especially noticeable in the posterior series. In passing to the ventral surface, the tubercles become larger and less dense. They advance up to limits of the ambulacra.

The labrum has the form of a $\mathrm{T}$ whose transverse branch is narrow. The longitudinal branch is relatively fairly elongated, approximately two times longer than wide, and limited by the nearly parallel straight sides. The posterior border reaches exactly the end of the adjacent first ambulacral plate. The anterior side is a little convex. It is thick and ends in a projecting rim. But this does not form a very important protrusion on the ventral surface. Behind this thick border are some secondary tubercles. The two sternums are fairly elongated and narrow. They measure $22 \mathrm{~mm}$ in length and $6 \mathrm{~mm}$ in width at the base. The posterior borders of these two plates correspond approximately to the most swollen part of the ventral surface. They nearly reach the same level. Plate $a$ is however slightly ahead of the other. The primary tubercles that cover them are fairly small and dense. They are arranged in longitudinal and divergent rows. The two episternal plates that follow are unequal. Plate a3 is a little more developed and longer than the other. It encroaches on the median line. On the external side, these plates hardy pass the alignment of the sternums. They ae uniformly covered with small primary tubercles. Preanal plates 4-4 are, to the contrary, strongly widened transversely and pass the alignment of the preceding plate in a way to form an episternal corner that is in large part occupied by plate I a6 (or V b6) and also by a part of the plate following Ia7 (or Vb7) . These preanal plates are very unequal in length, plate a4 largely passing b4. This result in a very conspicuous alternation in the following plates. Both plates 5-5 contribute to limiting the lower border of the periproct, but plate $b 5$ touches the latter only by a very narrow side. The following plates of the series $a$, i.e., a 6 and a7 form by themselves the periphery of the periproct, while on the other side, it is limited by three plates 6,7 and 8 of series $b$. The following plates, that belong to the dorsal surface, constitute the posterior interradial prominence. The posterior branch of the peripetalous fasciole crosses plates a9 and b10. After the preanals, the width of the plates decreases gradually on the posterior surface and especially on the dorsal surface of the test. The border between the two surfaces nearly corresponds to the joining of plates 7-7 and 8-8. The posterior end of the body has the form of a triangle elongated vertically and a dorsal top, The base, fairly narrow, forms on each corner a wide prominence, low and obtuse, located toward the middle of each preanal plate. The following plates a5-a7 and b5-b8 have also each a similar projection but less accentuated. It attenuates toward the dorsal surface at the same time that the projection nears the periproct. 
The peristome (fig. 5) is slightly sunken, short and very wide. Its anterior border is not very convex. Its sides are rounded. In front, the ambulacra of the trivium and the interradii 2 and 3 contribute nearly equally to limit the periphery. The border of the first plate of each interradius 2 and 3 that touches it is perhaps a little wider than the sum of the borders of each ambulacal row. The peristome is covered with very numerous plates, irregularly polygonal and forming several more or less distinct series in which the size decreases from front to back.

The periproct (fig. 7 and 9) is much taller than wide and oval. The two ends each end in an obtuse point more accentuated at the top. The marginal plates are very large and not numerous along the upper border. Then they diminish very rapidly in size toward the lower part. The anus is located nearer the latter.

The peripetalous fasciole, whose path is slightly sinuous, reaches its maximum width a little behind the end of the anterior petals. In its anterior half, it follows approximately a demi-ellipse while remaining nearly parallel to the ambitus of which it is however a little nearer in front. Then, several millimeters behind the anterior petal, it forms an obtuse angle, at first following the posterior border of this petal. It then takes a very slightly concave form to reach the end of the posterior petal that it goes around. Finally, it is directed transversely to approach the median interradial line on which it connects to the opposite branch after having formed an obtuse angle.

The lateral fasciole is very little developed. It can even be completely rudimentary. On specimen $\mathrm{C}$ and on the other intact individual of station 274, there is, below the bare space that I reported above at the posterior end of the test, a very conspicuous ventral branch that curves at both ends to form a very short lateral branch. But this disappears before having reached the level of the periproct (fig. 7). This portion of the fasciole is very apparent in these individuals because of the deep color that contrasts with the much paler adjacent parts. In specimen A, the formation is less distinct. I can recognize only the left part of the lower branch that crosses the internal region of the preanal plate and then curves to produce a small branch that reaches plate a5 where it is fades away.

Nearly all the primary spines of the dorsal surface widen and flatten at the end in a very gradual manner. At the same time, the widened part raises its borders in a way to form a concavity turned upward. These spines are particularly developed the length of the petals and on the borders of the anterior groove and lean toward each other in a way to more or less cover the sunken parts. The length of these spines reaches 5 to $6 \mathrm{~mm}$. They are more developed on the anterior petals than on the posteriors. On the ventral surface most of the spines are missing or incomplete in the anterior or posterior interradii where they appear to remain rather cylindrical. To the contrary, on the sternum, they take again the form of a spatula and the widened end is more noticeable. It is done more abruptly than on the dorsal surface.

The miliary spines are more or less enlarged at the end, but this is due in large part to the thickening of their membranous part. The calcareous stem does not become much larger (Pl. XIX, fig. 1). A large number of these spines are bent toward the end in a very obtuse angle (fig. 2). Transverse calcareous rods develop on the terminal part in a series of teeth that are at first isolated but then are joined by anastomosis at the end of the spine. The calcareous stem of the clavules remains, to the contrary, straight for all its length. The terminal head is more or less three times wider than the stem.

The pedicellariae have the three types: tridactyle, rostrate and globiferous.

The tridactyle pedicellariae are thin and delicate with a very narrow, elongated head. They recall the small tridactyles that Mortensen represented in Brisaster fragilis (07, Pl. XIV, fig. 12) and in Echinocardium pennatifidum (Pl. XVII, fig. 26), without their being however, completely 
identical. The valves (Pl. XIX, 8, 9 and 10) are narrow and their basal part is remarkably short because it reaches only a tenth or a twelfth of its total length. The blade forms an extremely elongated spoon that widens very slowly and keeps nearly the same width up to the end that is round. Toward the middle appear teeth at first extremely thin and close together, conical and pointed. They progressively separate and elongate as they approach the end, while still remaining fairly thin. The perforations are large and oval, especially in the second half. In the larger pedicellariae, the length of the valves reaches $0.6 \mathrm{~mm}$. These pedicellariae are fairly widespread on all the surface of the test. They greatly resemble the narrow form of the tridactyle pedicdllariae that I have described above in Hemiaster Hickmani and vanus.

The rostrate pedicellariae are much less widespread than the preceding. I have mainly encountered them in the area of the periproct. They are very like those that Mortensen has figured in Schizaster orbignyanus (07, Pl. XIV, fig. 23). The valves are, however, a little thicker and relatively shorter. The blade does not completely reach twice the length of the basal part (Pl. XIX, fig. 13). It widens very slowly for the greatest part of its length, much more rapidly toward the end that ends in a convex border having about twenty fairly strong teeth, conical, pointed and fairly elongated. The perforations are large and oval. The neck is very short.

The globiferous pedicellariae are of large size. Their head measures at least $0.8 \mathrm{~mm}$ in length. They are fairly abundant and particularly widespread in the area of the peristome. They recall the globiferous pedicellariae described and figured by Mortensen in Brisaster fragilis (07, Pl. XIV, fig. 14 and 16). But the valves are more elongated and narrower in their distal half. They end in a curved and pointed hook, always single, having at its base the glandular opening (fig. 6 and 7), while according to Mortensen, there are two hooks in P. limicola (PI. XIV, fig. 1 to 4). The valves are surrounded by a membranous and pigmented envelop that is continuous with that of the stem. The head articulates directly with the enlarged end of the latter.

The peristomial pedicels, very developed, end a tuft of numerous digitations. I have not found spicules in the stem. The branches alone have their axial rod. The anal pedicels, that occur in the ambulacral plates posterior to 8 , are, to the contrary, not important. The have only a small number of digitations. The have the same structure as the preceding.

The frontal pedicels are very developed. Each ends in a rosette whose festooned border has nineteen to twenty small lobes, short and very obtuse. Each contains a small elongated plate measuring approximately $0.3 \mathrm{~mm}$ (fig. 11 and 12), while their width is fairly variable. These plates are sometimes bifurcated. The calcareous network is fine and delicate in the distal half that is more or less widened. The borders always remain smooth. The stem of these pedicels does not contain spicules.

The specimens in alcohol are brownish yellow in color. The fascioles are deep brown. The enlarged end of the spines is whitish.

Regarding the internal organization, I have been able to see that the digestive tube follows the same path as in Hemiaster Hickmani, but it is comparatively wider. It keeps the same very deep brownish color over its entire length, with no modification either at the level of the distal opening of the siphon or at the dorsal loop. The two gonads are little developed in the individual where I see them. They remain at the end of the posterior interradii.

Similarities AND DifFERENCES. - The limits of the genus Periaster are not very clear. The synonymy of the genus has been a little complicated by the paleontologists. Fortunately, the characters of $P$. limicola have been recently specified by Mortensen who has described the apical 
system, the pedicellariae, etc. I am of the opinion to give to this genus the significance that has been attributed to them by the Danish naturalist scholar.

The species of the Indian Ocean is incontestably very near $P$. limicola. It is completely logical to place it in the same genus. It is distinguished from the latter by its much lower anterior end and by the profile of the test, whose height increases gradually from the anterior end to the posterior end, this being relatively very elevated; by the very convex ventral surface; and by the more divergent anterior petals that causes a modification in the contour of the peripetalous fasciole. The pedicellariae also give some important characters. The tridactyles are very similar in the two species, but the globiferous have only one terminal tooth in the new species instead of two lateral teeth indicated by Mortensen in P. limicola, which constitutes a large difference. Since the time at which Mortensen published the second part of his remarkable studies on the echinoids of the INGOLF, other species have been referred to the genus Periaster. Agassiz had already described, under the name of P. tenuis (04, p. 200), a species collected by the ALBATROSS off Panama and that Mortensen did not mention in his work. Then Agassiz and Clark have made known another Periaster from the Hawaiian Islands, P. maximus (06, p. 259) and, the same year (06, p. 138), two other species from Japan $P$. rotundus and fragillus. None of these have been completely described and the American scholars have devoted only a few lines to them. It is thus very difficult to have an idea of their characters. $P$. rotundus has only two gonopores. Agassiz and Clark considered it as very close to $P$. linicola. $P$. fragilis is known only by an immature individual without gonadopores. Finally, there is only a fragment of the test of $P$ maximus and permits suggesting that the test had a total length of $110 \mathrm{~mm}$, but the number of gonopores is not mentioned. As for $P$. tenuis, it is very regrettable that Agassiz, while publishing some figures or photographs, has given only an imprecise and completely inadequate description of it. I am forced to admit that I remain very perplexed about the affinities of his species. If we understand the genus Periaster like Mortensen, it is certain that we could not introduce this echinoid with four gonopores. On the other hand, we know very little about the characters of the test and the pedicellariae are completely unknown. Regarding specifically Periaster Kempi, it is separated from $P$. tenuis first of all by the existence of only two gonopores, then by its shorter anterior petals, by the dorsal groove comprised of a fewer number of plates, by the more elongated test, more elevated in the posterior part and very low to the contrary in front, etc. There is nothing similar between the two forms.

I dedicate this new species to Stanley W. Kemp, Secretary of the Indian Museum of Calcutta.

\section{Paraster (Schizaster) gibberulus (Agassiz) et Savignyi (Fourteau)}

(Pl. VIII, fig. 1, 6, 10 to 15; Pl. IX, fig. 1 to 3, 11, 13 to 16; PI. XX, fig. 14 to 27)

Although these two forms are not represented in the collection of the Indian Museum, it seems to me indispensable to devote here some lines to them in order to better specify the limits of the genus Paraster, which is characterized mainly by the presence of four gonopores. Two specimens have been sent to me with the label Schizaster gibberulus. They were reported under this name by Anderson in 1899 ((99, p. 11). These specimens have four gonopores. I find, in addition, in the collection that has been sent to me, other similar echinoids but different from the latter, that have the same number of openings. All these species would formerly have been placed in the genus Schizaster. But we know that Mortensen, taking into account not only the number of gonopores, but also the form of the test, the characters of the pedicellariae, etc., has been able to establish in 
the old genus Schizaster, very natural sections to which correspond respectively the genera Paraster, Brisaster, Schizaster and Tripylaster. Now, the two species presently known in the genus Paraster are distinguished from all those included in the old genus Schizaster by the presence of four gonopores. If thus, we take this single character, the various species of the INVESTIGATOR to which I just referred, and that will be described below, should be placed in the same genus Paraster. But, as we shall see, they are separated by several important characters from the only two known species. So, I have been led to create, beside the genus Paraster, at least one other genus having like it four gonopores. It is thus important, before any description, to clearly establish the characters of the genus Paraster.

It seems that two distinct forms, although very close, have been confused formerly under the name Schizaster gibberulus. But from the point of view that interests us more particularly, the distinction of these two forms has only a secondary interest. Moreover, the history of $S$. gibberulus has been reviewed in detail in 1904 by Fourteau (04, p. 434-436) and I shall not return to it. I shall recall only that, according to this author, the type of $S$. gibberulus is lost, and that we have not found the form described and figured by Savigny that came from the Red Sea. All the individuals encountered by Fourteau in this sea have a more elongated form than in S. gibberulus. They correspond to figures 6 and 6a of Pl. VII published by Savigny in the Atlas de l'Histoire Naturelle de l'Egypte. Also, Fourteau believed it necessary to separate it under the name S. Savignyi. He applied this name to all the specimens that he collected in the Gulf of Suez. This author indicated in his memoir that the types he described were deposited in the Jardin des Plantes. Unfortunately, in spite of all the investigations that I have been able to make, and that Professor Joubin had already wanted to begin in the galleries of the Museum, it has been impossible to find these types that do not appear in any entry register. We can thus, up to the present, have an idea of the characters of S. Savignyi only by the figures of Savigny cited above, as well as by the description of the figures of Fourteau.

I must say, however, that the Jardin des Plantes possesses seven small specimens collected by Jousseaume in the Red Sea and were labeled $S$. gibberulus. I have examined these specimens that Joubin has kindly sent me. They correspond exactly to the $S$. savignyi of Fourteau.

Moreover, the Museum of Copenhagen has three Schizaster that Lüken has called $S$. gibberulus. Dr. Mortensen has kindly sent them to me. They have been very precious because they are larger than the specimens of the Museum. These three specimens can be referred to the form Savignyi of Fourteau. They agree very well with the description of this author. The respective lengths of the test are 23, 28 and $35 \mathrm{~mm}$. They do not reach, as we see, the dimensions of the specimens collected by Fourteau, in which the length varied between 40 and $53.5 \mathrm{~mm}$ and reached $71 \mathrm{~mm}$ in a variety major distinguished by this author. The four gonopores are already distinct in the individual of medium size that can thus be considered adult.

In addition, I have been able to compare to these specimens a Paraster that I have in my collection that was sent to me from New Caledonia. It is of fairly large size. Its length reaches 47 $\mathrm{mm}$. Its form is quite different from those of the specimens of the Museum of Copenhagen. It has a shorter and stockier test. I believe it preferable to refer it rather to $P$. gibberulus.

All these individuals are unfortunately dried. The test completely lacks spines. Thanks to the kindness of Rudmose Brown and J. Stimpson, I have been able to complete my study by examining a specimen collected by the latter at Kerimba. It is preserved in alcohol. Its length reaches $12 \mathrm{~mm}$. By its exterior form, this individual appears to me also nearer to $P$. gibberulus than to $P$. savignyi.

I cannot enter here into a detailed description here of these two species or into a discussion of their characters. I want to especially call attention to the peculiarities of the species presently 
accepted in the genus Paraster, in order to be able to establish useful comparisons with the close forms collected by the INVESTIGATOR. P. gibberulus and Savignyi greatly recall Schizaster canaliferus of our seas. They have, like it, an extremely deep and wide dorsal groove that determines in front a very conspicuous notch. The very deep anterior petals expand a little transversely to their origin. But they are not slow to curve to move obliquely forward. Their posterior border is very convex. The first third of the anterior border is covered by the projection that forms the anterior interradius. The ambulacral groove itself is constituted of extremely numerous and dense plates, very short, eight or ten times wider than long as in all the species placed formerly in the genus Schizaster. The successive pore pairs have some alternation. They are found sometimes more inward and sometimes more outward. The sternum is covered with extremely numerous and dense primary tubercles, rather small, arranged as usual in divergent series. The two sternal plates are large, wide and long. In the specimens of Copenhagen, $23 \mathrm{~mm}$ in length, that I represent in Pl. VIII, fig. 14, the length of these plates is $17 \mathrm{~mm}$ to the left and 18 $\mathrm{mm}$ to the right. Their maximum width, that is found toward the middle, is $7 \mathrm{~mm}$. The external border is very convex. The difference in length between the two sternal plates determine the alternation of the following plates that will continue on each side and above the periproct. The episternal plates 3-3 have nearly the same form and height. Plate a3 is a half-length ahead of plate b3. Preanal plates 4-4 extend toward the periproct (P1. VIII, fig. 12), but plate 4a, already in front of the other, elongates more and limits the lower border of the periproct, while plate b4 remains quite far from it. It is only plate b5 that touches the other side, at the lower edge of the periproct. The periphery of the periproct is completed on one side by plates a5, 6 and 7 and on the other by plate b6, 7 and 8. Plate 8 of series $a$ is no longer contiguous with the periproct. The two sternal plates have, at the posterior and interior angle, each a small conical projection very near the median line and its congener. The following plates up to the pair 6-6 have similar prominences, still rather near the median line on plates 3-3 and located toward the middle on the other plates. The lateral fasciole encounters these prominences on plates 4, 5 and 6 on each side.

Because of the convex form of the sides of the sternum, their posterior and external end is found nearer the median line than the middle part that is widened. This results in the formation of reentrant angle that is very round, whose other side is limited by the external borders of plates 3 , 4 and 5. The width of these increases gradually so that the external border of plate 5 is found nearly on the alignment of the widest part of the sternum. This episternal angle is filled by the ambulacral plates of adjacent series $1 \mathrm{a}$ and $\mathrm{Vb}$ and notably by plates 7, 8, 9 and 10 that are particularly widened. Each of these plates has, toward its internal border, a geminate pair surrounded by a small peripode. The two following plates 11 and 12 still have one. As, moreover, plate 5 is already a little enlarged and has a geminate pore, we see that there are in this region seven pedicels on each side. The two pores are always very close, often even combined. The anterior pore is much smaller than the posterior pore.

The apical system has interesting characters that have not been indicated by Fourteau. The smallest example from Copenhagen has only three gonopores. The left anterior, extremely small, is found exactly in front of the posterior opening on the same side and in the same alignment as it, while the right opening is not yet formed (Pl. IX, fig. 14). The middle specimen has four gonopores. The two anteriors are small than the two others. The left one is located, as in the preceding individual, exactly in front of the posterior left opening, while the right anterior opening is moved a little inside the alignment of the corresponding posterior opening (Pl. VIII, fig. 6). The right anterior gonopore has the same characters as that of the left. It does not have water pores. These are found exclusively on the madreporite that occupies the middle of the 
apical system. It is widely pear-shaped, a little wider than long, with a proximal end included a little to the right and in contact with the right anterior genital plate but not fused with it. The madreporite occupies all the space between the posterior genital plates and extend backwards for a length a little greater than a third of its total length. This plate represents evidential the posterior basal that appears here in a very apparent way and quite isolated from the other plates of the apical system.

As for the small specimens of the Jardin des Plantes, their length is between 17 and $9 \mathrm{~mm}$. The form of the test is a little different from that of the largest individuals of the Museum of Copenhagen. The anterior region is less flattened in relation to the posterior end that is also less elevated (Pl. IX, fig. 3 and 11). However, by the elongated body, they relate well to $P$. savignyi and they do not have at all the stocky and massive form of $P$. gibberulus. It is important to note that the apical system is moved a little more forward than in the specimens of Copenhagen. In the largest individual, it is moved to $9.8 \mathrm{~mm}$ from the anterior end, i.e., to 57/100 of the total length of the test instead of 64/100 indicated by Fourteau. The largest specimen, that exceeds $17 \mathrm{~mm}$ in length, still has only the two posterior gonopores (Pl. IX. Fig. 13).

The individual that I possess from New Caledonia (Pl. IX, fig. 1 and 2) is larger than those of which I just spoke. The length reaches, in fact, $47 \mathrm{~mm}$, the width $41 \mathrm{~mm}$ and the height $30.8 \mathrm{~mm}$. We can see, in comparing the photograph of the test in profile (Pl. IX, fig. 2), to that representing $P$. Savignyi from the Museum of Copenhagen (Pl. VIII, fig. 1) that the form is different. The test is shorter, thicker, its anterior part is more swollen and it recalls more the $P$. gibberulus represented by Savignyi in fig. 5a and 5b. The distance between the middle of the apical system and the anterior end is $29 \mathrm{~mm}$. The two gonopores on each side are fairly near each other (Pl. IX, fig. 16). The anterior openings are a littler nearer than the posteriors. The arrangement of the openings is symmetrical. Each of them occupies the angle of a trapezoid. The madreporite always remains distinct from the right anterior genital plate. It greatly widens behind the posterior genital plates and extends into the posterior interradius for a length greater than that of the apical system. The arrangement of the interradial plates at the posterior end is a little different from that I have indicated in the individuals from the Museum of Copenhagen. This is without doubt due to their larger size. The plates of the interradial series $a$ after the sternum are always in front of their congeners but none of the plates 4-4 reach the periproct. Although both are elongated upward, especially plate a4, the periphery of the periproct is thus formed by plates 5, 6, 7 and 8 of each side. These plates are arranged nearly symmetrically following plates 5-5 that limit a small part of the lower border of the periproct. The episternal angle is filled only by the ambulacral plates 7,8 and 9. Each of them has a geminate pore, as well as the two following plates. The sixth ambulacral plates also has a pore similar to the following. The anal pedicels thus number six on each side instead of seven. They are supported by plates 6 to 11, but no longer exist on pair 12-12.

Finally, the last individual that remains for me to discuss, and that is not the least interesting, is that J. Stimpson collected in the Kerimba Archipelago on the coast of Mozambique and that Rudmose Brown mentioned under the name Schizaster gibberulus (10, p. 44). Thanks to the kindness of Stimpson and R. Brown, I have been able to study this specimen that is in alcohol and has kept its spines. I did not believe myself authorized to strip the test, even only on one-half. My observations remain strongly incomplete. Nevertheless, I have been able to obtain some fairly interesting information and notably to study the pedicellariae that, up to now, were completely unknown in the genus Paraster.

The principal dimensions of the specimen were indicated by R. Brown. The test measures 42 $\mathrm{mm}$ in length. If it cannot be referred to $P$. gibberulus, which appears to me impossible to confirm 
in a formal manner in the present state of our knowledge, it is in any case a form extremely close to the latter and that is separated from, to the contrary, P. Savignyi. It also recalls the specimen from New Caledonia that I just discussed.

Seen from above, the test is less wide at the level of the apical system in the figure of Savigny, but when observed from the side, we find absolute this short, thick form indicated by this author and that we see in the photograph that I reproduce here (Pl. VIII, fig. 11). The structure of the apical system is a little different from that we have observed in the P. Savignyi from the Museum of Copenhagen. There is notably a considerable difference in size between the anterior and posterior gonopores (Pl. VIII, fig. 10). The latter have a medium size, a little large, and separated from each other by an interval that equals their diameter, while the anterior openings are extremely reduced, especially those of the left. The space that separates them is a little wider than we have observed between the posterior openings. They are very near the anterior border of the latter. The madreporite very narrow in the anterior part that advances in the form of a narrow wedge between the two posterior openings, elongates behind into the posterior interradius for a rather great distance at the same time that it gradually decreases in width.

The anterior gonopores are always smaller than the posteriors in the P. Savignyi that I have been able to examine. This also occurs in my specimen from New Caledonia that I referred to $P$. gibberulus, but the difference is far from being as great as in the specimen from Kerimba. What is the value of this variation and is it of specific importance? I cannot respond to this question that can perhaps be ignored because, for the moment it is especially important to clearly establish the limits of the genus Paraster. I am sorry nevertheless for not being able to examine the gonads of this individual. The anal pedicels number seven. The first is seen on the sixth ambulacral plate. The pedicel that follows on the seventh remains still rather developed.

Although the pedicellariae are not very abundant on this specimen, I have been able, nevertheless, to study them in a sufficient manner to state that they are near especially to those of the genus Schizaster in the restricted sense that Mortensen gave the term. Their characters thus confirm the affinities shown by the form of the test. I have been able to recognize the three forms: globiferous tridactyle and rostrate.

The globiferous pedicellariae are naturally the most characteristic. The head articulates directly with a stem that greatly widens a little before its end into a broad expansion of tronco-conic form. From the base of this leaves a small pedicle on which the head articulates (Pl. XX, fig. 15). This measures $0.55 \mathrm{~mm}$ in length. The valves (fig. 14, 16 and 18) have a structure similar to that we know in $S$. canaliferus, but they are a little thicker. The basal part exceeds the length of the terminal tube and is a little wider than in this latter species. The very wide glandular space extends up to the articulating part. The terminal opening is small and triangular, with round angles. The end of the valve has on each side three hooks, conical and curved backwards. These pedicellariae are seen mainly on the posterior end of the test and the area of the anal pedicel.,

The tridactyle and rostrate pedicellariae are encountered on the dorsal groove, in the area of the periproct and the peristome, as well as among the spines of the ventral surface. The rostrates have two forms that differ only in size. The length of the head reaches $0.45 \mathrm{~mm}$ in the largest (fig. 19). It does not exceed 0.2 to 0.3 in the smallest (fig. 20). The valves resemble those that Mortensen figured in S. canaliferus (07, Pl. XIV, fig. 26). The basal part is not clearly separated from the blade, especially in the small pedicellariae. The blade is relatively larger than in S. canaliferus. It ends in some very small, conical teeth, numbering five or six only. Its borders are not connected by crossbeams. 
The tridactyle pedicellariae have three rather distinct forms. The first recalls that of $S$. orbignyanus of which Mortensen represented a valve (ib., Pl. XIV, fig. 17). Their head reaches 0.3 $\mathrm{mm}$ in length. The blade is enlarged into a spoon wider than in S. orbignyanus and especially than in $S$. canaliferus where it remains very narrow for all its length. It has in its first half, or for twothirds of is length, lobes that are very developed, elongated and rather thin, with parallel borders while in the terminal third, these lobes are replaced with some conical, spaced teeth, that rapidly become very fine and dense on the round terminal border of the valve (Pl. XX, fig. 20 and 27).

In the other tridactyle pedicellariae, the valves that have nearly the same length as in the preceding, are a little wider. The blade has, in its first half or first two-thirds, some low teeth, conical and wide, and, in the terminal part, dense teeth, small, elongated and pointed (fig. 17).

Finally, there are very small pedicellariae, whose valves never exceed $0.2 \mathrm{~mm}$ in length and that in general are between 0.12 and $0.15 \mathrm{~mm}$ (fig. 21 to 25). The basal part equals a third of its total length. The blade forms a wide spoon whose borders have rather strong and conical teeth in the largest pedicellariae and that become very small in the smallest. The size of the teeth increases a little from the base to the top that ends in a tooth a little stronger than the preceding

The spines recall, as a group, those of $S$. canaliferus as R. Brown noted. The spines of the sternal plastron are very dense, arranged regularly in oblique rows and widened into spatulas at the end.

As a result of what we just said, the genus Paraster can have some variations. Some affect the plates of the apical system. Others concern the form of the test and these are fairly noticeable. Fourteau has used the latter to separate from $P$. gibberulus a second species which he even distinguished a variety major. We can wonder, on this subject, if the differences between $P$. gibberulus and $P$. Savignyi are much more important than those between the latter and its variety major. Perhaps, in summary, there is only a single fairly polymorphic species. The specimens that I have had in hand are too few and especially too incomplete, since only one had kept its spines, to be able to usefully discuss this question. Besides, I have never tried to make here a revision of the species of the genus Paraster. I have only wanted to clarify the characters of the genus in order to be able to compare it usefully to the related forms collected by the INVESTIGATOR. However, it seems essential to me to add to the diagnosis given by Mortensen of the genus Paraster that the test keeps the same fundamental structure as in other species of the old genus Schizaster. In particular, that the dorsal groove is formed of numerous, extremely short plates and that the primary tubercles of the ventral plastron are small and very dense. As for the globiferous pedicellariae, they are constituted as in the genus Schizaster s. str. and Paraster compactus, nov. sp. with their opening surrounded by several teeth ${ }^{2}$.

\footnotetext{
${ }^{2}$ This memoir was nearly completely printed and the plates were pulled, when I discovered in a small lot of dried echinoids coming from the Red Sea and that I had bought under the name Metalia sternalis, a small specimen of Paraster gibberulus relating in a remarkable way exactly to the figures of Savigny. The profile of the test, in particular, is absolutely identical to that represented in fig. $5 \mathrm{~b}$ of this author. The anterior region is comparatively thicker and taller than in the small specimens of the Jardin des Planes and in the two individuals of New Caledonia and Kerimba mentioned above. I am extremely sorry not to be able to give here a photograph of this specimen that I propose to study later with some details.

It has, in fact, a great interest because no Paraster conforming exactly to the figure of Savigny has yet been found and the type figured by this author has been lost. It is thus proven now that the figures of this author refer clearly to a form existing in the Red Sea.

I shall content myself to note here that the test I remarkable for the gibbous form and that its length is relatively small in relation to it width. It has the following dimensions: length $22 \mathrm{~mm}$; width $21 \mathrm{~mm}$; height $15 \mathrm{~mm}$.
} 
Paraster compactus, nov. sp.

(PI. IX, fig. 4 to 10 and 12)

Coast of Madras, 20 fathoms. - Two specimens. N 1893-94.

Bay of Bengal. 599 fathoms. - One specimen. $\mathrm{N}^{\circ} 8172$.

The specimens were labeled Schizaster gibberulus, but, as we shall report in the description that follows, this determination is incorrect, and it is certainly a new species. Unfortunately, the individuals are of small size and the test completely lacks spines. One of the specimens from Madras was completely macerated and its test, attacked by alcohol, is completely disarticulated. The other specimen had several fractures on the ventral and posterior surfaces. The specimen from the Bay of Bengal, that is the smallest, is nearly intact except at the posterior end. But it appears not to have acquired its definitive characters and the gonopores, which number four in the preceding specimen, are not yet formed in it. Whatever it is, it is possible to make a fairly complete description of these specimens and to compare them to the two known species of the genus Paraster in which, in appears to me, it is possible to place them. Although they come from very different depths, they certainly belong to the same species.

Here are the principal dimensions that I have been able to take:

\begin{tabular}{|c|c|c|}
\hline & $\mathrm{A}$ & $\mathrm{B}$ \\
\hline & $\begin{array}{l}\text { Larger specimen } \\
\mathrm{mm}\end{array}$ & $\begin{array}{l}\text { Smaller specimen } \\
\mathrm{mm}\end{array}$ \\
\hline Length. & 19 & 14.5 \\
\hline Nidth. ..................... & 17.4 & 14 \\
\hline 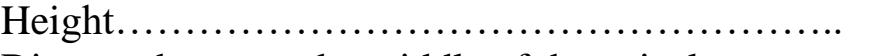 & & \\
\hline $\begin{array}{l}\text { Distance between the middle of the apical system } \\
\text { and the anterior border of the test. ............... }\end{array}$ & 13.2 & 10 \\
\hline $\begin{array}{l}\text { Distance between the middle of the apical system } \\
\text { and the posterior border. ..................... }\end{array}$ & 10 & 8 \\
\hline $\begin{array}{l}\text { Distance between the anterior border of the } \\
\text { peristome and the anterior border of the test. ...... }\end{array}$ & 9 & 6.5 \\
\hline Distance between the posterior border of the & 4 & 3.5 \\
\hline peristome and the posterior border of the test. ..... & 11.9 & 7.8 \\
\hline Length of the anterior petal. ......................... & 6.5 & 5.2 \\
\hline Maximum width of the anterior petal. . & 2.2 & 2.1 \\
\hline
\end{tabular}

The two anterior gonopores are not very much smaller than the posteriors and they are not very near to the latter. Here are the measurements I have taken on the apical system:

Diameter of the anterior gonopores.

$\mathrm{mm}$

Diameter of the posterior gonopore.

1.6

Distance between the centers of the anterior openings.

1.9

Distance between the centers of the posterior openings.

0.7

Distance between the centers of the anterior opening and the posterior opening of the same side. 
Length of posterior petal. .......................

3.2

2

12

$3.2 \times 1.3$

$3 \mathrm{X} 2$
2.6

1.5

9

$3 \mathrm{X} 2$

$2.2 \mathrm{X} 1.8$

I shall describe the species mainly according to the specimen from Madras, despite its bad state, and completing the description when necessary by the smallest individual.

The body is globular, short, stocky, wide and tall. Seen from the dorsal surface (Pl. IX, fig. 5 and 8 ), the test has a regular and convex contour from the anterior end that is fairly weakly notched by the ambulacral groove, up to the middle of the body where the maximum width is attained. This width then decreases rapidly up to the posterior end that is more pointed in the large individual than in the small. The apical system is sub-central, a little nearer the posterior end. Seen in profile (fig. 4 and 12), the test has in front a very convex contour. The anterior end, thick and tall, passes to the dorsal surface by a very round border. The height of this surface increases gradually up to the level of the apical system after which it increases still a little, but very weakly, up to a third or to the middle of the posterior interradial prominence, where the test reaches its maximum height. Behind this prominence, the profile decreases and joins the posterior surface by a very round curve. The ventral surface is very convex from front to back. It rises to the end of the sternum in a small prominence and joins by an obtuse angle the posterior surface that is vertical.

The two anterior gonopores are very far apart and smaller than the posteriors to which they are very close (fig. 10). The two genital plates are narrow and broadened transversely. The left plate is small and the opening is found in its middle. The right plate, elongated in the interradial direction, is continuous with the madreporite that is short, hardly as long as wide, and occupying only half the space separating the posterior genital plates that it hardly passes. These latter are narrow, much wider than long and directed obliquely outwards. The posterior openings are a little more separated than the anteriors. The ocellar plates are small and triangular.

The anterior ambulacral groove is not very deep (fig. 7 and 8). Its sides, slightly oblique, continue outside by fairly projecting edges. It measures approximately $3 \mathrm{~mm}$ in the widest part. The plates that constitute it remain very short for approximately three-quarters of the length between the apical system and the peripetalous fasciole. I count twenty-two pairs of plates over this interval in the large individual. The successive pairs of pores are rudimentary and scarcely visible on the first three or four plates. They remain very near each other over the largest part of the groove. The peripodial imprints are nearly contiguous but the five or six pairs preceding the fasciole are separated more and more from each other. The poriferous zones are very near the sides of the groove. They are, as a consequence, strongly separated from each other The two pores of each pair, separated by a fairly wide projection, are found nearly on the same transversal alignment. The two rows of pores of each side keep a very regular alignment. The internal pores are often doubled in the middle part of the groove. Immediately inside the pores is a small, more or less regular row of secondary tubercles, only one per plate. In the anterior region some similar tubercles are added, not numerous and generally a little smaller. All the interporiferous space is occupied by miliary granules that form very regular transverse rows, only one per plate at first then two in the anterior half of the groove. 
The anterior petals take first an exactly transverse direction in relation to the antero-posterior axis of the body. Then they curve and form an angle of $40^{\circ}$ with this axis, while the posterior petals keep the same direction their entire length and make an angle of $30^{\circ}$ with interradius 5 . The two petals of the same side make together an angle of at least $110^{\circ}$. The interior petals are very thin at their origin because of the development of the anterior interradial areas that push their anterior wall backward. The anterior border is a little convex over a good part of its length. But it becomes fairly round in the terminal region. The posterior border forms, to the contrary, a very pronounced curve toward its first anterior quarter. The pore pairs number twenty-four. But those of at least the first ten remain very small in the posterior poriferous zone, while in the anterior zone, the first six or seven pairs only are rudimentary. The interporiferous zone is narrower than each of the poriferous zones. The successive pore pairs are separated by a non-projecting line on which we see a row of small granules, but only between the external pores.

The posterior petals are oval and round outside. Their anterior poriferous zones contain thirteen pore pairs of which the first five o six are malformed. The posterior zones contain fourteen, the first six likewise rudimentary. The structure is the same as those of the anterior petals.

The anterior interradial areas of the dorsal surface are elongated and narrow inside the fasciole. They are strongly narrowed in their proximal part that is very projecting. They encroach very little on the anterior border of the anterior petals and never completely hide the anterior poriferous zone. Only a few pores of the external row are invisible when we look at the animal from above. But those of the internal row remain always visible. The paired posterior interradii are very short and less projecting at their origin than the preceding. Finally, the projection formed by the posterior interradius is not very noticeable. It widens in attenuating gradually outside the fasciole to continue with the posterior end of the body.

The unpaired anterior ambulacrum, that narrows beyond the fasciole, remains very narrow on the ventral surface up to the peristome. The two plates 1-1 are extremely reduced in their part adjacent to the peristome. The anterior of the latter is in large part limited by the first plate of each of the interradii 2 and 3 that is extremely large. The peristome is not sunken. The five ambulacra remain flush with the test at the moment they approach it. The left and right ambulacra are very wide near the peristome and the posterior ambulacra keep a relatively fairly large width for the entire length. Some fairly developed tubercles occur at the beginning of ambulacra II, III and IV. In addition, the left and right anterior ambulacra acquire at the ambitus, some large primary tubercles as developed as the adjacent interradial tubercles, and that are continued on the lateral surfaces of the test. Except for some secondary tubercles that exist in the area of the peristome, the posterior ambulacra have scarcely anything other than miliary granules up to the ambitus, where appear some primary tubercles that pass to those of the dorsal surface.

The labrum has the usual T form (Pl. IX, fig. 5 and 9). It narrows to the origin of its posterior branch. Its two sides then diverge. It is nearly as long as wide. Its posterior border does not quite reach the end of the adjacent first ambulacral plate. Its anterior border, slightly convex, turns toward the bottom to form a fairly projecting lower lip. The plates that follow it in interradius 5 are more distinct and better preserved in the small specimen (fig. 9). The two sternums are very elongated. The left one is a little longer than the right. This produces the alternation of the two following episternal plates. Both the latter have the same form and same length. They are polygonal with the two large sides parallel and a narrow angle whose top is on the median line. All the plates that follow have the same length in each pair and they continue to alternate regularly on the posterior surface (fig. 7), then on the dorsal surface (fig. 8) of the test, those of series $a$ always before their congeners of series $b$. 
The episternal corner is very obtuse on the small individual (fig. 4). It is however quite apparent as well as the enlargement of the corresponding ambulacral plates. Perhaps this corner would be more accentuated on the large individual, and would recall then the very conspicuous corner that exists in P. Savignyi (Pl. VIII, fig. 15), but this part of the body is missing in this specimen.

There is a very great difference from the point of view of the dimensions and the number of tubercles between the dorsal surface and the ventral surface. The tubercles remain, in fact, small and dense on nearly the entire extent of the first principally inside the fasciole. They become naturally a little larger on the prominent parts of the interradii in the area of the petals and the length of the anterior groove. But, outside the fasciole, they always remain very small in all the posterior half of the test. It is only on the lateral parts of the anterior region that they become larger and merit the name of primary tubercles. Their dimensions increase when they pass the ventral surface on which they become remarkably large, especially in the anterior interradii 2 and 3 and on the anterior region of the two posterior interradii. But, on the latter, their size rapidly decreases. On the plastron sternum, they form, as usual, oblique rows from the posterior corner and rapidly increase their dimensions in a way to become very large (fig. 6 and 9). They remain few in number, but they do not quite attain the dimensions of the large tubercles that we see on the two anterior interradii.

The peristome (fig. 6 and 9) is large and especially very wide. It has an anterior row of only six extremely large, triangular or rectangular plates. Behind, the plates are much smaller, but not numerous. The periproct (fig. 7) is vertically elongated, longer than wide and in the form of an oval with a point at its two ends. The anus is nearly in the middle.

The peripetalous fasciole keeps, on all its path, a large width. It is particularly wide in the parts around the end of the petals to which it remains exactly contiguous. Its path is not very angular. After having crossed the anterior groove a little behind the ambitus, it curves parallel to it, then takes a nearly rectilinear path in crossing the anterior interambulacral pair. Behind them, it forms a very conspicuous obtuse angle, then follows a slightly concave curve and approaches the ambitus to bypass the end of the posterior petal. It crosses the posterior interradius and becomes slightly convex. The plates of the lateral interradii have, on its path, each a small prominence that is not very pointed.

The lateral fasciole detaches from the peripetalous fasciole at the angle the latter forms behind the anterior petals. It always remains extremely narrow. It follows, on the sides of the test, a slightly convex curve that is strongly accentuated when it approaches the posterior end and is rapidly directed downward to join the opposite branch at a fairly great distance below the periproct and forming a fairly narrow angle in the form of a $\mathrm{V}$.

The test is pinkish gray in the large specimen, while it is greenish gray in the small.

SIMILARITIES AND DIFFERENCES. - The two individuals that I just described were labelled, as I said above, Schizaster gibberulus. Anderson had reported them under this name in his reports on the campaigns of the INVESTIGATOR (99, p. 11). The character which this author based his determination was evidently the presence of four gonopores because, during the period when Anderson published his note, $S$. gibberulus was the only known form of the genus (understood in its broadest sense) that had four gonopores. A slightly attentive examination would certainly permitted avoiding this error, because all the other characters of the specimens separate them from $P$. gibberulus, even if we give this species a very extended sense. The test is stockier, shorter and more elevated than in $P$. gibberulus. Its anterior region also is less thin. Moreover, the apical system is moved forward and the primary tubercles of the ventral surface acquire a very great size. 
We could even wonder if the species should be maintained in the genus Paraster. But if we consider that the individuals of small size, like those of the Jardin des Plantes, have relatively short and stocky tests, with the apical system fairly near the middle of the body, we shall consider without doubt that the characters taken from the form exclusively do not have a generic importance here, and should be used especially for the separation of the species. If we compare, in fact, the photograph representing one of the specimens of the Museum (Pl. IX, fig. 3 and 11) and the new species of the INVESTIGATOR (fig. 4, 5, 8 and 12), we see that the differences in the exterior form are not very important ${ }^{3}$. But it is no longer the same for the other character that seems to me to have a fairly great importance, and that is related to the size of the primary tubercles on the ventral surface and their arrangement on the plastron sternum. While these are relatively small, always numerous and dense, not only in Paraster Savignyi and gibberulus, but also in all the species of the old genus Schizaster considered in its broadest sense, we note, to the contrary, that in our species, the plastron has only very large tubercles, few in number and spaced. The difference is striking if we compare the photographs reproduced in Pl. IX, fig. 6 and 9 to that of P. Savignyi from Copenhagen (Pl. VIII, fig. 14) ${ }^{4}$. In the small individuals of the Museum, the primary tubercles of the sternum are comparatively a little larger, but they are always more numerous and smaller than in $P$. compactus. In the latter, the plastron is, moreover, narrower and the posterior ambulacra are wider than in $P$ Savignyi. We shall find, moreover, the same arrangement of the sternal tubercles in the two other species that I shall describe below, classifying them in a different, new genus. But the creation of the latter will be justified by other characters that are not possessed by $P$. compactus and that are furnished notably by the plates of the dorsal ambulacral groove. Here, the plates of the groove have exactly the same characters, not only in the genus Paraster but also in the different genera dismembered by Mortensen in the old genus Schizaster. Moreover, the anterior and posterior gonopores are very close together in our species, while the two openings on each side are widely separated. This character recalls that which exists in the specimens from the Museum of Copenhagen and Kerimba, while the arrangement is different in the specimen from New Caledonia. Thus, we cannot find generic differences in the structure of the apical system. Finally, as the two specimens are of small size and in such bad state that it was impossible for me to make a complete study of them, I have believed it necessary to keep them in the genus Paraster. But we see that they differ greatly from the known forms of this genus and the peculiarities that I have just emphasized, i.e., the short, compact form and very tall test that is even stockier than in $P$. gibberulus, and the very large primary tubercles, not numerous and fairly spaced, that exist not only on the plastron sternum, but also on the interradial pairs of the ventral surface clearly characterize the new species.

\section{Prymnaster nov. gen.}

The genus Prymnaster is very close to the genus Paraster. It has, like the latter, four gonopores. It is distinguished by the form of the test and by the plates of the dorsal ambulacral groove. The latter, instead of being very short, dense and numerous as we know in the genera Paraster,

\footnotetext{
${ }^{3}$ These differences are even less important if we take for comparison the $P$. gibberulus of which I spoke in the note above.

${ }^{4}$ The same difference is also seen in the $P$. gibberulus from the Red Sea.
} 
Schizaster, Brisaster and Tripylaster, are not numerous and nearly as long as wide. Moreover, the pores of the groove, always arranged by pairs, are small, fairly separated from each other, arranged obliquely and surrounded by an inconspicuous peripodial imprint. The groove itself is shallow. It forms on the anterior border of the test only a very inconspicuous notch. The unpaired posterior interradius extends backwards in a kind of beak that protrudes above the periproct and overhangs the posterior surface. The peristome is covered by a very small number of large plates. The anterior petals are elongated, rectilinear and very divergent, quite separated from the anterior groove. The posterior petals are short. The apical system is subcentral. The primary tubercles of the sternal plastron are large and relatively very few in number. In the specimen that I consider the type of the genus, the test is short, thick, stocky, very tall and nearly as wide as long. The globiferous pedicellariae have valves ending in two large pointed hooks.

It appears necessary to me to separate the new genus from the genus Paraster in which Mortensen has placed the Schizaster possessing four gonopores. The differences that I see are, in fact, too important to permit a union that would be based on only the latter characteristic. The form of the test, thick in the anterior region and generally very short, the extension in the form of a beak above the posterior end, the relatively narrow, shallow dorsal groove, the divergent anterior petals and, finally, the subcentral position of the apical system constitute essential differences with the genus Paraster. But the most important character appears to me to be offered by the structure of the dorsal anterior ambulacrum that contains only a small number of plates. These are large and elongated. They contrast with the extremely short, numerous and dense plates that constitute the groove in all the species of the old genus Schizaster.

\section{Prymnaster angulatus nov. sp.}

(Pl. X, fig. 1 to 8 ; Pl. XX, fig. 44 to 49 )

Station 247. $-27^{\circ}$ N.: $71^{\circ} 41^{\prime}$ E. $56-58$ fathoms. - Thirteen specimens. $N^{\circ} \frac{398-410}{7}$.

The jar that contained these individuals was labeled Schizaster angulatus. I happily keep this specific name, but these echinoids cannot be maintained in the genus Schizaster. I make them the type of the new genus Prymnaster, whose characters I have just given.

Some specimens are entire and have their spines. Others are in poor condition and five of them are even reduced to very incomplete fragments, mainly of the dorsal surface. The length of the test varies between 20.5 and $12.5 \mathrm{~mm}$.

I shall describe this species after two individuals, of which one reaches $20 \mathrm{~mm}$ (A) and the other (B) $17.5 \mathrm{~mm}$ in length. The latter lacks the ventral part of the test. I indicate in the following table the principal dimensions of these two individuals, as well as those of two others, of which one (C) has the same length as B but with a little narrower test and a last (D) of small size.

\section{Specimens}

\begin{tabular}{|c|c|c|c|c|}
\hline & $\begin{array}{c}\mathrm{A} \\
\mathrm{mm}\end{array}$ & $\underset{\mathrm{mm}}{\mathrm{B}}$ & $\begin{array}{c}\mathrm{C} \\
\mathrm{mm}\end{array}$ & $\underset{\mathrm{mm}}{\mathrm{D}}$ \\
\hline (2) & 20 & 17.5 & 17 & 12.5 \\
\hline Width. ................................... & 18.4 & 15.5 & 14.4 & 10 \\
\hline Height at the level of the apical system. ........ & 15.8 & $?$ & 11.5 & 9 \\
\hline Height of the posterior end. ................... & 13 & 10 & 10 & 7 \\
\hline
\end{tabular}




\begin{tabular}{|c|c|c|c|c|}
\hline $\begin{array}{l}\text { Distance between the middle of the apical } \\
\text { system and the anterior end of the test.... }\end{array}$ & 11.5 & 10 & 9.5 & 7 \\
\hline $\begin{array}{l}\text { Distance between the middle of the apical } \\
\text { system and the posterior end. .............. }\end{array}$ & 8.5 & 7.5 & 6.5 & 5 \\
\hline $\begin{array}{l}\text { Distance between the anterior border of the } \\
\text { peristome and the anterior end of the test. }\end{array}$ & & & & \\
\hline $\begin{array}{l}\text { peristome and the anterior end of the test. } \\
\text { Distance between the posterior border of the }\end{array}$ & 5 & $?$ & 2.5 & 2 \\
\hline peristome and the posterior end of the test. & 14 & ? & 12 & 9 \\
\hline Length of the anterior petal. ..................... & 10 & 9 & 8 & 5 \\
\hline Width of the anterior petal. ..................... & 3 & 2.7 & 2.6 & 1.5 \\
\hline Length of the posterior petal. ..................... & 7 & 4 & 4 & 3 \\
\hline Width of the posterior petal. ................... & 2.5 & 2 & 2 & 1.2 \\
\hline Width of the dorsal ambulacral groove. ........... & 3 & 3 & 2.8 & 2 \\
\hline Length of the peripetalous fasciole. ............ & 16 & 14.5 & 14 & 10 \\
\hline Width of the peripetalous fasciole.............. & 14 & 12.5 & 12 & 9 \\
\hline Peristome (with and length). ................. & $4.2 X 4.5$ & $?$ & $3.6 \mathrm{X} 1$ & $3 \times 0.8$ \\
\hline 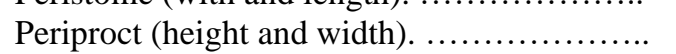 & $3 \mathrm{X} 2$ & $3 \mathrm{X} 2.5$ & $2.5 \times 1.8$ & $1.4 \mathrm{X} 1$ \\
\hline
\end{tabular}

The body is remarkably short stocky, compact and tall. Seen in profile (Pl. X, fig. 7), the anterior surface rises at first nearly vertically. It follows a convex curve to join approximately 4 $\mathrm{mm}$ behind the anterior border of the ventral surface, the dorsal surface that is very elevated. The latter remains nearly horizontal up to the level of the distal end of the posterior petals. Then it turns little by little and abruptly stops above the periproct. It extends beyond the posterior surface and forms a kind of small beak, short and obtuse, that extends backwards over this surface. This is nearly as tall as the anterior region of the test. It is vertical and has, in its upper part, the periproct, under which it is excavated. Then it joins the ventral surface by a very round angle. This surface remains horizontal before the peristome but, behind the lower lip that is fairly projecting, the profile of the test is a little swollen. See from above (Pl. X, fig. 1 and 3), the dorsal surface has in front a shallow notch. On each side of this, it follows a very convex curve while rapidly widening. It reaches its maximum width a little behind the apical system, toward the middle of the posterior interradius. From there, it narrows rapidly up to the posterior end that is narrow. The contour of the test is a little angular and we can distinguish notably an obtuse corner immediately outside the anterior groove and another, more noticeable, where the body is widest. The plates of the two posterior interradii have, on both sides of the median line, each a small round prominence. The apical system is subcentral and a little nearer the posterior end. The anterior groove is narrow and fairly shallow. The petals are likewise shallow. The two anterior petals are very widened. They develop in a straight line without any inflexion. The interradial pairs become fairly projecting in the area of the apical system, without forming however very noticeable prominences.

Seen from the ventral surface (fig. 4), the test has a more regular and less angular contour than the dorsal side and the anterior groove has only a very shallow and round depression at the ambitus. The apical system (fig. 1 and 8 ) is small and located on a horizontal area that is limited in front and on each side by the prominent tops of the lateral interradial areas and behind by the posterior interradius that is less projecting. This flat area is lowered at the level of each radius to continue with the petals that are deeply sunken. The anterior genital plates are small and elongated, longer than wide, with a pentagonal contour. The openings are round, very small and near their internal angle. The posterior plates are wider and shorter, as long as wide and rather triangular in form. Their openings are scarcely larger than the preceding and a little nearer the proximal top. The four pores are located at the angles of a rectangle. The space that separates the anterior and posterior pores is a little smaller than that which separates the two pores of each pair. The right anterior 
genital plate is nearly identical to the left plate and it is not invaded by the aquifer pores. The madreporite, very narrow in front, is pear-shaped. Its anterior half moves, like a wedge, between the two posterior genital plates. Behind, it widens and develops in the unpaired interradius over a length equal to half the apical system. Its pores are localized in a central triangular area outside of which there is a fairly wide border. The proximal part of the madreporite is very narrow, and we have the impression that it represents an independent plate, which is the fifth basal, fused by its anterior corner to the right genital plate. The ocellar plates are of average size, triangular with a round opening.

The dorsal ambulacral groove is not very accentuated. Its walls are oblique. Its depth decreases even before it reaches the peripetalous fasciole. Beyond this fasciole, which is moreover very near the anterior end of the test, the groove becomes narrower and rises more and more in a way that it forms in front only an unimportant notch. Its apparent depth is mainly due to the ridges formed by the adjacent interradii. Very small granules, dense and round, cover all the surface. We observe in addition, on each plate, two small secondary tubercles that constitute a fairly regular row inside each poriferous zone. The plates of the groove rapidly elongate. They are relatively few. I count sixteen pairs only on the dorsal surface of the test. The fifteenth is crossed by the fasciole. These plates are pentagonal, one and a half times wider than long. But the last pair or the last two pairs that precede the fasciole are as long as wide, and even a little longer than wide. As for the pair crossed by the fasciole, it is nearly two times longer than wide. The pores near the external border are extremely small and one could even say completely rudimentary on the first plates. They become again fairly small on the plates that precede the fasciole. In the middle region, the two pores of each plate, placed obliquely in relation to each other, are fairly separated. The anterior pore is a little elongated in the direction of the anterior border of the plate which it nears. Sometimes it can split. The two pores of the same pair are separated by a small round grain, a little prominent. It is surrounded by an inconspicuous peripodial circle.

The anterior petals form an angle of approximately $50^{\circ}$ with the antero-posterior axis, and posterior petals, an angle of $30^{\circ}$ with the same axis. The two petals of each side make together an angle of $100^{\circ}$. The anterior petals, thin at their origin, widen gradually over approximately threequarters of their length. They reach a width of $3 \mathrm{~mm}$, then they narrow a little, but their distal end is round. The anterior border is a little more convex than the posterior border that is nearly straight. The entire ensemble remains rectilinear and their proximal part is not curved. The poriferous zones are wide, while the interporiferous zone is very narrow. The successive pores are separated by a transverse row of very small and dense miliary grannules, applied the length of the proximal border of the plate. The interporiferous zone has only a very small number of granules. I count twentythree pairs of pores in the specimen A and twenty only in specimen B. The posterior petals, much shorter, especially in the small specimens, are fusiform, narrow and pointed at their origin. The maximum width is toward the middle. I count in each poriferous zone fifteen pairs of pores in individual A and only eleven to twelve in individual B.

The plates of the anterior ambulacrum that are found outside the fasciole become narrower than the preceding. They are always longer than wide. There are only three pairs in all. They have some primary tubercles that continue onto the ventral surface up to the area of the peristome. On the anterior lateral ambulacra, the width remains nearly the same outside the fasciole up to the ambitus. It decreases only a little in reaching the ventral surface. Their plates also have some primary tubercles that become more numerous and denser on the posterior ambulacra. These tubercles disappear on the posterior ambulacra that remain nearly bare after the posterior end of 
the ventral plastron and hardly have anything other than milliary granules except in the area of the peristome, where the first two or three plates each has a primary tubercle.

In a general way, the ambulacra are very narrow on the ventral surface. The anterior ambulacrum, slightly sunken at the ambitus, becomes flush with the test in the area of the peristome. The first plate of each row strongly narrows in approaching the latter. It only touches it by an extremely narrow border, while the first plate of the anterior interradius is very enlarged and takes the form of a shoe. The lateral ambulacra II and IV keep nearly the same width on the ventral surface of the test. They narrow only very gradually in the area of the peristome. The posterior ambulacra that are narrower than the anterior ambulacra, are very slightly widened in the area of the peristome. Then they remain very narrow up to the level of the posterior border of the sternum. Beyond this, the fifth plate of each internal row widens in forming a convex, round lobe that fills the episternal angle. But this widening is of little importance. It does not persist on ...192 ... the following plates. It is at the level of the fifth plate that the primary tubercles appear, which will continue on the sides and on the dorsal surface of the test. The primary tubercles, identical to those of the adjacent interradii, appear on the first plates of the anterior ambulacrum. They exist also, although a little smaller, on the left and right anterior ambulacra in the area of the ambitus where they equal the adjacent interradial tubercles. As for the posterior ambulacra, they have as usual only miliary granules for nearly their entire length. They acquire primary tubercles only at their posterior end. The phyllode peripodia appear only on the first pair of plates of each radius. On the dorsal surface of the test, the two anterior interradii each form a triangle with an elongated and narrow top. They are very projecting toward the top as well as the length of the anterior groove where they have rather large and dense tubercles forming two or three irregular rows. These tubercles become smaller in approaching the peripetalous fasciole. Then their size increases again outside it and in the area of the ambitus.

The two posterior interradii are extremely short, but they remain very wide inside the fasciole. Their tubercles are arranged as on the preceding. On the dorsal surface and the sides of the test, each plate rises in a small conical and obtuse very conspicuous prominence, closer to the median interradial line, especially in the posterior rows where these prominences are also more noticeable. Similar tuberosities exist also on the anterior interradii, but they are much less accentuated. The unpaired posterior interradius forms a less pronounced projection than the others. But this one extends up to the upper and posterior corner of the test and overhangs the posterior surface as I said above. The tubercles that it has are larger in the area of the apical system. They become smaller toward the fasciole. Then, beyond that, their size increases again and they remain from there fairly large and dense on all the rest of the dorsal surface up to the posterior end of the test.

On the ventral surface (fig. 4), the anterior interradial zones are fairly short because of the position of the peristome. The first plate of each interradius, in the form of a shoe, is relatively very wide in its posterior region. It limits a good part of the anterior border of the peristome. It has, in its distal half, some primary tubercles. Outside, we see on the ventral surface of the test only plates 2-2 of each series that are covered with large primary tubercles identical to the preceding. In the paired posterior interradii, the first plate is small, very narrow inside as usual. Its tubercles rapidly become small toward the ambitus.

The labrum is very short. It does not pass the first third of the adjacent ambulacral plate. It has only a few secondary tubercles. Its anterior border is swollen, slightly convex and smooth. It encroaches a little on the peristome by a fairly weak projection directed obliquely forward. It is connected by very narrow corners to the posterior part of the plate that is two and a half times narrower than the lower lip. The two sternal plates, very elongated and narrow, extend nearly up 
to the point that limits the ventral surface in the back. The plate of series $a$ passes the other. On the contrary, in the two episternals that follow, plate $a$ is extremely small and narrow, while its congener is much larger. From the sternal prominence leave, as usual, oblique and divergent rows of primary tubercles that become larger and larger. Episternal plate $b$ is large and tall, much wider than long. However, its anterior border has the same width as the base of the adjacent sternum, but its posterior border is much shorter and it is directed obliquely inward. This results in the formation of an episternal angle, moreover not very deep, that is less emphasized to the right. Plate a3 is, to the contrary, very short because of the extension of the corresponding sternum. Its posterior border nearly reaches to the same level as that of plate b3. Plates 4-4 that follow are larger and elongated, especially a4, a little taller than wide. They reach the periproct, plate b4 by its upper angle and a4 by a truncated top, forming a distinct small side. Each of them has, toward its middle, a small conical and round prominence that is found in the path of the lateral fasciole. The periphery of the periproct is completed by plates 5, 6 and 7 on each side. The upper region of plates 7-7 meet on the median line. They go beyond the periproct and form a kind of short beak that I reported above and that overhangs the posterior end of the test.

The peristome (fig. 4) is slightly sunken and directed a little obliquely forward. It is very short and relatively wide. In individual A, it is nearly completely covered by three plates that are very large and triangular, on both sides of which is found a much smaller plate occupying the side. Some other very small plates are located the length of the posterior border, completely covering the peristome. I have said above that the lower lip makes only an inconspicuous projection and its free border is slightly swollen.

The periproct (fig. 6) is located on the portion of the posterior surface of the test that is directed a little obliquely inward and that is surmounted by a prominence in the form of an obtuse beak terminating the dorsal surface. It is of average size, taller than wide, and terminates at both ends in a point that is more or less noticeable. It is covered by very numerous plates, among which we distinguish a larger marginal row. The anus is located near the middle, a little nearer however the upper corner.

The peripetalous fasciole has a very angular path. I think that it is this character that Anderson wanted to recall in the name angulatus that was used to label the specimens. Most of the angles that we see correspond to the interradial prominences reported above. The fasciole remains fairly narrow for its entire path. It is very near the anterior end of the test. Its round anterior branch crosses the dorsal groove at the level of plates 4-4. Then it is directed backward, nearly parallel to the anterior groove, up toward the middle of it. Then it abruptly makes a curve of approximately $90^{\circ}$, to be directed toward the end of the anterior petal that it goes around, following an acute but rounded angle. It then runs parallel to the posterior border of the petal. But, at the height of the apical system it makes an obtuse angle to approach the posterior petal that it accompanies for some distance, goes around its end in forming an obtuse angle. It is finally directed toward the median interradial line nearly parallel to the posterior border of the petal. It crosses this line to join the opposite branch in forming an obtuse angle. During all this path, the width of the fasciole does not change much. It increases only a little at the end of the anterior petals.

The lateral fasciole leaves the peripetalous fasciole at the level of the external third of the anterior petals, toward the prominence of the last plate of the rows there 1a (or 4b). From there, it is directed toward the posterior end of the test approaching little by little the ambitus. When it approaches the posterior surface, it is inclined downward, goes around the periproct at a fairly short distance from it and following the prominences of the posterior interradial plates 4-4 and 55. At this level, it crosses the posterior interradius in forming a round angle. The internal regions 
of plates a4 and 5 and b4, 5 and 6, which are found between the fasciole and the periproct, are poor in primary tubercles. The lateral fasciole is narrower than the peripetalous. It widens a little at the level of the posterior interradius, but its dorsal branch becomes less distinct and it merges somewhat with the milliary granules at the posterior end of the body.

The spines are fine and elongated. The smallest alone remain cylindrical to the end that, in the others, is often flattened and widened. This character is hardly noticeable in the ordinary spines of the dorsal and lateral interradii, but they are more accentuated in the large spines of the petals and anterior groove The widening and flattening occur gradually at the same time that the spine curves a little. But it is especially the spines of the ventral plastron that undergoes this modification and enlargement occurs in such an abrupt manner as to give them a spatulate form, the pallet not being much longer than wide (Pl. XX, fig. 46). At the same time, the pallet becomes concave and the concavity is turned downward. The edges are perfectly smooth and the reticulated calcareous tissue continues over all the blade, leaving only a very thin hyaline border that is transparent. The miliary spines are fine, elongated, ordinarily straight but sometimes slightly curved toward the end (fig. 47). They acquire, in their third or distal half some small denticulations, low and obtuse that elongate and anastomose at the end to form slightly enlarged head.

The pedicellariae that I have encountered belong to four forms: globiferous. rostrate, tridactyle and trifoliate. The three latter have nothing peculiar, but the globiferous are very interesting. They are fairly abundantly widespread on all the surface of the test, especially in the areas of the periproct and peristome as well as the dorsal ambulacra. They are extremely like those that Mortensen figures in his Periaster limicola (107. Pl. XIV, fig. 1 and 4). The valves ae 0.4 to 0.5 $\mathrm{mm}$ in length (Pl. XX, fig. 45) and the basal part is approximately two-fifths. This part is longer than wide. It passes insensibly to the blade that is tubular and becomes thinner gradually up to the end. This is armed with two large hooks, thin and pointed between which is an opening. The perforations are very small.

The rostrate pedicellariae are fairly numerous, but they are very small. Their valves do not exceed $0.2 \mathrm{~mm}$ in length (fig. 29). The basal part is as tall as wide. It reaches a quarter of the total length. The blade is first very narrow and in the form of a gutter for approximately two thirds of its length. Then it rapidly enlarges into a spoon having nearly the form of a semi-ellipse with extremely small and regular teeth. The tridactyle pedicellariae (fig. 48) are not numerous and still smaller than the preceding, the length of the valves not exceeding $0.1 \mathrm{~mm}$. The fairly short basal part is wider than long. The blade, a little narrow at the base, immediately widens into a concave spoon whose end is an obtuse point that has extremely fine, elongated and pointed teeth.

The stem of the penicillate pedicels of the peristome does not have calcareous rods. The stems of the pedicels of the dorsal groove contain fairly dense spicules in the form of curved rods with asperities, of which several may join limiting small perforations. This can thus produce very irregular small plates. Each pedicel ends in some thin and elongated extensions, whose number varies from six to ten. They are cylindrical with a slightly swollen end. The ensemble can be compared to a kind of rosette, but whose lobes are very elongated. They thus recall a penicillate pedicel that has only a very small number of digitations. These lobes lack calcareous deposits but the base of each of them has a small plate, short and widened in the form of an irregular lozenge made of a very fine calcareous network (fig. 44). The basal part is narrow, short, and formed of a very dense mesh that becomes wider on the rest of the plate in acquiring large perforations limited by the extremely fine beams. They can extend to the periphery in the form of small projecting points. 
I have represented ( $\mathrm{Pl}$. X, fig. 5) the dorsal region of the test seen by the internal side in order to show the four gonads. The two anterior gonads are small, moved far forward. They pass the end of the anterior petals. The two posterior gonads are large, located on each side and a little behind the apical system, to which they are very close.

\section{Prynmaster Investigatoris nov. sp.}

(Pl. IX, fig. 17 to 21: PI. XIX, fig. 71 and 72).

Port Blair. - A single specimen. $\mathrm{N}^{\circ} \frac{397}{7}$

This single individual is very small. It was lacking a very great part of its spines. Here are its principal dimensions:

Length.

$\mathrm{mm}$

Width.

15

Height of apical system.

12

Distance between the middle of the apical system and the anterior end of the test.

Distance between the middle of the apical system and the posterior end of the test.

Distance between the anterior border of the peristome and the anterior end of the test.

Distance between the posterior border of the peristome and the posterior end of the test.

Length of the anterior petals.

Length of the posterior petals.

Length of the peripetalous fasciole.

Width of the peripetalous fasciole ..................................

The test is oval and elongated. Seen from above (Pl. IX, fig. 18), it has a flat anterior border, hardly notched in its middle by the dorsal groove. It first widens rapidly and then very slowly to attain its maximum width at the height of the apical system that is moved a little backward. After this level, it narrows fairly rapidly to the posterior end that is narrow but round. Seen from the side (fig. 20), the profile of the test rises at first very quickly and nearly vertically. Then it joins, following a very convex curve, the dorsal surface that rises gradually, but very slowly to the level of the apical system. This is located on a small horizontal area beyond which the height of the test increases again a little over approximately the first half of the posterior interradius. From there, the dorsal surface drops rapidly to its end that forms a beak, short and obtuse but very pronounced, above the posterior surface. This is directed first a little obliquely forward in its upper third. Then it continues vertically downward and is connected by a round angle to the ventral surface. The latter is horizontal in its anterior part up to the peristome. Beyond the lower lip, which is fairly projecting, the profile is very convex up to the end of the ventral plastron that forms, on the median 
interradial line, a small projection marking the meeting point of the ventral surface with the posterior surface.

The gonopores, four in number (fig. 17), are very close to each other and nearly equal in size. However, the two left openings are a little larger than those on the right. The posterior gonopores are scarcely more separated from each other than the anterior pores. The genital plates, fairly small, are polygonal. The two anteriors are a little longer and denser, the posteriors as wide as long. The pore, relatively large, covers a good part of the surface of each plate. It is a little closer to the posterior border of the anterior plates. The madreporite is extremely small and located in the central part of the apical system. It does not even reach the level of the posterior gonopores and has only a very small number of pores. Between the two posterior genital plates, and over approximately a quarter of their length, is insinuated the obtuse anterior corner of a median and unpaired plate, fairly elongated and narrow, that also separates the two posterior ocellar plates and ends interradius 5. This plate occupies the region that the madreporite occupies in other species of the genus Schizaster s. lat. and related genera, as well as in Prymnaster angulatus. I suppose that it represents a fifth basal plate that has remained completely independent of the genital plates and has not yet fused with any of them. The ocellar plates are triangular, with a very large opening. They are arranged symmetrically.

The anterior ambulacrum (fig. 17 and 18) forms a wide and fairly depressed groove on the dorsal surface of the test. But its apparent depth is mostly due to the projection of the adjacent interradii. A little before reaching the peripetalous fasciole, the bottom of the groove gradually rises in a way that it becomes nearly flush with the test. Its maximum width is $2 \mathrm{~mm}$, its borders are very flared and its corners round. The groove is formed by a few relatively large plates, scarcely wider than long in its middle part. There are in fact only a dozen pairs up to the fasciole. Each plate has a pair of widely separated pores arranged obliquely. These are near the external and interior borders of the plate. The two pores of each pair are extremely small, round and equal, surrounded by a very faint oval peripodial imprint. Inside the poriferous zone, we note a fairly regular row of small secondary tubercles. Then all the interporiferous zone is covered with miliary tubercles dispersed without order.

The anterior petals are fairly strongly divergent. They form an angle of $50^{\circ}$ with the anteroposterior axis, while the posterior petals make an angle of $30^{\circ}$ with the same axis. The angle formed by the two petals on the same side is $100^{\circ}$. The anterior petals are lanceolate. They form a blunt point at their origin. The end is also a little narrow. The anterior border is directed first obliquely in following a nearly rectilinear path Then it becomes convex. To the contrary, the posterior border is first very convex, then it becomes nearly straight. I count, in the anterior poriferous zone, twenty pairs of pores of which the first six are extremely small. In the posterior zone, only the first three pairs are rudimentary. These zones are very wide, while the interporiferous zones remain very narrow. The successive pairs of pores are separated by small slight projections on which we hardly distinguish very fine granules.

The posterior petals are relatively fairly elongated, pointed inwards. They are a little more round at their end than the anterior petals. They have, on both sides, thirteen pair of pores, of which the first four on the anterior zone and only the first two on the posterior zone are rudimentary.

Beyond the fasciole, the anterior ambulacrum acquires dense and fairly large primary tubercles identical to those of the adjacent interradii. These tubercles continue up to the area of the peristome. I distinguish phyllode peripodia only on the first plate of each series. This first plate is extremely narrow in its posterior part and the border that touches the peristome is very small, while the first plate of the anterior interradius is remarkably wide. It is this that forms, with its congener, 
nearly all the anterior periphery of the peristome. The paired ambulacral rapidly widen beyond the fasciole, especially the two posteriors. They then immediately acquire primary tubercles. On the ventral surface, the anterior lateral ambulacra (fig 19) are located approximately on the extension of each other. The first three pairs of plates have phyllode peripodia. The following pairs have primary tubercles whose size increases up to the ambitus. The posterior ambulacra are relatively narrow. They are covered with small, fairly numerous miliary granules, in the middle of which appear primary tubercles toward the posterior end. I see phyllode peripodia only on the two first plates of each series.

The dorsal interradii are not very projecting along the peals of the ambulacral groove. They are uniformly covered with dense and unequal primary tubercles. But these become larger toward their top and along ambulacra II, III and IV, as well as on the anterior interradius in the area of the ambitus. The unpaired posterior interradius forms a round and convex prominence that continues, as I said already, to form above the posterior surface, a beak comparable to that of $P$. angulatus, but relatively more accentuated. This beak is found at the meeting point where the posterior interradial plates 7-7 and 8-8.

In a general way, the tubercles are larger on the ventral surface than on the dorsal surface. They keep a regular size on the anterior interradii, while on the posterior interradii, their size decreases from front to back and inside to outside. The labrum is extremely short, two and a half times wider than long. Its anterior border, very widened but not very convex, occupies nearly all the width of the posterior border of the peristome. Behind, the labrum narrows very strongly and is notched to receive a round lobe formed by the adjacent ambulacral plate, which does not reach even the first third. Some secondary tubercles appear on its swollen border. The plastron sternum is elongated, covered in front by large, dense primary tubercles arranged in very regular rows. It has, on the median line, a projecting, round prominence that limits posteriorly the ventral surface of the test and which is the meeting point of the two sternal plates and the two episternal plates that follow. The ventral surface is thus very short. It is bordered posteriorly by the dorsal surface. The right sternal plate is obviously longer than the left. The two following episternal plates are also very unequal. The left plate, b3, is very large and wide. It goes inside the median interradial line, while plate a3, pushed back from it by the elongation of the preceding sternal, is very small and narrow. Also, the lower border of the two preanal plates 4-4 is nearly at the same level. The latter are very large, triangular, a little taller than wide and with a very broad truncated top to form a small side limiting the lower rim of the periproct. Plate a4 is a little larger than the other. The plates of the following pair 5-5, that limit, with the preceding, the lower border of the perioproct, are a little unequal, a5 being a little narrower than b5. The upper half of the of the periproct is limited by pairs 6-6 and 7-7. These form by their upper corners the end of the terminal beak. The two preanal plates each have in their middle a small projection that meets the lateral fasciole.

The peristome is short, wide and slightly sunken. The posterior lip hides only by a very small portion. It is covered by a first row of five large plates, very developed, triangular or quadrangular, to which is added, on each side, a much smaller plate. These seven plates alone cover nearly all the peristome that we see when we regard our urchin by its ventral surface. The posterior part, very narrow and hidden by the lower lip, is occupied by two rows of very small plates. The anterior border, very convex, of the peristome is in large part limited by the first plates of interradii 2 and 3 , as I have said above.

The periproct is located fairly high. It occupies the oblique region of the posterior end of the test. It is a little longer than wide (fig. 21), with an obtuse lower corner and a narrower upper corner. We distinguish, all along the lower border, a row of larger marginal plates. The lower part 
of the periproct is completed by some smaller plates. Finally, other plates, numerous and extremely small, surround the anus that is near the upper corner.

The peripetalous fasciole is very large. Its path is a little angular. It crosses the anterior groove very near the ambitus in taking a slightly convex form. Then, outside the groove, it abruptly changes direction and goes backwards parallel to the groove for approximately the first third of its length. At this point, it abruptly forms a very obtuse angle to reach the end of the anterior petal where it changes direction in following an angle still fairly obtuse. It then separates from the posterior border of the petal. Then, after having formed a fairly open angle, it follows a concave curve to reach the end of the posterior petal that it bypasses following an acute angle. Finally, it reaches the middle of the posterior interradius to go to the other side of the test by a slightly concave curve. The fasciole is quite apparent and of medium width. It becomes, as usual, a little wider at the level of the ends of the petals.

The lateral fasciole originates at an obtuse angle of the peripetalous fasciole behind the anterior petal. It goes, slightly curving, toward the posterior surface of the test that it reaches in the area of plates a5 and b5. Then it crosses the posterior interradius a little below the periproct and in the area of plates 4-4 that, at this level, have each the prominence that I reported above. In this course on the posterior end of the test, it forms a curve with a large open radius upward. This fasciole is narrower than the peripetalous fasciole, but it widens sensibly below the periproct.

I have only a little to say on the subject of the spines, the pedicellariae and the pedicels, the specimen being nearly completely bare. I have, however, encountered two very small pedicellariae apparently belonging to the rostrate type (Pl. XIX, fig. 73). The basal part is very short, wide and triangular. The blade, whose length equals that of the basal part, remains fairly narrow. It widens, however, a little in its distal part and ends in a round point. It has very fine denticulations that are very close to each other on one of the pedicellariae, stronger on the other that is a little larger and in which the values reach $0.3 \mathrm{~mm}$. The perforations are small and very dense in the basal region. They become larger and oval on the blade. A similar form of pedicellariae exists in P. angulatus. The rare primary spines that are preserved are all broken toward the base. There remain only some miliary spines that show nothing in particular.

SIMILARITIES AND DIFFERENCES. - I have placed P. Investigatoris in the genus Prymnaster, First, because of the structure of the dorsal ambulacral groove that is identical to that we have recognized in $P$. angulatus, then from the beak-shaped projection that ends the dorsal surface above the posterior end. The apical system also has a structure similar in the two species. But the form of the test is quite different. In $P$. angulatus, it is, in fact, very elongated and fairly flat, much longer than wide, and the interradial regions of the dorsal surface are less projecting than in $P$. angulatus. This difference is fairly great and the classification of our species in the genus Prymnaster should not be considered definitive. There would perhaps reason to create a new genus for it. But as it is a matter of a single individual and without doubt, young, of whom I know neither the spines nor the pedicellariae in a satisfactory manner, I have preferred to place it provisionally, and in making some reservations, beside Primnaster angulatus. 


\section{Brisaster indicus nov. sp.}

(PI. X, fig. 9 to 13)

Andaman Islands (no depth is indicated). — Two entire specimens, plus some debris of two others. $\mathrm{N}^{\circ} \underline{5493-5496}$.

The specimens are both of very small size. They were labeled Schizaster japonicus, but this determination is manifestly erroneous because the specimens are completely different from this species. They cannot even be placed in the genus Schizaster in the restricted sense established by Mortensen. They approach, to the contrary, S. Towsendi and especially latifrons, without being able to refer it to either of these species. I believe they represent a new genus belonging to the genus Briaster of Mortensen.

The largest specimen measures only $11 \mathrm{~mm}$ in length and the other intact individual, 10 .

Here are the principal dimensions of the first that will serve me as type:

Length.

$\mathrm{mm}$

Width.

11

Height at the apical system.

Maximum height toward the posterior end of the test.

Distance between the middle of the apical system and the anterior end of the test.

Distance between the middle of the apical system and the posterior end of the test.

Distance between the anterior border of the peristome and the anterior end of the test.

Distance between the posterior border of the peristome and the posterior end of the test.

Length of the anterior petals.

Length of the posterior petals.

Maximum width of the dorsal ambulacral groove.

Length of the peripetalous fasciole.

Width of the peripetalous fasciole.

Peristome (width and length).

Periproct (height and width).

Seen from above (Pl. X, fig. 10), the test is fairly wide and slightly elongated, with sides regularly round, joined by equally round corners. The anterior end is truncated and has a very wide but shallow notch in its middle. The maximum width is found near the middle of the length, but it decreases less rapidly in the posterior half than the anterior half of the test. The posterior end is widely rounded. The ventral side is fairly strongly convex. The plastron sternum is raised on the median line, but without forming a keel. It ends behind in a blunt angle and goes by a very rounded curve to the posterior end that is vertical. The periproct is found placed in the upper part of the latter that meets above it with the dorsal surface by a very rounded border. The test is much taller in its posterior region than it its anterior region (fig. 11). Bit it keeps, however, a fixed thickness 
and is not at all shortened. Seen from the side, the profile of the test first rises fairly rapidly, then more slowly toward the apical system. Behind it, the height increases still a little more over approximately half the space that separates the apical pole from the posterior end.

The apical system (fig. 12) recalls, as a whole, that of the young S. latifrons figured by Agassiz 04, p. 200, fig. 297, and pl. CII, fig. 3). It is a little nearer the posterior end than the anterior end of the test. The gonopores are still not formed, but we distinguish three genital plates, two to the left and one to the right. The two posterior plates are small, polygonal and the same, or even a little smaller, size than the ocellar plates. The left anterior plate is elongated, two times longer than wide, a little longer and narrower than in the young S. latifrons figured by Agassiz. The madreporite is very elongated and widened in its middle. In front, it is extended in the direction of interradius 2 by a naaarrow part that represents the right anterior genital plate to which it is fused. At the opposite end, it is continued in interradius 5 by a shorter part that stops exactly at the level of the two posterior ocellar plates. The pores are not numerous. They occupy the central part of the plate. The lateral ocellar plates occupy the four angles of a trapezoid. The two posteriors are closer together than the two anteriors. They are polygonal, with a fairly large opening. The anterior ocellar plate III is notably larger than the others. It has the form of a triangle. Its base corresponds the large base of the trapezoid whose four other plates form the corners. As a result, the openings of the three ocellar plates II, III and IV are found on the same transverse line. This apical system differs from that of $S$. latifrons mainly by the smaller lateral ocellar plates, by the comparatively larger anterior ocellar plate and by the madreporite that is narrower in its terminal part.

The anterior ambulacrum (fig. 10 and 12), forms with the dorsal surface a groove that very rapidly becomes deep, and especially very wide, with vertical lateral borders. It reaches its maximum width toward its middle. It then narrows but in a scarcely perceptible way. It has about twenty pairs of plates that are extremely short and very elongated, as usually happens. The length increases in the two or three last plates that precede the fasciole, and especially on the last that is only two times wider than long. Finally, the plate that is crossed by the fasciole is as long as wide. The median suture forms a very regular sinuous line. The pores are moved very close to the external sides. The first eight or nine pairs ae very small, very close to each other, and without distinct peripodial formation. The following become larger with oval peripodia. Finally, the last three or four pairs are more and more separated at the same time that their pores become again smaller. These pores are placed obliquely in each pair. The external or posterior pore is round. The internal or anterior pore is a little elongated, but on the two plates, very large, that precede the fasciole and on which their size is smaller, they tend to be arranged parallel to the axis of the groove. The The peripetalous fasciole, fairly wide, crosses the groove at a short distance behind the base of the anterior notch. Each plate has some very small tubercles, more or less regularly aligned. Then, in the area of the poriferous zones, appear some larger tubercles but that do not exist on all the plates. These tubercles become more numerous and more developed in the area of the fasciole.

The anterior petals are two times longer than the posteriors. They make an angle of $50^{\circ}$ with the anterio-posterior axis. The posterior petals make an angle of $35^{\circ}$ with this axis. As for the petals of the same side, they form together a nearly straight angle. The anterior petals are separated from the ambulacral groove by an interradial region very narrow and strongly projecting. They are very narrow at their origin. Then they gradually widen up to the area of their end where they reach $1.4 \mathrm{~mm}$. They then become a little narrower up to the peripetalous fasciole. The posterior border is at first directed nearly transversely. Then it follows a convex curve, while that of the anterior border, at first slightly concave and overhung by the corresponding interradius, becomes convex 
in the second half. I count twenty to twenty-one pairs of pores in each poriferous zone. In the anterior zone, the first ten pairs are extremely small and more or less atrophied, while in the posterior zone, the first four only are rudimentary. The following pores are quite developed, transversely widened and nearly the same form in each row. The poriferous zones are wide. The interporiferous zone is narrower than each of them. A row of extreme small granules is seen toward the posterior border of each plate. The interporiferous zone is nearly completely bare.

The posterior petals are separated from the anteriors by narrow interradial areas, but less projecting than the two anteriors. These petals, extremely short and pear-shaped, rapidly enlarge from their proximal point up to three-quarters of their length where they reach a width of $1 \mathrm{~mm}$. They then narrow slightly. Each poriferous zone contains about a dozen pairs of pores of which the first three or four are rudimentary.

Outside the fasciole, the anterior ambulacrum has some primary tubercles that become less numerous in passing to the ventral surface. The depression that it forms at the ambitus attenuates gradually at the same time that the ambulacrum narrows as it approaches the peristome. The anterior petals stop at the internal border of the fasciole. Their plates, very short, are immediately followed by a pair of large plates, rectangular, a little longer than wide, and whose surface is nearly entirely covered by the peripetalous fasciole that is very wide at this level. The plates then become shorter. They acquire primary tubercles, not numerous and often only one per plate. They mostly disappear on the ventral surface, to reappear in the immediate area of the perisome. The posterior petals are also followed by a pair of large plates, smaller however than on the anterior ambulacra and whose surface is nearly completely filled by the fasciole that has also become narrower. The following plates have more numerous primary tubercles than in front. These disappear on the posterior ventral ambulacra that have only miliary tubercles, except two or three primary tubercles in the area of the peristome.

The two anterior interradii remain very narrow on the dorsal surface inside the fasciole, thanks to a considerable widening of the anterior ambulacra. At first low in their proximal part, the regions form a very considerable projection in the area of the fasciole, at the same time that the interradii become wider. The two posterior interradii, at first as narrow as the anteriors, rapidly widen, but they remain less projecting. Moreover, the part inside the fasciole is very short. Finally, interradius 5 remains narrow, short and little projecting inside the fasciole. All these parts are covered with very dense primary tubercles, particularly developed on the borders of the anterior groove. Outside the fasciole, the tubercles are especially large and dense in the two anterior interradii, but they remain smaller in the other three. On the posterior end, the tubercles are small and dense above the periproct, but they very separated below the latter between the periproct and the lateral fasciole. They again become more numerous between these and the ventral surface.

The primary tubercles of the ventral surface are not very dense in the paired interradii, but they are larger on the anterior interradii than on the posteriors. The ventral plastron is covered with very dense primary tubercles arranged, as usual, in oblique longitudinal rows. The labrum is longer than wide but does not quite reach the end of the first ambulacral plate. Its anterior region is wide and triangular. Its free border, very convex, follows the concavity of the peristome that it does not hide. It only forms only an insignificant projection on the ventral surface. The posterior part of the labrum is narrow, two times longer than the anterior part to which it is joined by slightly sinuous borders. It widens very slowly up to the posterior border.

The two sternums are large and wide. They widen gradually up to the area of their posterior border. They are a little more than two times longer than wide and a little longer on the right than on the left, in a way to produce an alternation of the following plates. Plates 3-3 are unequal, at 
least two and a half times wider than long. Plates 4-4 elongate toward the periproct, especially plate b4 that is already a little in front of its congener and that touches the periproct by a small distinct border, while plate a4 ends in an acute corner not touching the periproct. After b4, the periproct is limited by plates b5 to b7 and, on the other side by plates a5 to a8, while b8 is separated from the periproct. The peripetalous fasciole crosses plates b9 and a10.

There is only, on my specimen, a single indication of an episternal corner, or rather a concave curve with a large radius formed by a slight narrowing of the posterior end of the sternum and the two following plates, 3 and 4 (fig. 11). To this very shallow concavity corresponds plates 6-6 of rows $1 \mathrm{a}$ and $\mathrm{Vb}$ that are found on each side at the level of the posterior border of the sternum. They are followed by plates 7, 8 and 9, plate 9 being a little longer and wider than the preceding. The plates of the series $1 \mathrm{a}$ and $\mathrm{Vb}$ are not wider than their corresponding series $1 \mathrm{~b}$ and $\mathrm{Va}$. Even after the ninth inclusively, those of the internal series are narrower than the externals.

The peristome is kidney-shaped, with a strongly concave posterior border. It is covered with numerous plates arranged in several rows. Among them are distinguished larger plates all along the anterior border. The other plates are unequal and smaller.

The periproct, very close to the dorsal surface, is oval, much taller than wide, with an upper and a bare lower corner. The plates that cover it form a very projecting cone. They have small miliary tubercles. The anus is located toward the middle.

The peripetalous fasciole has a fairly regular contour. After having crossed the anterior groove, it runs parallel to the ambitus to beyond the anterior petals. Then it turns slightly inwards toward the middle of the posterior interradius. After having gone around the end of the posterior petals, it meets the opposite branch by a convex border. It is constituted of a very wide band in front and on the sides, but that becomes narrower after the point where the lateral fasciole is detached and especially between the posterior petals.

The lateral fasciole is well developed. It is perfectly continuous for its entire length. It leaves the peripetalous fasciole a little after the end of the anterior petal and describes a very regular curve on the lateral surfaces of the test in approaching the ventral surface. It passes at a great distance below the periproct, forming a very slight concavity preceded by an obtuse corner at the level at which the test rises in a slight projection. It is wider than the posterior part of the peripetalous fasciole.

The test is completely bare on the individual that is my type. The second specimen, a little smaller, has kept only some rare incomplete spines in the dorsal groove.

SIMILARITIES AND DIFFERENCES. - By its relatively low test and the arrangement of its plates, this echinoid obviously comes into the genus Brisaster such as Mortensen has defined. It especially recalls $S$. latifrons Agssiz. But despite the small size of my individuals, it is without doubt that it is another form. The comparison can be made all the easier as Agassiz has indicated the characters of a young $S$. latifrons having only $17 \mathrm{~mm}$ in length while the species can reach $40 \mathrm{~mm}$. B. indicus differs from it by its subcentral apical system and the differences in the form of the plates that constitute it, by the lateral fasciole that is relatively very wide and perfectly continuous with peripetalous faciole. The labrum also appears to me narrower in the species of the Indian Ocean.

In S. Towsendi Agassiz, whose apical system is more central, and that, from this point of view, approaches the new species, the posterior petals are relatively longer. In the specimen of $10 \mathrm{~mm}$ represented by Agassiz (04, pl. CI, fig. 6 to10), the petals are all the same length, the peristome and the periproct are round and nearly as long as wide. These characters do not exist in my specimen whose length is nearly the same. 


\section{Brissopsis luzonica (Gray).}

(Pl. XIII, fig. 16; Pl. XIV. fig. 4, 5, 7, 12 and 13: PL. XX, fig. 51 to 54)

See for the bibliography:

Brissopsis luzonica, Meijere (04), p. 188.

Brissopsis luzonica, Döderlein (06), p. 258.

Brissopsis luzonica Mortensen (07), p. 168.

Brissopsis luzonica, Rudmose Brown (10 bis), p. 44.

Station 79. - Coast of Ganjam. 33 fathoms. - One small specimen. $\mathrm{N}^{\circ} \underline{5528}$.

Station 85. - Coast of Ganjam. — 31 fathoms. — Three specimens. N ${ }^{\circ} \underline{5530-5532}$.

Station 98. — Côte de Vizigapatam. 9 miles S. E. of Santapillay. 20 fathoms. — One specimen. $N^{\circ} \frac{5529}{7}$.

Station 167. - Coast of Madras. 20-33 fathoms. - Several small specimens.

Station 384. - $18^{\circ} 00^{\prime}$ N.; $93^{\circ} 37^{\prime}$ E. 40 fathoms. - One small specimen. $N^{\circ} \underline{5255} \frac{5}{7}$

Station 389. - $9^{\circ} 01^{\prime} 50^{\prime \prime}$ N.; 75 $55^{\prime} 50 "$ E. 81 fathoms. — One specimen in alcohol. $\mathrm{N}^{\circ} \frac{5254}{7}$.

Southwest of Puri. 25 fathoms. - A fragment of the dorsal surface. $N^{\circ} \frac{5527}{7}$.

West coast of Andaman Islands. 15 fathoms. - Seven small specimens. $\mathrm{N}^{\circ} \frac{5520-5526}{7}$.

Gulf of Martaban. 53 fathoms. - One specimen. $N^{\circ} \frac{5857}{7}$.

Nearly all the specimens are of small size. The length of the test varies between 15 and $18 \mathrm{~mm}$. Some are even smaller. One individual from station 98 is of fairly large size. It measures $40 \mathrm{~mm}$ in length. It lacks its spines, as do most of the other specimens collected by the INVESTIGATOR, but the test is entire. One of the specimens of station 85 and that from Puri also come from individuals a little larger than the others. Finally, the specimen from station 389 is in very good condition and has kept all its spines. Its length is $33 \mathrm{~mm}$.

I am persuaded that we have often confused different species under the name of B. luzonica. It is certain that among the forms collected by the SIBOGA and reported by Meijere as B. luzonica $(\mathbf{0 4}$, p. 188) there are several distinct species. Mortensen has already noted that the globiferous pedicellariae figured by this author surely do not belong to B. luzonica. On the other hand, in a specimen that Prof. Max Weber has had the kindness to send me and of which I shall speak later, I have encountered two kinds of ophiocephalous pedicellariae. We can also wonder if the individuals having posterior petals arranged parallel, like that Meijere has represented in Pl. V, fig. 44 , is really $B$. luzonica. I shall add that the name often has been given to some specimens coming from great depths without mentioning their characters. I observe for my part, that some fragments, unfortunately very incomplete, of Brissopsis collected by the INVESTIGATOR at a definite depth, are obviously different from the littoral individuals and cannot be considered as B. luzonica. These specimens that have elongated posterior petals arranged parallel, recall the individual photographed by Meijere of which I spoke above. A review of all the forms reported as $B$. luzonica 
and coming from very different depths, as those of the SIBOGA that were captured between 10 and 1,788 meters, would give without doubt some very interesting and unexpected results.

Unfortunately, the specimens that the INVESTIGATOR has collected, for the most part of very small size or incomplete, do not permit me to resolve these questions. I can, however, specify certain characters of $B$. luzonica and study some related forms which it appears to me necessary to distinguish.

The specimen from station 92 , that is the largest, seems to me to correspond exactly to $B$. luzonica. It is dried and all the spines have fallen off, but the test is in excellent condition. It is identical to a specimen from the coast of Siam that my excellent friend, Dr. Mortensen, has had the extreme amiability to send me. It has furnished a precious element for comparison in order to confirm my determination (the individual of the INVESTIGATOR has only a slightly more elongated test). I reproduce (Pl. XIV, fig. 4, 5, 7, 12 and 13) some photographs representing this specimen from different surfaces. Without going into a detailed description of the test, it appears useful to me to call attention to some essential characters of B. luzonica.

I shall note first, from the point of view of the exterior form, that the anterior end is not very thick and that the profile of the dorsal surface gradually rises up to the area of the posterior end that is very tall (fig. 12). The maximum height is reached a little in front of this end and found at the level of a quite conspicuous prominence that the ventral surface has on the median line, at the posterior and internal corner of the sternal plates. Behind this prominence, the test rises obliquely to meet the posterior end that is nearly vertical. The periproct is fairly small and elongated vertically. The profile of the dorsal surface shows three successive protuberances, of which the second is the most elongated, and that correspond respectively to the anterior and posterior interradial pairs and the unpaired interradius. The prominences are separated by depressions formed by the ambulacra, especially the anterior. The plates of the interradial pairs show, at the dorsal surface and on the sides of the test, each a low and round projection, but quite noticeable. The contour of the posterior surface, that is narrow, is equally noticeable by a projecting line. This surface is ended below by an obtuse point that separates it from the ventral surface. The apical pole is found at nearly equidistance between the two ends of the test. The four gonopores are large, very close to each other and nearly equal. They occupy a large part of the surface of the genital plates (Pl. XIII, fig. 10). The madreporite is pear-shaped, very elongated in interradius 5 where its length is one and a half that of the apical system.

The dorsal anterior groove is moderately sunken. Its borders are very oblique. It widens fairly rapidly a little after its origin. It keeps nearly the same width over nearly all its length. The first five pairs of the plates are extremely small and very narrow, with rudimentary pores, The following plates develop fairly abruptly and reach a very large width (Pl. XIII, fig. 10). The pores that are at first very near their external border, withdraw as the plates widen. As a result, the two poriferous zones remain parallel with either other over nearly all the extent of the groove. After the first five pairs of rudimentary plates, I count twenty pairs of plates up to the one that crosses the fasciole exclusively. The width of the plates increases only very slowly as they approach the anterior end of the test. They are fairly short and approximately two and a half times wider than long. But the two plates crossed by the fasciole are much longer than the preceding. The pores are extremely close together and ordinarily are joined in each pair, the anterior pore being much smaller than the other. The pores are located in the external part of the plate and adjacent to its anterior border. There is an inconspicuous peripodial imprint that is raised in a small granule behind the pair of pores. 
The form of the petals has often been indicated by authors. The anterior petals are confluent with the anterior groove at their origin. They are fairly divergent for three-quarters of their length. The posterior petals are confluent for more than half their length. They are first directed nearly parallel to each other. Then they separate from the median line and curve outward. The anterior petals are fairly wide toward their middle, at the point where the normal pores succeed the first rudimentary pores of the zone. Their anterior border is very convex. The anterior petals make an angle of $40^{\circ}$ with the grand axis of the body. The posterior petals make an angle of $15^{\circ}$ with the same axis. The two petals of each side are separated by an angle of $125^{\circ}$. The posterior poriferous zone of the anterior petals has twenty pairs of pores whose first three are completely rudimentary. In the anterior zone, the first eight pairs are scarcely apparent, the two following are better formed. Only the nine following pairs are normally developed.

In the posterior petals, the anterior or external poriferous zone has eighteen pairs of pores of which the first two are rudimentary. The posterior zone has nineteen pairs, but only the last eight are well formed. They are preceded by four smaller pairs. The first seven are quite rudimentary.

On the ventral surface, the posterior ambulacra are very wide. The plastron sternum is fairly narrow. The length of each sternal plate is $16 \mathrm{~mm}$. The posterior border is immediately behind the unpaired median projection that I reported above, at $8.5 \mathrm{~mm}$ before the posterior end. The episternal plates have, in the path of the subanal fasciole, each a small conical tuberosity near the median line and smaller than the unpaired median projection found a little forward. These sternal plates are covered with primary tubercles, of fairly small dimensions, that go in oblique lines from the posterior projection and from which follow on the episternal plates similar tubercles forming oblique rows from the small tuberosity that each has. The transverse branch of the labrum extends nearly the width of the posterior border of the peristome. Its longitudinal branch does not quite reach the posterior border of the first ambulacral plates.

I recall for the record that five ambulacral plates, from the sixth to the tenth, penetrate the subanal fasciole. This is relatively narrow. It is nearly completely located on the ventral surface of the test, as we see in Pl. XIV, fig. 5.

The pedicellariae of B. luzonica have been described and photographed by Dôderlein, except the globiferous ones that this author did not encounter. These pedicellariae do not have very conspicuous characters that permit their distinction from other species of Brissopsis that I shall have to describe later. Mortensen has indicated that the globiferous pedicellariae have two terminal hooks (07, p. 188). I represent in Pl. XX, fig. 53, a valve of a globiferous found on one of the specimens from the coast of Madras.

The rods of the rosettes that end the frontal pedicels are constituted of a fine and delicate network (fig. 51). The ends of the trabeculae are usually a free point on the sides of the rods. These are often widened in the middle region and thinned at the end.

I have believed it necessary to distinguish quite recently, under the name of B. Lemonnieri (13. p. 81), a Brissopsis coming from New Caledonia, of which I possess two specimens. It is obviously very near $B$. luzonica. I believe, however, that it represents more than a simple variety. Externally, the peripetalous fasciole forms, at the end of the anterior petals, a more acute angle than in $B$. luzonica that I have had in hand, but the pedicellariae and spicules of the pedicels principally offer the special characters. The pedicellariae are mainly represented by the globiferous that are particularly numerous on the ventral surface in the area of the peristome and on the ambulacra, and by ophiocephalous pedicellariae that are seen at the end of the posterior ambulacra. The tridactyle and rostrate pedicellariae are, to the contrary, very small and rare. I have not been able to find, on my two specimens, the relatively large and abundant tridactyle and rostrate pedicellariae 
that we know in B. luzonoica and that Dôderlein has represented. Perhaps we would find them in individuals less rich in globiferous that appear to have taken here the place of other pedicellariae. The valves of the globiferouos have a more developed basal part while the blade is narrow and longer than in typical B. luzonica. The spicules of the pedicels are short and constituted of perforated plates whose openings are more or less numerous. Finally, the rods of the rosettes of the frontal pedicels are less swollen than in B. luzonica. These different characters have appeared to me to justify a specific separation.

On the other hand, I possess in my collection a specimen coming from Java, unfortunately incomplete and dry, whose test measures $22 \mathrm{~mm}$ in length. I had first referred it, according to its exterior characters, to $B$. luzonica, but in investigating the pedicellariae, I have been very surprised to encounter, in the posterior part of the ventral ambulacra, next to ophiocephalous pedicellariae of the ordinary form, other larger and more abundant pedicellariae than the latter and having very particular characters. heir valves are in very good condition although the individual is dried. I reproduce in $\mathrm{Pl}$. XX, fig. 50, a photograph of one of them comparatively with a valve of an ophiocephalous pedicellariae of $B$. luzonica at the same magnification (fig. 52). I do not know similar pedicellariae in irregular echinoids. They recall a little a form found by Mortensen in Hemiaster expergilus (07, fig. 31), but they are totally different in the large teeth of the blade. They would approach rather, but only by the contour of the valves, claviform pedicellariae represented by Döderlein in the genus Aspidodiadema (06, p. 70, fig. 8, d). The valves measure 0.22 to 0.23 $\mathrm{mm}$ in length, while in ophiocephalous pedicellariae ordinarily they are only 0.12 , or only nearly half. The head is borne by a stem whose distal end is enlarged into a cup, as happens in ophiocephalous pedicellariae. The valves have very distinct lower arches, although fairly short. It seems difficult to me not to give the name ophiocephalous to these pedicellariae. The basal region is very developed. It reaches nearly three-fifths of the total length of the valve. It remains very wide for most of its length. It narrows only in the terminal part that precedes the blade. The convex borders lack teeth and remain smooth. The blade has a contour nearly exactly circular. It is rather small and narrower than the basal part. It is armed, all around its periphery, with conical teeth, elongated with a blunt point, that decrease in size on the upper part of the apophysis, which widens to continue with the borders of the blade. The perforations are large, especially on the blade.

I must add that I have found these two forms of ophiocephalous pedicellariae associated, always in the posterior part of the ventral ambulacra, in a specimen of Brissopsis encountered by the SIBOGA in a littoral station and identified by Meijere as B. luzonica that Prof. Max Weber has had the kindness to send to me. These two specimens, mine that is incomplete and dried and that of the SIBOGA that I was not able to study in depth, appear to me no different in exterior form from $B$. luzonica, but the presence of two forms of ophiocephalous pedicellariae is so remarkable that it appears necessary to me to separate this latter species. I propose to attribute to it the name of Brissopsis duplex.

It finally remains for me to speak of another species of Brissopsis that was not encountered by the INVESTIGATOR that came from a definite depth and that we distinguish immediately by its elongated petals that are directed parallel to each other. This Brissopsis cannot be united with $B$. luzonica and I consider it as new. I study it below under the name of B. parallela. 


\section{Brissopsis parallela, nov. sp.}

(Pl. XII, fig. 12; Pl. XIII, fig. 17; Pl. XIV, fig. 6, 10. 11 and 14; Pl. XX, fig. 55 to 62)

Station $235 .-14^{\circ} 38^{\prime} 15^{\prime}$ N.; $96^{\circ} 24^{\prime} 30^{\prime \prime}$ E. 370-419 fathoms. - A fragment of the dorsal surface.

Station 315. — 10' 06' N.; 92' 29" E. 705 fathoms. — A nearly entire specimen.

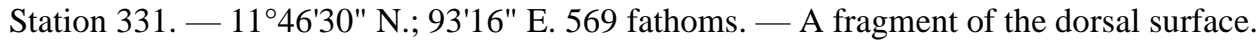

$13^{\circ} 17^{\prime} 15^{\prime \prime}$ N.: $93^{\circ} 10^{\prime}$ E. 185 fathoms. - A fragment of the dorsal surface.

The specimen from station 315 is the most complete, although it is lacking a portion of the posterior end, but it is the smallest of all because its length is only $37 \mathrm{~mm}$. I shall designate it by the letter A. The other specimens that are represented only by more or less complete dorsal surfaces, come from specimens of larger size, especially the latter. That was dried, the bottle that contained it being broken. I shall designate it by the letter B. I shall use it mainly for the study of the dorsal surface.

Here are the principal dimensions that I have taken on the different specimens:

Total length.

Width of the dorsal surface.

Height of the posterior end.

Distance between the middle of the apical system and the anterior end of the test.

Distance between the middle of the apical system and the posterior end of the dorsal surface.

Distance between the anterior border of the peristome and the anterior end of the test. ...

Distance between the posterior border of the peristome and the posterior end of the test...

Length of the anterior petals.

Length of the posterior petals.

Length of the peripetalous fasciole.

Width of the peripetalous fasciole.

Distance between the apical system and the anterior branch of the peripetalous fasciole. ..

Peristome (width and length).

Periproct (width and length). ...214...

\section{Specimens}

A $\mathrm{mm}$

37

33.6

29

23

17

17

\section{8}

26

6.7

8.4

24

11

14

$6 \times 3$

$4.5 \times 4.2$

\section{B}

$\mathrm{mm}$

50 at least

?

?

?

17

?

?

?

8

12

32

15

16

?

20

$?$

23

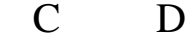

$\mathrm{mm} \quad \mathrm{mm}$

40 ?

$35 \quad 46$

? ?

20 ?

? ?

? ?

78

$11 \quad 13$

$28 \quad 30$

$\begin{array}{ll}17 & 17\end{array}$

$17 \quad 17$

? ?

? ?

I shall describe the species mainly after individuals A and B.

The form of the body is rather elongated, except in the individual of station 331 that appears a little wider than the others. Seen in profile (PI. XIV, fig. 6), the dorsal surface gradually rises from 
the anterior end, which is narrow, up to the posterior surface which it meets by a very obtuse corner. This latter is directed obliquely backward so that the ventral surface is longer than the dorsal surface. The interradii are not very prominent. The profile of the test is much more regular than in B. luzonica, as we can see by comparing fig. 6 and 12 of this same plate. The groove is also less accentuated than in this species and the anterior notch is scarcely apparent. The anterior petals are short (Pl. XII, fig. 17 and Pl. XIV, fig. 14), little divergent. The posterior petals are parallel, confluent for nearly their entire length. The ventral surface is nearly flat, without a median keel. The posterior sternal prominence, not very conospicuous, is located more posterior than in $B$. luzonica (Pl. XIV, fig. 10).

The apical system (Pl. XIII, fig. 17) does not differ sensibly from that we know in the latter. The madreporite is a little narrower and more elongated. The ocellar plates are wider and the openings of three plates II, III and IV are larger than the others.

The dorsal anterior groove is narrower and shallower than in B. luzonica. The portion between the apical system and the peripetalous fasciole is also shorter. Thus, in the B. luzonica represented in Pl. XIV, fig. 4, whose total length is $40 \mathrm{~mm}$, this distance is $17.5 \mathrm{~mm}$ and the anterior branch of the fasciole is found at scarcely $3 \mathrm{~mm}$ behind the anterior border of the test. In B. parallela, this distance measured in individual $\mathrm{B}$ that is at least $50 \mathrm{~mm}$ in length, is only $10 \mathrm{~mm}$. The fasciole crosses the dorsal groove at $6 \mathrm{~mm}$ behind the anterior border of the test.

In addition, the plates of the groove themselves are narrow and relatively long. Those that follow the first four, very small as usual, are in fact a little longer than wide and hexagonal in form. Their poriferous zones are very close together so that the interporiferous zone is extremely narrow. Finally, the peripodial imprint, very large, is located nearly in the middle of the plate.

All these characters give the dorsal groove of $B$. paralleli an appearance very different from that we see in $B$. luzonica, as we can be convinced by comparing the photographs I reproduce in $\mathrm{Pl}$. XIV, fig. 4 and 14, and especially Pl. XIII, fig. 16 and 17 . I count, at the origin of the dorsal ambulacrum III, four pairs of very small plates. The fifth to the right has a peripodial imprint that its congener does not yet have. The width of these plates increases very slowly, as also that of the following plates. Each of them has one or two secondary tubercles and some miliary granules.

There are twelve pairs of plates in all, with the first four very small, up to the plate crossed by the peripetalous fasciole. The latter is two and a half times longer than wide. Beyond the fasciole, the plates nearly completely lack tubercles. In B. luzonica represented in Pl. XIV, we have found twenty-five plates, instead of twelve, on this same portion of the dorsal groove.

Contrary to what exists in B. luzonica, the petals are not very sunken and the interradial regions that limit them are hardly raised. The anterior petals deviate little from the antero-posterior axis with which they make an angle of $30^{\circ}$. The posterior petals, nearly exactly parallel with each other, hardly make an angle of $10^{\circ}$ with this axis. The angle between the two petals on each side is thus $140^{\circ}$.

The anterior petals are largely confluent with the anterior groove for half their length. The fairly well-formed pores are scarcely apparent in the external third or fourth of the anterior border that is convex. They form only five or six pairs. The last two are very small. The other pairs, approximately ten in number, that precede them are quite rudimentary. by thirteen normal ones, of which the last, however, is very small. The pores are pear-shaped and equal in each row. The successive pairs are separated by a slight protuberance that is very poor in granules. The interporiferous zone alone has some miliary granules.

The posterior petals are confluent for two thirds of their length. They ae separated by a narrow band that remains with them on the same horizontal plane, except toward the end of the petals 
where they are slightly sunken. This band is covered with fairly dense miliary granules with some primary tubercles. The anterior or exterior poriferous zone alone is well formed. It has twenty-two pairs of pores, of which the first two are quite rudimentary and the last is also very small. The internal row has fairly developed pores only in its external part. I have counted six to the right and nine to the left, and still the first two or three remain very small. The preceding pairs are quite rudimentary. The external zones are slightly curved inward at their origin. Then they follow a nearly straight path for the rest of their length.

Beyond the petals, ambulacra II and IV remain very narrow. They have only miliary granules. To the contrary, the posterior ambulacra are much widened, especially in rows Ib and Va. They have primary tubercles mixed with miliary granules identical to those of the adjacent interradial plates.

The interradii of the dorsal surface are scarcely noticed in the area of the apical system. Outside the fasciole, the plates of the interradial pairs have each the usual small protuberance, but this is less apparent than in B. luzonica. These plates are covered with primary tubercles mixed with miliary granules and arranged fairly regularly in concentric rows. The tubercles become larger toward the ambitus, especially in the anterior half of the test. They have a very large development on arriving on the ventral surface. where their size increases as they approach the ambulacral zones. But as they are extremely wide, the interradial regions are little developed on the ventral surfaces. The posterior ambulacra especially are very wide. Their development is due to widening of the plates of the external row that is still more conspicuous here than in B. luzonica.

Unfortunately, all the lower part of the posterior end of the test is missing in my specimen A, and I cannot indicate the characters of the fasciole, nor the number of ambulacral plates that cross it. The anterior branch of the labrum does not extend on all the posterior border of the peristome that is very wide. The posterior branch is shorter than in B. luzonica. It does not exceed half of the adjacent ambulacral plate.

The peristome is large and especially very wide. It is covered first of all by an anterior row of large plates, about ten in number. Behind them are smaller plates.

The periproct is found just below the rounded and obtuse corner that connects the dorsal surface to the posterior surface of the test. It is large, in the form of a flat lozenge, with very obtuse upper and lower corners and very widely rounded lateral corners. It is a little wider than long. Because of its location and oblique direction of the posterior surface of the test, we can see all of it when looking at the urchin from the dorsal surface.

Because of the arrangement of the petals, the peripetalous fasciole is narrow, It extends further behind the apical system than in B. luzonica, thanks to the elongation of the posterior petals. Its path is also not very sinuous. It barely curves in the interradial pairs and takes rather in its ensemble a form a strongly elongated oval with the two ends truncated (Pl. XII, fig. 12).

The pedicellaria have nothing special. They resemble those that we know in various Brissopsis, notably in B. luzonicus. I represented here some values of tridactyle and rostrate pedicellariae. The large tridactyles have valves widened into a spoon in the terminal half of the blade, with fine denticulations on the borders, while the narrow part has some large teeth, very spaced and some elongated into round lobes (Pl. XX, fig. 55). Others, smaller, have fairly wide and elongated valves, armed with fairly strong teeth for nearly all their length (fig. 57 and 58). There exists, finally, tridactyle pedicellariae with a very short head and whose valves, relatively wider, have fairly strong teeth (fig. 59). The rostrate pedicellariae show nothing special (fig. 60 and 61). It has been impossible for me to find a single globiferous pedicellaria. 
The rosettes of the frontal pedicels are supported by strong rods that enlarge gradually after the basal part (fig. 56 and 62). The calcareous network that constitutes them is rather robust. The terminal trabeculae rarely end in a free point. Their length is $0.6 \mathrm{~mm}$. The spicules of the pedicels, like those of the peristomial pedicels, resemble those of B. luzonica. They are arched, with more or less numerous teeth likely to be curved toward each other and fused at their ends to limit holes. They can thus be transformed into small perforated plates but remain very simple and elongate.

SIMILARITIES AND DIFFERENCES. - B. parallela constitutes incontestably a very distinct species that cannot be combined with $B$. luzonica, with which it perhaps has been sometimes confused. The principal differences that separate if have already been emphasized in the description I just gave. I shall recall that the test has a more regular contour, with the interradii little protruding on the dorsal surface and a ventral plastron without a keel. The petals, barely sunken, are unequal. The posterior petals are longer than the anterior petals. They extend parallel to each other. The dorsal anterior groove, little noticeable, is constituted by a succession of a few plates, longer than wide, having pores toward their middle. The posterior end is directed obliquely backward. The periproct is wider than long. Finally, the known specimens have been encountered only at a definite depth.

\section{Brissopsis Oldhami Alcock}

(PI. XIV, fig. 1. 2, 3, 8, 9 and 15; PI. XV, fig. 12: PI. XX, fig. 28 to 43.)

Brissopsis Oldhami, Alcock (93), p. 6, Pl. VIII, fig. 7 and 8.

Brissopsis Oldhami, Anderson (94), p. 8.

Brissopsis Oldhami, Agassiz and L. Clark (07), p. 256.

Brissopsis Oldhami, Agassiz and L. Clark (07 bis), p. 136.

Brissopsis Oldhami, Mortensen (07), p. 168.

The type of this specimen has been described by Alcock after a specimen of small size found in the Bay of Bengal at a depth of 753 fathoms. It is represented at natural size in the plate cited above. Its length is only $32 \mathrm{~mm}$. The following year, Anderson reported that two entire specimens and several incomplete ones of this "large and fragile echinoid" had been dredged off Trincomale at a depth of 609 fathoms.

I have been able to examine the type of the species whose dorsal surface alone is preserved. I reproduce it in the photograph in Pl. XIV, fig. 1. In addition, I have found several specimens of B. Oldhami in the collection that has been sent to me. Here is the enumeration.

Station 231. - 7 $34^{\prime} 30^{\prime \prime}$ N.; 7608’22” E. 835 fathoms. Some fragments of which one must come from a fairly large individual, the distance between the apical system and the anterior end being $26 \mathrm{~mm}$; these fragments are nearly completely bare.

Station 264. - 1050'39' N.; 8041’30" M. 987 to 900 fathoms. — One specimen. N$^{\circ} 962$ (B).

Station 274. - $10^{\circ} 33^{\prime}$ N.; $74^{\circ} 15^{\prime} 15^{\prime}$ E. $1150-1170$ fathoms. - One specimen. $\mathrm{N}^{\mathrm{o}} \underline{1294}$.

Station $315 .-10^{\circ} 6^{\prime}$ N.; $92^{\circ} 24^{\prime}$ E. 705 fathoms. - One specimen. 
Two other specimens have no indication of provenance. One of them gives only a mention of the depth, 777731 fathoms. $\mathrm{N}^{\circ} 1293(\mathrm{C})$.

There exists in addition, in the collection that was sent to me, some debris of Brissopsis that appears to me should be referred to B. Oldhami, although I cannot guarantee the determination. However, a fragment of the dorsal surface coming from my individual of large size, captured in the Bay of Bengal at a depth of 753 fathoms, belongs certainly to B. Oldhami.

I have not received the specimens reported by Anderson in 1894 and found at Triconale at a depth of 609 fathoms $(\mathbf{9 4}, \mathrm{p} .8)$. On the other hand, three specimens from station $318\left(7^{\circ} 28^{\prime} \mathrm{N}\right.$., $79^{\circ} 19^{\prime} 30^{\prime \prime}$ E., 1085 fathoms), having $\mathrm{N}^{\circ} 1865-67 / 7$, that was addressed to me under the name of B. Oldhami, belong to the form that I shall describe later under the name of B. bengalensis.

Here are the principal dimensions that I have taken on the four individuals that I have designated above by the letters A, B, C, and D, respectively.t

Length.

Width.

Height.

Distance between the middle of the apical system and the anterior border of the test.

Distance between the apical system and the posterior end.

Length of the anterior petals.

Width of the anterior petals.

Length of the posterior petals.

Width of the posterior petals.

Width of the anterior groove.

Distance between the anterior border of the peristome and the anterior end of the test. ......

Distance between the anterior border of the labrum and the posterior end of the test.

Distance between the anterior border of the labrum and the subanal fasciole.

Length of the peripetalous fasciole.

Maximum width of the peripetalous fasciole in the anterior part.

Maximum width of the fasciole in the posterior part.

Width of the subanal fasciole.

Peristome (width and length).

Periproct (height and width).

\begin{tabular}{ccccc}
\multicolumn{5}{c}{ SPECIMENS } \\
$\mathrm{A}$ & $\mathrm{B}$ & $\mathrm{C}$ & $\mathrm{D}$ & $\mathrm{E}$ \\
$\mathrm{mm}$ & $\mathrm{mm}$ & $\mathrm{mm}$ & $\mathrm{mm}$ & $\begin{array}{c}\mathrm{mm} \\
\text { (ype) }\end{array}$ \\
40 & 43 & 40 & 53 & 32 \\
35 & 35 & 33 & 43 & 27 \\
24 & $?$ & 24 & 31 & $?$ \\
& & & & \\
21 & 21.5 & 20 & 26 & 16 \\
& & & & \\
19 & 21.5 & 20 & 27 & 16 \\
10.5 & 12 & 11 & 15 & 8.4 \\
$?$ & $?$ & 5 & 6 & 2.6 \\
10 & 11 & 10 & 15 & 8.2 \\
$?$ & $?$ & 4 & 5 & 2.5 \\
$?$ & $?$ & 4.5 & 5.5 & 3.2 \\
& & & & \\
9 & 11 & 9 & 14 & $?$ \\
& & & & \\
28 & 32 & 28 & 37 & $?$ \\
& & & & \\
25 & 26 & 25 & 32 & $?$ \\
30 & 31 & 30 & 40 & 22 \\
& & & & \\
18 & 20 & 18 & 25.5 & 21.5 \\
12 & 12 & 13 & 15 & 16 \\
16 & 15 & 18 & 22 & $?$ \\
$?$ & $?$ & $7 X 4$ & $10 X 5$ & $?$ \\
$6 X 5.5$ & $6 X 5$ & $6.2 X 5$ & $?$ & $?$
\end{tabular}

As this species has been described by Alcock, although in a slightly summary manner, after a specimen of small size, it appears useful to me to make a study using larger specimens. I shall use mainly individual D for the description of the test. The two specimens A and B will be used for the various appendages: spines, pedicellariae, ambulacral tubes, etc.

The body is elongated (Pl. XIV, fig. 2), fairly regularly oval. The apical system is located equidistance between the anterior and posterior ends. Seen from the dorsal surface, the contour of the test does not follow an absolutely regular curve. It has a slight flattening at the level of the two 
anterior ambulacra, while it is widened slightly at the level of the paired interradials, The anterior groove forms, at the ambitus, a very slight notch. On both sides of the notch, the width increases rapidly up to the middle of the anterior row of posterior interradial plates. From this point, the width of the test decreases regularly to the posterior end that is fairly narrow and flat transversely. The apical system occupies a horizontal area that is found exactly at the same level as the beginning of the five ambulacra. This system is not at all sunken. It is the interradial regions that are raised along the length of the petals. These are not sunken much except in their external half, while the apical system and the beginning of the five ambulacra that leave from it remain on a horizontal plane.

Seen in profile (fig. 8), the test has a fairly thick and strongly rounded anterior end. This continues on the dorsal side by a very convex curve formed first by a gibbosity that stops at the anterior ambulacra. It is followed by two similar gibbosities to those we know in B. luzonica. The extreme posterior is directed nearly vertical or slightly obliquely backward in individual D, which is the largest. It is a little more oblique in specimen A and remains nearly vertical in the two others. The posterior surface measures 22 by $23 \mathrm{~mm}$ in height in individual $\mathrm{D}$. The periproct is located very near the upper rounded border of this surface. The dorsal branch of the subanal fasciole is very close to the lower border that is wider and slightly sunken in its middle. Because of the nearly vertical surface that follows the posterior surface, we can scarcely see it in the same way as the periproct when we look at the urchin exactly from above.

The ventral surface is at first strongly rounded and convex in front. Then it is directed obliquely backwards and below following a very open curve so that the height of the test rapidly increases up toward the middle of the space separating the peristome from the posterior end or a little behind this point. Then, always following the same curve, it rises up to the posterior end to which it is connected by nearly straight but very rounded angle. The ventral plastron thus has a very swollen form, but the curve that we see when we look at the test in profile is fairly regular. It is difficult to see on the median line, a little before the posterior end of the sternum, a slight prominence that is not at all comparable to that of B. luzonica. The labrum follows the same curve as the ventral surface. Its anterior border forms only an inconspicuous projection. What is striking, in summary, when we look at the profile of the test of B. Oldhami, is the relatively great thickness that it reaches in the middle region, caused mainly by the very convex form of the ventral surface that does not decrease much toward the posterior end that, however, remains much taller than the anterior end that, however, still keeps a fairly great height despite the rounded form in front.

The apical system has nothing special (Pl. XIV, fig. 15). The four gonopores are very close together, especially the two anteriors that are the smallest. The two anterior genital plates are narrow, pentagonal, elongated in the direction of their respective interradius, with an opening located quite near their proximal corner. The two posterior plates are notably larger and wider. Their openings are moved inward. The madreporite is behind the posterior gonopores over a fairly great length in the unpaired interradius, taking a pear-shape but remaining fairly narrow. The ocellar plates are triangular, wider than long, with a more or less concave base, to which the opening is near. The five dorsal ambulacra converge toward the system in a way to be, at their beginning, in the same horizontal plane as the latter. The anterior ambulacrum is separated from the anterior petals by a small round edge that is little accentuated. The anterior and posterior petals on the same side are found nearly on the extension of each other. They are separated only by a narrow blade, very slightly raised.

The anterior ambulacrum remains very narrow up to the point where the first primary tubercles appear on the anterior interradii. Then it gradually widens at the same time it sinks slightly up to 
the anterior branch of the peripetalous fasciole. It then becomes narrower and rises over a very short space to the anterior border of the test. I count twenty-seven pairs of plates on the large individual (D) between the apical system and that which crosses the fasciole. Each of them has a peripodial imprint, large and very apparent, except on the first seven or eight pairs, that is a little nearer the external border than the internal corner of the plates. The two pores of each plate, located near the anterior border of the peripode, are very small, very near each other and joined by a groove. Inside these peripodia, each plate usually has two secondary tubules. Then the number of tubercles increases toward the fasciole. Beyond the latter, the plates greatly elongate and become three or four times longer than wide. There are only two pairs up to the ambitus. Each has several secondary tubercles. The plates also remain very long on the ventral surface, except those that touch the peristome. They have only miliary tubercles, except some secondary tubercles in the area of the latter. The large penicillate pedicels exist only on the two first plates of each series.

The petals are not very long. Their ends are always a fairly great distance from the ambitus. The anterior petals are fairly divergent, especially in their distal part. The curve in fact outwards, a little before their middle in a way they after having made first an angle of $30^{\circ}$ with the dorsal groove, they then make an angle of $50^{\circ}$ with it. At their origin, they are separated from the posterior petals by an angle of $130^{\circ}$. The anterior poriferous zones have only indistinct pores for the first half of their length. I count eight pairs of these rudimentary pores, of which the first five are nearly invisible. The follow, numbering a dozen pairs, are well developed, except the last whose pores are small and close together. The two pores of each pair, of the same form, elongated transversely and widely separated. The successive pairs are separated by a slight protrusion that scarcely has a small granule at each end.

The posterior zones begin with two pairs of rudimentary pores, followed by a third more developed. These three pairs follow a line curved transversally. Afterwards are eighteen pairs of very developed pores that follow each other in a nearly straight line. These pores are a little larger and a little more separated than in the anterior row. The tubercles are also not very numerous in this poriferous zone. This is also what happens in the interporiferous zone that is even nearly completely bare.

The posterior petals are a little divergent. They form each with the median interradial line an angle of $20^{\circ}$. They are largely confluent for more than half their length and remain nearly straight or slightly arched. They are nearly as long as the anterior petals. They are a little more curved in small individuals where they are also a little narrower. The external row of pores has first two very small pairs that follow a line curved inward and, afterwards, eighteen pairs that follow each other in a nearly straight line. The internal zone has nine pairs of well-formed pores, preceded first by four very small pairs, then by five others quite rudimentary and indistinct. Some very rare miliary granules occur in the interporiferous zone and on the small prominences that separate the successive pairs.

Beyond the petals, the anterior ambulacra are slightly sunken in relation to the adjacent interradii. They remain very narrow. Their width hardly exceeds $4 \mathrm{~mm}$. In contrast, their plates, hexagonal in form, become three times longer than wide. They immediately acquire primary tubercles identical to those of the of the adjacent interradii, more numerous on the posterior row than on the anterior row. These tubercles leave bare the portion of the plate adjacent to the radial suture. Between them are miliary granules. I count five pairs of plates up to the ambitus. On the ventral surface, the plates of the two anterior ambulacra have secondary tubercles. The acquire some rare primary tubercles only in the area of the peristome. The phyllode peripodia exist on the first three plates of each row. 
The posterior ambulacra, a little sunken beyond the fasciole, greatly widen to the contrary after the petals. They attain nearly immediately a width of $10 \mathrm{~mm}$, which is mainly due to widening of the plates of the posterior row. These then acquire numerous and dense primary tubercles that cover the entire surface. They become still denser, but smaller, as they approach the posterior border of plates contiguous with the unpaired interradius 5. To the contrary, the primary tubercles are not dense on the plates of the anterior row. They occupy only the posterior half, leaving bare the other portion. They completely disappear before reaching the ambitus.

The characters of the posterior ambulacra of the ventral surface are important to note. They form, as usual, wide ambulacra that remain nearly entirely bare up to the posterior end. We observe, in fact, only a small number of secondary tubercles on the first plate of each row, especially plates Ia1 and Vb1. The others only have very spaced miliary granules. Phyllode peripodia occur on the first three plates of each row. Plates 3, 4, 5 and 6 of the internal rows are very elongated. The sixth extends inside the anal plastron. It is crossed toward its middle by the subanal fasciole. The following three plates 7,8 and 9 alone, with the preceding, penetrate into the subanal fasicular area. Each of them has, inside the fasciole, a penicillate pedicel. There are thus in all, in our species, four ambulacral plates crossed by the subanal fasciole and filling the episternal corner. These are plates 6 to 9. There are three anal pedicels.

The primary tubercles, first completely absent on the first five posterior ambulacral plates, make their appearance on plate 6 of each internal series, a little outside the subanal fasciole, leaving bare all the external part of the plate, while the part inside the fasciole has very dense primary tubercles. The following three plates 7,8 and 9 are partly located inside the fasciole. The primary tubercles they have outside of it develop over a larger and larger portion. The plates that come afterwards are covered with primary tubercles over all their surface. As for the plates of the external series $\mathrm{Va}$ and $\mathrm{Ib}$, they remain bare up to the eleventh pair. The tubercles appear only on the twelfth or toward the upper border of the eleventh. These are plates 16-16 of series $\mathrm{Vb}$ and $1 \mathrm{a}$, as well as plates 17-17 of the two other series that are crossed by the peripetalous fasciole.

The two anterior interradii form, on each side of the dorsal groove, a convex surface that is not very prominent. The triangular area limited outside by the fasciole is covered with very dense primary tubers, larger toward the top and in the part that borders the anterior groove and becoming smaller toward the fasciole. Apart from this, the tubercles, which were first very small, increase in sizes. They cover uniformly the plates while leaving the sutures bare and quite distinct. Their size gradually increases toward the ambitus.

The two posterior interradii are limited inwardly by a very obtuse corner and a strongly rounded top. They form, all along the external border of the petals, a more conspicuous protrusion than on the anterior interradii, but that is never very great. The space limited by the fasciole is very narrow. It has fairly small primary tubercles. Outside the fasciole, the very large plates are covered by tubercles a little smaller than on the anterior interradii. They become larger only on the ventral surface. Their dimensions also decrease a little toward the median interradial line. They form fairly regular longitiudinal series parallel to the long side of the plates, always leaving the sutures bare. Each plate has a small round prominence that is hardly projecting, nearer the median line in the plates of the posterior row.

On the ventral surface, the primary tubercles of the paired interradii become larger and less dense. In the posterior interradius, these tubercles, which decrease and become very small toward the posterior end, do not quite reach the ambulacral border of the plates. In general, they do not extend onto the first plate of each interradius, while on the anterior interradii, these first plates have some primary tubercles. The unpaired posterior interradius determines on the dorsal surface 
a round protrusion, shorter than that of the paired posterior interradii, but that contributes to the increase in height of the test in its posterior region. It has only small primary tubercles, except some larger ones in the part separating the non-confluent parts of the posterior petals. The median region forms a fairly wide band that remains bare.

In passing to the posterior surface of the test, the tubercles become a little larger and less dense on each side of the periproct. But, below this, there is as usual a small area completely lacking tubercles. They reappear a little lower and become more numerous and smaller as they approach the anal fasciole.

On the ventral surface, the unpaired interradius is elongated and narrow. The labrum is short. Its posterior border reaches the middle of the first adjacent ambulacral plate. Its transverse region has a convex free border, not very thick or protruding Behind it are secondary granules. The posterior branch, fairly wide, is hardly longer than wide. The two sternal plates are very long, fairly narrow, and extend up to the edge of the fifth ambulacral plate. The two plates form a very swollen ventral plastron that scarcely rises toward its end in a rudimentary prominence. This is notable, less for its elevation than that it is the origin of the oblique and divergent lines followed by the primary tubercles of the sternum. The episternal plates are large. They are crossed in their middle by the ventral branch of the anal fasciole. They reach nearly the middle of the subanal plastron. They are widened outside in a way to form a truncated corner at the top. The two following plates 4-4 are elongated, triangular and crossed near their top by the dorsal branch of the subanal fasciole. Plates 5-5, also triangular, are very elongated. They are crossed near their base by the fasciole. They symmetrically reach the lower edge of the periproct by a truncated and narrow top. Finally, the following plates 6, 7 and 8, rapidly become narrower and shorter. They symmetrically surround the periproct. Their external edges correspond approximately to the sides of the posterior end of the test. They make a slight projection.

The large primary tubercles of the anterior part of the edges of the sternum have the same dimensions as the large tubercles of the adjacent interradii. The others are smaller.

The peristome, of medium size, is very widened transversely. Its contour is pentagonal with an obtuse and rounded anterior corner. It is covered by several rows of plates whose dimensions decrease from the anterior row. The eight plates that limit the anterior border and part of the sides, i.e., the two first plates of radii II, III and IV, and the first of each interradii 2 and 3, have nearly all the same width. The first plate of interradii 1 and 4 is, as usual, strongly narrowed in its internal part. The two first plates of the posterior ambulacra, constricted between it and the sides of the labrum, each only touch the peristome by a very narrow border.

The periproct (Pl. XIV, fig. 9) is oval with the two ends a little pointed, especially at the top. It is taller than wide. It approaches the upper border of the test. It has a marginal row of larger plates, narrow on its sides. Within are numerous, much smaller plates, irregularly arranged and unequal. The anus is nearer the upper corner.

The peripetalous fasciole is elongated and rather narrow as a whole. It has, on each side, two concave parts corresponding to the middle of each paired interradius. It is not widened in its posterior part where its two branches remain nearly parallel and even converge a little toward each other. Its posterior border is round.

The subanal fasciole is wide and relatively short. As its dorsal branch is more or less concave in its middle, its width is more than two times greater than its height measured at interradius 5. This increase in width of the fasciole constitutes its most prominent character. Its short length is related to the few number of ambulacral plates, only four, that it crosses. The arrangement is quite different from that which is known in B. luzonica where the subanal fasciole limits a relatively 
narrow, but elongated, area, enclosing the internal parts of five ambulacral plates. I cannot explain how Morensen has written that in B. Oldhami the number of ambulacral plates crossed by the subanal fasciole is five. The anterior or ventral branch of the fasciole is nearly straight. It is connected by round corners to the sides that are themselves strongly rounded. The band that constitutes it is wider than the peripetalous fasciole. Its width reaches approximately $1.5 \mathrm{~mm}$ on the sides and on the dorsal branch. The vertical branches are a little narrower. The fasciole is moved rather strongly backward. The area it limits includes the end of the ventral surface of the test with a small part of the posterior surface. In the middle of the tubercles that cover this area, we can distinguish a narrow and bare transverse band that corresponds to the posterior border of the episterna. The tubercles are very small toward the median interradial line and in the area of the two anterior and posterior borders of the fasciole. They are larger toward the sides of the subanal plastron where they are arranged in small rows, more or less apparent, that correspond to the ambulacral plates whose internal parts are in included in the fasciole. There is not the least indication of lateral branches leaving the peripetalous fasciole.

The spines of the dorsal surface of the test are fine and fairly elongated, straight or slightly curved. Those that are adjacent to the ambitus are often a little flat and widened at the end into a spatula with the dorsal surface concave. On the sides of the anterior groove and the petals, the spines are greatly elongated, especially those of the anterior petals as well as those of the external border of the posterior petals. They are directed in a way to cover the petals. They are also slightly widened into a spatula at the end. The spines have similar characters on the ventral surface, where they are more developed except toward the anterior end. Most of them are in the form of a narrow spatula. On the ventral plastron, their length does not exceed that of the other spines, but their widened end is fairly strongly curved.

The milliary spines and clavules have the usual structure.

The pedicels of the dorsal groove end in a widened disk whose borders always have very distinct small, round lobes. The rods of these rosettes are constituted of a generally very fine calcareous network, limiting very irregular mails, unequal, and ended in a point on the borders (Pl. XX, fig. 31). The spicules, very abundant, are curved and have spaced, fairly strong teeth. These spicules are found in the anal pedicels. The occur even toward the end of the peristomial pedicels, but they are not numerous.

I have encountered four forms of pedicellariae: tridactyle, rostrate, trifoliate and globiferous. The globiferous alone are characteristic. The others greatly resemble those of $B$. luconica.

There are first the large tridactyles, whose head reaches 1.5 to $1.8 \mathrm{~mm}$ in length. The valves are strongly narrowed in the middle part. They lean against each other only in their terminal third. The basal part (Pl. XX, fig. 28, 30, 34, 36 and 38) is wide and relatively short, approximately five or six times shorter than the blade in the large pedicellariae. This blade is first narrow for approximately half its length. Then it widens in its latter half into a spoon that does not reach a great width. Its edges have a row of very small teeth, short, blunt, becoming a little stronger toward the end. The narrow part of the blade has, to the contrary, large, very spaced teeth, ordinarily elongated and wide, rounded at the end. Their development is very variable. They generally number three to five. The form of valves greatly recalls that which Mortensen has figured in $B$. alta (07, pl. XIX, fig. 26) and Dôderlein in B. luzonica (06, pl. XLI, fig. 4 a-d). The neck is fairly short. The calcareous stem of the peduncles is mainly formed of longitudinal rods. These pedicellariae can become much smaller and their head reaches only 0.5 to $0.6 \mathrm{~mm}$ in length without their characters being sensibly modified (fig. 29). The relative dimensions of the widened and narrowed parts of the blade can vary to some extent. 
In a second form of tridactyles, which derive from the preceding, we can no longer distinguish a narrow part and a widened part in the blade (fig. 43). The basal region is very short. The blade widens in a little noticeable manner. It reaches its maximum width only short distance from its end. Its edges have, in the first fourth or third quarter, some teeth, unequal, not numerous, fairly strong and conical. After them come extremely small teeth, very dense, a little sharper than in the preceding form. The head is very narrow. The valves are applied against each other for nearly all their length. This form appears to me similar to that which Dôderlein has represented in $B$. luzonica (06, Pl. XLI, fig. 2 a-c). We shall find them again in B. bengalensis (Pl. XX, fig. 63). The head of the pedicellariae varies greatly in length. It reaches $0.7 \mathrm{~mm}$ in the largest and does not exceed $0.25 \mathrm{~mm}$ in the smallest. The tridactyle pedicellariae are very widespread on all the test. The largest are found especially in the areas of the peristome and periproct as well as in the petals.

The rostrate pedicellariae are also very abundant. The have two forms that differ mainly in size. In the larger, the head measures 0.8 to $0.9 \mathrm{~mm}$. The very developed basal part (fig. 35) is wide, but still taller than wide with very convex sides. Its edge often has in its second half some low teeth, conical and to the number of three to five. The blade is very narrow, fairly strongly curved in the form of a gutter without beams connecting the edges. It widens a little toward its end that has on each side a series of eight to ten triangular teeth, large, very pointed and unequal. The neck is very short. The calcareous stem of the peduncle ends in a flat head. The calcareous network is fairly compact in the terminal part, but looser and fibrous in the rest of the stem. The pedicellariae are seen especially in the areas of the periproct and the posterior petals.

The other rostrate pedicellariae (fig. 33) are smaller. The length of their head does not exceed $0.5 \mathrm{~mm}$. They differ in addition from the preceding by a narrower and shorter basal part, as well as by their relatively elongated blade. Its length equals at least one and half times that of the basal part. This form is similar to that which Mortensen and Döderlein have indicated in B. luzonica and atlantica.

The ophiocephalous pedicellariae are very rare. They appear to be replaced by the trifoliates and the very small tridactyles. The latter are, in particular, very abundant toward the posterior end of the body. I have, however, encountered some ophiocephalous pedicellariae in the individual from station 264. The head is extremely small. Its length does not exceed 0.1 to $0.12 \mathrm{~mm}$ (fig. 40). The valves recall those of B. luzonica and atlantica figured by Mortensen (07, pl. XVIII, fig. 2 and $10)$, but the blade is narrower and more elongated. It is a little longer than wide. The distal edge is not very convex. The teeth, strong, elongated and pointed, continue to the basal part without changing character.

The trifoliate pedicellariae are very abundant. Their head, larger than that of the preceding, varies between 0.15 and $0.2 \mathrm{~mm}$ in length. The blade is elongated and oval. Their structure has nothing special.

The globiferous appear very rare. I have found some only on the posterior ambulacra of the two individuals from stations 264 and 274. They are remarkable for their very elongated and narrow head that measures $1.2 \mathrm{~mm}$ in length (fig. 32). The valves greatly recall those that Mortensen has figured in B. atlantica (07, fig. 24). The basal part is taller than wide, nearly rectangular. It narrows rapidly to continue as a tubular blade, very elongated and narrow. This narrows very slightly to the end. This has two divergent hooks, fairly large, pointed, not curved, between which opens an elongated hole occupying all the width of the valve. The perforations are small, round, numerous and dense, except in the terminal part of the valves.

The specimens in alcohol are a light brownish yellow. The fascioles have a deeper color. 
I also refer to B. Oldhami two fragments of the dorsal surface from station 135 (Bay of Bengal, 753 fathoms). One of them comes from a fairly small individual and the other from a little larger individual. The ventral surfaces are completely lacking. The determination of these fragments cannot be absolutely rigorous, but the form of the petals and the low relief of the adjacent interradial regions conform well with what I see in B. Oldhami and prevent me from referring them to the next species, the only one with which we could confuse it.

It is also because of the form of the petals and their fairly shallow depth that I refer to $B$. Oldhami the fragment of the dorsal surface already reported above and coming from an individual that certainly reaches a size much greater than both of those about which I just spoke. It was labeled "Gulf of Bengal, 735 fathoms." The fragment contains a large part of the dorsal surface with the four complete petals and the anterior ambulacrum as well as the anterior end of the left side of the test. The fasciole measures more than $50 \mathrm{~mm}$ in length. The test, which we can evaluate according to the preserved half, was greater than $60 \mathrm{~mm}$. These numbers show that the individual was not only larger than all I have reported for B. Oldhami, but also than all those that I have separated from this species and that I shall describe below under the name B. bengalensis. Our species can thus reach a very great size.

Finally, the collection of the Indian Museum contains several fragments of dorsal surfaces without indication of provenance and that must belong to individuals whose length varies from 25 to $35 \mathrm{~mm}$. These fragments greatly recall the type of Alcock. I am inclined to refer them to $B$. Oldhami but without being able to give an absolute guarantee.

Similarities AND DifFERENCES. - In establishing B. Oldhami, Alcock did not discuss its affinities with the other species of the genus. As has already been noted, Agassiz and L. Clark, in reporting $B$. Oldhami from the Hawaiian Islands (07, p. 257), his description and the two figures that accompanied it scarcely permit knowing the characters that distinguish it from $B$. luzonica. The American authors have indicated the more salient characters in the relative dimensions of the test in the two species, but I wonder if the form that they report from the Hawaiian Islands is quite identical to that of the Indian Ocean because they did not have a basis for comparison.

As I have been able to examine the type of Alcock, I believe I am certain in the determination of my specimens. One of the most important characters of B. Oldhami, and that permits it to be distinguished immediately from $B$. luzonica, is furnished by the number of ambulacral plates that are crossed by the subanal fasciole. These number five in the latter species and four only in $B$. Oldhami. To this difference, I add a second that is determined, moreover, by the preceding. This is the form of the subanal fasciole that is wider and relatively shorter in B. Oldhami. These differences are easily seen when we compare the photographs of the posterior part of the ventral surface seen a little obliquely, like those that I reproduce here (Pl. XIV, fig. 13 and PL. XV, fig 12). The test is also comparatively taller, especially in the posterior region, and the ventral surface is more swollen in B. Oldhami. As for the pedicellariae, the tridactyle and rostrate forms do not furnish any distinctive character. But the globiferous are quite different. They are sufficient by themselves to justify a specific separation. They are rather close to those which Meijere has represented (07, pl. XXIII, fig. 474) as belonging to B. luzonica, but that come from another species as Mortensen has already noted. It is possible, moreover, that B. Oldhami is found among the Brissopsis that the SIBOGA has captured in the deep sea.

I shall add, finally, that $B$. Oldhami has always been encounterd at fairly great depths. I am very disposed to consider that $B$. luzonica is especially a littoral form. I must recognize, however, 
that this point of view would need to be supported by more precise observations than we possess now.

\section{Brissopsis bengalensis, nov. sp.}

(PI. XV, fig. 1-11; Pl. XX, fig. 63 and 64)

Station 318. $-7^{\circ} 28^{\prime}$ N.; $79^{\circ} 19^{\prime} 30^{\prime \prime}$ E. 1085 fathoms. - Several specimens. No $^{\circ} \frac{1865-67}{7}$ and $\frac{1880-85}{7}$.

$7^{\circ}$ N.; $76^{\circ} 36^{\prime} 15^{\prime \prime}$ E. 1,022 fathoms. — Some fragments.

This species must have been confused with B. Oldhami. Three specimens from the Indian Museum with a label having this name have been sent to me. In fact, B. bengalensis is very close to this latter species. I shall say even that I have hesitated to separate it specifically and to make it only a simple variety. However, the differences, especially in the external form, are so constant and they strike the observer in a way so obvious, that it appears rational to consecrate them by a specific name.

$B$. bengalensis is characterized especially by an exaggeration of some prominences that accentuate the contours or parts of the test in a way much more conspicuous than in B. Oldhami. The petals are more sunken, the dorsal groove is deeper and especially the anterior notch that it determines is more noticeable. The interradial areas are much more projecting on the dorsal surface between the ambulacra, and to the ambitus, so that the contour of the test is more irregular than in B. Oldhami. The apical system is nearer the anterior end than the posterior end. The anterior petals reach closer to the ambitus, while the posterior petals are a little divergent. This results in a little different form of the peripetalous fasciole. All these characters combine to give the specimens, to which I propose to apply the name $B$. bengalensis, an appearance quite different from that of $B$. Oldhami.

These differences are especially important to note because I find in B. bengalensis two distinct forms that keep all the characters that I just briefly summarized. In one of these forms, the test is wide and short, rather flat, with the posterior end low and the periproct near the dorsal branch of the subanal fasciole. In the other, the test is relatively much longer and narrower, at the same time that it is taller. The posterior end is also taller and the periproct is farther from the dorsal branch of the subanal fasciole. I reproduce in Pl. XV, various photographs that will make these differences clear. The elongated form is represented in fig. 2, 4, 9 and 11, the widened form in fig. 1, 5, 6, 7 and 8. It is unusual that the fairly numerous specimens that the INVESTIGATOR has collected cannot be referred at first glance to one or the other of the forms that are fairly distinct. The first idea that comes to mind is that they represent a sexual difference. I have examined several gonads coming from either elongated or widened individuals, but the tissues are not in a state of preservation sufficient to permit histological examination and I can say nothing on the subject.

Nearly all the individuals that I have had in hand are of fairly large size. Their dimensions are in general greater than in B. Oldhami. In most of them, the test reaches 60 to $65 \mathrm{~mm}$ in length. The width is 50 to $55 \mathrm{~mm}$ in the largest. Unfortunately, all the specimens have been subjected to numerous blows and they are not in a very good state of preservation. Although they are fairly numerous, I have not been able to find a single individual in perfect state. It is, as usual, the ventral 
surface that is especially damaged and several specimens ae reduced to the dorsal surface. Most of the spines are also missing. Nevertheless, the characters of the species can be perfectly established.

I have believed it preferable to choose, for the examination of the external form of the test and the comparison with $B$. Oldhami, some specimens of rather medium size and near to those that have served me to describe the latter. These are those that are represented in Pl. XV, fig 2, 3, 5, 8 and 12. I have more especially studied the characters of the test of a dried individual belonging to the elongated form (specimen A, fig. 2, 3 and 12), without, however, having an elongation of the test as conspicuous as in several others of which fig. 4 gives a good idea.

Here are the principal dimensions that I have taken of this specimen, as well as three others, one of which is very elongated (C). The other, a little smaller, is wide (D). The last, equally wide, is larger $(\mathrm{B})$.

Length.

Width.

Maximum height.

\begin{tabular}{cccc}
\multicolumn{4}{c}{ SPECIMENS } \\
$\mathrm{A}$ & $\mathrm{B}$ & $\mathrm{C}$ & $\mathrm{D}$ \\
$\mathrm{mm}$ & $\mathrm{mm}$ & $\mathrm{mm}$ & $\mathrm{mm}$ \\
57 & 64.5 & 64 & 50 \\
48 & 58 & 50 & 45 \\
32 & $?$ & 31 & 25 \\
& & & \\
27 & 29 & 27 & 24 \\
30 & 34.5 & 37 & 26 \\
& & & \\
$?$ & $?$ & 16 & 10 \\
& & & \\
43 & $?$ & 44 & 37 \\
18 & 18 & 17 & 14 \\
16 & 18 & 17 & 13 \\
41 & 47 & 42 & 35 \\
27 & 31 & 32 & 22 \\
21 & 24 & 21 & 18 \\
26 & $?$ & 21 & 22 \\
& & & \\
36 & $?$ & 35 & 32 \\
$?$ & $?$ & $11 \mathrm{X} 4$ & $10 \mathrm{X} 3$ \\
$8.5 \mathrm{X} 7$ & $8 \mathrm{X} 7.8$ & $8 \mathrm{X} 7$ & $6.8 \mathrm{X} 6.5$
\end{tabular}

Because of its very close affinities with $B$. Oldhami, it does not appear necessary to me to give a detailed description of $B$. bengalensis that would oblige me to repeat what I have said regarding the first species. My study will be mainly comparative.

The test has a contour less regularly oval and the dorsal surface has a succession of convex and depressed parts more accented than in B. Oldhami (Pl. XV, fig. 1, 2 and 4). It is relatively narrow in its anterior region in front of the two paired anterior ambulacra, while the two paired posterior interradii are more convex and wider. The two anterior ambulacra are quite sunken, and, at the ambitus, make quite conspicuous depressions. On the other hand, the two anterior interradii are very swollen. They form, on both sides of the dorsal groove, a very conspicuous gibbosity. The 
two rows of plates of the paired posterior interradii are also more projecting in their middle than in B. Oldhami, while the median interradial line is very slightly sunken on the suture.

Seen from the side, the test has, on the dorsal side, the successive prominences that we know and that remain very conspicuous here. But the profile of the ventral surface is less convex than in B. Oldhami, so that the height of the test is a little smaller towards the end of the sternal plastron than in the latter (fig. 7 and 9). In the flat form especially (fig. 7), the test is little swollen on the ventral surface. It is a little more so in the elongated form (fig. 9), but without ever becoming as prominent as in B. Oldhami. The posterior end is directed obliquely backward.

The apical system is always moved forward (fig. 1, 2 and 4), while it is subcentral in $B$. Oldhami. This arrangement produces some modifications in the form and relations of the petals. As the anterior petals are as developed as in B. Oldhami, and, in any case, at least equal in length to the posteriors, the results are first, their end is nearer the ambitus, and, in the second place, the paired anterior interradial pairs are shorter and narrower, as we can see in comparing fig. 1 and 2 of Pl. XV to fig. 2 of Pl. XIV. In specimen A (Pl. XV, fig. 2), the distance between the external edge of the dorsal groove to the ambitus and the internal edge of the paired anterior ambulacral is $11 \mathrm{~mm}$, while this distance is $14 \mathrm{~mm}$ in a B. Oldhami a little smaller, coming from a depth of 888 fathoms. In addition, the apical system is more sunken than in B. Oldhami and we note especially that the anterior petals, already sunken at their origin, become deeper still in their external half. The petals are perhaps a little less wide than in B. Oldhami, although this difference is hardly apparent, but they are deeper. This depth is especially increased by the considerable elevation of the adjacent interradii. Regarding their form itself, we note that they curve a little less in their second half than in B. Oldhami, Their path remains straight, except at their origin toward the apical system where they curve to the contrary in a very apparent way, but for a very short distance. The posterior petals are also curved inward at their origin. As a result, the two petals on the same side do not continue together as in B. Oldhami, especially as their inflected proximal regions are separated by a small transverse ridge. The anterior border of the anterior petal is convex, but less than in B. Oldhami. The posterior border is nearly straight instead of being concave as in the latter species. I have said above that the petals are strongly sunken, especially in their second half.

The posterior petals have nearly the same length as the anteriors. They are often even a little shorter. They appear especially shorter when the test is not bare because they are very little sunken in the area of the apical system, so that they seem to begin a little behind their real origin. Their external edge is slightly sinuous. They are a little shallower than the anterior petals. The portion of the unpaired posterior interradius that separates them in their first half is not raised. Behind, the interradius is raised a little.

The anterior petals make an angle of $45^{\circ}$ with the antero-posterior axis. This angle is only $25^{\circ}$ for the posterior petals. The angle between the anterior petals and the dorsal groove being more acute than in B. Oldhami, the paired anterior interradii are rather narrow on the dorsal surface. The protrusion they form is extended more toward the apical system and reaches the anterior genital plate. The anterior petals are thus quite separated from the dorsal groove at their origin, while in B. Oldhami, the separation is poorly indicated and the three ambulacra are confluent at their beginning. In addition, the large primary tubercles at the top of the anterior interradii, that stop 7 $\mathrm{mm}$ from the apical system in B. Oldhami represented in Pl. XIV, fig. 2, extends to $1 \mathrm{~mm}$ of this system in $B$. bengalensis of similar size.

As for the posterior petals, we note that the internal poriferous zones are more separated and that the unpaired posterior interradius, while being flat in its proximal part, remains wider there than in B. Oldhami. These two petals are thus, in a general way, a little more separated from each 
other in the new species. As, on the other hand, the two posterior interradii pairs each sends toward the apical system, a small ridge that separates the two petals on each side. As a result of these different arrangements, the four petals recall, as a whole, the form of an $\mathrm{H}$ rather than that of an $\mathrm{X}$ that we observe in B. Oldhami.

I note in the structure of the petals only one difference. The prominences that separate the successive pairs of pores have, in B. bengalensis, each a very regular row of small, dense miliary granules that extend up to the median suture. These granules are missing in B. Oldhami.

The dorsal groove is deeper than in B. Oldhami. The anterior notch is especially conspicuous and wider. The groove is also a little shorter, the apical system being moved slightly forward. The only other difference in its structure in the two species that I report is the presence of secondary tubercles that are a little more numerous in B. bengalensis. The four interradial pairs are very projecting all along the petals, especially along the two posterior petals. The rounded prominences dThe unpaired posterior interradius, to the contrary, forms only a slight elevation inside the fasciole. It rises by rounding outside of it.

Finally, as a consequence of the greater separation of the anterior and posterior petals of each pair, the peripetalous fasciole remains wider towards the part where it crosses the ambulacra. In particular, it widens sensibly before crossing the posterior ambulacra and it follows a very convex curve. In B. Oldhami, to the contrary, it remains nearly straight and its branches, instead of separately slightly, converge toward the median interradial line.

The labrum is a little more elongated and the two sternal plates are also a little wider and more pointed in front in B. bengalensis than in B. Oldhami. It seems to me likewise that the ventral branch of the subanal fasciole is moved a little more forward in the first species. But I can say nothing precise on this subject because of the very small number of specimens having an intact posterior surface that I have been able to examine.

All the peculiarities that I just indicated occur in the two forms of $B$. bengalensis. It remains for me to add some remarks on the differences that separate them.

In the widened form (Pl. XV, fig. 1, 5 and 6), the length of the test of the largest specimens is scarcely greater than the width. The ratio is approximately 1.11 . This widened form has a low test and, in the specimen I represent in Pl XV, fig. 7, the height is only $28 \mathrm{~mm}$. The posterior end is low. The space that separates the periproct from the upper border of the subanal fascial is fairly short, as we can see in fig. 8. We note also, in this figure, that the periproct is scarcely taller than wide and that the upper and lower corners are extremely obtuse and scarcely noticeable.

In the elongated individuals (fig. 2, 4, 9 and 11), the ratio between the length and width reaches and even exceeds 1.20. The posterior end is very tall. The test becomes much thicker behind. The space between the upper branch of the subanal fasciole and the periproct is much greater thanks especially to the extension of interradial plates 4-4. The latter reache the middle of this space, while they scarcely pass the subanal fasciole in the widened form. We can easily judge these differences by comparing the two photographs that I reproduce in Pl. XV, fig. 8 and 11 . The periproct is also sensibly taller than wide. It is extended into upper and lower corners, of which the first especially is very noticeable. The two sternal plates are naturally much longer. But I have not had a sufficient number of intact specimens to give an account of the differences that the ventral surface of the test could have in the two forms.

We see, by the preceding, that these variations in the form of the test do not affect the essential characters that distinguish $B$. bengalensis from B. Oldhammi.

Despite very meticulous investigation, it has been impossible for me to find a single globiiferous pedicellariae in B. bengalensis. The tridactyle, rostrate, ophiocephalous and trifoliate 
pedicellariae have the same characters as in B. Oldhami. I content myself with reproducing here the photograph of a large tridactyle ( $\mathrm{Pl}$. XX, fig 36). As for the rods of the rosettes of the frontal pedicels, they also greatly resemble those of the later species. They are perhaps a little smaller and their calcareous network thinner, but the difference is scarcely sensible (fig. 64). 


\section{LIST OF CITED WORKS}

72. Loven (Sven). Etudes sur les Echinoïdées. Kngl. Vet. Ak. Forh. Bd. XI. 1873.

74. Agassiz (A.). Revision of the Echini. III. Cat. Mus. Camp. Zool. 1872-1874.

81. Agassiz (A.). Report on the Echinoidea. Report on the Scientific Results of the voyage of the CHALLENGER. Zoology, Vol. III, part. 9.

83. Agassiz (A.). Report on the Echini, in: Reports on the Results of Dredging by the Blake. Ill. Cat. Mus. Comp. Zool. Vol. X.

83. Kœhler (R.). Recherches sur les Échinides des côtes de Provence. Ann. Mus. Hist. Nat. Marseille. Vol. I.

83. Loriol (P. de). Catalogue raisonné des Échinodermes recueillis par M. V. de Robillard à l'île Maurice. Mém. Soc. Se. Phys. et Nat. Genève. Vol. XXVIII.

83. Loven (Sven). On Pourtalesia. Kngl. Vet. Ak. Forh. Bd. XIX, 1883.

85. Rathbun (R.). Report upon the Echini collected by... ALBATROSS. Proc. U. S. Nat. Museum. Vol. VIII. 1885.

90. Duncan (P.-M.). Revision of the Genera and great Groups of the Echinoidea. Journ. Linn. Soc. London. Vol. XXIII.

91. Wood-Mason (J.) and Alcock (A.). Natural history from Indian Marine Survey INVESTIGATOR. Ser. 2, n 1 . Ann. Mag. Nat. Hist. (6). Vol. VIII.

92. Gregory (J.-W.). Archeopneustes abruptus, a new genus and species of Echinoid. Quart. Journ. Geol. Soc. London. Vol 48, 1892.

94. Anderson (A.-R.-S.). Natural History from INVESTIGATOR. Journ. Asiatic Soc. Bengal. Vol. LXIII.

98. Alcock (A.) and Anderson (A.-R.-S.). Natural History Notes from... INVESTIGATOR. Ser. A., $\mathrm{n}^{\circ}$ 9. Journ. Asiatic Soc. Bengal. Vol LXII.

98. Kœhler (R.). Echinides et Ophiures provenant des Campagnes de l'HIRONDELLE. Résultats des campagnes scientifiques du Prince de Monaco.

Fasc. XII.

99. Anderson (A.-R.-S.). Report of the Surgeon Naturalist for the Season 1898-90. Administration Report of the Marine Survey of the India for the year 1898-99. Calcutta 1899.

02. Alcock (A.). Naturalist in Indian Seas. London, Murray. 1902.

03. Wagner (J.). Anatomie des Paleopneustes niasicus. Wiss. Ergeb. Deutsche TiefseeExpcdition. Bd. V, Lief. I.

04. Agassiz (A.). The Panamic deep sea Echini. Mem. Mus. Comp. Zool. Vol. XXXI. Cambridge, 1904.

04. Fourteau (R.). Contribution à l'étude des Echinides vivant dans le golfe de Suez. Bull. Institut Egypte. (4). Vol. IV. 
04. Meijere (J.-G.-IH.) de. Die Echinoidea der SIBOGA Expédition. Siboga Expeditie.

Vol. XLIII. Leiden, 1904.

06. Döderlein (L.). Die Echinoiden der deutschen Tiefsee Expédition. Wiss. Ergebnisse der Tiefsee-Expedition. Bd. v, Lf. 2.

07. Agassiz (A.) and Clark (H. Lyman). Preliminary report of the Echini collected, in 1902, among the Hawaian Islands by.... ALBATROSs. Bull. Mus. Comp. Zool. Vol. L, $\mathrm{n}^{\circ} 3$.

07 $^{\text {bis }}$. Agassiz (A.), and Clark (H. Lyman). Prelim. report on the Echini collected in 1906, among the Aleutian Islands... and Japan, by... ALBATROSS. Ib. Vol. LI, ${ }^{\circ} 5$.

07. Mortensen (Th.). Echinoidea. II. The Danish Ingolf Expedition. IV, part. 2.

08. Clark (H. Lyman). Some Japanese and East Indian Echinoderms. Bull. Mus. Comp. Zool. Vol. LI.

09. Kœhler (R.). Ecliinodermes provenant des campagnes du yacht PRINCESSE ALICE. Résultats des campagnes scientifiques du Prince de Monaco. Fasc. XXXIV.

10. Brown (R.-N., Rudnose). Echinoidea and Asteroidea from the Mergui Archipelago. Proc. $R$. Soc. Edinburgh. Vol. XVIII.

$\mathbf{1 0}^{\text {bis }}$ Brown (R.-N., Rudmose). Echinoidea from the Kerimba Archipelago (Mozambique). Ib. Vol. XVIII.

11. Döderlein (L.). Ueber Echinoidea von der Arn-Inseln. Abhandb. Senkenb. Gesell. Frankfürt a/M. Vol. XXXIV.

13. Kœhler (R.). Description d'un Échinide nouveau, Brissopsis Le Monnieri. Recueil publié à l'occasion da Jubilé scientifique du Prof. G. Le Monnier. Nancy, 1913. 


\section{PLATES}




\section{PLATE I}

Pourtalesia Alcocki, fig 1 to 14; Aceste Annandalei, fig. 15 to 17.

Fig. 1 and 2. Dorsal surface of two Pourtalesia Alcocki, with spines (specimens C and D). Magnification 1.4.

Fig. 3. Ventral surface of specimen D. Magnification 1.4.

Fig. 4. Ventral surface of specimen C. Magnification 1.8.

Fig. 5. Dorsal surface lacking spines (specimen A). Magnification 1.7.

Fig. 6. Dorsal surface lacking spines (specimen B). Magnification 1.7.

Fig. 7. Anterior end of specimen B. Magnification 3.5.

Fig. 8. Lateral view of specimen B. Magnification 1.7.

Fig. 9. Anterior end with spines of specimen B. Magnification 1.7. (The ventral surface is turned upward.)

Fig. 10. Posterior end of specimen A, with spines. Magnification 1.7.

Fig. 11. Terminal surface of the posterior end of the test (specimen B). Magnification 4.

Fig. 12. Terminal surface of the posterior end of the test (specimen A). Magnification 4.

Fig. 13. Apical system and adjacent regions (specimen A). Magnification 5.

Fig. 14. Apical system and adjacent regions (specimen B). Magnification 5.

Fig. 15. Dorsal region of the test seen from the internal surface of an Aceste Annandalei to show the two large gonads. Magnification 1.8.

Fig. 16. Apical system and adjacent regions of an Aceste Annandalei (specimen B). Magnification 4.2.

Fig. 17. Apical system and adjacent regions of an Aceste Annadalei (specimen C). Magnification 4.2. 


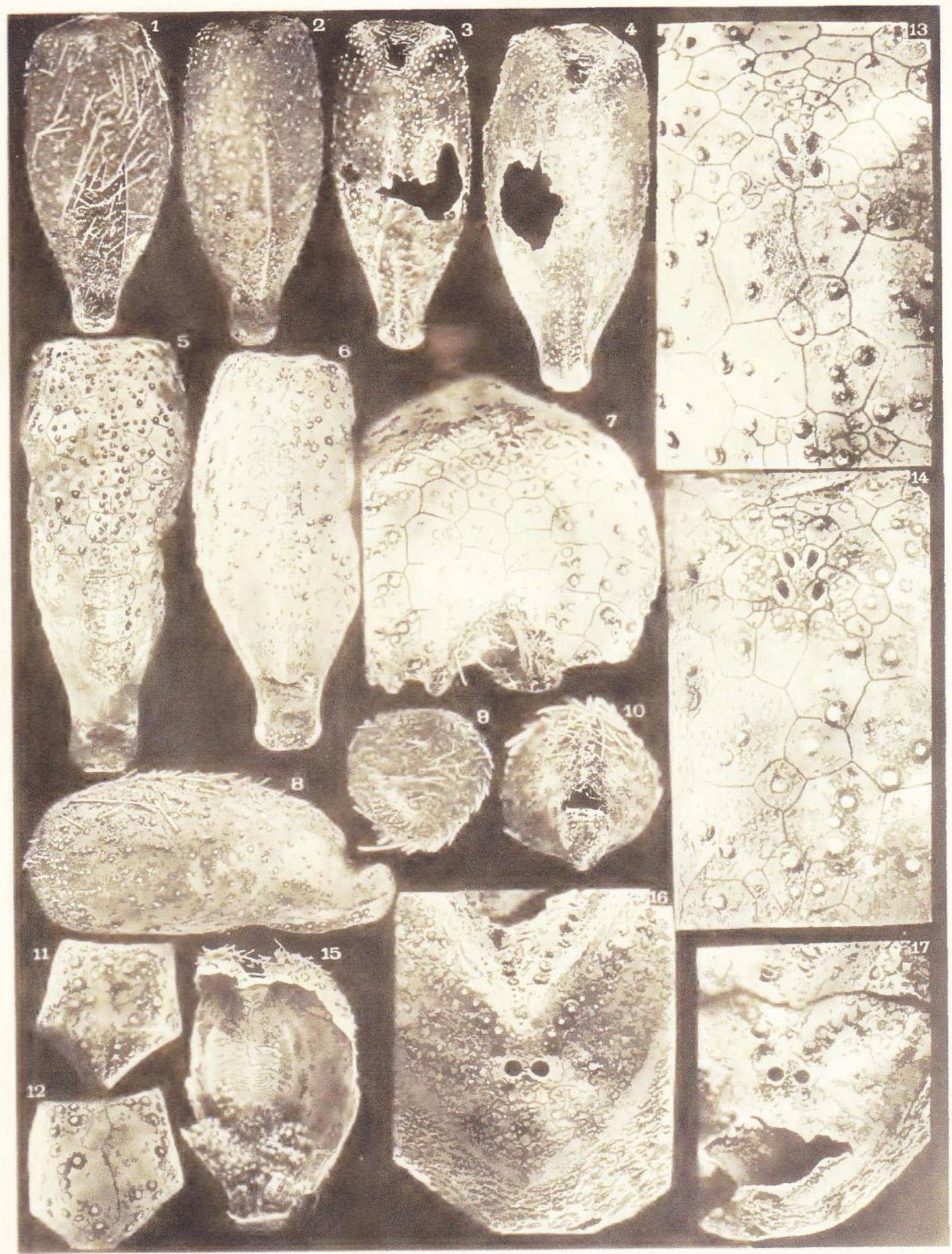




\section{PLATE II}

Acestes Annandalei, fig. 1 to 3, 5 to 7 and 9 to 16; Acestes Siboga fig. 4 and 8; Aeropsis Weberi, fig. 17 to 19.

Fig. 1. Acestes Annandalei. Dorsal surface of specimen D, with spines. Magnification 1.7.

Fig. 2. Acestes Annandalei. Dorsal surface of specimen F, with its spines. Magnification 1.7.

Fig. 3. Acestes Annandalei. Dorsal surface of specimen H, with its spines. Magnification 1.7.

Fig. 4. Ancestes Siboga. Dorsal surface, with spines. Magnification 1.4.

Fig. 5. Ancestes Annandalei. Dorsal surface with spines. (specimen A). Magnification 1.7.

Fig. 6. Dorsal surface, with spines (specimen E). Magnification 1.7.

Fig. 7. Lateral view of specimen H. Magnification 1.7.

Fig. 8. Ancestes siboga. Lateral view. Magnification 1.4.

Fig. 9. Ancestes Annandalei. Ventral surface of Specimen D, with spines. Magnification 1.7.

Fig. 10. Ventral surface of specimen B, without spines. Magnification 1.7.

Fig. 11. Dorsal surface of the same, without spines. Magnification 1.7.

Fig. 12. Dorsal surface of specimen C, without spines. Magnification 1.7.

Fig. 13. Posterior end of specimen C, without spines. Magnification 1.7.

Fig. 14. Digestive tube seen from the ventral side. Magnification 1.7.

Fig. 15. Ventral view of specimen A, with spines. Magnification 1.7.

Fig. 16. Lateral view of specimen B, without spines Magnification 1.7.

Fig. 17. Aeropsis Weberi. Lateral view. Magnification 1.7.

Fig. 18. Aeropsis Weberi. Ventral surface. Magnification 1.7.

Fig. 19. Aeropsis Weberi. Dorsal surface. Magnification 1.7. 


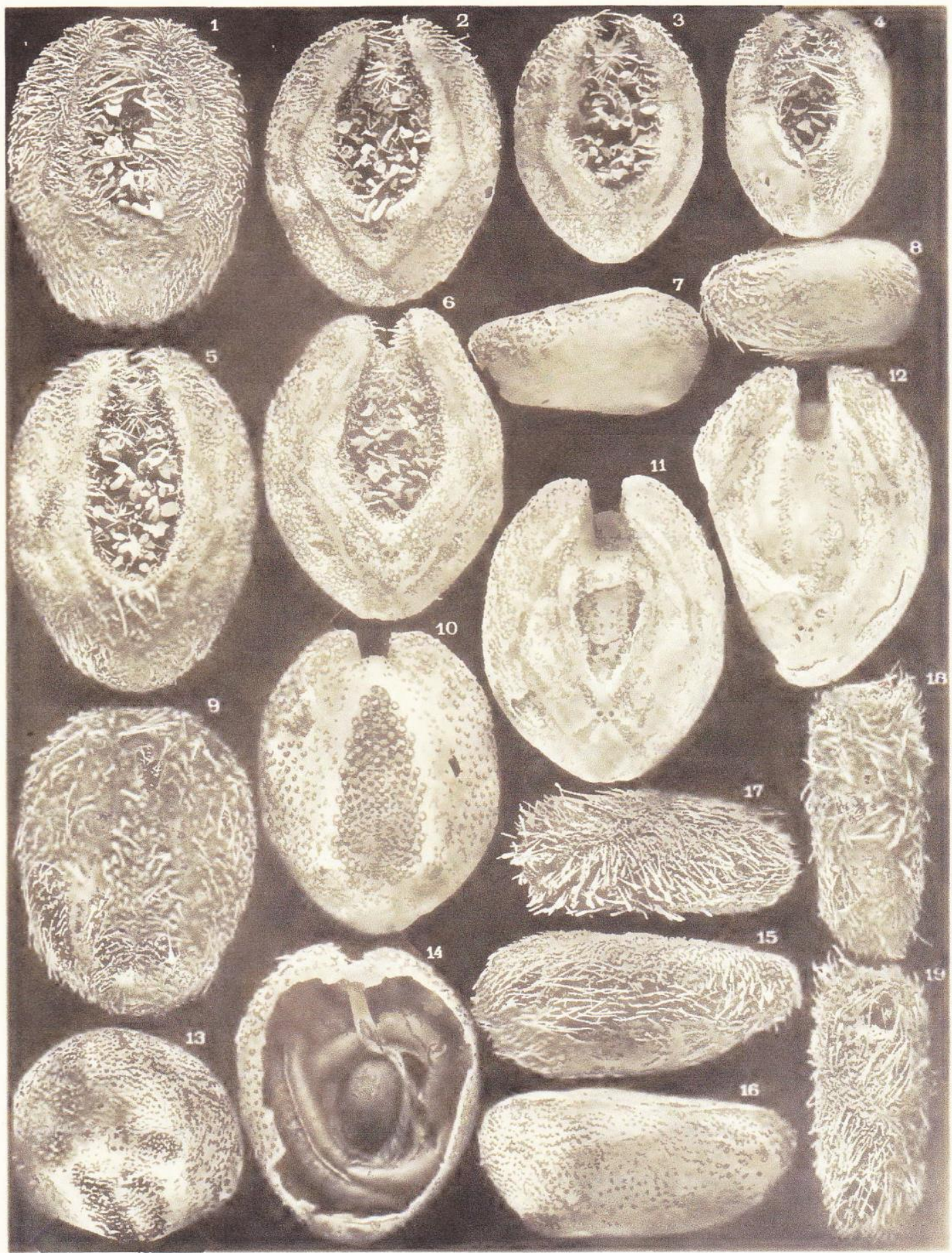

1.. Kinhler plint. 


\section{PLATE III}

Paleostoma mirabile, fig. 1, 2, 6, 8 and 9; Paleotropus ovatus, fig. 3 to 5, 11 and 12; Paleotropus Hirondellei, fig. 7; Homolampas glauca, fig. 10.

Fig. 1. Paleostoma mirabile. Dorsal surface. Magnification 8.

Fig. 2. Paleosoma mirabile. Lateral view. Magnification 8.

Fig. 3. Paleotropus ovatus. Dorsal surface. Magnification 6.

Fig. 4. Paleotropus ovatus. Ventral surface. Magnification 6.

Fig. 5. Paleotropus ovatus. Apical system and adjacent regions. Magnification 10.

Fig. 6. Paleostoma mirabile. Ventral surface. Magnification 8.

Fig. 7. Paleotropus Hirondellei. Apical system and adjacent regions Magnification 10.

Fig. 8. Paleostoma mirabile from the SIBOGA. Ventral surface magnified a little more than five times.

Fig. 9. Paleostoma mirabile from the SIBOGA. Dorsal surface. Same magnification.

Fig. 10. Homolampas glauca. Apical system and adjacent regions. Magnification 4.

Fig. 11. Paleotropus ovatus. Lateral view. Magnification 6.

Fig. 12. Paleotropus ovatus. Periproct. Magnification 6. 


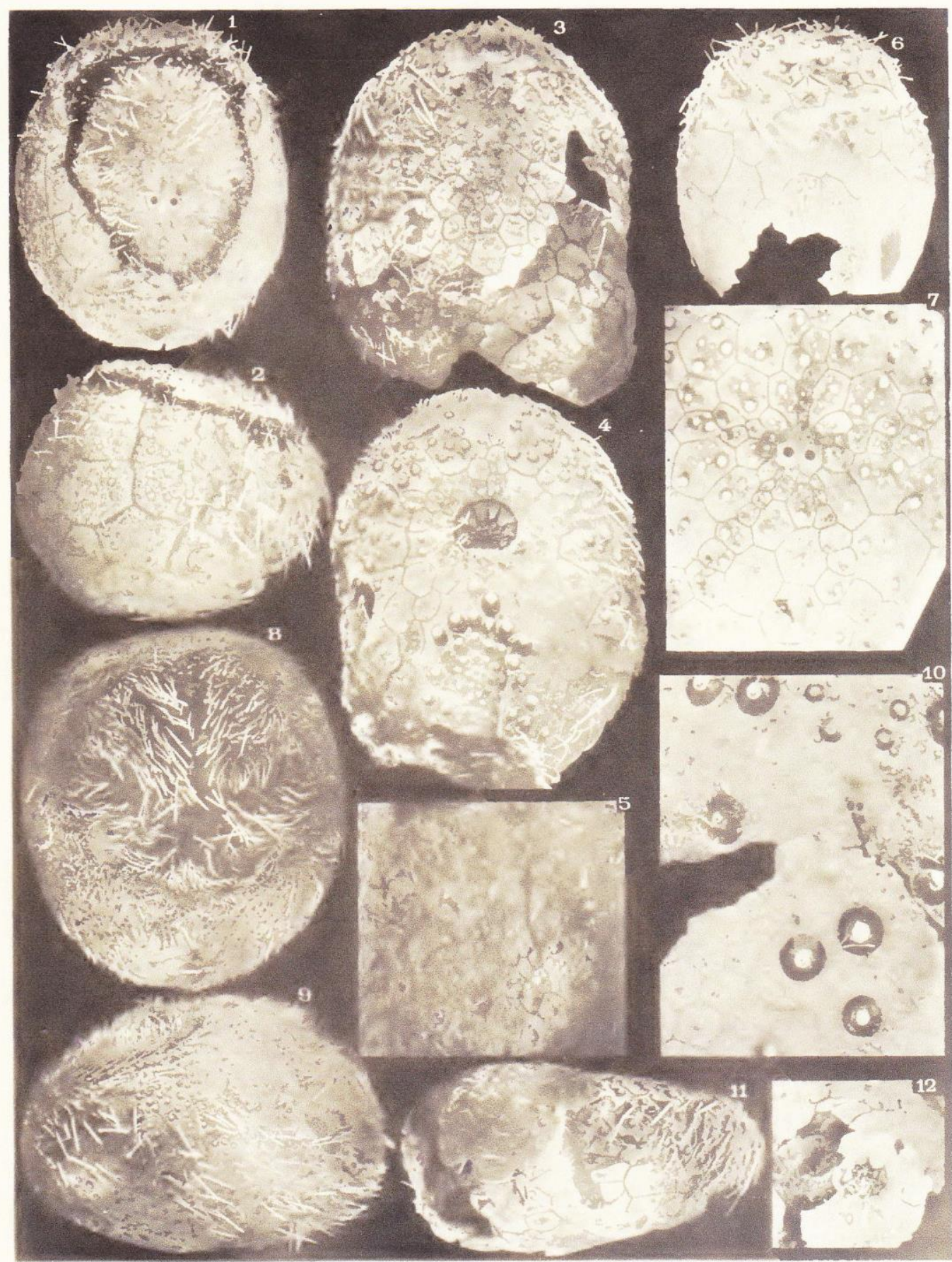

1. Kuther phot. 


\section{PLATE IV}

Archeopneustes Hemingi, fig. 1 and 2; Eurypneustes denudatus, fig. 3;

Homolampas glauca, fig. 4 and 5.

Fig. 1. Archeopneustes Hemingi. Ventral surface of specimen A, slightly reduced.

Fig. 2. Archeopneustes Hemingi. Lateral view of specimen B, reduced by two-tenths.

Fig. 3. Eurypneustes denudatus. Dorsal surface of specimen D. Natural size.

Fig. 4. Homolampas glauca. Dorsal surface, very slightly enlarged.

Fig. 5. Homolampas glauca. Lataeral view, slightly enlarged 


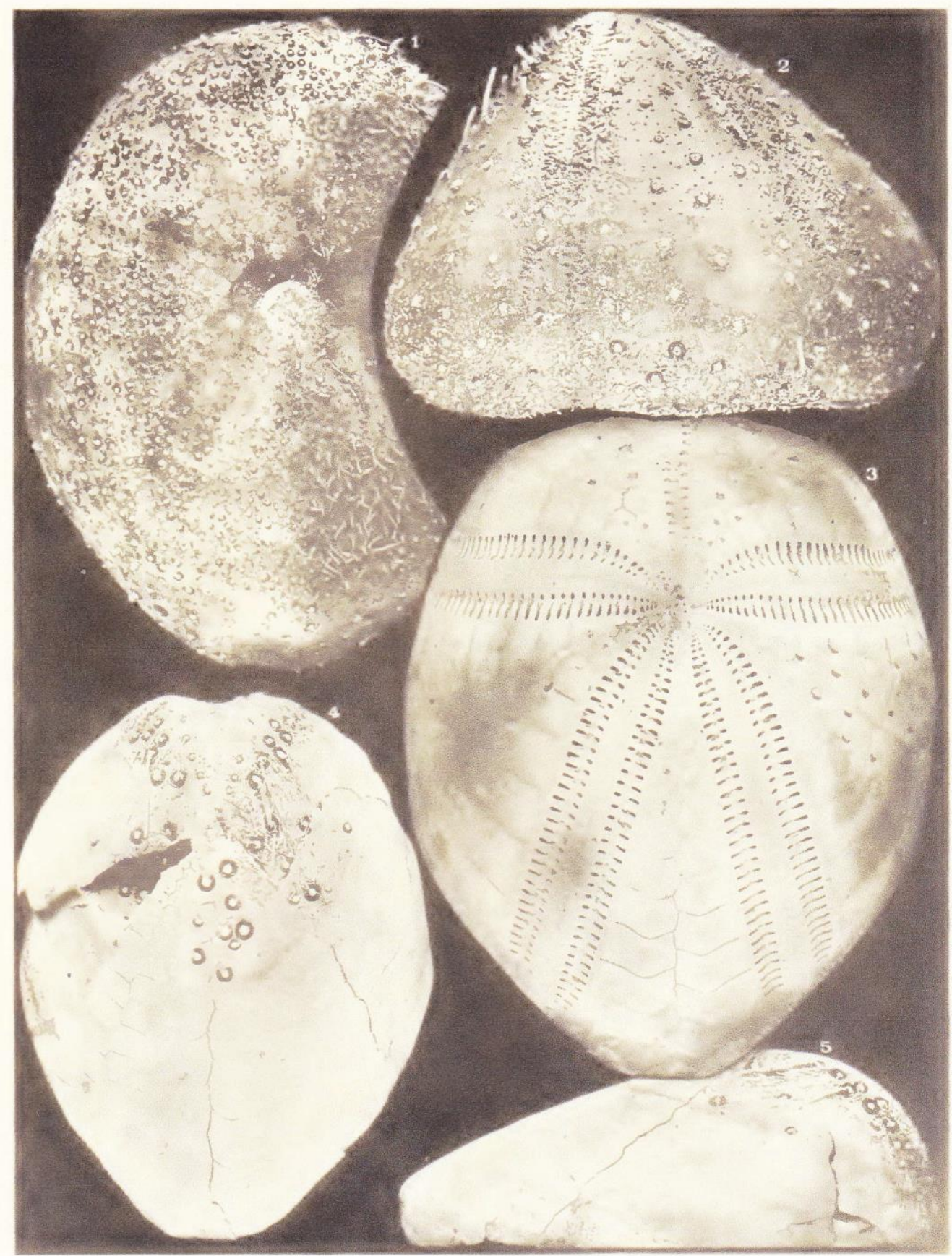




\section{PLATE V}

Archeopneustes Hemingi, fig. 1, 2, 4, 5 and 8; Linopneustes spectabilis, fig. 3 and 6; Eurypneustes denudatus, fig. 7.

Fig. 1. Archeopneustes Hemingi. Dorsal surface of specimen A, reduced by 1/8.

Fig. 2. Lateral view of specimen C, slightly reduced.

Fig. 3. Linopneustes spectabilis. Portion of the internal surface of the test, as the level of the episternal corner; reduced by $1 / 5$.

Fig. 4. Archeopneustes Hemingi. Posterior end of specimen A; reduced by 1/8.

Fig. 5. Archeopneustes Hemingi. Lateral view of specimen 8; reduced by $1 / 8$.

Fig. 6. Linopneustes spectabilis. Internal surface of the test at the ambitus; reduced 1/3.

Fig. 7. Eurypneustes denudatus. Oblique view of the posterior end of the test of specimen A; slightly enlarged.

Fig. 8. Archeopneustes Hemingi. Apical system and adjacent regions. Magnified 5. 


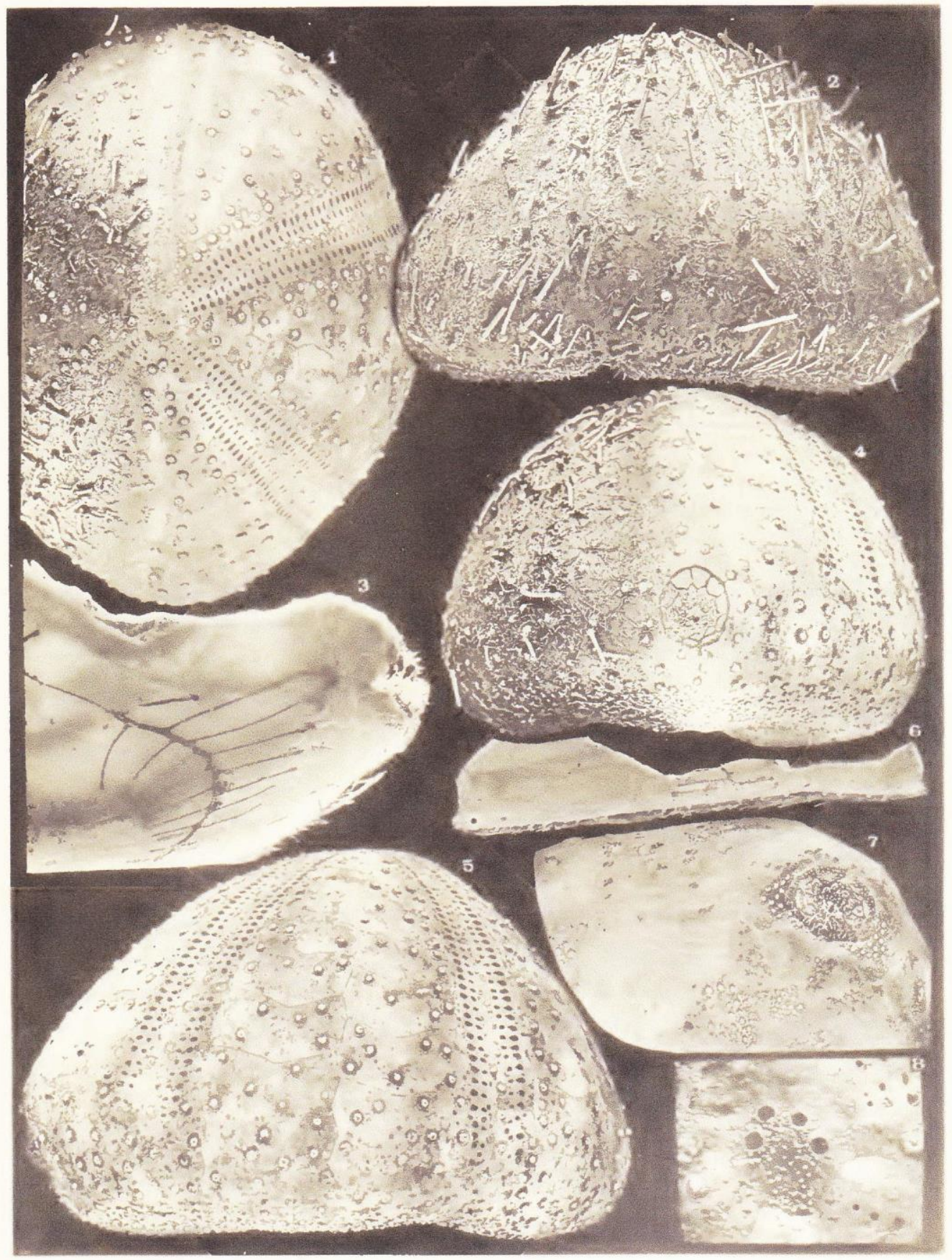

1:. Kinther pitot 


\section{PLATE VI}

Eurypneustes denudatus, fig. 1 to 10.

Fig. 1. Eurypneustes denudatus. Dorsal surface of specimen A, slightly magnified.

Fig. 2. Ventral surface of specimen E, slightly magnified.

Fig. 3. Ventral surface of specimen B, slightly reduced.

Fig. 4. Apical system. Magnified 5.

Fig. 5. Posterior end of specimen A, slightly magnified.

Fig. 6. Oblique view of the posterior end of the test of specimen C. Magnified 1.25.

Fig. 7. Lateral view of specimen A, slightly magnified.

Fig. 8. Ventral surface of specimen A, slightly magnified.

Fig. 9. Anterior end of specimen A, slightly enlarged.

Fig. 10. Lateral view of specimen C. Magnified 1.25. 


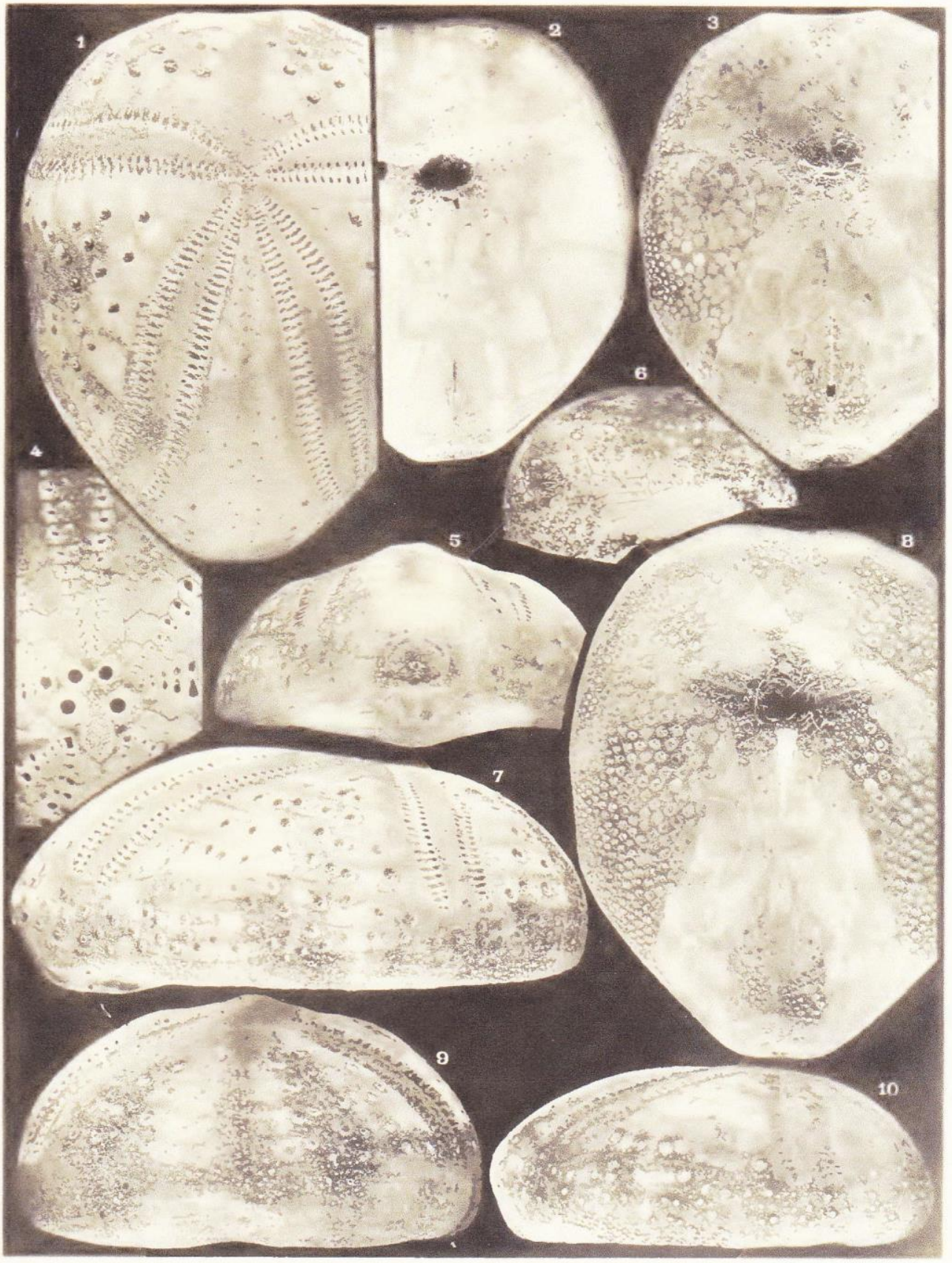




\section{PLATE VII}

Hemiaster vanus. fig. 1 to 3, 11 and 12; Hemiastcr Hickmani, fig. 4 to 10.

Fig. 1. Hemiaster vanus. Dorsal surface of the specimen from station 97. Magnified 1.6.

Fig. 2. Ventral surface of the same specimen. Magnified 1.6.

Fig. 3. Posterior end of the same specimen. Magnified 1.6.

Fig. 5. Hemiaster Hickmani. Dorsal surface of the denuded specimen. Magnified 1.6.

Fig. 6. Ventral surface of the same specimen. Magnified 1.6.

Fig. 7. Apical system and adjacent regions. Magnified 6.

Fig. 8. Posterior end of the specimen without spines. Magnified 1.6.

Fig. 9. Lateral view of the same. Magnified 1.6.

Fig. 10. Ventral surface, with spines. Magnified 1.6.

Fig. 11. Hemiaster vanus. Apical system. Magnified 8.

Fig. 12. Hemiaster vanus. Lateral view. Magnified 1.6. 


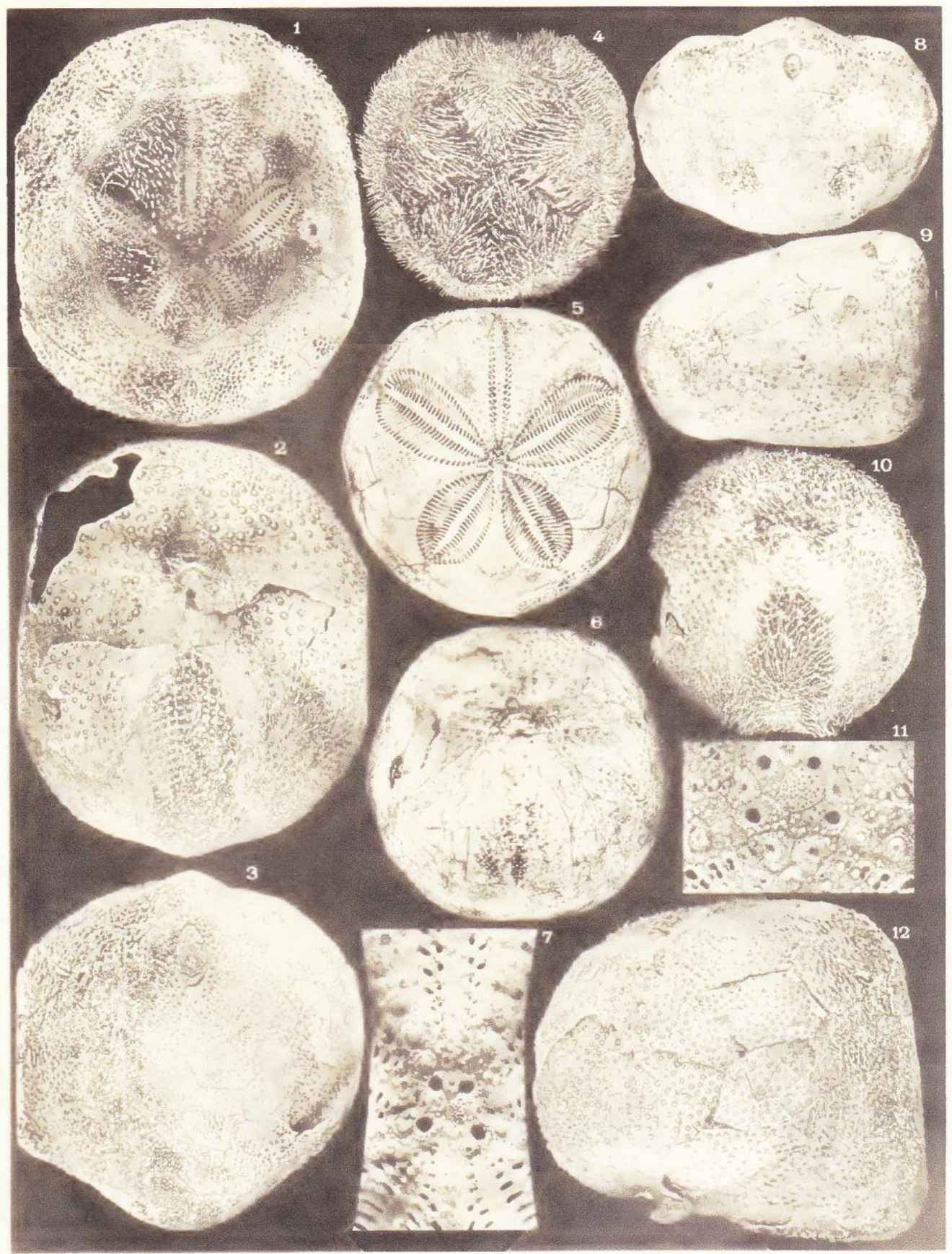

16. Kintaler pho 


\section{PLATE VIII}

Periastcr Kcmpi, fig. 1 to 3, 5, 7 to 9 and 16; Paraster Savignyi, fig. 4, 6, 12 to 15;

Paraster gibberulus, fig. 10 and 11.

Fig. 1. Periaster Kempi. Dorsal surface of specimen A, in large part lacking spines. Magnified 1.5 .

Fig. 2. Lateral view of the same. Magnified 1.5.

Fig. 3. Dorsal surface of the same individual, before the spines were removed. Magnified 1.5.

Fig. 4. Paraster Saviynyi. Specimen from the Museum of Copenhagen measuring $28 \mathrm{~mm}$ in length; lateral view. Magnified 1.5.

Fig. 5. Periaster Kempi. Ventral surface of specimen A. Magnified 1.5.

Fig. 6. Paraster Savignyi from the Museum of Copenhagen; apical system of the average specimen. Magnification 7.

Fig. 7. Periaster Kempi. Posterior end, with spines. Specimen C. Magnification 1.5.

Fig. 8. Periaster Kempi. Apical system. Magnification 4.

Fig. 9. Periaster Kempi. Oblique view of the posterior end of specimen A. Magnification 1.5.

Fig. 10. Paraster gibberulus from Kerimba. Apical system. Magnification 5.

Fig. 11. Paraster gibberulus from Kerimba. Lateral view of the test. Magnification 1.2.

Fig. 12. Paraster Savignyi from the Museum of Copenhagen, posterior surface of the test. Magnification 1.5.

Fig. 13. Same specimen; dorsal surface. Magnification 1.5.

Fig. 14. Same specimen; ventral surface. Magnification 1.5.

Fig. 15. Same specimen; oblique view of the posterior end. Magnification 5.

Fig. 16. Periaster Kempi. Posterior end of individual A. Magnification 1.5. 


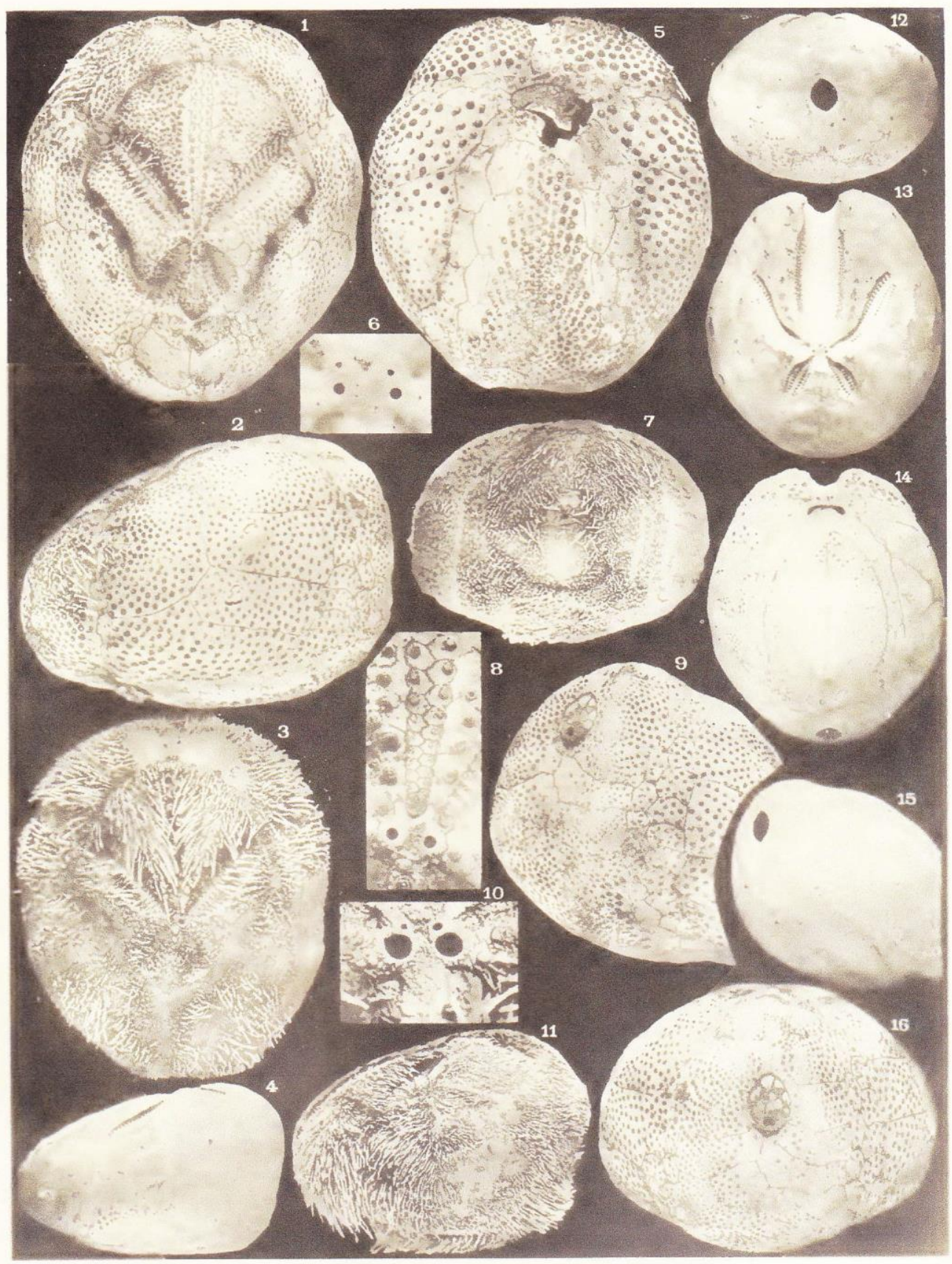




\section{PLATE IX}

Parastcr gibberulus, fig. 1, 2 and 16; Paraster Savignyi, fig. 3, 11, 13 to 15; Prymnaster compactus, fig. 4 to 10 and 12; Prymnaster Investigatoris, fig. 17 to 21 .

Fig. 1. Paraster gibberulus from New Caledonia; dorsal surface. Magnification 1.3.

Fig. 2. Paraster gibberulus from New Caledonia; lateral view. Magnification 1.3.

Fig. 3. Paraster Savignyi from the Jardin des Plantes; dorsal surface. Magnification 1.6.

Pig. 4. Prymnaster compactus. Lateral view of the small specimen. Magnification 2.2.

Fig. 5. Prymnaster compactus. Dorsal surface of the large specimen. Magnification 2.2.

Fig. 6. Prymnaster compactus. Ventral surface of the same. Magnification 2.2.

Fig. 7. Prymnaster compactus. Posterior end of the small specimen. Magnification 2.2.

Fig. 8. Prymnaster compactus. Dorsal surface of the same. Magnification 2.2.

Fig. 9. Prymnaster compactus. Ventral surface of the same. Magnification .2.

Fig. 10. Prymnaster compactus. Apical system. Magnification 20.

Fig. 11. Paraster Savignyi from the Jardin des Plantes; lateral view. Magnification 1.6.

Fig. 12. Prymnaster compactus. Lateral view of the large specimen. Magnification 2.2.

Fig. 13. Paraster Savignyi from the Jardin des Plantes. Apical system. Magnification 6.

Fig. 14. Paraster Savignyi from the Museum of Copenhagen. Apical system of the small specimen. Magnification 7.

Fig. 15. Paraster Savignyi from the Museum of Copenhagen; portion of the dorsal ambulacral groove. Magnification 7.

Fig. 16. Paraster gibberulus from New Caledonia; apical system. Magnification 5.

Fig. 17. Prymnaster Investigatoris. Apical system and anterior ambulacrum. Magnification 7.

Fig. 18. Prymnaster Investigatoris. Dorsal surface. Magnification 4.

Fig. 19. Prymnaster Investigatoris. Ventral surface. Magnification 4.

Fig. 20. Prymnaster Investigatoris. Lateral view. Magnification 4.

Fig. 21. Prymnaster Investigatoris. Posterior end. Magnification 4. 


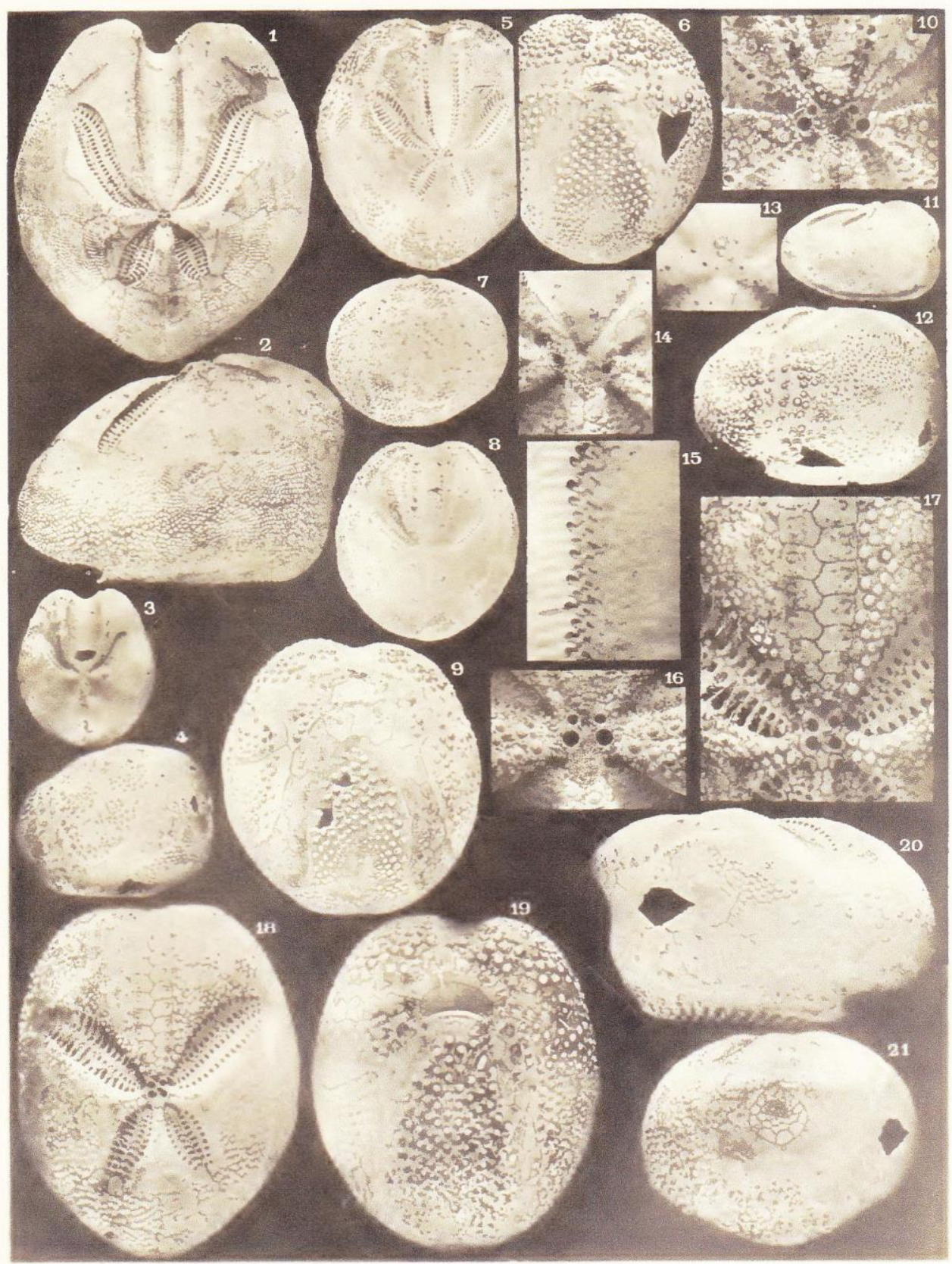




\section{PLATE $X$}

Prymnaster angulatus. fig. 1 to 8; Brisaster indicus, Fig. 9 to 13.

Fig. 1. Prymnaster angulatus. Dorsal surface of specimen B. Magnification 3.5.

Fig. 2. Prymnaster angulatus. Ventral surface of specimen D. Magnification 4.

Fig. 3. Prymnaster angulatus. Dorsal surface of specimen A. Magnification 3.3.

Fig. 4. Prymnaster angulatus. Ventral surface of the same. Magnification 3.3.

Fig. 5. Prymnaster angulatus. Dorsal surface of the test seen from the internal side. Magnification 3.3.

Fig. 6. Prymnaster angululus. Posterior end of specimen A. Magnification 3.5.

Fig. 7. Prymnaster angulatus. Lateral view of same. Magnification 3.5.

Fig. 8. Prymnaster angulalus. Apical system and anterior ambulacrum of the same. Magnification 9.

Fig. 9. Brisaster indicus. Ventral surface. Magnification 5.6.

Fig. 10. Brisaster indicus. Dorsal surface. Magnification 5.6.

Fig. 11. Brisaster indicus. Lateral view. Magnification 5.6.

Fig. 12. Brisaster indicus. Apical system and anterior ambulacrum. Magnification 11.

Fig. 13. Brisaster indicus. Posterior end. Magnification 5.6. 


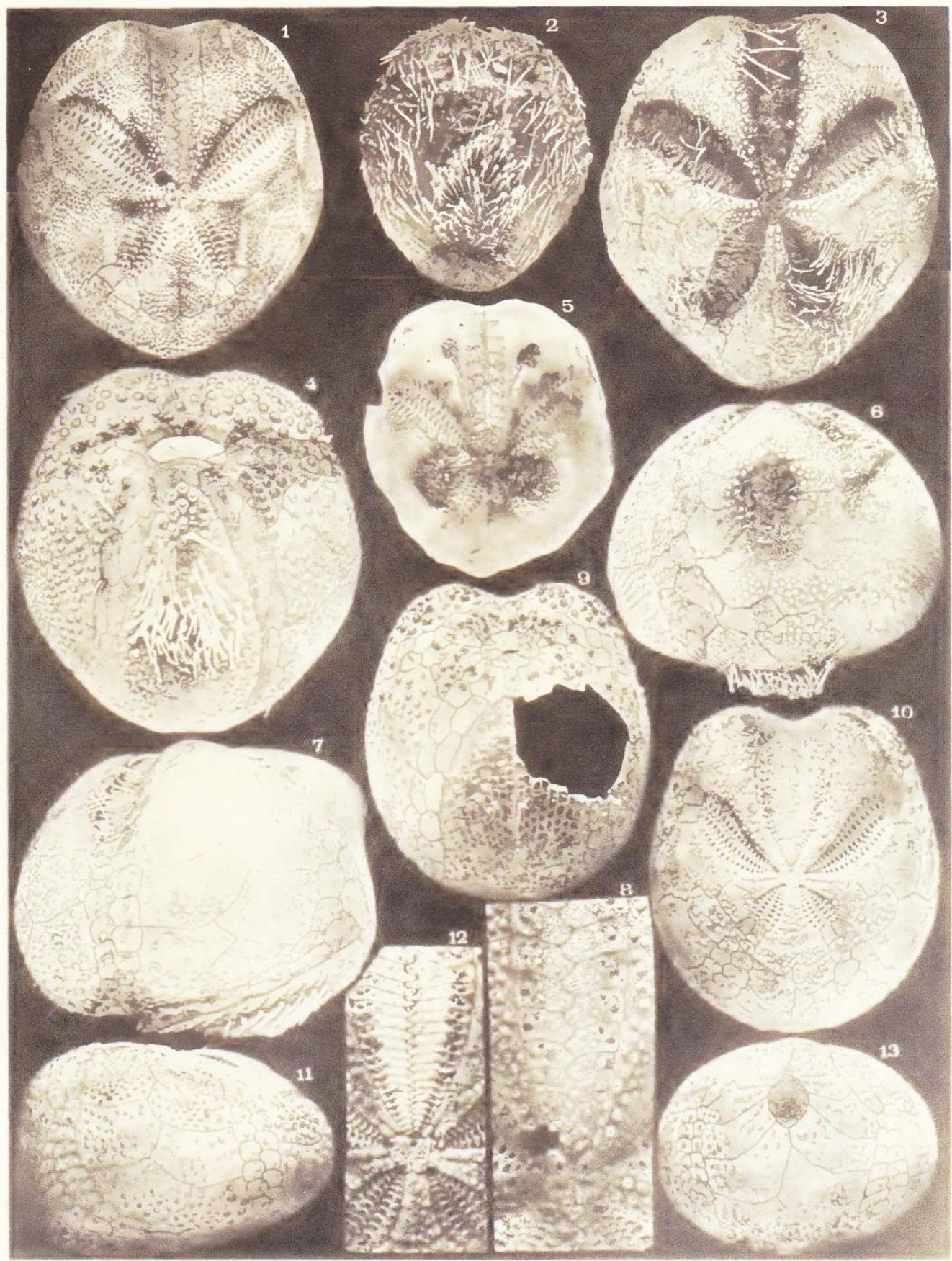

It. Riviter phat, 


\section{PLATE XI}

Eurypneustes rubens, fig. 1, 3, 4, 10 to 13; Eurypneustes denudatus, fig. 2. Lovenia elongata, fig. 5 and 6; Linopneustes spectabilis, fig. 7 and 8.

Pseudomaretia alta. fig. 9, 14 to 17 and 20; Maretia planulata, fig. 18 and 19.

Fig. 1. Eurypneustes rubens. Ventral surface of specimen A. Magnification 1.4.

Fig. 2. Eurypneustes denudatus. Posterior end of specimen C. Magnification 1.25.

Fig. 3. Eurypneustes rubens. Lateral view. Magnification 1.4.

Fig. 4. Eurypneustes rubens. Posterior end. Magnification 1.4.

Fig. 5 and 6. Lovenia elongata. Periproctal invagination seen from the internal surface of the test of two different specimens. Magnification 1.7.

Fig. 7. Linopneustes spectabilis. Anterior end of specimen A. Reduced approximately 1/4.

Fig. 8. Linopneustes spectabilis. Lateral view of specimen A. Same reduction.

Fig. 9. Pseudomaretia alta. Apical system. Magnification 8.

Fig. 10. Eurypneustes rubens. Oblique view of the posterior part of the test of specimen A. Magnification 1.4.

Fig. 11. Eurypneustes rubens. Apical system and anterior ambulacrum of specimen B. Magnification 6.

Fig. 12. Eurypneustes rubens. Apical system of specimen A. Magnification 6.

Fig. 13. Eurypneustes rubens. Dorsal surface of specimen A. Magnification 1.4.

Fig. 14. Pseudomaretia alta. Dorsal surface. Magnification 1.6.

Fig. 15. Pseudomaretia alta. Ventral surface. Magnification 1.6.

Fig. 16. Pseudomaretia alta. Posterior region of the test, seen from the internal surface. Magnification 1.6.

Fig. 17. Pseudomaretia alta. Posterior end. Magnification 1.6.

Fig. 18. Maretia planulata. Posterior end. Magnification 1.6.

Fig. 19. Maretia planulata. Lateral view. Magnification 1.6.

Fig. 20. Pseudomaretia alta. Lateral view. Magnification 1.6 


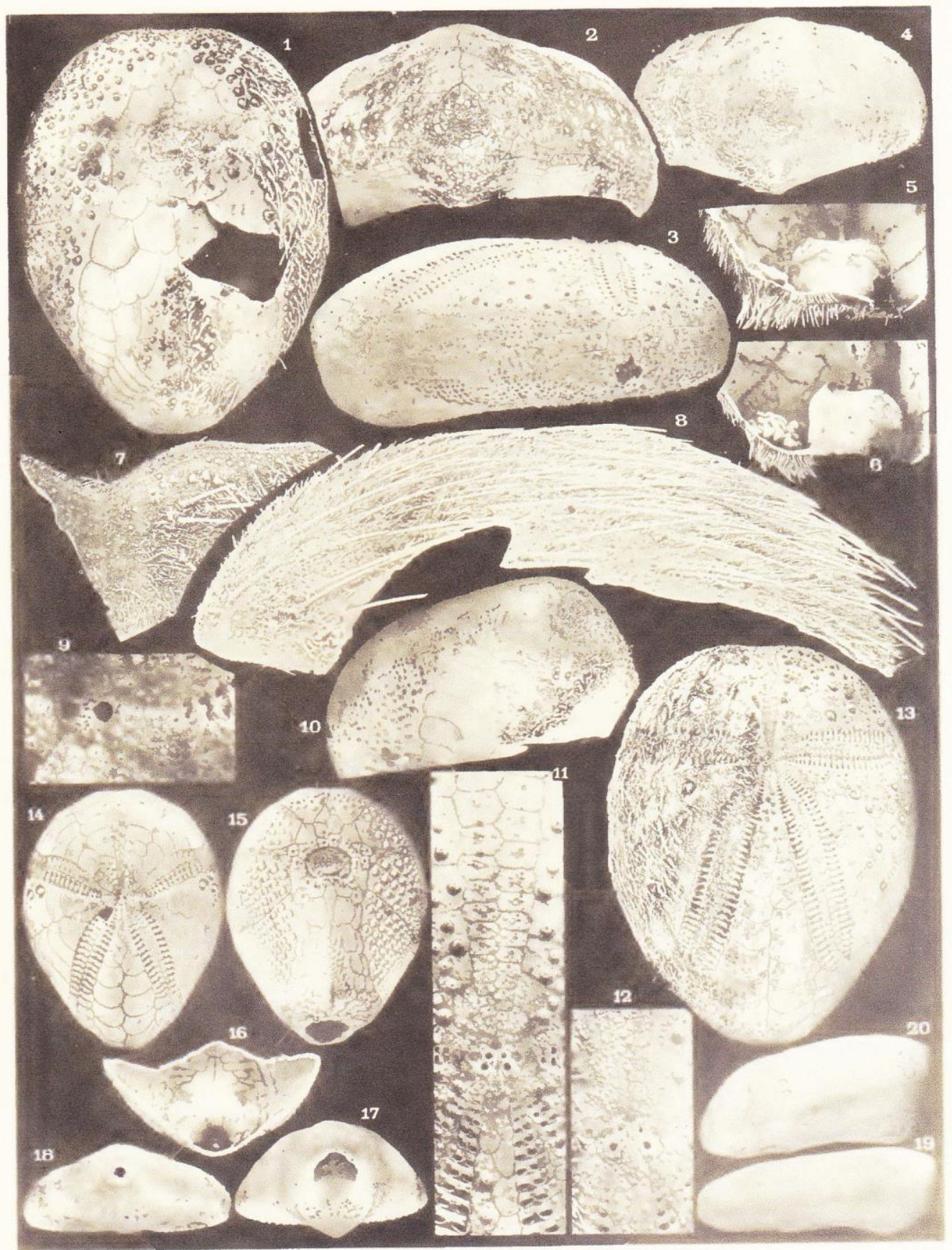




\section{PLATE XII}

Pericosmus macronesius, fig. 1 to 5; Lovenia gregalis, fig. 6 to 9 and 11;

Lovenia elongata, fig. 10; Brissopsis parallela, fig. 12 and 13.

Fig. 1. Pericosmus macronesius. Dorsal surface, slightly enlarged.

Fig. 2. Pericosmus macronesius. Ventral surface, slightly enlarged.

Fig. 3. Pericosmus macronesius. Lateral view, slightly enlarged.

Fig. 4. Pericosmus macronesius. Posterior end, slightly enlarged.

Fig. 5. Pericosmus macronesius. Apical system. Magnified 2.8.

Fig. 6. Lovenia gregalis. Posterior end. Natural size.

Fig. 7. Lovenia gregalis. Dorsal surface. Natural size.

Fig. 8. Lovenia gregalis. Ventral surface. Natural size.

Fig. 9. Lovenia gregalis. Lateral view. Natural size.

Fig. 10. Lovenia elongata. Internal surface of the test at the level of the two paired interradii.

Reduced 1/5.

Fig. 11. Lovenia gregalis. Ventral surface of a specimen with spines. Natural size.

Fig. 12. Brissopsis parallela. Dorsal surface of specimen C. Magnified 1.6.

Fig. 13. Brissopsis parallela. Dorsal surface of specimen A. Magnified 1.7. 


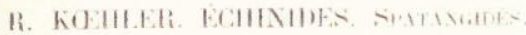

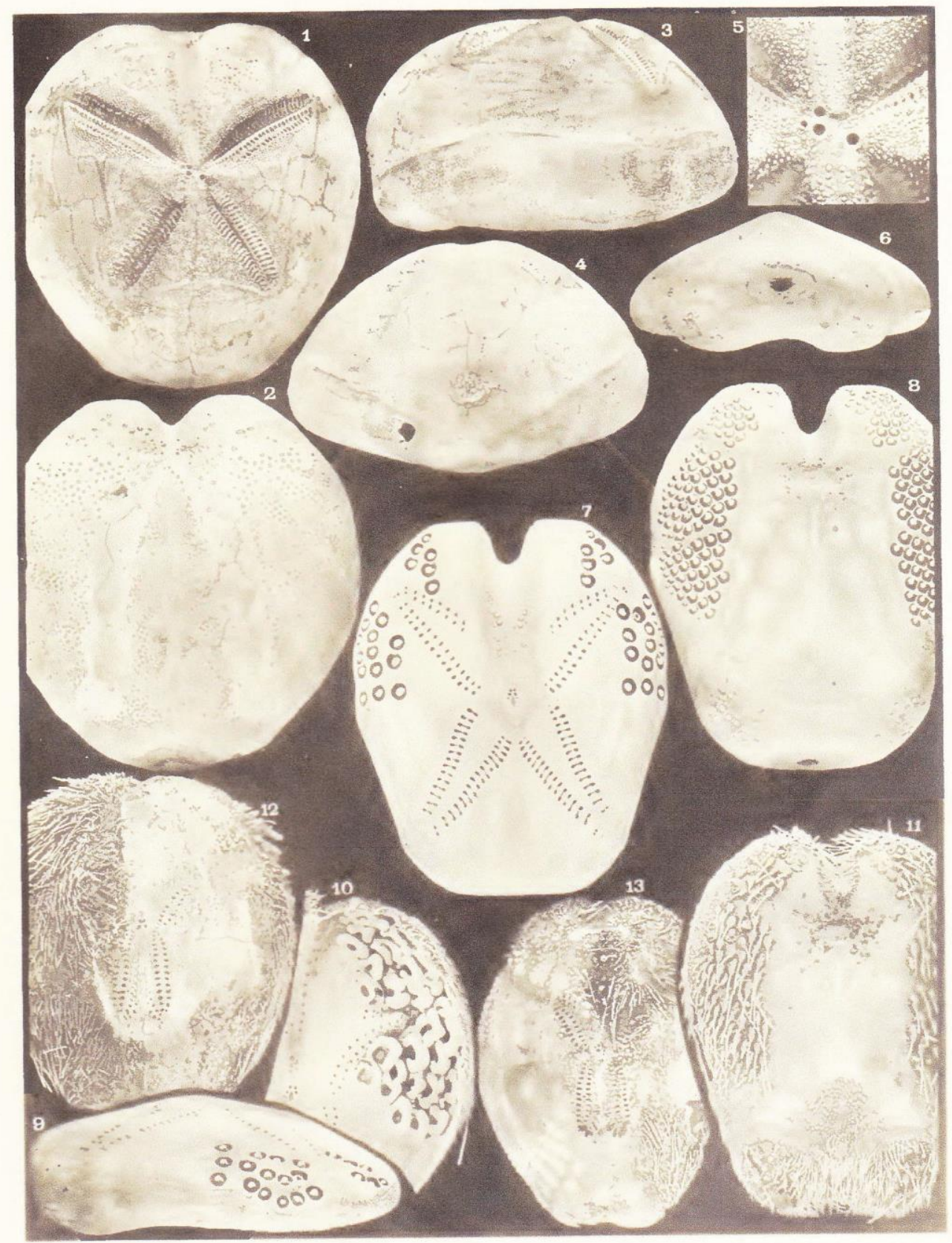




\section{PLATE XIII}

Gymnopatagus Sewelli, fig. 1 to 7; Lovenia elongata, fig. 8;

Lovenia trifolis, fig. 9 to 13; Faorina chinensis, fig. 14 and 15;

Brissopsis luzonica, fig. 16; Brissopsis parallela, fig. 17.

Fig. 1. Gymnopatagus Sewelli. Periproct. Magnification 1.2.

Fig. 2. Gymnopatagus Sewelli. Apical system and anterior ambulacrum. Magnified 5.

Fig. 3. Gymnopatagus Sewelli. Fragment from station 228, slightly enlarged.

Fig. 4. Gymnopatagus Sewelli. Dorsal surface of specimen A, very slightly enlarged.

Fig. 5. Gymnopatagus Sewelli. Lateral view of the same, very slightly enlarged.

Fig. 6. Gymnopatagus Sewelli. Anterior end of specimen C, slightly enlarged.

Fig. 7. Gymnopatagus Sewelli. Anterior end of specimen B, slightly enlarged.

Fig. 8. Lovenia elongata. Dorsal surface of a small individual. Magnification 1.6.

Fig. 9. Lovenia trifolis. Ventral surface. Magnification 1.7.

Fig. 10. Lovenia trifolis. Dorsal surface. Magnification 1.7.

Fig. 11. Lovenia trifolis. Posterior surface. Magnification. 1.7.

Fig. 12. Lovenia trifolis. Lateral view. Magnification 1.7.

Fig. 13. Lovenia trifolis. Apical system. Magnification 6.

Fig. 14. Faorina chinensis. Apical system. Magnification 4.

Fig. 15. Faorina chinensis. Digestive tube seen from the ventral side. Natural size.

Fig. 16. Brissopsis luzonica. Apical system. Magnification 7.5.

Fig. 17. Brissopsis parallela. Apical system. Magnification 8.5. 


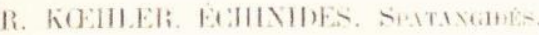

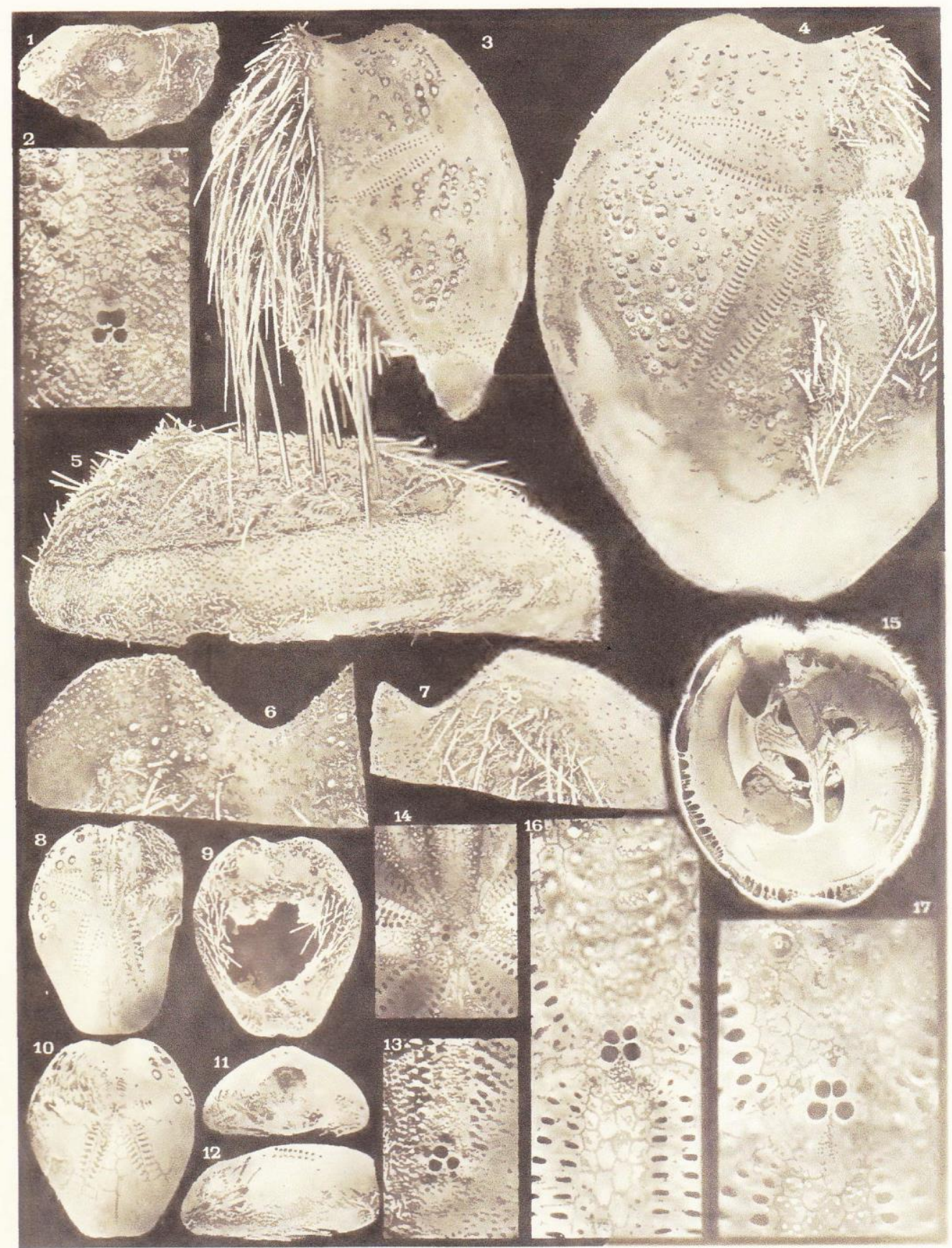




\section{PLATE XIV}

Brissopsis Oldhami, fig. 1 to 3; Brissopsis luzonica, 4, 5, 7, 12 and 13; Brissopsis parallela, fig. 6, 10, 11 and 14.

Fig. 1. Brissopsis Oldhami. Dorsal view of the type specimen E. Magnification 1.7.

Fig. 2. Brissopsis Oldhami. Dorsal view of specimen D. Magnification 1.3.

Fig. 3. Brissopsis Oldhami. Ventral surface of the same. Magnification 1.3.

Fig. 4. Brissopsis luzonica. Dorsal surface of the specimen from station 98. Magnification 1.5.

Fig. 5. Brissopsis luzonica. Ventral surface of the same. Magnification 1.5.

Fig. 6. Brissopsis parallela. Lateral view of specimen A. Magnification 1.7.

Fig. 7. Brissopsis luzonica. Posterior surface. Magnification 1.5.

Fig. 8. Brissopsis Oldhami. Lateral view. Magnification 1.3.

Fig. 9. Brissopsis Oldhami. Posterior surface. Magnification 1.3.

Fig. 10. Brissopsis parallela. Ventral surface. Magnification 1.7.

Fig. 11. Brissopsis parallela. Posterior surface. Magnification 1.7.

Fig. 12. Brissopsis luzonica. Lateral view. Magnification 1.5.

Fig. 13. Brissopsis luzonica. Oblique view of the posterior end. Magnification 1.5.

Fig. 14. Brissopsis parallela. Doral surface of specimen B. Magnification. 1.7.

Fig. 15. Brissopsis Oldhami. Apical system. Magnification 1.5. 


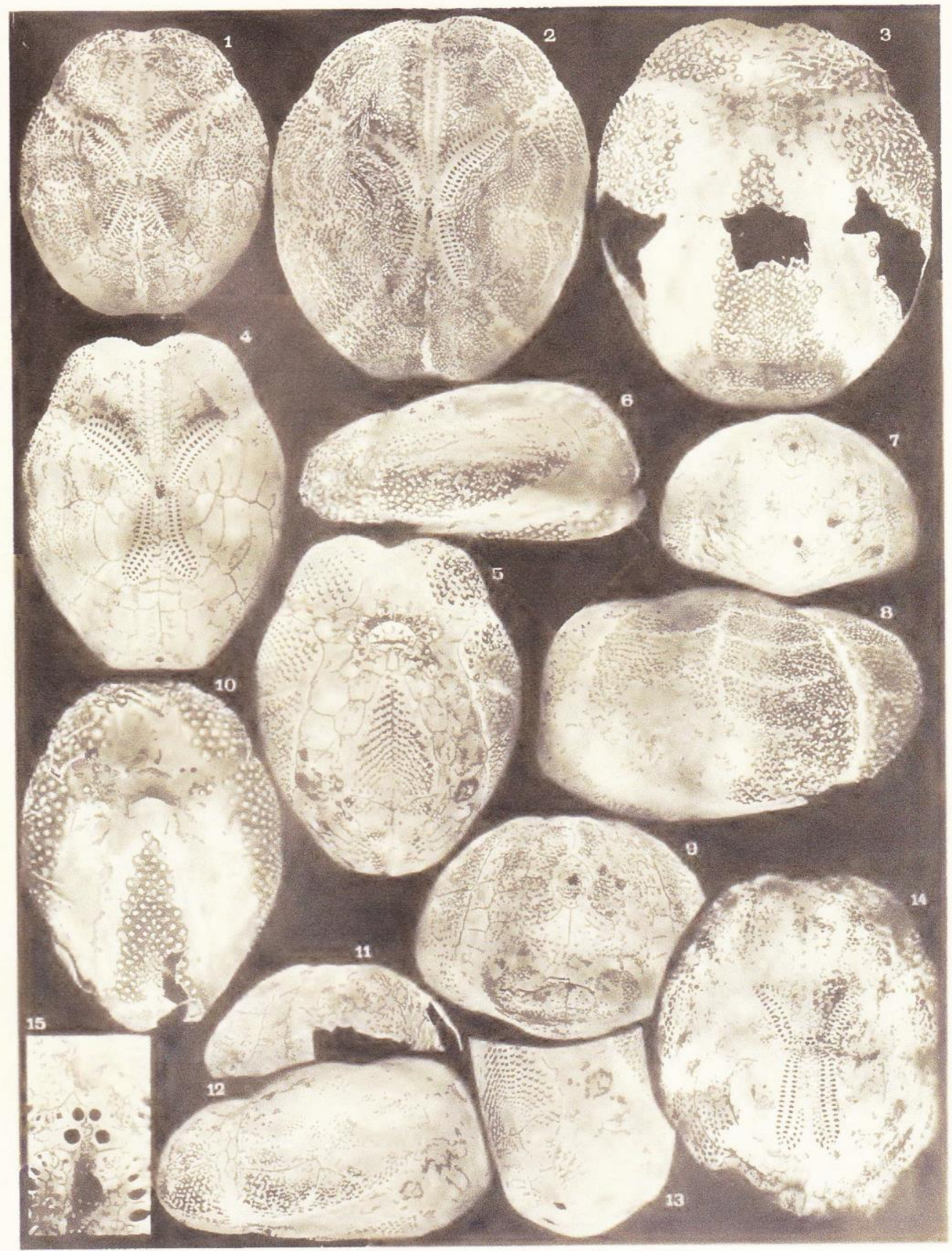

Ii. Kinkiler plut. 


\section{PLATE XV}

Brissopsis bengalensis, fig. 1 to 11; Brissopsis Oldhami, fig. 12.

Fig. 1. Bissopsis bengalensis. Dorsal surface of specimen B. Magnification 1.2.

Fig. 2. Bissopsis bengalensis. Dorsal surface of specimen A. Magnification 1.3.

Fig. 3. Brissopsis bengalensis. Oblique view of the posterior end of the same. Magnification 1.3.

Fig. 4. Brissopsis bengalensis. Dorsal surface of specimen C (elongated). Magnification 1.2.

Fig. 5. Brissopsis bengalensis. Ventral surface of specimen D (widened). Magnification 1.4.

Fig. 6. Brissopsis bengalensis. Dorsal surface of a very widened individual. Magnification 1.3.

Fig. 7. Brissopsis bengalensis. Lateral view of specimen D (widened). Magnification 1.4.

Fig. 8. Brissopsis bengalensis. Posterior surface of the same. Magnification 1.4.

Fig. 9. Brissopsis bengalensis. Lateral view of specimen C (elongated). Magnification 1.2.

Fig. 10. Brissopsis bengalensis. Apical system. Magnification 6.5.

Fig. 11. Brissopsis bengalensis. Posterior surface of specimen C (elongated). Magnification 1.2.

Fig. 12. Brissopsis Oldhami. Oblique view of the posterior end of specimen D. Magnification 1.2 . 


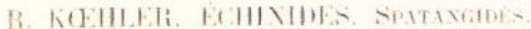

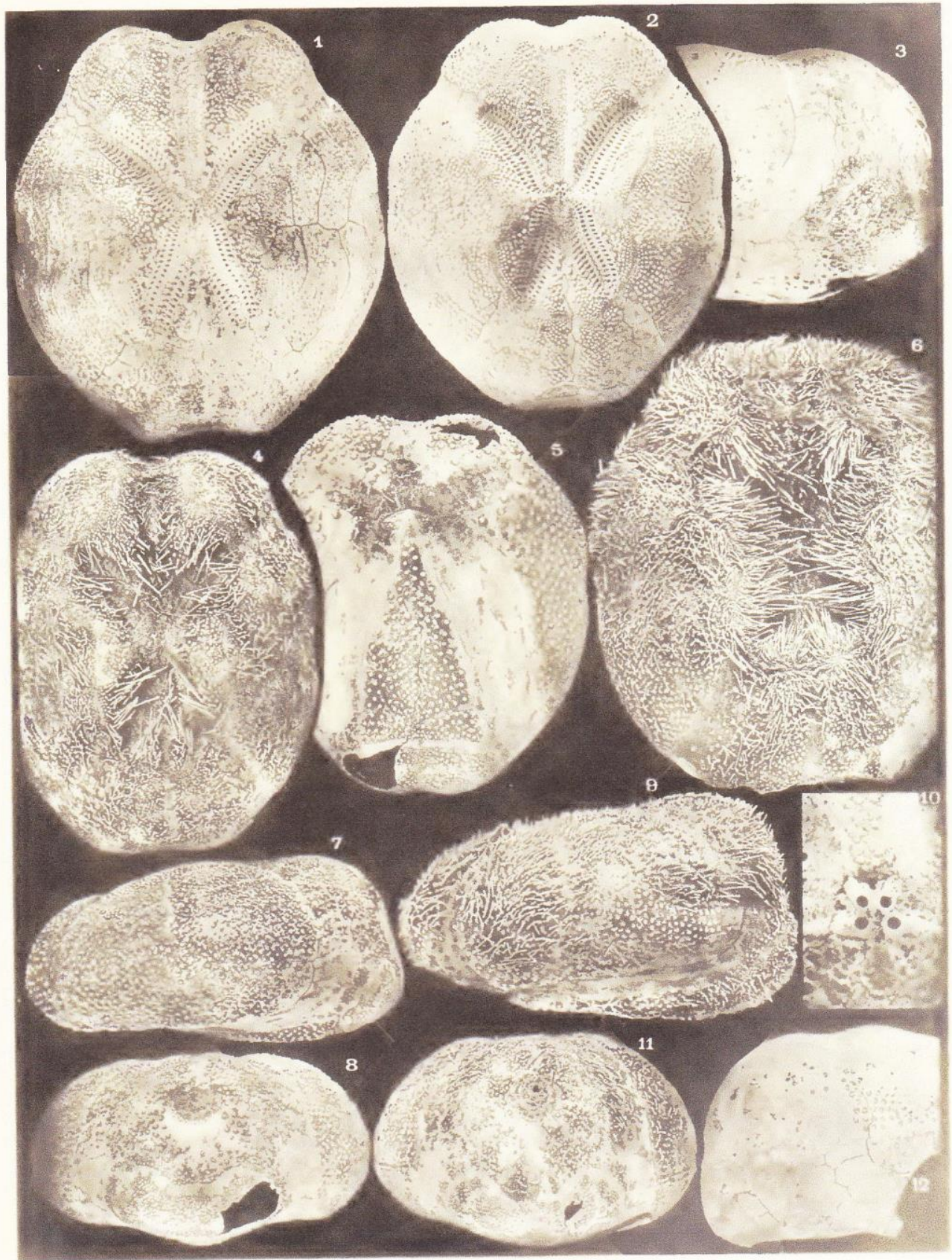




\title{
PLATE XVI
}

\author{
Pourtalesia Alcocki, fig. 1 to 15.
}

Fig. 1. Primary spine with teeth very close together, coming from the periproctal notch. Magnification 70.

Fig. 2 et 3. Terminal parts of two small spines of the periproctal notch. Magnification 115.

Fig. 4. Calcareous stem of a clavule. Magnification 100.

Fig. 5. Miliary spine with widened end. Magnification 100.

Fig. 6. Small primary spines of the periproctal notch. Magnification 35.

Fig. 7, 8, 9, 10 and 15. Different forms of spines, coming from the anterior invagination. Magnification 55.

Fig. 11. Cylindrical miliary spine. Magnification 90.

Fig. 12. Rostrate pedicellaria of the second form. Magnification 90.

Fig. 13. Tridactyle pedicellaria. Magnification 40.

Fig. 14. Rostrate pedicellaria of the first form. Magnification 100.

Aceste Annandalei, fig. 16 to 34.

Fig. 16. Tridactyle pedicellaria with a large and very wide head. Magnification 55.

Fig. 17 and 18. Smaller tridactyle pedicellariae of the fourth form. Magnification 70.

Fig. 19. Tridactyle pedicellaria of the fourth form with a very concave blade. Magnification 55.

Fig. 20 and 21. Two valves of a tridactyle pedicellaria of the second form. Magnification 55.

Fig. 22. Calcareous stem of a clavule. Magnification 100.

Fig. 23. Slightly capitate spine of the dorsal ambulacral groove. Magnification. 55.

Fig. 24. Small tridactyle pedicellaria of the first form. Magnification 115.

Fig. 25. Tridactyle pedicellaria of the second form. Magnification 5.5.

Fig. 26. Tridactyle pedicellaria of the fourth form with a very concave blade. Magnification 55 .

Fig. 27. Globiferous pedicellaria. Magnification 45.

Fig. 28. Small rostrate pedicellaria. Magnification 250.

Fig. 29 to 31. Tridactyle pedicellariae of the first form. Magnification 70 .

Fig. 32. Rod of a rosette of a frontal pedicel, seen in profile. Magnification 100.

Fig. 33 and 34. Two valves of tridactyle pedicellariae (fourth form), with very concave blade.

Magnification 55.

Aceste bellidifera. fig. 35 and 36.

Fig. 35. Capitate spine of the dorsal groove. Magnification 55.

Fig. 36. Rod of a rosette of a frontal pedicel. Magnification 100.

Aceste Weberi, fig. 37 to 43.

Fig. 37. Miliary spine. Magnification 55.

Fig. 38. Tridactyle pedicellaria of the second form. Magnification 70.

Fig. 39. Slightly capitate spine from the dorsal groove. Magnification 90. 
Fig. 40. Rostrate pedicellaria. Magnification 55.

Fig. 41. Tridactyle pedicellaria of the third form. Magnification 55.

Fig. 42. Tridactyle pedicellaria of the second form. Magnification 70.

Fig. 43. Rod of a rosette of a front pedicel. Magnification 100. 


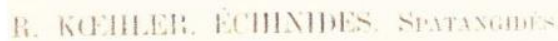

Pi. XY1

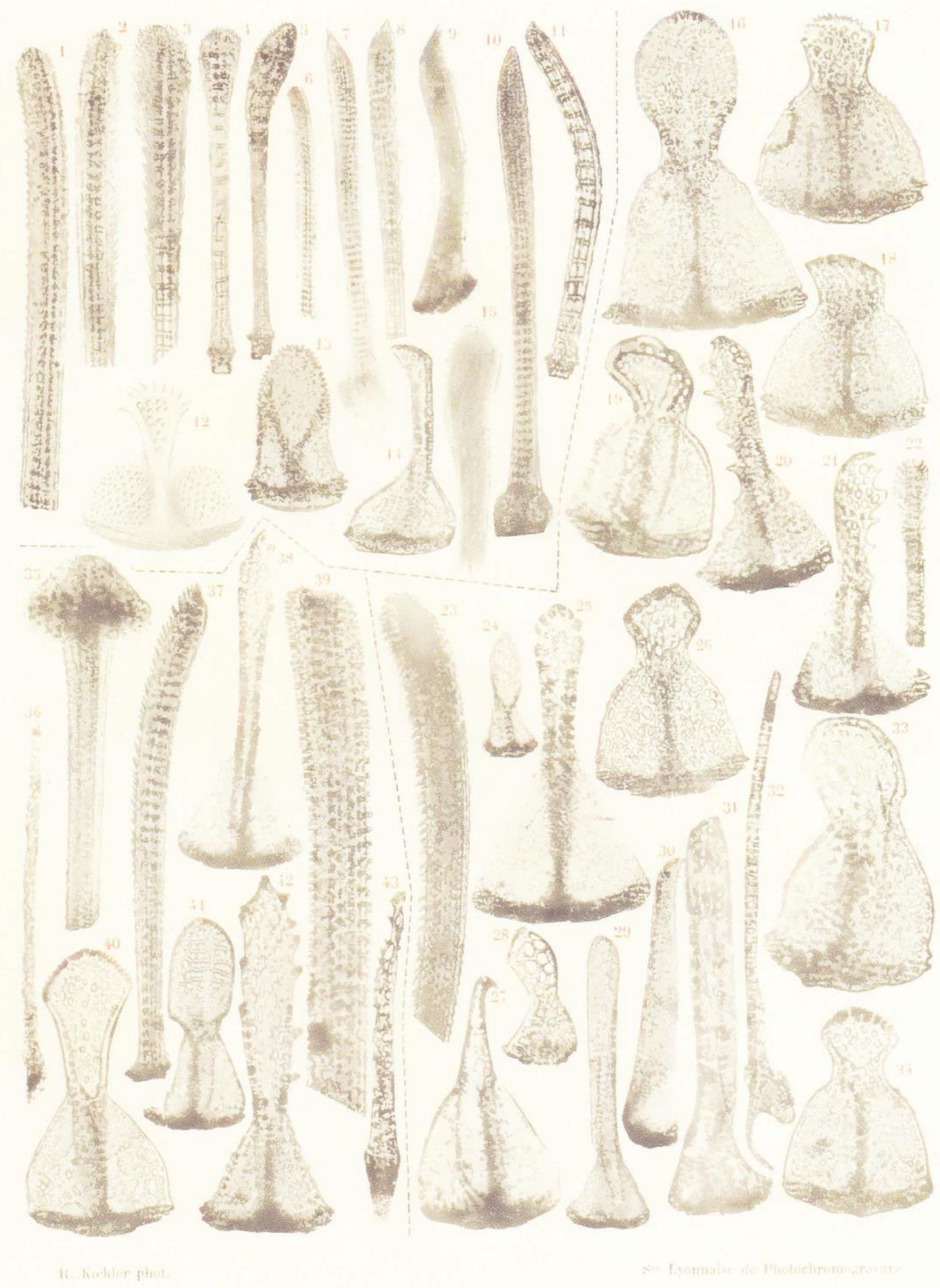

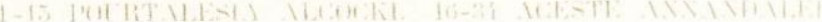

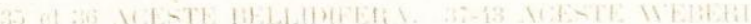




\title{
PLATE XVII
}

\author{
Aceste Annandalei, fig. 1 to 5.
}

Fig. 1. Primary spine of the anterior notch. Magnification 15.

Fig. 2. Spatulate spine of the sternum, seen from the front. Magnification 15.

Fig. 3. Primary spine of the ventral surface. Magnification 15.

Fig. 4. Spatulate spine of the sternum, seen from the side. Magnification 15.

Fig. 5. Primary spine of the ventral surface. Magnification 15.

Aeropsis Siboga, fig. 6 to 18.

Fig. 6. Large tridactyle pedicellaria with elongated valves. Magnification 55.

Fig. 7. Ordinary tridactyle pedicellaria. Magnification 55.

Fig. 8 and 9. Primary spines. Magnification 15.

Fig. 10. Capitate spine of the dorsal surface. Magnification 30.

Fig. 11. Portion of a rod of a rosette of a frontal pedicel, seen from the front. Magnification 70.

Fig. 12. Rod of a rosette of a frontal pedicel, seen in profile. Magnification 70.

Fig. 13. Miliary spine. Magnification 100.

Fig. 14. Small tridactyle pedicellaria. Magnification 100.

Fig. 15. Calcareous stem of the peduncle of a rostrate pedicellaria. Magnification 100.

Fig. 16. Calcareous stem of a clavule. Magnification 120.

Fig-. 17. Rostrate pedicellaria. Magnification 55.

Fig. 18. Calcareous stem of the peduncle of a tridactyle pedicellaria. Magnification 100.

Paleostoma mirabile, fig. 19 to 29.

Fig. 19. Secondary spine. Magnification 90.

Fig. 20. Miliary spine. Magnification 90.

Fig. 21. Ophiocephalous pedicellaria. Magnification 170.

Fig. 22 and 23. Valves of globiferous pedicellaria. Magnification 170.

Fig. 24. Secondary spine. Magnification 90.

Fig. 25. Primary spine. Magnification 55.

Fig. 26. Calcareous stem of a clavule. Magnification 100.

Fig. 27. Rods from a rosette of a frontal pedicel. Magnification 170.

Fig. 28. Primary spine. Magnification 55.

Fig. 29. Tridactyle pedicellaria. Magnification 170.

Fig. 30 and 31. Globiferous pedicellariae of Paleotropus Hirondellei. Magnification 120.

Paleotropus ovatus, fig. 32 to 35 .

Fig. 32. Calcareous stem of a clavule. Magnification 115.

Fig. 33. Secondary spine. Magnification 90/

Fig. 34. Ophiocephalous pedicellaria. Magnification 220.

Fig. 35. Tridactyle pedicellaria. Magnification 200. 
Fig. 36. Tridactyle pedicellaria of the second form. Magnification 55.

Fig. 37. Primary spine, middle region. Magnification 15.

Fig. 38. Primary spine, end. Magnification 15.

Fig. 39. Tridactyle pedicellaria of the second form. Magnification 55.

Fig. 40. Tridactyle pedicellaria with a very narrow blade (third form). Magnification 90.

Fig. 41. Trifoliate pedicellaria. Magnification 110.

Fig. 42. Large tridactyle pedicellaria of the first form. Magnification 55.

Fig. 43. Rostrate pedicellaria. Magnification 70.

Fig. 44. Ends of two primary spines of the ventral surface. Magnification 10.

Fig. 45 and 46. Large tridactyle pedicellariae of the first form. Magnification 55.

Pig. 47. Tridactyle pedicellaria of the second form. Magnification 55.

Fig. 48. Calcareous stem of a clavule. Magnification 115.

Fig. 49. Large tridactyle pedicellaria of the first form. Magnification 55.

Fig. 50. Small tridactyle pedicellaria of the first form. Magnification 90.

Fig. 51. Small tridactyle pedicellaria of the third form. Magnification 115.

Linopneustes longispinus, fig. 52 to 65.

Fig. 52. Large tridactyle pedicellaria with elongated valves (first form). Magnification 55.

Fig. 53. Tridactyle pedicellaria with widened valves of the fourth form. Magnification 90.

Fig. 54. Large tridactyle pedicellaria of the first form. Magnification 55.

Fig. 55. Tridactyle pedicellaria with widened valves of the fourth form. Magnification 90.

Fig. 56. Rostrate pedicellaria. Magnification 110.

Fig. 57. Large tridactyle pedicellaria of the first form. Magnification 55.

Fig. 58. Small tridactyle pedicellaria with elongated valves (second form). Magnification 150.

Fig. 59. Trifoliate pedicellaria. Magnification 130.

Fig. 60. Tridactyle pedicellaria, with a very narrow blade of the third form. Magnification 110.

Fig. 61. Miliary spine. Magnification 55.

Fig. 62. Very small tridactyle pedicellaria. Magnification 110.

Fig. 63. Tridactyle pedicellaria with a very narrow blade (third form). Magnification 110.

Fig. 64. Peduncle of a tridactyle pedicellaria. Magnification 35.

Fig. 65. Miliary spine with very dense denticulations. Magnification 65. 


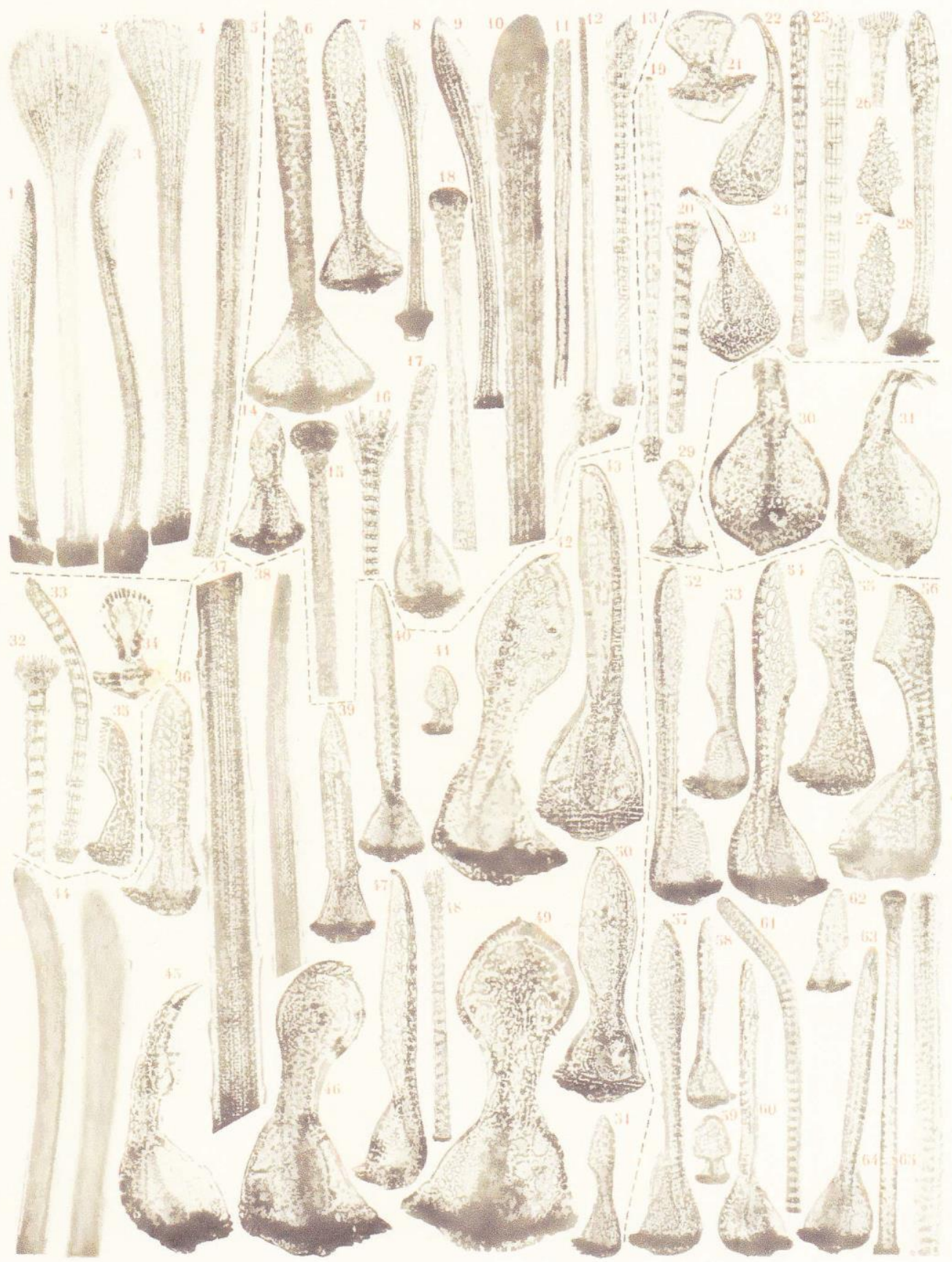

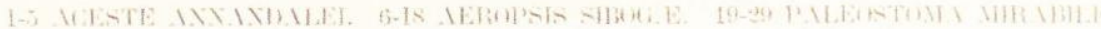

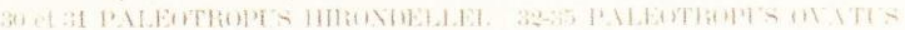

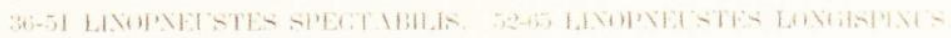




\section{PLATE XVIII}

Archeopneustes Hemingi. fig. 1 to 11.

Fig. 1. Small rostrate pedicellaria. Magnification 90.

Fig. 2. Large rostrate pedicellaria. Magnification 55.

Fig. 3. Globiferous pedicellaria. Magnification 90.

Fig. 4. Small rostrate pedicellaria. Magnification 120.

Fig. 5. Tridactyle pedicellaria. Magnification 120.

Fig. 6. End of a primary spine of the dorsal surface. Magnification 15.

Fig. 7. Primary spine of the dorsal surface. Magnification 5.

Fig. 8. Secondary spine covered with dense denticulations. Magnification 20.

Fig. 9. Trifoliate pedicellaria. Magnification 150.

Fig. 10. Spheridium. Magnification 60.

Fig. 11. Ophiocephalous pedicellaria. Magnification 80 .

\section{Eurypneustes denudatus, fig. 12 to 20}

Fig. 12. Tridactyle pedicellaria of the first form. Magnification 90.

Fig. 13. Tridactyle pedicellaria of the second form. Magnification 150.

Fig. 14. Trifoliate pedicellaria. Magnification 150.

Fig. 15. Miliary spine. Magnification 15.

Fig. 16. Spicules of peristomial pedicels. Magnification 120.

Fig. 17. Large pedicellariae with narrow and elongated valves (third form). Magnification 55.

Fig. 18. Stem of the peduncle of a tridactyle pedicellaria. Magnification 90.

Fig. 19. Tridactyle pedicellaria of the first form. Magnification 90.

Fig. 20. Spheridium. Magnification 40.

Homolampas glauca, fig. 21 to 28.

Fig. 21. End of a spine of the anterior groove. Magnification 10.

Fig. 22. Tridactyle pedicellaria of the second form. Magnification 100.

Fig. 23. Tridactyle pedicellaria of the first form. Magnification 70.

Fig. 24. Large tridactyle pedicellaria of the first form. Magnification 55.

Fig. 25. Small tridactyle pedicellaria with narrow valves Magnification 70.

Fig. 26. Rostrate pedicellaria, seen from the front. Magnification 55.

Fig. 27. Rostrate pedicellaria, seen from the profile. Magnification 55.

Fig. 28. Tridactyle pedicellaria of the second form. Magnification 100.

Eurypneustes rubens, fig. 29 to 38.

Fig. 29. Spheridium. Magnification 100.

Fig. 30. Small tridactyle pedicellaria of the second form. Magnification 150.

Fig. 31. Large tridactyle of the second form. Magnification 150.

Fig. 32. Small tridactyle of the second form. Magnification 150.

Fig. 33. Small tridactyle with very narrow valves. Magnification 150. 
Fig. 34. Rostrate pedicellaria. Magnification 55.

Fig. 35. Ophiocephalous pedicellaria, seen from the front. Magnification 150.

Fig. 36. Tridactyle pedicellaria of the first form, with narrow valves. Magnification 115.

Fig. 37. Tridactyle pedicellaria of the first form, with widened valves. Magnification 115.

Fig. 38. Ophiocephalous pedicellaria, seen from profile. Magnification 150.

Hemiaster Hickmani. fig. 39 to 48.

Fig. 39. Rod of a rosette of a frontal pedicel. Magnification 115.

Fig. 40. Tridactyle pedicellaria with elongated valves of the second form. Magnification55.

Fig. 41 and 42. Tridactyle pedicellaria with widened valves of the first form. Magnification 65.

Fig. 43 to 45. Rostrate pedicellariae of various forms. Magnification 55.

Fig. 46. Calcareous stem of a clavule. Magnification 115.

Fig. 47 and 48. Small tridactyle pedicellariae. Magnification 115.

Hemiaster vanus, fig. 49 to 59

Fig. 49 and 50. Small tridactyle pedicellariae, with elongated valves, of the second form. Magnification 100.

Fig. 51 and 53. Calcareous stems of two clavules. Magnification 115.

Fig. 52. Rod of a rosette of a frontal pedicel, seen from the front. Magnification 115.

Fig. 54. Rod of a rosette of a frontal pedicel, seen from the profile. Magnification 115.

Fig. 55. Rod of a rosette of a frontal pedicel, seen from the front. Magnification 115.

Fig. 56 and 57. Tridactyle pedicellariae with widened valves, of the first form. Magnification 65.

Fig. 58. Rostrate pedicellaria. Magnification 90.

Fig. 59. Tridactyle pedicellaria, with short valves, of the third form. Magnification 90 


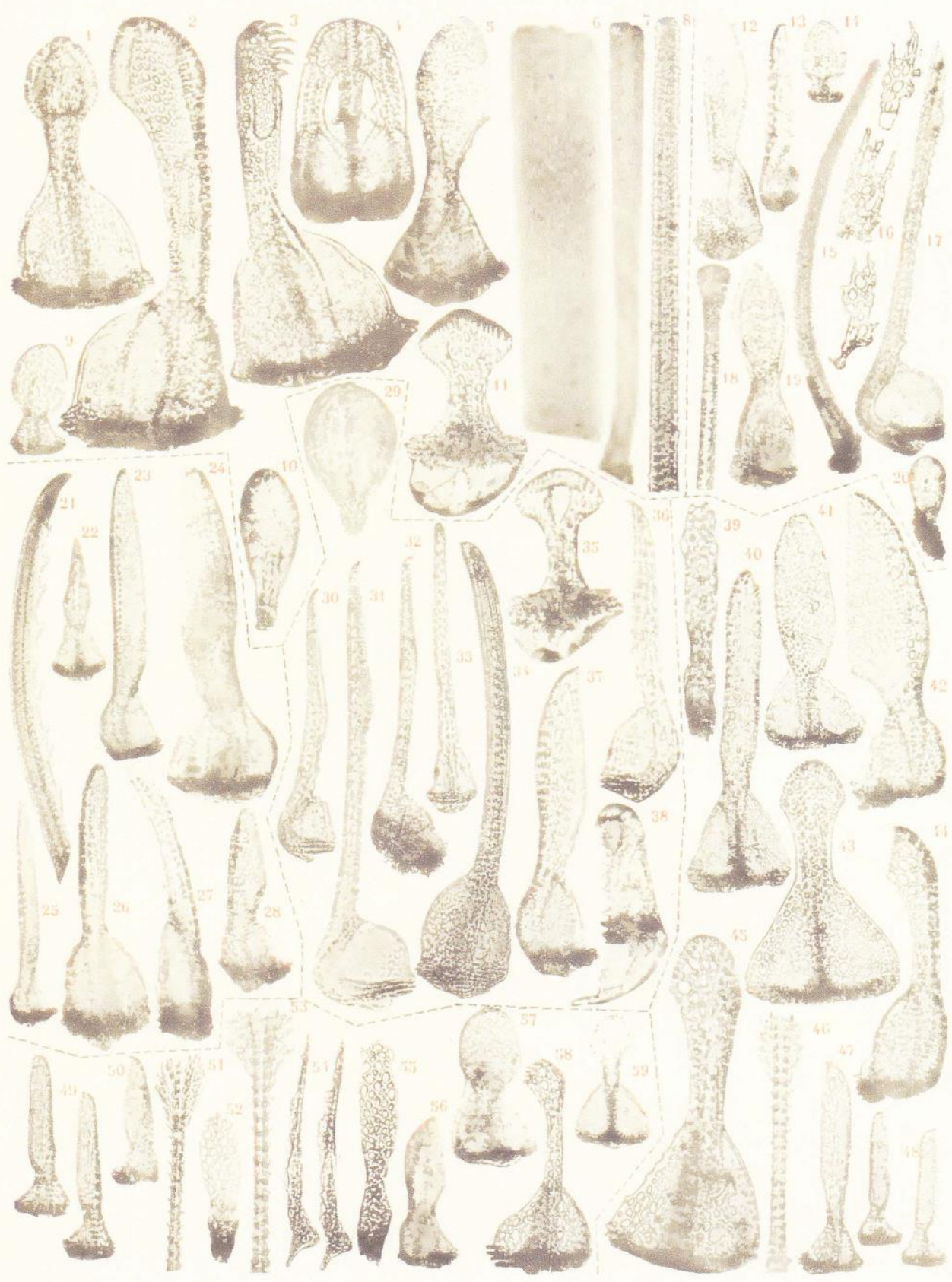




\section{PLATE XIX}

Periaster Kempi, fig. 1 to 13.

Fig. 1. Miliary spine. Magnification 100.

Fig. 2. Miliary spine. Magnification 100.

Fig. 3. Primary spine of the anterior groove. Magnification 15.

Fig. 4. End of the calcareous stem of a globiferous pedicellaria. Magnification 60.

Fig. 5. Primary spine enlarged as a spatula at the end. Magnification 15.

Fig.6 and 7. Valves of globiferous pedicellariae. Magnification 75.

Fig. 8 to 10. Valves of tridactyle pedicellariae. Magnification 100.

Fig. 11. Rod of a rosette of a frontal pedicel, seen from the front. Magnification 100.

Fig. 12. Rod of a rosette of a frontal pedicel, see from the profile. Magnification 100.

Fig. 13. Rostrate pedicellaria. Magnification100.

Faorina chinensis, fig. 14 to 24 .

Fig. 14. Tridactyle pedicellaria. Magnification 90.

Fig. 15. Small rostrate pedicellaria. Magnification 75.

Fig. 16 and 17. Tridactyle pedicellariae. Magnification 90.

Fig. 18. Small tridactyle pedicellaria. Magnification 120.

Fig. 19. Large rostrate pedicellaria, of the first form. Magnification 55.

Fig. 20 and 21. Miliary spines. Magnification 100.

Fig. 22. Secondary spine, with very dense denticulations. Magnification 90.

Fig. 23. Calcareous stem of rostrate pedicellaria. Magnification 60.

Fig. 24. Ophiocephalous pedicellaria. Magnification 120.

\section{Lovenia elongata, fig. 25 to 32 .}

Fig. 25. Tridactyle pedicellaria with fusiform calcareous stem, entire. Magnification 60.

Fig. 26. Isolated valves of the same pedicellaria. Magnification 100.

Fig. 27. Rostrate pedicellaria of the second form. Magnification 120.

Fig. 28. Trifoliate pedicellaria. Magnification 120.

Fig. 20. Isolated calcareous stem of the tridactyle pedicellaria represented in fig 25. Magnification 90.

Fig. 30. Tridactyle pedicellaria of the third form. Magnification 120.

Fig. 31. Rostrate pedicellaria of the first form. Magnification 60.

Fig. 32. Tridactyle pedicellaria of the second form. Magnification 120.

\section{Lovenia gregalis, fig. 33 to 45 .}

Fig. 33. Small tridactyle pedicellaria with fairly wide valves, of the second form. Magnification 75.

Fig. 34. Spine of the anterior groove. Magnification 15.

Fig. 35. Tridactyle pedicellariae with blade nearly lacking in perforations (third form. Magnification 75. 
Fig. 36. Small tridactyle pedicellaria of the second form. Magnification 75.

Fig. 37. Tridactyle pedicellaria of the first form. Magnification 55.

Fig. 38. Calcareous stim of a clavule. Magnification 75.

Fig. 39. Trifoliate pedicellaria. Magnification 120.

Fig. 40. Rostrate pedicellaria. Magnification 100.

Fig. 41. Calcareous stem of the peduncle of a globiferous pedicellaria. Magnification 60.

Fig. 42. Rostrate pedicellaria. Magnification 100.

Fig. 43 and 44. Valves of globiferous pedicellariae. Magnification 60.

Fig. 45. Tridactyle pedicellaria of the second form. Magnification 75.

$$
\text { Meijerea humilis, fig. } 46 .
$$

Fig. 46. Ophiocephalous pedicellaria. Magnification 75.

Lovenia subcarinata, fig. 47 to 50.

Fig. 47. Two valves of a tridactyle pedicellaria with a fusiform calcareous stem. Magnification 100.

Fig. 48. Miliary spine. Magnification 100.

Fig. 49. Rostrate pedicellaria. Magnification 100.

Fig. 50. Fusiform calcareous stem of the tridactyle pecicellaria whose two valves are represented in fig. 47. Magnification 100.

Gymnopatagus Sewelli, fig. 51 to 60 .

Fig. 51. Secondary spine. Magnification 18.

Fig. 52. Trifoliate pedicellaria. Magnification 120.

Fig. 53. Tridactyle pedicellaria, first form. Magnification 70.

Pig. 54. Calcareous stem of a clavule. Magnification 100.

Fig. 55. Rostrate pedicellaria. 75.

Fig. 56. Terminal part of a primary spine. Magnification 8.

Fig. 57. Tridactyle pedicellaria of the first form. Magnification 70.

Fig. 58 and 59. Small tridactyle pedicellaria of the second form. Magnification 100.

Fig. 60. Small tridactyle pedicellaria of the first form. Magnification 100.

\section{Metalia maculosa, fig. 61 to 70 .}

Fig. 61. Tridactyle pedicellaria of the first form. Magnification 100.

Fig. 62. Tridactyle pedicellaria of the first form. Magnification 55.

Fig. 63. Globiferous pedicellaria. Magnification 100.

Fig. 64. Rostrate pedicellaria. Magnification 90.

Fig. 65. Tridactyle pedicellaria of the second form. Magnification 100.

Fig. 66. Tridactyle pedicellaria of the second form, Magnification 100.

Fig. 67. End of a valve of a globiferous pedicellaria. Magnification 210.

Fig. 68. Trifoliate pedicellaria. Magnification 120.

Fig. 69. Tridactyle pedicellaria seen from the front (first form). Magnification 55. 
Fig. 70. Tridactyle pedicellaria of the third form. Magnification 120.

Prymnaster Investigatoris, fig. 71 and 72.

Fig. 71. Rostrate pedicellaria. Magnification 100.

Fig. 72. Primary spine. Magnification 100 


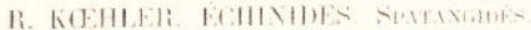

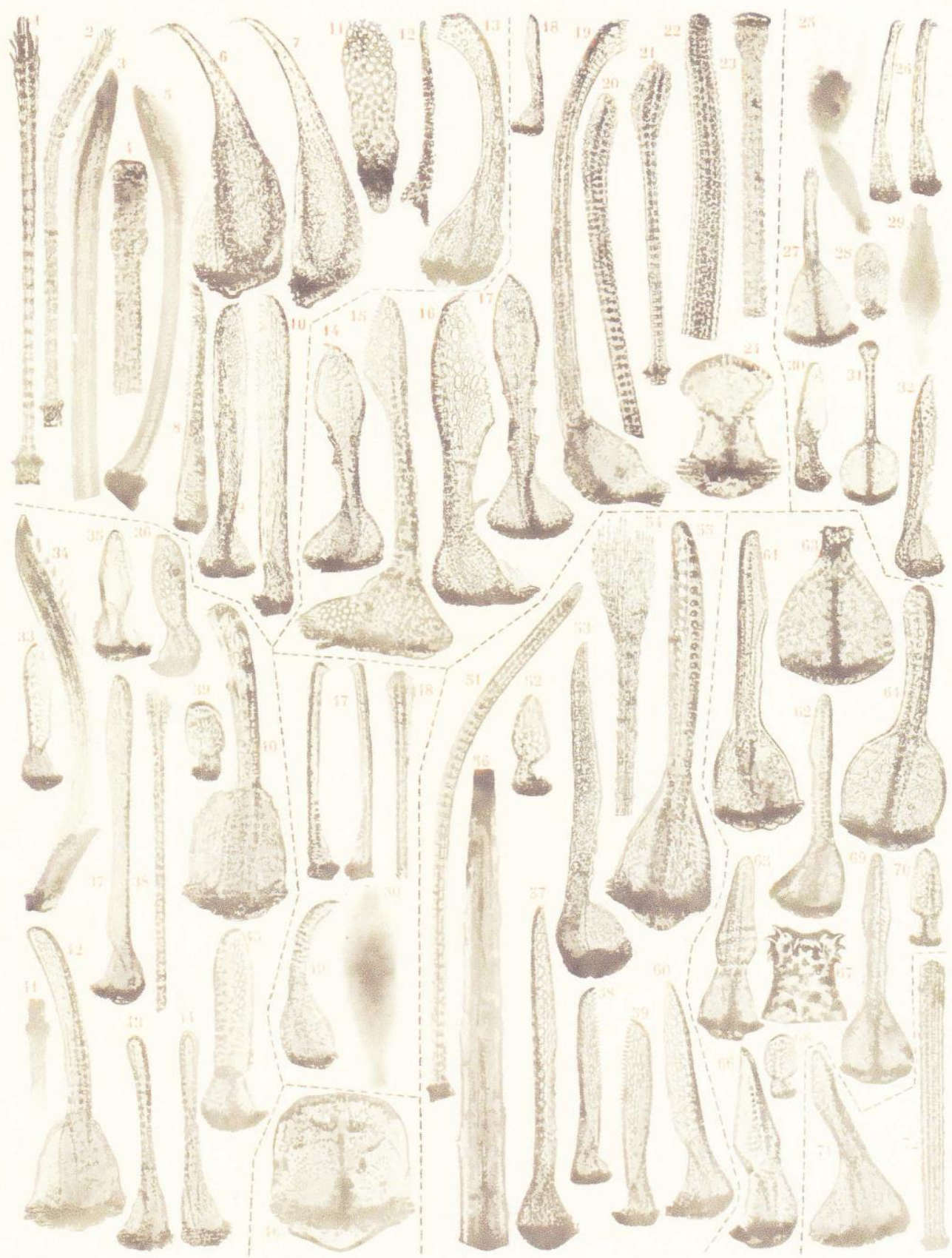




\section{PLATE XX}

\section{Pseudomaretia alta, fig. 1 to 7.}

Fig. 1 and 2. Milliary spines. Magnification 60.

Fig. 3. Spicules of the digitations of the anal pedicels. Magnification115.

Fig. 4. Fusiform calcareous stem of a tridactyle pedicellaria of the first form. Magnification 115.

Fig. 5. Two valves of one of these latter pedicellariae. Magnification 115.

Fig. 6. Spicules of the branches of the peristomial pedicels. Magnification 115.

Fig. 7. Tridactyle pedicellaria of the second form. Magnification 80.

Maretia planulata. fig. 8 to 13.

Fig. 8 and 9. Large tridactyle pedicellariae of the second form. Magnification 60.

Fig. 10. Small tridactyle pedicellaria of the third form. Magnification 120.

Fig. 11. Large tridactyle pedicellaria of the second form. Magnification 60.

Fig. 12. Tridactyle pedicellaria with a fairly short blade (second form). Magnification 105.

Fig. 13. Tridactyle pedicellaria of the first form with a narrow and elongated blade.

Magnification 90.

Paraster gibberulus, fig. 14 to 27.

Fig. 14. Globiferous pedicellaria, valve seen from the profile. Magnification 140.

Fig. 15. End of the calcareous stem of the peduncle of a globiferous. Magnification 140.

Fig. 16. Terminal part of the globiferous represented in fig. 14. Magnification 280.

Fig. 17. Tridactyle pedicellaria of the second form. Magnification 115.

Fig. 18. Valve of the globiferous pedicellaria seen from the front. Magnification 140.

Fig. 19. Large rostrate pedicellaria. Magnification 115.

Fig. 20. Small rostrate pedicellaria. Magnification 115.

Fig. 21 to 25. Diverse valves of small tridactyle pedicellariae of the third form. Magnification 115.

Fig. 26 and 27. Tridactyle pedicellariae of the first form. Diverse valve of small tridactyle pedicellariae of the third form. Magnification 115.

Brissopsis Oldhami, fig. 28 to 43.

Fig. 28. Large tridactyle pedicellaria of the first form. Magnification 55.

Fig. 29. Small tridactyle pedicellaria of the first form. Magnification 90.

Fig. 30. Large tridactyle pedicellaria of the first form. Magnification 55.

Fig. 31. Rod of a rosette of a frontal pedicel. Magnification 100,

Fig. 32. Globiferous pedicellaria. Magnification 55.

Fig. 33. Small rostrate pedicellaria. Magnification 70.

Fig. 34. Large tridactyle pedicellaria of the first form. Magnification 55.

Fig. 35. Large rostrate pedicellaria. Magnification 70.

Fig. 36. Large tridactyle pedicellaria of the first form. Magnification 90.

Fig. 37. Calcareous rod of a clavule. Magnification 100. 
Fig. 38. Large tridactyle pedicellaria of the first form. Magnification 90.

Fig. 39. Calcareous rod of a clavule. Magnification 100.

Fig. 40. Ophiocephalous pedicellaria. Magnification 210.

Fig. 41 and 42. Miliary spines. Magnification 100.

Fig. 43. Tridactyle pedicellaria of the second form. Magnification 90.

Prymnaster angulatus, fig. 44 to 49.

Fig. 44. Two rods from a rosette of the frontal pedicel. Magnification 100.

Fig. 45. Globiferous pedicellaria. Magnification 90.

Fig. 46. Spatulate spine of the sternum. Magnification 30.

Fig. 47. Miliary spine. Magnification 90.

Fig. 48. Two valves of a tridactyle pedicellaria. Magnification 210.

Fig. 49. Rostrate pedicellaria. Magnification 210.

Brissopsis duplex, fig. 50,

Fig. 50. Ophiocephalous pedicellaria of the second form. Magnification 210.

Brissopsis luzonica, fig. 51 to 54.

Fig. 51. Rod of a rosette of a frontal pedicel. Magnification 100.

Fig. 52. Ophiocephalous pedicellaria. Magnification 210.

Fig. 53. Globiferous pedicellaria. Magnification 90.

Fig. 54. The two hooks that end the preceding pedicellaria seen from the front. Magnification 90.

Brissopsis parallela. fig. 55 to 62 .

Fig. 55. Large tridactyle pedicellaria. Magnification 90.

Fig. 56. Rod of a rosette of a frontal pedicel. Magnification 100.

Fig. 57 and 58. Tridactyle pedicellariae of the second form. Magnification 120.

Fig. 59. Small tridactyle pedicellaria with short and enlarged valves. Magnification 120.

Fig. 60 and 61. Two valves of a rostrate pedicellaria. Magnification 70.

Fig. 62. Rod of a rosette of a frontal pedicel. Magnification 100.

Brissopsis bengalensis, fig. 63 to 64.

Fig. 63. Large tridactyle pedicellaria. Magnification 50.

Fig. 64. Rod of a rosette of a frontal pedicel. Magnification 100 


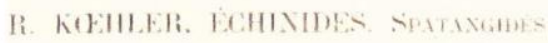

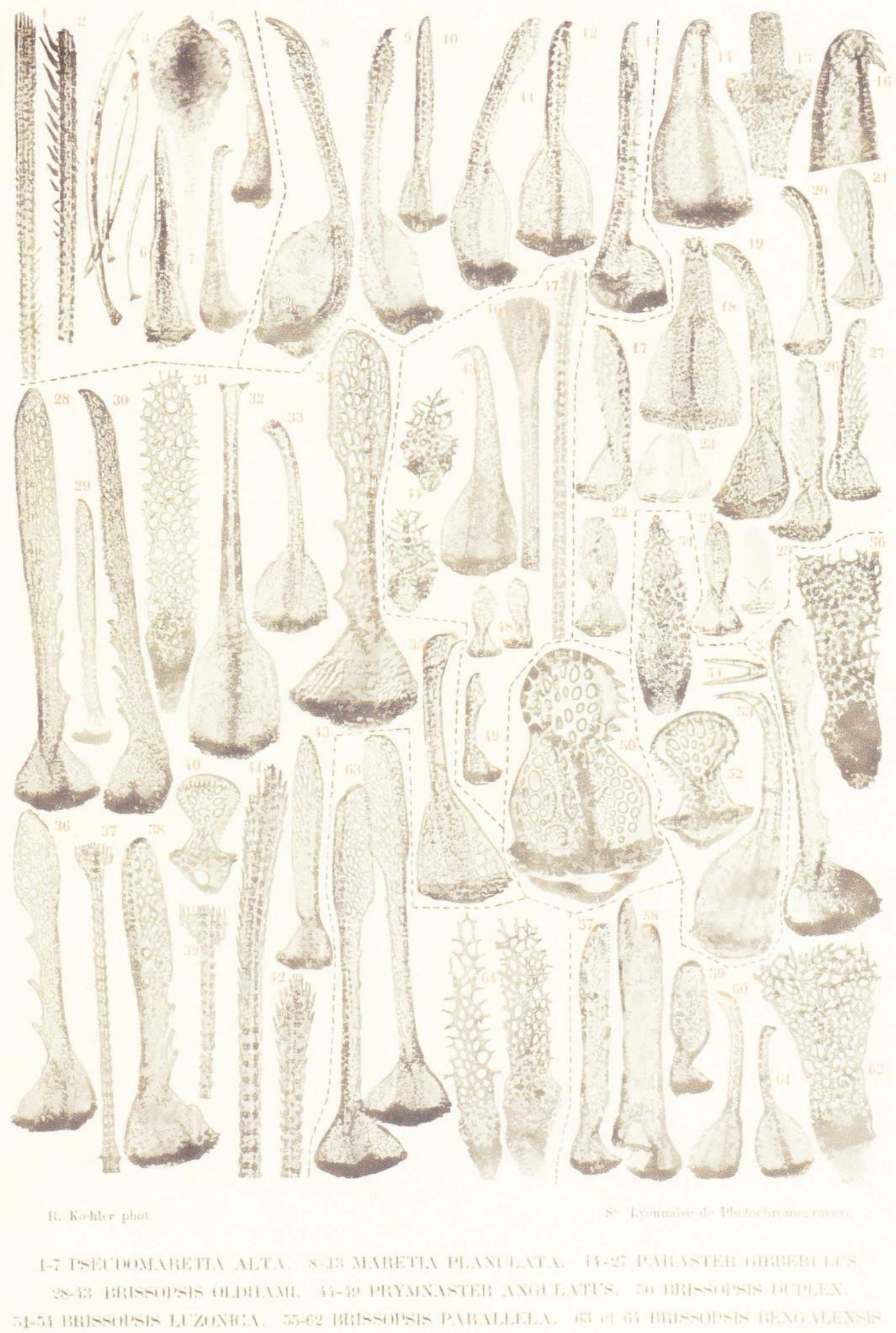

